\title{
Pharmacokinetics and pharmacogenetics of tacrolimus in renal transplant patients
}

Citation for published version (APA):

Op den Buisch, R. (2007). Pharmacokinetics and pharmacogenetics of tacrolimus in renal transplant patients. [Doctoral Thesis, Maastricht University]. Maastricht University. https://doi.org/10.26481/dis.20071025ro

Document status and date:

Published: 01/01/2007

DOI:

10.26481/dis.20071025ro

Document Version:

Publisher's PDF, also known as Version of record

\section{Please check the document version of this publication:}

- A submitted manuscript is the version of the article upon submission and before peer-review. There can be important differences between the submitted version and the official published version of record.

People interested in the research are advised to contact the author for the final version of the publication, or visit the DOI to the publisher's website.

- The final author version and the galley proof are versions of the publication after peer review.

- The final published version features the final layout of the paper including the volume, issue and page numbers.

Link to publication

\footnotetext{
General rights rights.

- You may freely distribute the URL identifying the publication in the public portal. please follow below link for the End User Agreement:

www.umlib.nl/taverne-license

Take down policy

If you believe that this document breaches copyright please contact us at:

repository@maastrichtuniversity.nl

providing details and we will investigate your claim.
}

Copyright and moral rights for the publications made accessible in the public portal are retained by the authors and/or other copyright owners and it is a condition of accessing publications that users recognise and abide by the legal requirements associated with these

- Users may download and print one copy of any publication from the public portal for the purpose of private study or research.

- You may not further distribute the material or use it for any profit-making activity or commercial gain

If the publication is distributed under the terms of Article $25 \mathrm{fa}$ of the Dutch Copyright Act, indicated by the "Taverne" license above, 


\section{Pharmacokinetics and}

pharmacogenetics of tacrolimus in renal transplant patients 
(C) Robert Op den Buijsch, Maastricht 2007

ISBN:

Cover design: Fabio Peltrera

Layout: Tiny Wouters

Production: Datawyse | Universitaire Pers Maastricht

Financial support by Nierstichting, EC Noyons Stichting, Roche Diagnostics b.v., Weyth, TIB MCLBICL, Astellas is gratefully acknowledged. 


\title{
Pharmacokinetics and
}

\section{pharmacogenetics of tacrolimus in renal transplant patients}

\author{
PROEFSCHRIFT \\ ter verkrijging van de graad van doctor \\ aan de Universiteit Maastricht, \\ op gezag van de Rector Magnificus, Prof. mr. G.P.M.F. Mols, \\ volgens het besluit van het College van Decanen, \\ in het openbaar te verdedigen \\ op donderdag 25 oktober 2007 om 14.00 uur
}

door

Robert Op den Buijsch

Geboren op 15 oktober 1973 te Nederweert 


\section{Promotor}

Prof. dr. M.P. van Dieijen-Visser

Co-promotores

Dr. O. Bekers

\section{Beoordelingscommissie}

Prof. dr. A. Bast (voorzitter)

Prof. dr. M. Drent

Prof. dr. H.J. Guchelaar, (LUMC, Leiden)

Prof. dr. K.M.L. Leunissen

Prof. dr. C. Neef 


\section{Contents}

Chapter 1 Outline and aim of the thesis 9

Chapter 2 Pharmacokinetics and pharmacogenomics of tacrolimus; 13 a review

Submitted in an adapted form

Chapter 3 Comparison of DNA isolation kits to extract DNA from whole blood samples

Current Genomics 2006;7:73-8

Chapter 4 Genotyping of the pregnane X receptor A11156C polymorphism with locked nucleic acid containing fluorogenic probes

The Pharmacogenomics Journal 2005;5:72-4

Chapter 5 Rapid genotyping of the organic anion transporter polypeptide 1B1 polymorphisms A388G and T521C with real-time polymerase chain reaction fluorescence resonance energy transfer assays

Pharmacogenomics 2005;6:393-7

Chapter 6 Evaluation of limited sampling strategies for tacrolimus

European Journal of Clinical Pharmacology: accepted for publication

Chapter 7 Influence of different allelic variants of the cytochrome 3A and adenosine triphosphate-binding casserre $\mathrm{B} 1$ gene on the tacrolimus pharmacokinetic profile of Chinese renal transplant recipients

Pharmacogenomics 2006;7:563-74

Chapter 8 Tacrolimus pharmacokinetics and pharmacogenetics: influence of adenosine triphosphate-binding cassette B1 (ABCB1) and cytochrome (CYP) 3A polymorphisms Fundamental \& Clinical Pharmacology, 2007;21:427-35

Chapter 9 Cytochrome P450 (CYP3A7) *1C allelic variant is associated with the tacrolimus pharmacokinetics in renal transplant recipients Submitted 
Chapter 10 Influence of allelic variants of uridine diphosphateglucuronosyltransferase (UGT) 2B7 on the tacrolimus exposure

Submitted

Chapter 11 Pregnane $\mathrm{X}$ receptor (PXR) polymorphisms involved in 163 the tacrolimus pharmacokinetics

Submitted

Chapter 12 Influence of pregnane $X$ receptor (PXR) polymorphisms on 179 the pharmacokinetics of tacrolimus in renal transplant recipients

Submitted

Chapter 13 General discussion

Summary 203

Samenvatting 209

Abbreviations 215

Publications

Dankwoord

Curriculum vitae 



\section{Chapter 1}

Outline and aim of the thesis 


\section{Outline and aim of the thesis}

A number of enzymes in humans are capable of biotransforming lipid-soluble xenobiotics in such a way as to render them more water soluble. There are two types of enzyme reactions: phase I and phase II type reactions. Phase I type reactions are involved in hydrolysis, oxidation and reduction reactions, whereas phase II type reactions have been referred to as conjugative reactions which include glucuronidation, sulfation, acetylation, methylation, conjugation with glutathione (mercapturic acid synthesis), or with amino acids (e.g., glycine, taurine and glutamic acid). Although it is well known that not all conjugation reactions are secondary phase II reactions since many endobiotics (e.g. bilirubin, steroids, retinoids, and bile acids) and xenobiotics (e.g. acetaminophen, morphine, and oxazepam) are conjugated without prior conversion to products generated from oxidative, reductive or hydrolytic enzymes. Conjugative biotransformation results in an increase in the hydrophilicity of a compound which promotes its excretion. The balance between the cytochrome P450 and conjugative drug biotransforming enzymes is responsible for either the detoxification or the accumulation of toxic metabolites in the body. The calcineurin inhibitor tacrolimus has highly variable pharmacokinetic characteristics and therefore close therapeutic drug monitoring is required especially to prevent subtherapeutic and toxic blood levels. Subtherapeutic drug levels increase the risk of rejection significantly while toxic drug levels cause serious side effects, as described in CHAPTER 2. Additionally, this CHAPTER includes a complete review of the pharmacokinetics and pharmacogenetics of tacrolimus. Although several commercial DNA isolation kits are available to extract deoxyribonucleic acid (DNA) from whole blood samples, less information is available regarding the extraction efficiency and the quality of the isolated DNA. CHAPTER 3 presents a study that compares three commercially available DNA isolation kits regarding their ability to extract DNA from whole blood samples as well as the DNA quality.

In CHAPTER 4 a locked nucleotide acid (LNA) on the polymorphic position in the sensor probe is introduced. By using a LNA on the polymorphic position, a better discrimination between the wild type allele and the variant allele is possible. The influence of a LNA in a FRET probe and its consequence on the melting curves is described in CHAPTER 4. Due to the introduction of real-time PCR technology it is possible to detect single nucleotide polymorphisms (SNPs) faster, with less contamination risk and less hands on time than previously used PCR methods, like PCR restriction fragment length polymorphism (RFLP) and PCR amplification refractory mutation system (ARMS). CHAPTER 5 reports new real-time PCR fluorescence resonance energy transfer (FRET) assays for SNPs which are compared with PCR RFLP and PCR ARMS assays. CHAPTER 6 evaluates 24 limited sampling strategies for tacrolimus that have been published by other research groups in an independent renal transplant recipient group. This comprehensive study demonstrates that a limited sampling strategy using two $\left(\mathrm{C}_{2}\right.$, $\left.\mathrm{C}_{4}\right)$ or three $\left(\mathrm{C}_{0}, \mathrm{C}_{2}, \mathrm{C}_{4}\right)$ sample time points are a better indication for the tacrolimus 
exposure than the trough $\left(\mathrm{C}_{0}\right)$ levels alone. In most transplant centres monitoring of the tacrolimus blood concentration is performed by $\mathrm{C}_{0}$ concentrations after the morning tacrolimus administration. However, conflicting evidence is present regarding the usefulness of these morning tacrolimus $\mathrm{C}_{0}$ concentrations. Knowing this, several studies recently developed a limited sampling strategy for tacrolimus using stepwise multiple regression analysis or Bayesian fitting to predict the $\mathrm{AUC}_{0-12}$ as accurate as possible, since the $\mathrm{AUC}_{0-12}$ is considered to be the gold standard of measuring the total tacrolimus exposure. Most of these studies that developed a limited sampling strategy for tacrolimus used no independent transplant patient population to validate their limited sampling strategies. Several studies reported an association between the ABCB1 polymorphisms C1236T, G2677T/A and C3435T or ABCB1 haplotypes and the tacrolimus $\mathrm{C}_{0}$ levels or the pharmacokinetic parameters of tacrolimus in different transplantation patients, while other studies found no correlation between the ABCB1 polymorphisms and the tacrolimus blood levels. In CHAPTER 7 and 8 the influence of CYP3A and ABCB1 polymorphisms is studied in a Caucasian and a Chinese renal transplant recipient group while CHAPTER 9 examines the presence of the CYP3A $7{ }^{*} 1 \mathrm{C}$ variant allele in Chinese and Caucasian renal transplant recipients and investigates the association between the CYP3A7*1C variant allele and the pharmacokinetic tacrolimus parameters. Previously, it was demonstrated that UGT2B7 is the most important member of the UGT family involved in the tacrolimus glucuronidation although the influence of the recently identified UGT2B7 polymorphisms on the tacrolimus blood levels was never reported. CHAPTER 10 reports the contribution of three UGT2B7 polymorphisms on the tacrolimus blood levels in a Chinese renal transplant recipient group. The nuclear receptor pregnane $X$ receptor (PXR) activates transcription as a response to a diversity of natural and synthetic compounds. Recently, it was demonstrated that eight SNPs present in the untranslated and intron regions of the PXR gene showed a significant difference or trend in the erythromycin breath test, in the CYP450 3A located in the human hepatocytes or intestines and in the ABCB1 expression in the intestines after induction with rifampicin. The role of PXR polymorphisms in correlation with a limited sampling strategy for tacrolimus is examined in a Chinese renal transplant recipient group as described in CHAPTER 11. Since it is also known that corticosteroids can induce the CYP3A enzymes, these PXR polymorphisms may also play a role in the tacrolimus metabolism, especially in the early transplant period when transplant patients receive high daily doses of corticosteroids. In CHAPTER 12 the influence of corticosteroids on the contribution of the PXR polymorphism demonstrates that the role of CYP3A enzymes may be significantly influenced by the combination of an induced PXR gene and the presence of PXR polymorphisms. The corticosteroids activate the PXR gene which as a result induce the CYP3A enzymes that lead to lower tacrolimus blood levels. CHAPTER 13 presents some general conclusions and comments on the obtained results. Future perspectives and recommendations on the different pharmacokinetic and pharmacogenetic 
approaches used nowadays and possibly in the (near) future and its consequences for transplantation patients in daily practice are also discussed.

This thesis includes three important aims which have been studied:

I A comparison and validation of limited sampling strategies for tacrolimus previously published, which may provide a better indication of the tacrolimus exposure in different transplant patients (CHAPTER 6).

II The introduction of real-time PCR FRET technology that makes genotyping of several SNPs present in different genes possible in a shorter analytical time, with less hands on time, and with less contamination risk compared to the conventional PCR methods (CHAPTER 3, 4 and 5).

III Knowledge on the presence of SNPs in the phase I and phase II enzymes, in transporters and nuclear receptors in the tacrolimus metabolism may contribute to decrease the high inter-individual pharmacokinetic variation in the tacrolimus blood levels of Caucasian and Chinese renal transplant patients (CHAPTER 7, 8, 9, 10, 11 and 12). 
CHAPTER

Pharmacokinetics and pharmacogenomics of tacrolimus; a review 


\section{Introduction}

Tacrolimus (FK506) is a 23-membered macrolide lactone $\left(\mathrm{C}_{44} \mathrm{H}_{69} \mathrm{NO}_{12}\right.$; for molecular structure see Figure 2.1) which is isolated from the fermentation broth of Streptomyces tsukubaesis ${ }^{1,2}$. Additionally, tacrolimus like cyclosporin is an immunosuppressive agent belonging to the calcineurin inhibitor group that has emerged as a valuable therapeutic alternative to cyclosporine following solid organ transplantation ${ }^{3}$. It is highly effective at preventing rejection in heart ${ }^{4-7}$, small bowel ${ }^{8,9}$, pancreas ${ }^{10-14}$, bone marrow ${ }^{10-14}$, lung $^{15-19}$, liver $^{20-24}$, and kidney ${ }^{25-28}$ recipients and for the therapy of autoimmune diseases ${ }^{29,30}$.

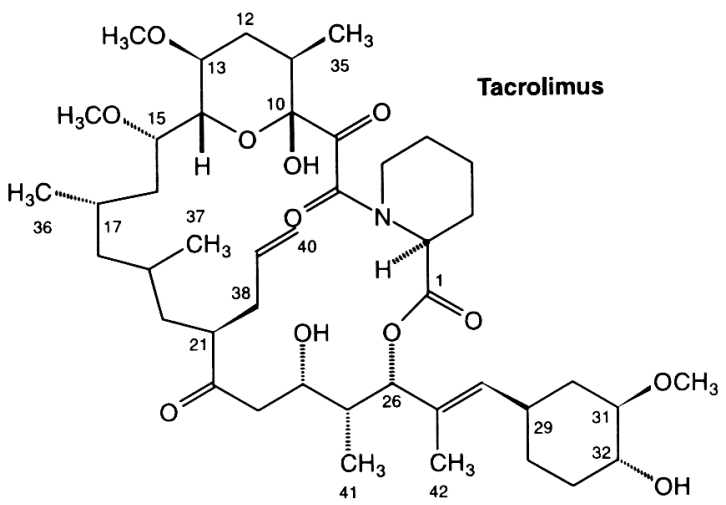

Figure 2.1 Structure of tacrolimus.

Although there are structural differences, cyclosporin and tacrolimus share a similar cellular mechanism of action, though tacrolimus, is 10 to 100 times more potent at the molecular level ${ }^{31}$. After entry into the cell, both agents bind to their respective cytosolic immunophilins: cyclosporine to cyclophilin and tacrolimus to the FK506-binding proteins FKBP-12 and FKBP-52, a component of the glucocorticoid receptor complex. Immunophilins are a family of highly conserved proteins that likely participate in protein folding. The drug-immunophilin complex binds to and inhibits the activity of the enzyme calcineurin, a calcium/calmodulin-dependent protein phosphatase that is expressed in all mammalian tissues. As a result, the complex interrupts the calcium-dependent signal transduction pathway in T-cells. Inhibition of calcineurin by cyclosporin or tacrolimus leads to interference with translocation to the nucleus of various nuclear factors involved in the transcription of cytokine genes, such as the cytosolic subunit of the nuclear factor of activated T-cells (NF-ATc). It also antagonizes the interaction of the transcription factor, cyclic adenosine monophosphatase (CAMP)-response element binding protein (CREB), with its putative deoxyribonucleic acid (DNA) binding site, which in turn inhibits 
cAMP-directed transcriptional events. As a result of calcineurin inhibition, the transcription of early T-cell activation genes is suppressed, affecting the production of interleukin-2 (IL-2) and many other cytokines, such as interleukin-3 (IL-3), interferon- $\gamma$ (INF- $\gamma$ ), and tumor necrosis factor- $\alpha$ (TNF- $\alpha$ ). Figure 2.2 illustrates a simplified model of the intracellular mode of action of tacrolimus and cyclosporine.

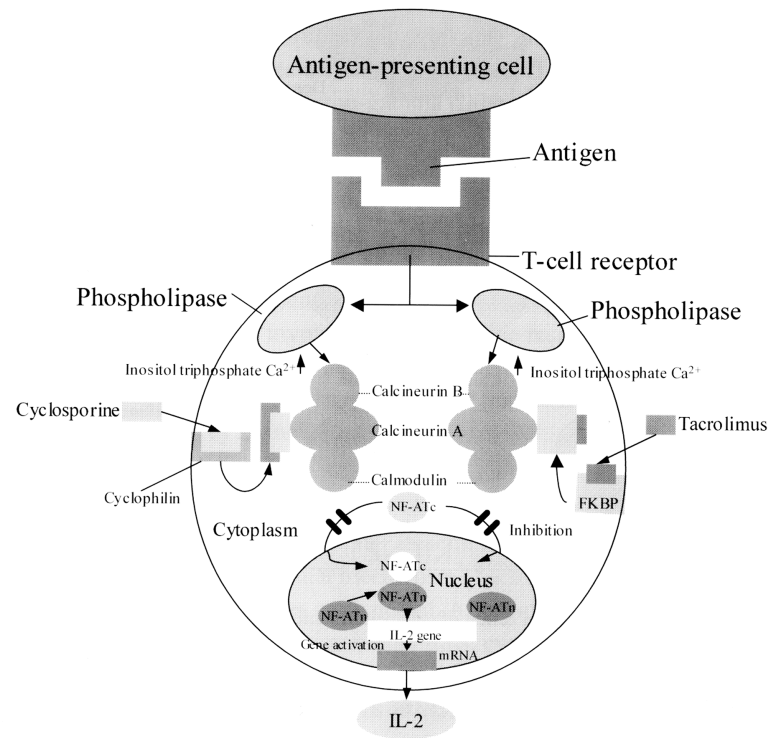

Figure 2.2 Intracellular mode of action of tacrolimus and cyclosporine. Adapted from LC Paul. Mechanistic differences of cornerstone immunosuppressants. ISBN 1-898729-15-8.

\section{Absorption, distribution, metabolisation and elimination}

\subsection{Absorption}

Tacrolimus, orally administrated, has a large variability in the rate of absorption and absolute bioavailability which implies that the mean bioavailability is approximately $25 \%$ but can range from $5 \%$ to $93 \%{ }^{32,33}$. In general oral doses of tacrolimus should be 3 to 4 times higher than intravenous doses to achieve comparable drug exposure after oral and intravenous administration. A reduced bioavailability has been reported in patients awaiting renal transplantation ${ }^{34}$, in small bowel recipients with open stomas ${ }^{35}$, in African American and non-Caucasian individuals ${ }^{36-40}$, in diabetic patients ${ }^{41,42}$, and following administration of food with a moderate fat content ${ }^{43-45}$. However, the bioavailability is 
similar for paediatric and adult transplant patients ${ }^{42}$. In most patients tacrolimus is absorbed rapidly with peak plasma/blood concentrations obtained in $0.5-1$ hour $^{32}$ however a lag time of 0 to 2 hours has also been reported in some liver transplant recipients ${ }^{37}$ or an extended lag time or secondary peaks ${ }^{34,46,47}$.

The shape of the plasma concentration-time profile in some patients (sharp peaks), and higher dose-normalised maximum blood concentration at lower doses is seen in some patients who received different doses, are suggestive of the involvement of a zero order/saturable process in the absorption of tacrolimus ${ }^{38}$. The poor aqueous solubility of tacrolimus and alterations in gut motility in transplant patients may be partially responsible for poor and erratic drug uptake. Presystemic metabolism of tacrolimus by gastrointestinal cytochrome P450 (CYP) 3A iso-enzymes and removal by P-glycoprotein transport is extensive ${ }^{48-50}$. P-glycoprotein lowers the intracellular concentration of tacrolimus by pumping absorbed drug back out into the intestinal lumen. P-glycoprotein may also regulate access of tacrolimus to CYP3A enzymes and prevents these enzymes from being overwhelmed by high drug concentrations in the intestine ${ }^{51,52}$. As tacrolimus is repeatedly transported out of the intestinal mucosa cells and then passively reabsorbed, this continous repeated exposure should lead to more efficient metabolism $^{52,53}$. P-glycoprotein belongs to a family of adenosine triphosphate-binding cassette transporters with considerable overlap in substrate specificity. Bile is not essential for tacrolimus absorption ${ }^{54-56}$. Simultaneous administration of enteral feeds does not appear to interfere with tacrolimus bioavailability. Contrasting studies appeared regarding the role of $A B C B 1$ polymorphisms in the tacrolimus metabolisation process. $A$ number of studies ${ }^{57-65}$ found a significant association between the ABCB1 polymorphism C3435T or the ABCB1 haplotype consisting of the polymorphisms C1236T, G2677T/A and $\mathrm{C} 3435 \mathrm{~T}$ and tacrolimus $\mathrm{C}_{0}$ concentrations or pharmacokinetic parameters, while other studies $^{66-76}$ found no significant correlation between these parameters. A large diversity of transplant recipient populations were used to examine this $A B C B 1$ genotype tacrolimus blood concentration correlation which may explain the difference in the results observed. Especially, when the role of these ABCB1 polymorphisms is minor compared to the CYP3A polymorphisms.

\subsection{Distribution}

Transplant recipients have significantly higher blood tacrolimus concentrations (mean 15 times; range 4 to 114 times) than the corresponding plasma concentrations due to the extensive binding of tacrolimus to the red blood cells ${ }^{46,54,77-81}$. Venkataramanan et al. ${ }^{54}$ reported that the maximum amount of tacrolimus bound to red blood cells $\left(B_{\max }\right)$ is $418 \pm 258 \mu \mathrm{g} / \mathrm{l}$ with an apparent dissociation constant $\left(\mathrm{K}_{\mathrm{D}}\right)$ of $3.8 \pm 4.7 \mu \mathrm{g} / \mathrm{l}$ in transplant patients while $B_{\max }$ is $1127 \mu \mathrm{g} / \mathrm{l}$ and $K_{D}$ of $13.5 \mu \mathrm{g} / \mathrm{l}$ in healthy volunteers. The diffusion of tacrolimus from erythocytes is slow in comparison with the transit time of blood through an organ, but tacrolimus is readily released from the erythrocytes ${ }^{82-84}$, and the binding of tacrolimus to erythrocytes may in part protect it from hepatic metabolism ${ }^{85}$. An 
intracellular protein in erythrocytes, with a molecular weight range (14 to $15 \mathrm{kDa}$ ) corresponding to $\mathrm{FKBP}^{82}$, or a molecular weight of 11 to $12 \mathrm{kDa}^{86}$ appears to be primarily responsible for binding tacrolimus. Tacrolimus does not bind to haemoglobin. When the tacrolimus concentration in whole blood increases, the uptake of tacrolimus by erythrocytes is saturated, resulting in a lower blood versus plasma ratio ${ }^{81,82,84,86}$. Approximately $99 \%$ of tacrolimus in plasma is bound, with uptake not saturable at physiological drug concentrations ${ }^{87-89}$. Additionally, tacrolimus is principally associated with $\alpha_{1}$-acid glycoprotein, lipoproteins, globulins and albumin. Partitioning of tacrolimus between erythrocytes and plasma ex vivo is dependent on the haematocrit, tacrolimus concentration, temperature of the sample and plasma protein concentration ${ }^{87,90-92}$. Tacrolimus passes through the placenta and into the breast milk ${ }^{78,93,94}$. In one study ${ }^{94}$, 21 female liver transplant recipients treated with tacrolimus before and throughout gestation, the mean tacrolimus concentrations $(\mu \mathrm{g} / \mathrm{l})$ on the day of delivery were 4.3 in the placenta versus $1.5,0.7$ and 0.5 in the maternal, cord and child plasma, and 0.6 in the first breast milk specimens. In paediatric liver recipients, a volume of distribution up to 1.8 times higher than in adult recipients has been reported ${ }^{95}$. Possible reasons for this include increased membrane permeability of red blood cells and reduced amounts and affinity of plasma binding proteins in infants, enhancing drug entry into some compartments $^{96}$.

\subsection{Metabolism}

Tacrolimus undergoes O-demethylation, hydroxylation and/or oxidative metabolic reactions, predominantly by CYP3A4 and CYP3A5 in the liver and intestinal wall, with $<0.5 \%$ of the parent drug appearing unchanged in the urine or faeces ${ }^{88,90,93,97-108}$. Several metabolites are the product of a two-step reaction: oxidation by cytochrome P450 3A enzymes destabilising the macrolide ring and followed by its rearrangement ${ }^{92,102,105,109}$. Schüler et al. ${ }^{109}$ detected seven different isomers of 13-Odemethyl-tacrolimus by using two-dimensional homo- and heteronuclear magnetic resonance experiments. Figure 2.3 illustrates the major metabolic pathways of tacrolimus. Several other metabolites have been isolated, the structures of which have only partially been identified using mass spectrometry ${ }^{32}$. The CYP3A subfamily composed of four genes, CYP3A4, CYP3A5, CYP3A7, and CYP3A43, and three pseudogenes CYP3AP1, CYP3AP2 and CYP3AP3, consists of $231 \mathrm{~kb}$ and is located on chromosome $7 q 21-q 22.1^{56}$. The first human CYP3A to be identified was CYP3A4, which was independently cloned in two separate laboratories in $1986^{110,111}$. Another CYP3A member CYP3A5 was subsequently purified from liver ${ }^{112}$ and the corresponding complementary DNA (cDNA) was cloned in two separate laboratories ${ }^{113,114}$. A third CYP3A family member, CYP3A7, which is expressed at high levels in fetal liver, was also identified ${ }^{112,115}$ and cloned by Komori et al. ${ }^{116}$. More recently cDNA clones for a fourth CYP3A member, CYP3A43, have been isolated from the liver ${ }^{117-119}$. 


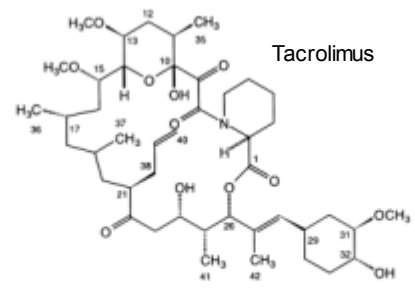

\section{First generation}

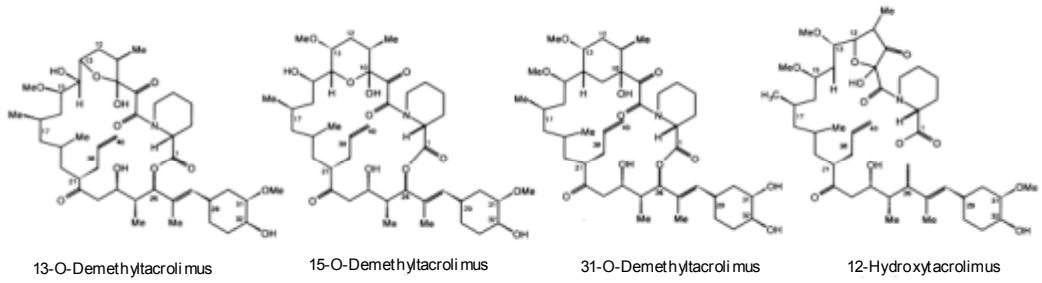

Second and higher generation

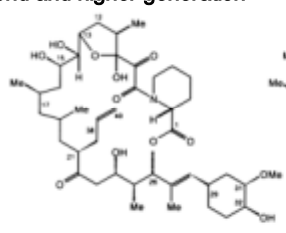

13, 15-O-Didemethyttacrolimus

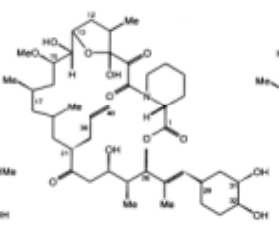

13, 31-O-Didemethytacrolimus

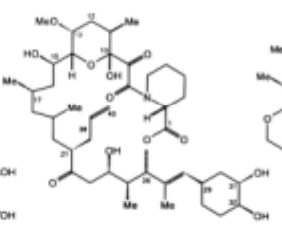

15,31-O-Didemethyttacrolimus

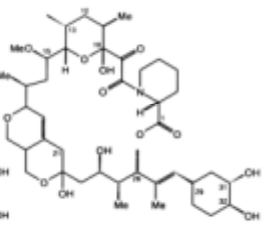

31-O-Demethy, 19-Hydroxy, 37, 39-Epoxytacrolimus

Figure 2.3 The reactions involved in the tacrolimus metabolism are cytochrome P450 3Amediated hydroxylation, demethylation and oxidation. The proposed metabolite structures and metabolic pathways are based on Iwasaki et $a l^{87,92}$. The metabolites are classified as first and second generation metabolites. First generation metabolites are those directly derived from tacrolimus and are changed in one position. Metabolic changes in certain positions such as 13-O-demethyltacrolimus, lead to secondary nonenzymatic rearrangement of the macrolide ring resulting in several isomers. This figure is derived from an illustration of a publication of Christians et $a l^{288}$ and used in this thesis with permission of the publisher.

\subsection{Elimination}

The metabolites of tacrolimus are for more than $95 \%$ eliminated by the biliary route ${ }^{97}$. Urinary excretion accounts for, on average, $2.4 \%$ of tacrolimus elimination. Biliary 
obstruction is reported to increase the concentration of tacrolimus metabolites in the blood $^{120,121}$.

\section{Pharmacokinetics}

\subsection{Genetic factors affecting the pharmacokinetics}

\subsubsection{Cytochrome P450 (CYP450) 3A4}

The CYP3A4 gene is encoded by a $27 \mathrm{~kb}$ sequence on chromosome $7 \mathrm{q} 21.3-\mathrm{q} 22.1$ and spans 13 exons $^{117,122,123}$. CYP3A4 consists of 502 amino acids with a molecular weight of $57 \mathrm{kDa}^{124}$. CYP3A4 accounts for approximately $30 \%$ of the total cytochrome P450 activity in the liver and $70 \%$ of the cytochrome P450 activity in the small intestines ${ }^{125,126}$. Since so much of the human cytochrome P450 activity is due to CYP3A4, it comes as no surprise that CYP3A4 performs the bulk of oxidative drug metabolism in humans. Therefore, the list of medicines that are metabolized by CYP3A4 is still growing and CYP3A4 may be involved in the metabolism of about $50 \%$ of all clinically used drugs. CYP3A4 is responsible for the hydroxylation, demethylation, and dealkylation of several endogenous and exogenous compounds. Due to the multiple enzymatic sites on the CYP3A4 molecule, CYP3A4 is able to affect so many compounds through multiple enzymatic steps. CYP3A4 is also an important enzyme in the metabolism of endogenous steroids, cholesterol and lipids through hydroxylation. Children and young adults seem to have more CYP3A4 function than do adults and this enzyme may be more active in women than in men, but studies of age and gender differences with regard to CYP3A4 have yielded conflicting results ${ }^{127}$. CYP3A4 has a vast amount of metabolic activity, and it is often thought of as a high capacity/low affinity enzyme as compared with the other cytochrome P450 iso-enzymes, particularly CYP2D6, CYP2C9 and CYP2C19 which are low capacity/high affinity enzymes. CYP3A4 may function as "sink" where many drugs go to be metabolized at relatively high levels. At low levels, the low capacity/high affinity enzymes perform more of the enzymatic activity. If CYP3A4 is inhibited, the drugs may spill over to the other enzymes, but because these enzymes are low capacity, serum levels of the drugs may increase significantly and lead to toxicity $^{128}$. Drugs with evidence of effective competitive or non-competitive CYP3A4 inhibition include the azole anti-fungals itraconazole ${ }^{129}$ and ketoconazole $^{130}$, diltiazem $^{131}$, the macrolide antibiotics clarithromycin, erythromycin ${ }^{132}$, and troleandomycin $^{133}$, norfluoxetine, nefazodone ${ }^{129}$, the quinolone antibiotics ciprofloxacin and norfloxacin ${ }^{134}$, quinupristin/dalfopristin ${ }^{135}$, and the protease inhibitors indinavir and ritonavir $^{136}$. Ketoconazole and ritonavir seem to be the most potent of all CYP3A4 inhibitors. A moderate CYP3A4 inhibitor is a chemical (or chemicals) in grapefruit and grapefruit juice ${ }^{137,138}$. The action of this chemical (or these chemicals) is probably through inhibition of the gut wall CYP3A4, although there is some evidence that the 
effect may be due to P-glycoprotein ${ }^{139}$. However, regardless of the mechanism, when a second drug is ingested after grapefruit juice has been drunk, serum levels of the second drug increase if it is a substrate of CYP3A4 or P-glycoprotein. The strongest known inducer of CYP3A4 is carbamazepine and its mechanism is described by Levy et al. ${ }^{140}$. Carbamazepine induces CYP3A4 and the drug is also metabolised by CYP3A4 however, carbamazepine induces not only CYP3A4 but also phase II conjugation enzymes $^{141}$. Other anti-epileptics such as phenytoin, phenobarbital and primidone ${ }^{142}$ also induce CYP3A4. Additionally, there is evidence that rifampicin and rifabutin ${ }^{143}$, nevirapine and efavirenz ${ }^{144,145}$, troglitazone ${ }^{146}$, dexamethasone and prednisone ${ }^{147}$ all induce CYP3A4. In addition, St. John's wort is a popular herbal product used to treat depressions and thought to be implicated in drug interactions involving CYP3A4 ${ }^{148,149}$ and/or P-glycoprotein ${ }^{150}$. Markowitz et al. ${ }^{151}$ found that a 14-day course of St. Johns' wort administration significantly induced the activity of CYP3A4 as measured by changes in the pharmacokinetics of alprazolam. This suggested that long-term administration of St. John's wort may result in diminished clinical effectiveness or increased dosage requirement for all CYP3A4 substrates. Use of St John's wort has led to decreased cyclosporine levels, ultimately causing transplantation rejection ${ }^{152-154}$. St John's wort has also been shown to decrease digoxin levels ${ }^{155}$. Given these reports, St John's wort may affect numerous other drugs and make them less effective. Unlike other cytochrome P450 iso-enzymes CYP3A4 is capable of being stimulated. Stimulation is similar to induction in that enhanced CYP3A4 activity occurs. It differs since it happens immediately while induction is delayed by 1 to 3 weeks. Stimulation is termed homotropic if performed by a substrate of CYP3A4 and heterotropic if performed by other effectors or drugs ${ }^{156}$. Although more than 30 CYP3A4 variants have been reported $^{157}$, most CYP3A4 variants are SNPs with low allelic frequencies and many of these SNPs are population specific ${ }^{157}$. In addition, the clinical implementation of all CYP3A4 polymorphisms of in drug metabolism have not been determined ${ }^{119}$. Rebbeck

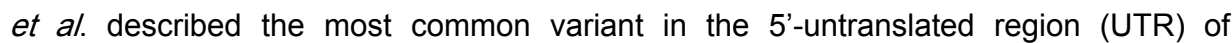
CYP3A4, CYP3A4*1B (A-392G) ${ }^{158}$. The frequency of CYP3A4*1B is highly variable in different racial populations with an allele frequency of $0 \%$ in Chinese, Taiwanese and Japanse $^{159-162}, \quad 4-10 \%$ (Caucasians) ${ }^{163-166}, 9-10 \%$ (Hispanics) $)^{161,162}$ and $48-80 \%$ (African-Americans) $^{161,162,165,167,168}$.

\subsubsection{Cytochrome P450 (CYP450) 3A5}

The CYP3A5 gene has 13 exons encoding 502 amino acids ${ }^{113,169}$. CYP3A5 has been reported to be expressed at higher levels than CYP3A4 in extra hepatic tissue, such as in the small intestine ${ }^{170}$, colon $^{171}$, lung ${ }^{172}$, oesophagus ${ }^{173}$, kidney ${ }^{174,175}$, adrenal gland ${ }^{176}$, anterior pituitary ${ }^{177}$, breast ${ }^{178}$, prostate ${ }^{179}$ and polymorphonuclear leukocytes ${ }^{180}$. The majority of compounds that are substrates for CYP3A4 are also metabolized by CYP3A5, usually with a higher catalytic efficiency. Rendic provided a detailed list of CYP3A4 and CYP3A5 substrates ${ }^{181}$. The induction mechanism for CYP3A4 and CYP3A5 is similar and it is therefore unlikely that drug interactions involving enzyme 
inducers such as rifampicin will be affected by the CYP3A5 genotype. However, the interactions involving CYP3A enzyme inhibition are probably more common than those involving induction. There is increasing evidence that CYP3A4 and CYP3A5 show differences in their response to enzyme inhibitors and it is therefore possible that CYP3A5 expression may be a determinant of individual susceptibility to drug interactions involving inhibition. In a detailed study regarding the differences between CYP3A4 and CYP3A5 with respect to inhibition, differences in the extent of inhibition by ketoconazole and diltiazem were confirmed and there was also less inhibition of CYP3A5 than CYP3A4 by erythromycin and nicardipine ${ }^{182}$. Regarding the mechanismbased inhibitors, it was suggested that the lower level of inhibition of CYP3A5 was due to a decreased ability to form the metabolites associated with metabolite-intermediate complex rather than an inability to form such a complex. The CYP3A5*3 variant allele designated for the presence of a genomic A6986G transition within intron 3 is the most common and functionally important variant across all ethnic populations studied ${ }^{183}$, while additional rare polymorphisms that affect CYP3A5 activity in individuals expressing the enzyme have also been identified ${ }^{184}$. The non-coding CYP3A5 A6986G polymorphism creates a cryptic consensus splice site in the pre-mRNA, resulting in the incorporation of $131 \mathrm{bp}$ of intron 3 sequence (named exon $3 \mathrm{~B}$ and inserted between exon 3 and exon 4) in the mature mRNA, and the production of improperly spliced mRNA containing exon $3 B$ (splice variant 1 ) and a small amount of properly spliced mRNA (wt-mRNA) ${ }^{157,185}$. The insertion causes a frameshift and a predicted premature termination codon, so that the encoded protein is truncated at amino acid residue 102 with loss of enzyme activity. According to the cytochrome P450 nomenclature (see website cytochrome P450 iso-enzyme nomenclature: http://www.cypalleles.ki.se/) any allele positive for $6986 \mathrm{~A}$ is designated CYP3A5* 1 while any allele positive for $6986 \mathrm{G}$ is designated CYP3A5*3. The CYP3A5*1 allele has a frequency of $5-7 \%$ in European Caucasians compared with approximately $40 \%$ among Africans and African Americans, and $25 \%$ in various Asian ethnic groups ${ }^{163,184-193}$. Additionally, Xie et al. ${ }^{183}$ performed a meta-analysis on the ethnic distribution of CYP3A5 alleles and genotypes.

A large number of studies demonstrated the influence of the CYP3A5 genotype on the dose requirement and clearance of the widely used immunosuppressants tacrolimus $^{58,60,61,64-67,69-71,74-76,194-205}$, cyclosporine ${ }^{42,66,67,203,206-213}$ and sirolimus ${ }^{74,214-216}$ in organ transplant patients. A number of studies found the CYP3A5*3 polymorphism a good predictor of the tacrolimus dose requirement and the tacrolimus plasma levels $^{58,60,61,64-67,69-71,74-76,194-203,205}$. Additionally, two studies ${ }^{67,201}$ determined using stepwise multiple regression analysis that the CYP3A5 genotype can explain approximately $35 \%$ of the variation observed in the tacrolimus concentrations of the transplant patients. The influence of CYP3A5 genotypes on the cyclosporin metabolism has also been examined in a number of studies ${ }^{66,67,203,206-213,217}$. Most of these studies $^{66,203,206-208}$ found no significantly increased rate of drug clearance in patients carrying a CYP3A5*1 allele, although some other studies observed a significant decrease in dose adjusted plasma trough levels ${ }^{67,210-213,217}$. Although the reason is not 
clear why the CYP3A5 genotype is less predictive for cyclosporin than for tacrolimus pharmacokinetics a few possible explanations can be given. The most evident explanation is that tacrolimus might be a better substrate for CY3A5 compared to CYP3A4 than is cyclosporin. Kamden et al. ${ }^{218}$ demonstrated that the turnover percentage for CYP3A5 with tacrolimus is approximately $60 \%$ higher than that for CYP3A4. This could explain the apparent higher requirement for tacrolimus in patients carrying a CYP3A5 1 allele. The published data on the cyclosporin metabolism is limited and is based on the CYP3A isoforms expressed in HepG2 cells using a vaccinia virus system $^{113}$. In this study the ability of CYP3A5 to form the M17 metabolite was approximately $60 \%$ of that of CYP3A4, and no formation of the other oxidation metabolites M1 and M21 could be detected by CYP3A5. Another in vitro study ${ }^{219}$ demonstrated that CYP3A5 may contribute to the formation of primary and secondary metabolites of cyclosporine, particularly in kidneys carrying the wild type CYP3A5*1 allele. Another possible explanation for the discrepancy between the effect of CYP3A5 genotype on the metabolism of the two immunosuppressants could be related to differences in the extent of the first-pass metabolism. Despite a twofold difference observed in a recent study ${ }^{201}$ between patients homozygous for the CYP3A5*1 allele and those homozygous for CYP3A5*3 variant allele, other factors like gender, age, body mass index (BMI), time since transplantation and the use of steroids also may contribute to the wide intersubject variability in dose requirement ${ }^{67,201,220,221}$. Although at the moment the clinical relevance of the association between tacrolimus pharmacokinetics and CYP3A5 remains unclear, it is possible that CYP3A5 genotyping could form part of a genetic test to predict tacrolimus dose requirement. A recent study ${ }^{202}$ proposed after examining 19 volunteers between two dialysis periods a twofold higher tacrolimus dose requirement for patients carrying at least one CYP3A5*1 compared to patients carrying a CYP3A5*3 variant allele.

\subsubsection{Cytochrome P450 (CYP450) 3A7}

The CYP3A7 gene is encoded by a $17.1 \mathrm{~kb}$ sequence on the human chromosome $7 q 22.1$ and spans 13 exons $^{222}$. CYP3A7 accounts for between 30 and $50 \%$ of the total cytochrome P450 activity in fetal liver ${ }^{223}$, although it is now apparent that it is also expressed in adult liver. In adult livers expressing high levels of CYP3A7, it has been suggested that this isoform may contribute up to $20 \%$ of the total CYP3A ${ }^{176}$. CYP3A7 is also expressed in adult extrahepatic tissues, including intestine, endometrium, adrenal gland and prostate ${ }^{176,224,225}$. In the endometrium, expression of CYP3A7 has been demonstrated to occur at high levels during the proliferative phase of the menstrual cycle $^{226}$. Expression patterns in adult intestine seem to parallel those in adult liver ${ }^{224}$ but it is still unclear whether expression in other tissues is subject to the same interindividual variability. The majority of the CYP3A7 substrates are similar to those for CYP3A4 and CYP3A5 except that the $V_{\max }$ values tend to be lower and $\mathrm{K}_{\mathrm{m}}$ higher in most cases. However, CYP3A7 shows a higher catalytic activity for the retinoic acid isomers all-trans retinoic acid, 13-cis retinoic acid and 9-cis retinoic acid compared with 
both CYP3A4 and CYP3A5 ${ }^{227,228}$. This may indicate a role for CYP3A7 in certain key developmental processes in view of the central role of retinoic acid in regulating some pathways and the need to maintain very specific local concentrations of this compound during the development ${ }^{229}$. In addition, CYP3A7 shows a high activity in the $16 \alpha-$ hydroxylation of estrone and dehydroepiandrosterone ${ }^{115,184}$. This may be of considerable relevance to both normal physiological processes and in relation to cancer susceptibility in view of the fact that CYP3A7 has now been shown to be expressed in several different steroidresponsive adult tissues. A study on the induction of CYP3A7 in fetal hepatocytes found induction by dexamethasone but not by rifampicin and suggested that induction was not mediated by the pregnane $X$ receptor (PXR) but by the glucocorticoid receptor ${ }^{230}$. The CYP3A $7{ }^{*} 1 \mathrm{C}$ variant allele was reported at a frequency of $3 \%$ in Caucasians, $6 \%$ in African American and $0 \%$ in Chinese ${ }^{185,224}$; Op den Buijsch et al. Submitted 2007. While the CYP3A7*1B and CYP3A7*1D variant alleles have allele frequencies of $1 \%$ in Caucasians and the CYP3A $7{ }^{*} 1 \mathrm{E}$ variant allele has been determined in African Americans at a frequency of $8 \%{ }^{185,224}$. The cause of CYP3A7 expression in the adult liver appears to be the G291T substitution which results in the creation of a binding site for the hepatocyte transcription factor hepatocyte nuclear factor-3 (HNF-3), whereas the A232C change destroys an HNF-3 binding site and creates a putative octamer motif identical to that found in the upstream sequence of CYP3A4 ${ }^{231}$.

\subsubsection{Uridine 5'-diphosphate glucuronosyltransferase (UGT) $2 B 7$}

The analysis of tacrolimus metabolites in humans has provided evidence not only for CYP3A catalysed metabolism, but also for the formation of glucuronides ${ }^{232}$. Strassburg et al. $^{233}$ examined the glucuronidation activities of different uridine 5'-diphosphate glucuronosyltransferase (UGT) subfamilies for both tacrolimus and cyclosporine and found that UGT2B7 showed the highest glucuronidation activity in the human gastrointestinal tract. The UGT family, a group of proteins responsible for the glucuronidation of several endogene and exogene compounds in humans, is mainly present in the liver. However, UGTs are also found throughout the gastrointestinal tract, where they are an integral part of prehepatic first-pass metabolism. In addition, UGTs also work in the kidneys, brain, placenta and in several other locations in the human body. The major function of glucuronidation is to increase the polarity of the target compounds, a process which facilitates their detoxification and excretion. However, glucuronidation can also result in compounds which are biologically active or demonstrate increased toxicity. After glucuronidation, intestinal bacterial $\beta$-glucuronidases break down glucuronidation products and release the unconjugated drugs via enterohepatic recirculation. This "recycling" system slowly clears conjugated compounds and releases glucuronides for re-use ${ }^{234-238}$. Metabolites of tacrolimus have been isolated from human plasma, bile and urine and have been generated in human liver microsomes ${ }^{98,120,239,240}$. Up to 15 metabolites (demethyl-, demethylhydroxy-, didemethyl-, didemethylhydroxy-, and hydroxytacrolimus) have been identified in blood 
samples obtained from liver and renal transplant recipients, with the demethyl (approximately $3 \%$ of the area under the concentrationtime curve (AUC) of tacrolimus) and the demethylhydroxy (approximately $10 \%$ of the AUC of tacrolimus) compounds being the most prevalent ${ }^{121}$. Tacrolimus is predominantly metabolised into 13-Odemethyltacrolimus in liver and blood $^{98,120,239,240}$. This metabolite was found to be approximately one-tenth as active as tacrolimus ${ }^{87,92}$. Based on the blood concentration data, tacrolimus is considered a low clearance drug with clearance equivalent to $3 \%$ of the liver blood flow ${ }^{97}$. Figure 2.4 illustrates an overview of the tacrolimus metabolism.

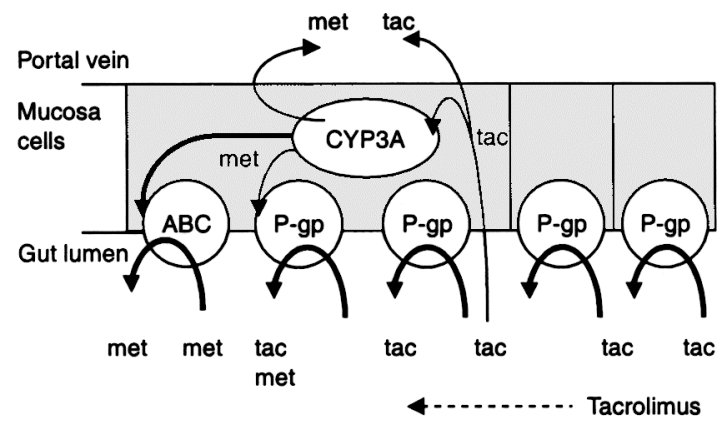

Figure 2.4 Proposed interactions between tacrolimus metabolism and active efflux in the small intestine mucosa. Two potential cooperative mechanisms between cytochrome P450 (CYP) enzymes and active efflux transporters have been proposed. P-glycoprotein regulates the access of drugs to CYP enzymes and prevents CYP enzymes from being overwhelmed by the high drug concentrations in the intestine ${ }^{51,52,369}$. With the drug being repeatedly transported out of the mucosa cells and being reabsorbed, repeated exposure leads to more efficient metabolism. The metabolites are better substrates of another active transporter than the parent, thus avoiding inhibition of metabolite efflux by the high concentrations of the parent drug ${ }^{370} . A B C=$ ATP binding cassette transporter other than P-glycoprotein; met = tacrolimus metabolite; P-gp = Pglycoprotein; tac $=$ tacrolimus.

\subsubsection{Pregnane X receptor (PXR)}

The pregnane $\mathrm{X}$ receptor $(\mathrm{PXR})^{241}$ also known as $\mathrm{SXR}^{242}$, hPAR ${ }^{243}$ or NR (nuclear receptor) 112 has been identified as a transcriptional regulator of CYP3A4 ${ }^{241,243}$ and $A B C B 1^{244,245}$. PXR binds as a heterodimer with the 9-cis retinoic acid receptor (RXR; NR2B) to previously characterized xenobiotic response elements in CYP3A gene promoters, and importantly, PXR is activated by the spectrum of chemicals that are known to induce CYP3A gene expression ${ }^{246,247}$. Single nucleotide polymorphisms (SNPs) in the PXR gene can possibly influence the PXR activity and thereby the CYP3A4 and ABCB1 expression. 


\subsubsection{Constitutive androstane receptor (CAR)}

The consititutive androstane receptor (CAR) encoded by NR1/3 is a member of the orphan nuclear receptor superfamily that plays a major role in the control of drug metabolism and disposition ${ }^{248}$. CAR binds to the DNA of target genes as a heterodimer with the retinoid $X$ receptor $(R X R \alpha)$ and regulates gene transcription ${ }^{249-251}$. CAR is predominantly expressed in the liver and intestine ${ }^{252,253}$. CAR regulates transcription of the genes encoding drug/steroid metabolizing enzymes as well as other physiologically important enzymes. Moreover, CAR transactivates several hepatic cytochrome P450s and other enzymes involved in drug metabolism including UGT1A $1^{254}, \mathrm{CYP} 2 \mathrm{~B} 6{ }^{255}$, CYP3A4 ${ }^{251}$, CYP2C9 ${ }^{251,255}$ and CYP2C19 ${ }^{256}$. Therefore, polymorphisms inducing changes in the function or expression of the NR1/3 are thought to be potential sources for variation in cytochrome P450 expression or drug metabolism in humans.

\subsubsection{Glucocorticoid receptor (GR)}

The glucocorticoid receptor (GR), encoded by NR3C1, is a member of the nuclear hormone receptor of transcription factors. In the cytosol, GRs are associated with heatshock and other proteins, and the binding of glucocorticoid leads to their nuclear translocation and positive or negative regulation of various genes ${ }^{257,258}$. The GR causes anti-inflammatory effects through transcriptional activation of glucocorticoid induced leucine zipper genes or transcriptional suppression of genes of inflammatory cytokines induced by NF-kappaB or AP-1 ${ }^{259-261}$. Therefore, it is possible that the altered transcriptional activity of GR associated with polymorphisms of NR3C1 might affect the expression levels of target genes including CYP450 enzymes. Furthermore the GR regulates the expression of many drug metabolising enzymes. For instance, it is reported that GR activates the transcription of drug metabolizing enzymes CYP2B6, CYP2C8, CYP2C9, CYP2C18, CYP2C19, CYP3A4 and CYP3A5 through GREs in the promoter/enhancer regions of these genes or induction of both pregnane $\mathrm{X}$ receptor and constitutive androstane receptor ${ }^{251,256,262-265}$. Individual differences of CYP450 enzymes are thought to result from differences in their expression levels and/or activities ${ }^{265}$.

\subsection{Non-genetic factors affecting the pharmacokinetics}

\subsubsection{Sex}

Fitzsimmons et al. ${ }^{36}$ observed no sexspecific effects on the pharmacokinetic profile of tacrolimus after examining the pharmacokinetic data collected from 127 adult (49 female and 78 male) who participated in three phase I studies and five multicentre, phase II clinical trails and 343 transplant recipients (149 female and 194 male) who participated in two phase III clinical trails. Healthy volunteers, pre and posttransplant renal recipients and bone marrow recipients demonstrated no sex differences in pharmacokinetics. However, Kuypers et $a l^{220}$ recently reported that female renal transplant recipients reached overall higher $C_{\max }$ levels compared to their male counterparts (mean 26.1 \pm 9.1 
$\mu \mathrm{g} / \mathrm{l}$ versus $22.5 \pm 8.8 \mu \mathrm{g} / \mathrm{l} ; P=0.04$, respectively) and six months after grafting, the tacrolimus $\mathrm{AUC}_{0-12}$ was significantly higher in female renal transplant recipients $(148.7 \pm 35.2 \mu \mathrm{g} \times \mathrm{hr} / \mathrm{l}$ versus $132.9 \pm 32.5 \mu \mathrm{g} \times \mathrm{hr} / \mathrm{l} ; P=0.003)$

\subsubsection{Age}

Numerous studies already demonstrated that paediatric transplant recipients require two to fourfold higher tacrolimus doses than adults to maintain similar trough concentrations $^{95,266-267}$. The higher tacrolimus doses required in pediatric patients have been attributed to differences in cytochrome P450 3A although differences in bowel length, hepatic blood flow and P-glycoprotein expression also need to be considered ${ }^{272}$. The CYP3A4 content in hepatic tissue is extremely low in the foetus but increases rapidly after birth to $120 \%$ of adult levels after the age of one year. In addition, CYP3A5 is expressed in nearly $50 \%$ of all infant livers, but could be found in only $29 \%$ of adult livers $^{273}$. However, it is unclear whether intestinal CYP3A expression changes in parallel with hepatic CYP3A expression during human maturation. Moreover, it is also not known whether P-glycoprotein expression changes with age. In addition Kuypers et al. ${ }^{220}$ found that six months after grafting the tacrolimus $\mathrm{AUC}_{0-12}$ increased with younger age $\left(\mathrm{R}^{2}=-0.20 ; P=0.007\right)$. Tacrolimus trough levels were lower with increasing age $\left(\mathrm{R}^{2}=-0.13 ; P=0.05\right.$ day 7 and $\mathrm{R}^{2}=-0.20 ; P=0.005$ at six months).

\subsubsection{Race}

African-American transplant patients require higher tacrolimus dosages $(\mathrm{mg} / \mathrm{kg})$ than Asians (Chinese or Japanese) and Caucasians ${ }^{36-40,274,275}$. Moreover, bioavailability was significantly reduced among Black patients $(9.9 \% \text { versus } 19 \%)^{36}$. After oral tacrolimus administration, tacrolimus $\mathrm{C}_{\max }$ were significantly lower in the African-American than in the White transplant patients. The differences between ethnic groups may result from racial differences in intestinal CYP3A or P-glycoprotein activity ${ }^{40,275}$.

\subsubsection{Haematocrit and albumin concentrations}

Undre et $a l^{276}$ found, after examining 303 renal transplant recipients, a correlation between the relative clearance and both haematocrit $(r=0.81)$ and albumin $(r=0.74)$ concentration over the first 12 weeks posttransplantation. After examining blood samples from 33 patients with autoimmune diseases and recipients of bone marrow and liver transplant undergoing cyclosporine immunosuppressive therapy, Kuzuya et al. ${ }^{277}$ found, after adding tacrolimus to each blood sample at a final concentration of $7.5 \mathrm{ug} / \mathrm{l}$ and $15 \mathrm{ug} / \mathrm{l}$, that haematocrit interferes with the MEIA II for tacrolimus. Furthermore that the magnitude of the interference is clinically significant, especially during the early posttransplantation period, because the haematocrit fluctuates widely and the target concentration of tacrolimus is variable. Additionally, Kuzuya et al. ${ }^{277}$ even proposed that beyond the range from $30 \%$ to $40 \%$ of haematocrit values, caution should be exercised in interpreting results as one may need to compensate for the levels of tacrolimus. 
Recently Brown et al. ${ }^{278}$ demonstrated, after examining 1156 blood samples obtained from 121 paediatric recipients of renal, liver and bone marrow grafts or hepatocyte or pancreatic islet cell implants, that patients with a low packed cell volume and plasma albumin are likely to show artificially high tacrolimus concentration when measured by MEIA. This increased risk of underimmunosuppression must be considered should doses be reduced to lower these seemingly high tacrolimus concentrations. More recently Cheung et $a l^{201}$ also reported, after using stepwise multiple regression analysis, that the haematocrit levels may explain $35 \%$ of the variability in the tacrolimus blood concentrations. Knowing that in this study Cheung et al. ${ }^{201}$ used blood samples obtained from a wide spread period after transplantation namely (133-4982 days) it is likely that this percentage will be much higher in a transplant recipient group just after transplantation. These results are in line with the strong binding of tacrolimus to red blood cells and serum albumin. Haematocrit and $\alpha_{1}$-acid glycoprotein concentrations are generally lower in renal transplant patients immediately post surgery and increase significantly when the patients recovers ${ }^{279}$. Ghoshal et al. ${ }^{280}$ demonstrated a correlation between IMx II and LC MS/MS of respectively $r=0.612$ and 0.829 for tacrolimus concentrations above and below $9 \mathrm{ng} / \mathrm{ml}$ which may imply that influence of a low haematocrit fraction is minor for tacrolimus concentration above $9 \mathrm{ng} / \mathrm{ml}$. Additionally, Ghosal et al. ${ }^{280}$ suggested that tacrolimus concentrations below $9 \mathrm{ng} / \mathrm{ml}$ measured by MEIA II are questionable and should be interpreted with caution.

\subsubsection{Time after transplant action}

Several studies among patients who underwent a different organ transplantation have reported a decrease in the dosage of tacrolimus required to maintain similar trough concentrations with increasing time posttransplant ${ }^{42,276,281,282}$. A generally considered cause for the decrease in the tacrolimus dosage is a decrease in the tacrolimus clearance with time, although an increased bioavailability also has to be considered as a feasible explanation. Pou et al. ${ }^{281}$ found, in 50 adult liver transplant recipients, significant reductions in the dose-normalised trough concentration of tacrolimus after the first and third month of treatment. Additionally, Undre et al. ${ }^{276}$ demonstrated in 303 renal transplant recipients after two years that the decline in the dose-normalised trough concentration was $61.1 \%$ and the tacrolimus dosage was reduced by $50 \%$. Potential explanations for this are a reduction in the corticosteroid dosage and the increased haematocrit and albumin concentrations.

\subsubsection{Corticosteroid dosage}

The concomitant use of corticosteroids, which may induce CYP3A iso-enzymes, also has the potential to influence the tacrolimus elimination although contradictory studies appeared. Undre et $a l^{276}$ found, after examining 303 renal transplant recipients, a significant correlation between the relative clearance and the mean oral corticosteroid dosage $(r=0.94)$ during months $2-12$ posttransplant which indicates that corticosteroids 
increase the tacrolimus metabolism. Other studies demonstrated, or at least suggested the opposite effect ${ }^{283,284}$, while researchers examining bone marrow transplant patients could not demonstrate any influence ${ }^{285}$.

\subsubsection{Population}

A higher tacrolimus clearance was found for adult renal transplant recipients compared to liver transplant recipients and healthy volunteers ${ }^{286,287}$. The presence of low haematocrit and albumin concentrations and differences in corticosteroid dosage may be partly responsible for this observations ${ }^{287,288}$. A $38 \%$ reduction in the $\mathrm{AUC}_{0-12}$ associated with tacrolimus was reported in diabetics compared to non-diabetic patients pre-transplant ${ }^{41}$. This may be due to disturbed gastrointestinal motility in patients with diabetes mellitus.

\subsubsection{Hepatic dysfunction}

Several studies already reported that a poor liver function can decrease tacrolimus clearance up to $67 \%$ and increase the elimination half-life with a threefold $283,286,289-292$. Cold ischaemia time and reperfusion injury to a transplanted liver may also alter the clearance of tacrolimus. However, tacrolimus clearance has been reported to be similar between healthy volunteers and patients with mild hepatic impairment ${ }^{289}$. Transplant patient who are hepatitis $C$ positive require a significantly lower mean dosage of tacrolimus than hepatic $\mathrm{C}$ negative patients to obtain the same trough concentrations $^{268,293,294}$. Horina et al. ${ }^{295}$ suggested that replication of the hepatitis virus in liver cells alters the cytochrome P450 system which results in reduced tacrolimus metabolism.

\subsubsection{Renal function}

No significant correlations have been reported between serum creatinine concentrations and the clearance of tacrolimus $(r=0.36)^{34}$. Patients with severe renal dysfunction (serum creatinine concentrations of $344-1061 \mu \mathrm{mol} / \mathrm{l}$ ) and patients on dialysis prior to renal transplantation have similar tacrolimus clearance to healthy volunteers .

\subsubsection{Donor liver characteristics}

The characteristics of the donor organ may influence the pharmacokinetics of tacrolimus in liver transplant recipients ${ }^{296}$. It is demonstrated in 118 liver transplant recipients that the mean dosage requirements were lower in patients who received a liver from donors of an older age group ( $\geq 65$ years) than from donors of a younger age group (10-25 years), possibly as a result of decreased metabolic capacity in older livers. Additionally, several studies have reported that transplant patients who received a partial liver from a living donor require significantly lower tacrolimus doses than transplant patients who received a whole liver from a deceased donor to achieve similar tacrolimus trough 
concentrations in the early posttransplant period ${ }^{297-299}$. Two studies performed in transplant patients of related living-donor liver transplant (LDLT), the tacrolimus dose needed to reach a target blood concentration correlated with the ratio of graft weight to recipient standard liver volume which indicating an increased metabolic capacity with increase graft size ${ }^{300,301}$.

\subsubsection{Impact of organ donor genotype}

CYP3A is expressed in the enterocyte and the liver, while the P-gp barrier to drug absorption probably only acts at the levels of the intestine. Liver transplantation offers a fascinating opportunity to study the impact of different genotypes in the intestine and liver with metabolism of drugs by the transplantated liver. A further layer of complexity is added by the functional regeneration of hepatic grafts with time which may lead to a progressively increasing role in drug metabolism over time ${ }^{302,303}$.

\subsubsection{Administration of food}

The influence of food on the oral absorption of tacrolimus appears to be dependent on its fat content and relative time of administration. Previous research indicated that coadministration of low fat food had minimal effect on the extent of absorption, but delayed the time to reach $\mathrm{C}_{\max }{ }^{304}$. A significant reduction in both the rate and extent of tacrolimus absorption (bioavailability reduced 27\%) was observed after concurrent administration of moderate fat food ${ }^{43}$. Another study examined the effect of meal-timing on the tacrolimus absorption and found that the tacrolimus absorption in the fasting state had a significantly greater relative bioavailability than all other treatments ${ }^{44}$. Moreover, the absorption of tacrolimus was also significantly prolonged after a meal. Van Duijnhoven et al. ${ }^{305}$ recently examined in 27 renal transplant recipients that conversion to non-fasting ingestion of tacrolimus, without dosage adjustments did not significantly change the tacrolimus trough concentrations in stable patients.

\section{$4 \quad$ Drug-drug interactions}

After oral administration, there are several factors involved in absorption of a drug which all can be the target of drug interactions: delivery to the intestine $(\mathrm{pH}$, gastric emptying and food), absorption from the intestinal lumen (dissolution, lipophilicity, stability active uptake), intestinal metabolism (phase I and phase II metabolism), active intestinal drug efflux pumps, and subsequent hepatic first pass extraction ${ }^{51,306}$. Previously, Christians et $a l^{288}$ summarizes many relevant drug interactions, the information on which the drug interactions are based (in vitro / animal studies, controlled clinical trails and clinical observations), their proposed mechanisms and their clinical effects. Recently, Wilkinson ${ }^{307}$ described in a review article about the influence of both inducers and inhibitors on felodipine blood levels (a blood pressure lowering drug). Similar reports 
have also been written tacrolimus interactions ${ }^{308-311}$. This emphasized that to decrease the variability in the tacrolimus exposure among transplant patients multiple factors like pharmacokinetics $\left(\mathrm{C}_{0}\right.$, abbreviated $\mathrm{AUC}_{0-12}$ or complete 12 hour $\left.\mathrm{AUC}\right)$, genetics (CYP3A, ABCB1, UGT2B7 and PXR polymorphisms, the possible influence of comedication and the influence of other compounds that the patient eventually use like St John's wort or grapefruit juice.

\section{$5 \quad$ Therapeutic drug monitoring}

Tacrolimus has a narrow therapeutic index and highly variable pharmacokinetic characteristics. Close monitoring of the tacrolimus concentration is required to achieve an optimal efficiency and thus minimizing the risk of subtherapeutic or toxic blood concentrations. Efficacy and side effects of tacrolimus are highly correlated with the area under the curve $\left(\mathrm{AUC}_{0-12}\right)^{312}$. The most exact way to monitor the total tacrolimus exposure is by creating 12 hour pharmacokinetic profiles, which implicates that the tacrolimus concentration should be measured at at least 6 different time points. The $\mathrm{AUC}_{0-12}$ can then be calculated according to the trapezoidal rule using the tacrolimus concentrations measured at different time points. Since recording a complete 12 hour pharmacokinetic profile for every patient is not feasible in clinical practice, traditionally many transplant centres use tacrolimus trough $\left(\mathrm{C}_{0}\right)$ concentrations to estimate the tacrolimus exposure. Although tacrolimus $\mathrm{C}_{0}$ concentrations are generally considered to be a good indication of the total systemic drug exposure ${ }^{312,313}$, its usefulness in differentiating graft rejection episodes from nephrotoxicity has been questioned ${ }^{314-317}$. Recently, the correlation between individual tacrolimus concentrations and $\mathrm{AUC}_{0-12}$ has been studied in kidney ${ }^{220,318-323}$, liver ${ }^{324}$, heart ${ }^{325,326}$ and lung ${ }^{327}$ transplant recipients. In these studies a poor association was found between the tacrolimus $\mathrm{C}_{0}$ concentrations and the $\mathrm{AUC}_{0-12}$ while tacrolimus concentrations measured at other time points showed much better correlations with the $\mathrm{AUC}_{0-12}$. Additionally, strategies have been developed that consisted of a limited number of sampling time points within a short time post dose, the so called limited sampling strategies. Several two and three time point sampling strategies showed a high correlation with the $\mathrm{AUC}_{0-12}$ in the published studies and were able to predict the $\mathrm{AUC}_{0-12}$ more accurately than the $\mathrm{C}_{0}$ concentration alone $^{318,320,321,323,325,327}$. Moreover, Op den Buijsch et al. ${ }^{328}$ recently evaluated 24 different limited sampling strategies for tacrolimus that already have been published in a different renal transplant recipient group. They found that the limited sampling strategies that used two $\left(\mathrm{C}_{2}\right.$ and $\left.\mathrm{C}_{4}\right)$ or three $\left(\mathrm{C}_{0}, \mathrm{C}_{2}\right.$ and $\left.\mathrm{C}_{4}\right)$ sample time points demonstrated the best results in their own renal transplant group. Based on the half-life of tacrolimus which is approximately ten hours, it is necessary to wait at least 36 hours ( 3.3 half-lives) to reach a steady state tacrolimus concentration after initiation of therapy or after a change in the administration regime of tacrolimus. Ideally, after starting the infusion, blood concentrations should be monitored on day 2 or 3 on average 3 to 7 times weekly 
during the first few weeks after transplantation, and less frequently thereafter. Special circumstances such as changes in liver function, presence of adverse effects or use of drugs that may alter tacrolimus kinetics may warrant more frequent monitoring ${ }^{329}$.

\section{Analytical methods used to determine the tacrolimus blood concentration}

Tacrolimus concentrations in biological fluids have been measured using a number of methods. However, the development of a simple, specific and sensitive assay method for measuring tacrolimus in biological fluids is limited by the low absorptivity of tacrolimus, the low concentrations of tacrolimus in plasma or blood and the presence of several other drugs in the blood samples of patients, which potentially interfere with the analysis of tacrolimus. The currently available assays can be categorized as enzyme immunoassays, chromatographic/mass spectrometric assays, radioreceptor assay and a bioassay.

\subsection{Enzyme immunoassays}

Tamura et al. ${ }^{330}$ reported in 1987 the first method for quantification of tacrolimus in plasma using an enzyme-linked immunosorbent assay (ELISA) method following a solid phase extraction procedure to separate tacrolimus from other components in the sample. The clinical application of this assay was first reported in $1990^{55}$ and a modification of this method has been used to measure tacrolimus in whole blood ${ }^{77,317}$. A number of drugs (Table 2.1) used to treat transplant patients do not appear to crossreact with the antibody used in the ELISA procedure ${ }^{77,331,332}$. A semi-automated technique, based on the principle of microparticle enzyme immunoassay (MEIA) method for the IMx analyser developed by Abbott that measures the concentrations of tacrolimus in whole blood has been reported ${ }^{333}$. The immunoassay MEIA I assay was found to have insufficient sensitivity to monitor patients with tacrolimus concentrations less than $5.0 \mathrm{ng} / \mathrm{ml}$ and is also not completely specific to tacrolimus with a cross reactivity of $56.2 \%$ and $5.4 \%$ for respectively $15-\mathrm{O}-$ demethyltacrolimus and 13-Odemethyltacrolimus ${ }^{334}$. Therefore, the development of a MEIA II method with a suggested lower analytical range $(1.5 \mathrm{ng} / \mathrm{ml})$ was released ${ }^{335}$. 
Table 2.1 Drugs which do not appear to cross-react with the antibody used in enzyme-linked immunosorbent assay (ELISA) $77,87,92,331,332$.

\begin{tabular}{ll}
\hline Amikacin & Netilmicin \\
Amphotericin B & Nifedipine \\
Azathioprine & Paracetamol (acetaminophen) \\
Carbamazepine & Phenobarbital (phenobarbitone) \\
Cyclosporin & Phenytoin \\
Digitoxin & Prednisolone \\
Digoxin & Primadone \\
Disopyramide & Procainamide \\
Erythromycin & Quinidine \\
Ethosuximide & Salicylates \\
Flecainide & Theophylline \\
Fluconazole & Tobramycin \\
Gentamycin & Valproic acid \\
Lidocaine (Lignocaine) & Vancomycin \\
Methylprednisolone &
\end{tabular}

\subsection{Chromatographic / mass spectrometric methods}

An LC tandem mass spectrometric (LC MS/MS) method for measuring tacrolimus and its metabolites in patients' blood, bile and urine samples is also available $120,239,240$. This method involves solid-phase extraction of the biological samples and the use of LC to separate various components, followed by the use of a mass spectrometer as a detector. Although the LC MS/MS assay is highly specific due to its capability of quantifying tacrolimus and its major metabolites and its sensitivity with a detection limit of $0.2 \mathrm{ng} / \mathrm{ml}$, the lack of routine availability of this instrumentation in transplant centres, and the difficulty in analysing large volumes of samples on a regular basis, the use of this technique is limited to pharmacokinetic and metabolism studies at the present time.

\subsection{Radioreceptor assay}

The radioreceptor assay uses tritiated dihydrotacrolimus for competition with tacrolimus extracted from the blood sample to bind partially purified preparation of FK binding protein $(\mathrm{FKBP})^{336}$. The radioreceptor assay is simple to perform, requires a small volume of blood, can provide a rapid turn-around time and the results of this assay correlate well with the whole blood ELISA assay $(r=0.97)$. However, consistently higher tacrolimus concentrations are estimated by this assay in comparison to the ELISA, indicating that the assay is non-specific. It is not clear whether the affinity of a molecule towards FKBP is related to the immunosuppressive activity of that molecule. Any further development of the radio receptor assay dependent on establishing a relationship between the factors mentioned above. 


\subsection{Bioassay}

Zeevi et al. ${ }^{337}$ reported a biological assay based on inhibition of the alloantigen-driven proliferation of a clone of allo-reactive T-cells. Although in this bioassay the metabolites with activity are being measured as tacolimus in a biological specimen, the limitations of this procedure are the slow turn around time ( $>72$ hours) and the inability to directly assay whole blood samples.

\section{$7 \quad$ Comparison of the analytical methods}

Venkataramanan et al. ${ }^{32}$ reviewed several studies that compared two or more analytical methods for measuring tacrolimus. The Protac ELISA, the MEIA and the LC tandem MS method are currently used clinically to measure the blood concentrations of tacrolimus. Whereas the ELISA method generally tends to have a higher coefficient of variation than the MEIA method, the MEIA method lacks the sensitivity required for routine clinical use. The tacrolimus blood concentrations measured by MEIA have been reported to correlate well with those of the ELISA method ${ }^{317,338,339}$ since both methods are non-specific as they also measure some of the tacrolimus metabolites. A method which uses LC prior to ELISA, MEIA or a mass spectrometric method is specific for the parent tacrolimus molecule. Other methods seem to measure additional tacrolimusrelated components in blood or plasma, owing to the non-specificity of the monoclonal antibody used. Larger discrepancies between different methods are observed in blood samples obtained from patients with an impaired liver function, indicating the accumulation of some metabolites of tacrolimus which cross-react with the antibody used in the assay procedure.

\section{Toxicity}

Generally occurring adverse effects associated with tacrolimus include nephrotoxicity, neurotoxicity, diabetogenesis, gastrointestinal disturbances, hypertension, infections and malignant complications $s^{3,340,341}$. Adverse reactions of tacrolimus tend to occur the most frequently in the first few months after transplantation and decrease with time possibly in line with reductions in tacrolimus concentration ${ }^{341,342}$. At higher tacrolimus concentrations nephrotoxicity, neurotoxicity, diabetogenesis, gastrointestinal disturbances and infections occur more frequently or are more severe ${ }^{340,341,343-347}$.

\subsection{Nephrotoxicity}

The use of tacrolimus can be limited by nephrotoxicity which occurs in approximately $50 \%$ of the patients treated with this drug ${ }^{340,341}$ although it is not always easy to attribute 
renal failure directly to tacrolimus toxicity since transplant patients often also receive other nephrotoxic drugs and may have pre-existing or ongoing kidney diseases (e.g. diabetic patients).

\subsection{Neurotoxicity}

Minor neurological adverse effects include insomnia, mild tremors, headache, photophobia, nightmares and hyperaethesis ${ }^{340,341}$. Clinical studies point out that tremors occurred in $35-56 \%$ of the transplant patients receiving tacrolimus while headaches occurred in $20-64 \%$, insomnia in $24-32 \%$ and paraesthesia in $14-40 \%^{341,342}$. Higher blood concentrations of tacrolimus are associated with less occurring severe neurological events like seizures, akinetic mutism, expressive aphasia, coma and delirium. Liver transplant recipients requiring a transplantation due to hepatitis $\mathrm{B}$ or $\mathrm{C}$ have an increased risk of severse tacrolimusinduced neurotoxicity ${ }^{344,348,349}$.

\subsection{Diabetogenic effects}

One of the most serious adverse effects of tacrolimus is posttransplant diabetes and this is most likely exacerbated by concomitant administration of corticosteroids ${ }^{347,350}$. Three major randomised, multicentre trails ${ }^{340,341}$ demonstrated that the incidence of diabetes in the first year after renal or liver transplantation ranged from $8 \%$ to $20 \%$. Bonomini et al. ${ }^{351}$ reported, after examining 245 renal transplant patients treated with triple therapy (tacrolimus, corticosteroids and azathioprine), an $4 \%$ incidence of new onset type I diabetes, while among the 246 patients receiving a dual therapy (tacrolimus and corticosteroids) the incidence of new onset type I diabetes was 5.6\% after a follow up period of three months. Posttransplant diabetes is reversible in some patients ${ }^{340,341}$. Risk factors for the development of posttransplant diabetes include, race, high tacrolimus trough concentrations and a high corticosteroid dosage ${ }^{341}$.

\subsection{Hypertension}

Hypertension occurred in up to $50 \%$ of the liver and renal transplant patients treated with tacrolimus in several clinical studies ${ }^{340,341}$ although it is difficult to determine with certainty an association between tacrolimus therapy and hypertension ${ }^{352,353}$. In transplant patients who were previously normotensive, hypertension may be caused by the excessive intravascular volume, intrinsic renal damage or increased vasomotor tone ${ }^{352}$. Moreover, corticosteroids may also lead to excess water retention, while liver failure prior to transplantation causing low peripheral resistance can mask pre-existing blood pressure problems ${ }^{353}$. 


\subsection{Gastrointestinal disturbances}

Several major clinical studies in renal and liver transplant recipients indicated that gastrointestinal disturbances like diarrhoea, nausea and constipation with frequencies of respectively $22-72 \%, 17-46 \%$ and $31-35 \%$ were common in patients treated with tacrolimus $^{340,341}$.

\subsection{Infectious complications and malignancies}

It is known that all immunosuppressive drugs increase the risk of infection and malignancy, especially lymphoma. In large clinical studies similar infection rates were found in the tacrolimus and cyclosporine treated groups in renal and liver transplant patients. Within the first year after transplantation approximately $75 \%$ of the patients had one or more infections ${ }^{341,344,354}$. According to two studies ${ }^{341,354}$ malignancies (excluding lymphoma or lymphoproliferative disease) developed in $1 \%$ of the adult renal transplant patients taking tacrolimus and the rate of lymphomas was approximately $1.5 \%{ }^{341,354}$.

\subsection{Other adverse effects}

During the tacrolimus therapy mild hyperkalaemia, associated with low or low-normal renin and aldosterone concentrations occur regularly ${ }^{352,355-357}$ and is not always correctable by dosage adjustment and may even occur at low blood tacrolimus concentrations $^{346}$. Furthermore, hypomagnesaemia has also been reported during tacrolimus treatment in renal transplant recipients and appears to be related to impairment of normal magnesium conserving mechanisms ${ }^{358}$.

\subsection{Paediatric patients}

The acceptability profile of tacrolimus in children is generally similar to that in adults $^{3,347,359-361}$. However, children appear to be at an increased risk of, to the EpsteinBarr virus related, posttransplant lymphoproliferative disorders ${ }^{22,347,362-367}$. Although some data suggest that paediatric patients may be at a particular risk of developing tacrolimus associated diabetes ${ }^{368,369}$, further study is required to confirm these findings.

\section{$9 \quad$ Concluding remarks}

Tacrolimus is an immunosuppressive drug with a large inter- and intra-individual variation in its pharmacokinetics, with variable rates and extents of absorption, variable extents of blood protein binding and variable rates of elimination. It is incompletely bioavaible after oral administration, is bound extensively to red blood cells (the binding being saturable), is primarily eliminated by hepatic metabolism and has a narrow therapeutic index. Furthermore, tacrolimus is predominantely metabolised by 
cytochrome P450 (CYP450) 3A iso-enzymes into 13-O-demethyltacrolimus which has a neglectable immunosuppressive activity. Previously, several studies have indicated that the CYP3A5 A6986G polymorphism is the most relevant polymorphism present in the CYP450 3A iso-enzyme family with a significant impact on both the tacrolimus exposure and the daily tacrolimus dose. In order to decrease the variability in the tacrolimus exposure of transplant recipients it is also recommendable to look for possible drug interactions and possible interactions with other CYP450 inducers or inhibitors like St John's wort or grapefruit juice. 


\section{References}

1. Tanaka H KA, Marusawa H. Physicochemical properties of FK506, a novel immunosuppressant isolated from Strepomyces tsukubaensis. Transplant Proc 1987;14:11-6.

2. Mierke DSP, Karuso P. Conformational analysis of the cis and trans isomers of FK506 by NMR and molecular dynamics. Helv Chim Acta 1992;1:47.

3. Plosker GL, Foster RH. Tacrolimus: a further update of its pharmacology and therapeutic use in the management of organ transplantation. Drugs 2000;59(2):323-89.

4. Pham SM, Kormos RL, Kawai A, Murali S, Hattler BG, Demetris AJ, Griffith BP. Tacrolimus (FK 506) in clinical cardiac transplantation: a five-year experience. Transplant Proc 1996;28:1002-4.

5. De Bonis M, Reynolds L, Barros J, Madden BP. Tacrolimus as a rescue immunosuppressant after heart transplantation. Eur J Cardiothorac Surg 2001;19:690-5.

6. Crespo-Leiro MG, Paniagua MJ, Mosquera I, Tabuyo T, De la Fuente L, Bouzas B, Rodriguez JA, Hermida LF, Juffe A, Castro-Beiras A. Replacement of cyclosporine by tacrolimus for immunosuppression in heart transplant patients: safety and efficacy. Transplant Proc 2002;34(1):113-4.

7. Swenson JM, Fricker FJ, Armitage JM. Immunosuppression switch in pediatric heart transplant recipients: cyclosporine to FK 506. J Am Coll Cardiol 1995;25(5):1183-8.

8. Reyes J, Mazariegos GV, Bond GM, Green M, Dvorchik I, Kosmach-Park B, Abu-Elmagd K. Pediatric intestinal transplantation: historical notes, principles and controversies. Pediatr Transplant 2002;6(3):193-207.

9. Kato T, Ruiz P, Thompson JF, Eskind LB, Weppler D, Khan FA, Pinna AD, Nery JR, Tzakis AG. Intestinal and multivisceral transplantation. World J Surg 2002;26(2):226-37.

10. Jindal RM, Dubernard JM. Towards a specific immunosuppression for pancreas and islet grafts. Clin Transplant 2000;14(3):242-5.

11. Stratta RJ, Taylor RJ, Castaldo P, Sindhi R, Sudan D, Weide LG, Frisbie K, Cushing KA, Jerius J, Radio SJ. FK 506 induction and rescue therapy in pancreas transplant recipients. Transplant Proc 1996;28(2):991-2.

12. Stratta RJ. Optimal immunosuppression in pancreas transplantation. Transplant Proc 1999;31(1-2):619-21.

13. Gruessner RW. Tacrolimus in pancreas transplantation: a multicenter analysis. Tacrolimus Pancreas Transplant Study Group. Clin Transplant 1997;11(4):299-312.

14. Jordan ML, Shapiro R, Gritsch HA, Egidi F, Khanna A, Vivas CA, Scantlebury VP, Fung JJ, Starzl TE, Corry RJ. Long-term results of pancreas transplantation under tacrolius immunosuppression. Transplantation 1999;67(2):266-72.

15. Horning NR, Lynch JP, Sundaresan SR, Patterson GA, Trulock EP. Tacrolimus therapy for persistent or recurrent acute rejection after lung transplantation. J Heart Lung Transplant 1998;17(8):761-7.

16. Kur F, Reichenspurner H, Meiser BM, Welz A, Furst H, Muller C, Vogelmeier C, Schwaiblmaier M, Briegel J, Reichart B. Tacrolimus (FK506) as primary immunosuppressant after lung transplantation. Thorac Cardiovasc Surg 1999;47(3):174-8.

17. Lipson DA, Palevsky HI, Kotloff RM, Edelman J. Conversion to tacrolimus (FK506) from cyclosporine after orthotopic lung transplantation. Transplant Proc 1998;30(4):1505-7.

18. Reichenspurner $\mathrm{H}$, Kur F, Treede $\mathrm{H}$, Meiser BM, Deutsch $\mathrm{O}$, Welz A, Vogelmeier $\mathrm{C}$, Schwaiblmair M, Muller C, Furst H, Briegel J, Reichart B. Optimization of the immunosuppressive protocol after lung transplantation. Transplantation 1999;68(1):67-71.

19. Treede H, Klepetko W, Reichenspurner H, Zuckermann A, Meiser B, Birsan T, Wisser W, Reichert B. Tacrolimus versus cyclosporine after lung transplantation: a prospective, open, randomized two-center trial comparing two different immunosuppressive protocols. J Heart Lung Transplant 2001;20(5):511-7.

20. Busuttil RW, Holt CD. Tacrolimus is superior to cyclosporine in liver transplantation. Transplant Proc 1998;30(5):2174-8. 
21. Cao S, Cox KL, Berquist W, Hayashi M, Concepcion W, Hammes GB, Ojogho OK, So SK, Frerker M, Castillo RO, Monge H, Esquivel CO. Long-term outcomes in pediatric liver recipients: comparison between cyclosporin $\mathrm{A}$ and tacrolimus. Pediatr Transplant 1999;3(1):22-6.

22. McDiarmid SV. The use of tacrolimus in pediatric liver transplantation. J Pediatr Gastroenterol Nutr 1998;26(1):90-102.

23. Reyes J, Jain A, Mazariegos G, Kashyap R, Green M, lurlano K, Fung J. Long-term results after conversion from cyclosporine to tacrolimus in pediatric liver transplantation for acute and chronic rejection. Transplantation 2000;69(12):2573-80.

24. Klein A. Tacrolimus rescue in liver transplant patients with refractory rejection or intolerance or malabsorption of cyclosporine. The US Multicenter FK506 Liver Study Group. Liver Transpl Surg 1999;5(6):502-8.

25. Berloco P, Rossi M, Pretagostini R, Sociu-Foca Cortesini N, Cortesini R. Tacrolimus as cornerstone immunosuppressant in kidney transplantation. Transplant Proc 2001;33(12):994-6.

26. Laskow DA, Neylan JF, 3rd, Shapiro RS, Pirsch JD, Vergne-Marini PJ, Tomlanovich SJ. The role of tacrolimus in adult kidney transplantation: a review. Clin Transplant 1998;12(6):489503.

27. Shapiro R. Tacrolimus in pediatric renal transplantation: a review. Pediatr Transplant 1998;2(4):270-6.

28. Shapiro R. Tacrolimus in solid organ transplantation: an update. Transplant Proc 1999;31(6):2203-5.

29. Dubinsky MC, Seidman EG. Novel immunosuppressive therapies for intestinal and hepatic diseases. Curr Opin Pediatr 1999;11(5):390-5.

30. Singer NG, McCune WJ. Update on immunosuppressive therapy. Curr Opin Rheumatol 1998;10(3):169-73.

31. Almawi WY, Melemedjian OK. Clinical and mechanistic differences between FK506 (tacrolimus) and cyclosporin A. Nephrol Dial Transplant 2000;15(12):1916-8.

32. Venkataramanan R, Swaminathan A, Prasad T, Jain A, Zuckerman S, Warty V, McMichael J, Lever J, Burckart G, Starzl T. Clinical pharmacokinetics of tacrolimus. Clin Pharmacokinet 1995;29(6):404-30.

33. Wallemacq PE, Furlan V, Moller A, Schafer A, Stadler P, Firdaous I, Taburet AM, Reding R, Clement De Clety S, De Ville De Goyet J, Sokal E, Lykavieris L, Van Leeuw V, Bernard O, Otte JB, Undre NA. Pharmacokinetics of tacrolimus (FK506) in paediatric liver transplant recipients. Eur J Drug Metab Pharmacokinet 1998;23(3):367-70.

34. Gruber SA, Hewitt JM, Sorenson AL, Barber DL, Bowers L, Rynders G, Arrazola L, Matas AJ, Rosenberg ME, Canafax DM. Pharmacokinetics of FK506 after intravenous and oral administration in patients awaiting renal transplantation. J Clin Pharmacol 1994;34(8):859-64.

35. Jain A, Venkataramanan R, Todo S, Abu-Elmagd K, Fung J, Warty V, Tzakis A, Reyes J, Alessiani M, Starzl TE. Intravenous, oral pharmacokinetics, and oral dosing of FK 506 in small bowel transplant patients. Transplant Proc 1992;24(3):1181-2.

36. Fitzsimmons WE, Bekersky I, Dressler D, Raye K, Hodosh E, Mekki Q. Demographic considerations in tacrolimus pharmacokinetics. Transplant Proc 1998;30(4):1359-64.

37. Neylan JF. Racial differences in renal transplantation after immunosuppression with tacrolimus versus cyclosporine. FK506 Kidney Transplant Study Group. Transplantation 1998;65(4):515-23.

38. Neylan JF. Effect of race and immunosuppression in renal transplantation: three-year survival results from a US multicenter, randomized trial. FK506 Kidney Transplant Study Group. Transplant Proc 1998;30(4):1355-8.

39. Mancinelli LM, Frassetto L, Floren LC, Dressler D, Carrier S, Bekersky I, Benet LZ, Christians $\mathrm{U}$. The pharmacokinetics and metabolic disposition of tacrolimus: a comparison across ethnic groups. Clin Pharmacol Ther 2001;69(1):24-31.

40. Felipe CR, Garcia C, Moreira S, Olsen N, Silva HT, Pestana OM. Choosing the right dose of new immunossuppressive drugs for new populations: importance of pharmacokinetic studies. Transplant Proc 2001;33(1-2):1095-6. 
41. van Duijnhoven E, Christiaans M, Schafer A, Undre N, van Hooff J. Tacrolimus dosing requirements in diabetic and nondiabetic patients calculated from pretransplantation data. Transplant Proc 1998;30(4):1266-7.

42. Hu RH, Lee PH, Tsai MK. Clinical influencing factors for daily dose, trough level, and relative clearance of tacrolimus in renal transplant recipients. Transplant Proc 2000;32(7):1689-92.

43. Mekki QLC, Carrier S. The effect of food on oral bioavailability of tacrolimus (FK506) in liver transplant patients [abstract]. Clin Pharmacol Ther 1993;53(2):229.

44. Bekersky I, Dressler D, Mekki Q. Effect of time of meal consumption on bioavailability of a single oral $5 \mathrm{mg}$ tacrolimus dose. J Clin Pharmacol 2001;41(3):289-97.

45. Bekersky I, Dressler D, Mekki QA. Effect of low- and high-fat meals on tacrolimus absorption following $5 \mathrm{mg}$ single oral doses to healthy human subjects. J Clin Pharmacol 2001;41(2):176-82.

46. Jusko WJ, Piekoszewski W, Klintmalm GB, Shaefer MS, Hebert MF, Piergies AA, Lee CC, Schechter P, Mekki QA. Pharmacokinetics of tacrolimus in liver transplant patients. Clin Pharmacol Ther 1995;57(3):281-90.

47. Venkataramanan R, Jain A, Warty VS, Abu-Elmagd K, Alessiani M, Lever J, Krajak A, Flowers J, Mehta S, Zuckerman S, et al. Pharmacokinetics of FK 506 in transplant patients. Transplant Proc 1991;23(6):2736-40.

48. Tuteja S, Alloway RR, Johnson JA, Gaber AO. The effect of gut metabolism on tacrolimus bioavailability in renal transplant recipients. Transplantation 2001;71(9):1303-7.

49. Benet LZ. Impact of intraindividual variability of drugs on therapeutic outcomes: lessons from outside transplantation. Transplant Proc 1998;30(5):1650-1.

50. Zhang $Y$, Benet LZ. The gut as a barrier to drug absorption: combined role of cytochrome P450 3A and P-glycoprotein. Clin Pharmacokinet 2001;40(3):159-68.

51. Wacher VJ, Silverman JA, Zhang Y, Benet LZ. Role of P-glycoprotein and cytochrome P450 $3 \mathrm{~A}$ in limiting oral absorption of peptides and peptidomimetics. J Pharm Sci 1998;87(11):1322-30.

52. Benet LZ, Izumi T, Zhang Y, Silverman JA, Wacher VJ. Intestinal MDR transport proteins and P-450 enzymes as barriers to oral drug delivery. J Control Release 1999;62(1-2):25-31.

53. Gan LS, Moseley MA, Khosla B, Augustijns PF, Bradshaw TP, Hendren RW, Thakker DR. CYP3A-like cytochrome P450-mediated metabolism and polarized efflux of cyclosporin A in Caco-2 cells. Drug Metab Dispos 1996;24(3):344-9.

54. Venkataramanan R, Jain A, Warty VW, Abu-Elmagd K, Furakawa H, Imventarza O, Fung J, Todo S, Starzl TE. Pharmacokinetics of FK 506 following oral administration: a comparison of FK 506 and cyclosporine. Transplant Proc 1991;23(1 Pt 2):931-3.

55. Cadoff EM, Venkataramanan R, Krajack A, Jain AS, Fung JJ, Todo S, Starzl TE. Assay of FK 506 in plasma. Transplant Proc 1990;22(1):50-1.

56. Bottiger $Y$, Undre NA, Sawe J, Stevenson PJ, Ericzon BG. Effect of bile flow on the absorption of tacrolimus in liver allograft transplantation. Transplant Proc 2002;34(5):1544-5.

57. Anglicheau D, Verstuyft C, Laurent-Puig P, Becquemont L, Schlageter MH, Cassinat B, Beaune $\mathrm{P}$, Legendre $\mathrm{C}$, Thervet $\mathrm{E}$. Association of the multidrug resistance-1 gene singlenucleotide polymorphisms with the tacrolimus dose requirements in renal transplant recipients. J Am Soc Nephrol 2003;14(7):1889-96.

58. MacPhee IA, Fredericks S, Tai T, Syrris P, Carter ND, Johnston A, Goldberg L, Holt DW. Tacrolimus pharmacogenetics: polymorphisms associated with expression of cytochrome p4503A5 and P-glycoprotein correlate with dose requirement. Transplantation 2002;74(11):1486-9.

59. Asano T, Nishimoto K, Hayakawa M. Increased tacrolimus trough levels in association with severe diarrhea, a case report. Transplant Proc 2004;36(7):2096-7.

60. Zheng H, Webber S, Zeevi A, Schuetz E, Zhang J, Bowman P, Boyle G, Law Y, Miller S, Lamba J, Burckart GJ. Tacrolimus dosing in pediatric heart transplant patients is related to CYP3A5 and MDR1 gene polymorphisms. Am J Transplant 2003;3(4):477-83. 
61. Zheng H, Zeevi A, Schuetz E, Lamba J, McCurry K, Griffith BP, Webber S, Ristich J, Dauber J, lacono A, Grgurich W, Zaldonis D, McDade K, Zhang J, Burckart GJ. Tacrolimus dosing in adult lung transplant patients is related to cytochrome P4503A5 gene polymorphism. J Clin Pharmacol 2004;44(2):135-40.

62. Li D, Gui R, Li J, Huang Z, Nie X. Tacrolimus dosing in Chinese renal transplant patients is related to MDR1 gene C3435T polymorphisms. Transplant Proc 2006;38(9):2850-2.

63. Akbas SH, Bilgen T, Keser I, Tuncer M, Yucetin L, Tosun O, Gultekin M, Luleci G. The effect of MDR1 (ABCB1) polymorphism on the pharmacokinetic of tacrolimus in Turkish renal transplant recipients. Transplant Proc 2006;38(5):1290-2.

64. Wei-lin W, Jing J, Shu-sen Z, Li-hua W, Ting-bo L, Song-feng Y, Sheng Y. Tacrolimus dose requirement in relation to donor and recipient $A B C B 1$ and CYP3A5 gene polymorphisms in Chinese liver transplant patients. Liver Transpl 2006;12(5):775-80.

65. Wang J, Zeevi A, McCurry K, Schuetz E, Zheng H, lacono A, McDade K, Zaldonis D, Webber S, Watanabe RM, Burckart GJ. Impact of ABCB1 (MDR1) haplotypes on tacrolimus dosing in adult lung transplant patients who are CYP $3 A 5{ }^{*} 3 /{ }^{*} 3$ non-expressors. Transpl Immunol 2006;15(3):235-40.

66. Hesselink DA, van Schaik RH, van der Heiden IP, van der Werf M, Gregoor PJ, Lindemans J, Weimar W, van Gelder T. Genetic polymorphisms of the CYP3A4, CYP3A5, and MDR-1 genes and pharmacokinetics of the calcineurin inhibitors cyclosporine and tacrolimus. Clin Pharmacol Ther 2003;74(3):245-54.

67. Haufroid V, Mourad M, Van Kerckhove V, Wawrzyniak J, De Meyer M, Eddour DC, Malaise J, Lison D, Squifflet JP, Wallemacq P. The effect of CYP3A5 and MDR1 (ABCB1) polymorphisms on cyclosporine and tacrolimus dose requirements and trough blood levels in stable renal transplant patients. Pharmacogenetics 2004;14(3):147-54.

68. Mai I, Perloff ES, Bauer S, Goldammer M, Johne A, Filler G, Budde K, Roots I. MDR1 haplotypes derived from exons 21 and 26 do not affect the steady-state pharmacokinetics of tacrolimus in renal transplant patients. Br J Clin Pharmacol 2004;58(5):548-53.

69. Tsuchiya N, Satoh S, Tada H, Li Z, Ohyama C, Sato K, Suzuki T, Habuchi T, Kato T. Influence of CYP3A5 and MDR1 (ABCB1) polymorphisms on the pharmacokinetics of tacrolimus in renal transplant recipients. Transplantation 2004;78(8):1182-7.

70. Tada H, Tsuchiya N, Satoh S, Kagaya H, Li Z, Sato K, Miura M, Suzuki T, Kato T, Habuchi T. Impact of CYP3A5 and MDR1(ABCB1) C3435T polymorphisms on the pharmacokinetics of tacrolimus in renal transplant recipients. Transplant Proc 2005;37(4):1730-2.

71. Goto M, Masuda S, Kiuchi T, Ogura Y, Oike F, Okuda M, Tanaka K, Inui K. CYP3A5*1carrying graft liver reduces the concentration/oral dose ratio of tacrolimus in recipients of living-donor liver transplantation. Pharmacogenetics 2004;14(7):471-8.

72. Goto M, Masuda S, Saito H, Uemoto S, Kiuchi T, Tanaka K, Inui K. C3435T polymorphism in the MDR1 gene affects the enterocyte expression level of CYP3A4 rather than Pgp in recipients of living-donor liver transplantation. Pharmacogenetics 2002;12(6):451-7.

73. Hebert MF, Dowling AL, Gierwatowski C, Lin YS, Edwards KL, Davis CL, Marsh CL, Schuetz EG, Thummel KE. Association between ABCB1 (multidrug resistance transporter) genotype and post-liver transplantation renal dysfunction in patients receiving calcineurin inhibitors. Pharmacogenetics 2003;13(11):661-74.

74. Mourad M, Mourad G, Wallemacq P, Garrigue V, Van Bellingen C, Van Kerckhove V, De Meyer M, Malaise J, Eddour DC, Lison D, Squifflet JP, Haufroid V. Sirolimus and tacrolimus trough concentrations and dose requirements after kidney transplantation in relation to CYP3A5 and MDR1 polymorphisms and steroids. Transplantation 2005;80(7):977-84.

75. Mourad M, Wallemacq P, De Meyer M, Brandt D, Van Kerkhove V, Malaise J, Chaib Eddour $D$, Lison D, Haufroid V. The influence of genetic polymorphisms of cytochrome P450 3A5 and $A B C B 1$ on starting dose- and weight-standardized tacrolimus trough concentrations after kidney transplantation in relation to renal function. Clin Chem Lab Med 2006;44(10):1192-8.

76. Zhang X, Liu ZH, Zheng JM, Chen ZH, Tang Z, Chen JS, Li LS. Influence of CYP3A5 and MDR1 polymorphisms on tacrolimus concentration in the early stage after renal transplantation. Clin Transplant 2005;19(5):638-43. 
77. Warty VS, Venkataramanan R, Zendehrouh P, Mehta S, McKaveney T, Flowers J, Zuckerman S, Krajak A, Zeevi A, Fung, et al. Practical aspects of FK 506 analysis (Pittsburgh experience). Transplant Proc 1991;23(6):2730-1.

78. Beysens AJ, Wijnen RM, Beuman GH, van der Heyden J, Kootstra G, van As H. FK 506: monitoring in plasma or in whole blood? Transplant Proc 1991;23(6):2745-7.

79. Ericzon BG, Ekqvist B, Groth CG, Sawe J. Pharmacokinetics of FK 506 during maintenance therapy in liver transplant patients. Transplant Proc 1991;23(6):2775-6.

80. Machida M, Takahara S, Ishibashi M, Hayashi M, Sekihara T, Yamanaka H. Effect of temperature and hematocrit on plasma concentration of FK 506. Transplant Proc $1991 ; 23(6): 2753-4$.

81. Jusko WJ, D'Ambrosio R. Monitoring FK 506 concentrations in plasma and whole blood. Transplant Proc 1991;23(6):2732-5.

82. Habucky K. FK506: its pharmacokinetics and interactions with other drugs [dissertation]. Pittsburgh: University of Pittsburgh; 1992.

83. Kay JE, Sampare-Kwateng E, Geraghty F, Morgan GY. Uptake of FK 506 by lymphocytes and erythrocytes. Transplant Proc 1991;23(6):2760-2.

84. Habucky K. Blood protein binding (BPB) of FK506 (F) in various species [abstract]. Pharm Res 1992;9(Suppl):334.

85. Piekoszewski W, Jusko WJ. Plasma protein binding of tacrolimus in humans. J Pharm Sci 1993;82(3):340-1.

86. Nagase K, Iwasaki K, Nozaki K, Noda K. Distribution and protein binding of FK506, a potent immunosuppressive macrolide lactone, in human blood and its uptake by erythrocytes. J Pharm Pharmacol 1994;46(2):113-7.

87. Iwasaki K, Shiraga T, Nagase K, Tozuka Z, Noda K, Sakuma S, Fujitsu T, Shimatani K, Sato A, Fujioka M. Isolation, identification, and biological activities of oxidative metabolites of FK506, a potent immunosuppressive macrolide lactone. Drug Metab Dispos 1993;21(6):9717.

88. Karanam BV, Vincent SH, Newton DJ, Wang RW, Chiu SH. FK 506 metabolism in human liver microsomes: investigation of the involvement of cytochrome P450 isozymes other than CYP3A4. Drug Metab Dispos 1994;22(5):811-4.

89. Perotti BY, Prueksaritanont T, Benet LZ. HPLC assay for FK 506 and two metabolites in isolated rat hepatocytes and rat liver microsomes. Pharm Res 1994;11(6):844-7.

90. Sattler M, Guengerich FP, Yun CH, Christians U, Sewing KF. Cytochrome P-450 3A enzymes are responsible for biotransformation of FK506 and rapamycin in man and rat. Drug Metab Dispos 1992;20(5):753-61.

91. Iwasaki K, Matsuda H, Nagase K, Shiraga T, Tokuma Y, Uchida K. Effects of twenty-three drugs on the metabolism of FK506 by human liver microsomes. Res Commun Chem Pathol Pharmacol 1993;82(2):209-16.

92. Iwasaki K, Shiraga T, Matsuda H, Nagase K, Tokuma Y, Hata T, Fujii Y, Sakuma S, Fujitsu T, Fujikawa A, et al. Further metabolism of FK506 (tacrolimus). Identification and biological activities of the metabolites oxidized at multiple sites of FK506. Drug Metab Dispos 1995;23(1):28-34.

93. Perotti BY, Okudaira N, Prueksaritanont T, Benet LZ. FK 506 metabolism in male and female rat liver microsomes. Drug Metab Dispos 1994;22(1):85-9.

94. Gusev AM, DC Proctor, A. In vitro hepatic metabolism of tacrolimus (FK506) using SIMS and MALDI mass spectrometry [abstract]. 43rd ASMS Conference on Mass Spectrometry and Allied Topics: 1995 May 21-26, Atlanta (GA) 1995:560.

95. Jain AB, Fung JJ, Tzakis AG, Venkataramanan R, Abu-Elmagd K, Alessiani M, Reyes J, Irish W, Warty V, Mehta S, et al. Comparative study of cyclosporine and FK 506 dosage requirements in adult and pediatric orthotopic liver transplant patients. Transplant Proc 1991;23(6):2763-6.

96. Wallemacq PE, Verbeeck RK. Comparative clinical pharmacokinetics of tacrolimus in paediatric and adult patients. Clin Pharmacokinet 2001;40(4):283-95. 
97. Moller A, Iwasaki K, Kawamura A, Teramura Y, Shiraga T, Hata T, Schafer A, Undre NA. The disposition of $14 \mathrm{C}$-labeled tacrolimus after intravenous and oral administration in healthy human subjects. Drug Metab Dispos 1999;27(6):633-6.

98. Christians U, Radeke HH, Kownatzki R, Schiebel HM, Schottmann R, Sewing KF. Isolation of an immunosuppressive metabolite of FK506 generated by human microsome preparations. Clin Biochem 1991;24(3):271-5.

99. Shiraga T, Matsuda H, Nagase K, Iwasaki K, Noda K, Yamazaki H, Shimada T, Funae Y. Metabolism of FK506, a potent immunosuppressive agent, by cytochrome P450 3A enzymes in rat, dog and human liver microsomes. Biochem Pharmacol 1994;47(4):727-35.

100. Vincent SH, Karanam BV, Painter SK, Chiu SH. In vitro metabolism of FK-506 in rat, rabbit, and human liver microsomes: identification of a major metabolite and of cytochrome P450 3A as the major enzymes responsible for its metabolism. Arch Biochem Biophys 1992;294(2):454-60.

101. Tata P VR, Gusev A. Tacrolimus metabolism in baboon liver microomes [abstract]. Pharm Res 1994;11:S354.

102. Lhoest G, Maton N, Verbeeck RK. Isolation and identification of a novel isomerized epoxide metabolite of FK-506 from erythromycin-induced rabbit liver microsomes. Drug Metab Dispos 1993;21(5):850-4.

103. Lhoest G, Maton N, Verbeeck R. Isolation and mass spectrometric identification of two metabolites of FK 506 from rat liver microsomal incubation media. Pharm Acta Helv 1992;67(9-10):270-4.

104. Lhoest G, Maton N, Laurent A, Verbeeck RK. Isolation and identification of a FK-506 C36C37 dihydrodiol from erythromycin-induced rabbit liver microsomes. J Pharm Biomed Anal 1994;12(2):235-41.

105. Lhoest G, Dieden R, Verbeeck RK, Maton N, Ingendoh A, Latinne D. In vitro immunosuppressive activity, isolation from pig liver microsomes and identification by electrospray ms-ms of a new FK-506 C19-C20 epoxide metabolite. J Pharmacol Exp Ther 1998;284(3):1074-81.

106. Lhoest $G$, Wallemacq $P$, Verbeeck $R$. Isolation and mass spectrometric identification of five metabolites of FK-506, a novel macrolide immunosuppressive agent, from human plasma. Pharm Acta Helv 1991;66(11):302-6.

107. Lhoest G, Verbeeck RK, Maton N, Muthelet P, Latinne D. The in vitro immunosuppressive activity of the C15-demethylated metabolite of FK-506 is governed by ring- and open-chain tautomerism effects. J Pharmacol Exp Ther 1995;274(2):622-6.

108. Lhoest GJ, Maton N, Latinne D, Laurent A, Verbeeck RK. 15-Desmethyl FK-506 and 15,31desmethyl FK-506 from human liver microsomes: isolation, identification (by fast atom bombardment mass spectrometry and NMR), and evaluation of in vitro immunosuppressive activity. Clin Chem 1994;40(5):740-4.

109. Schüler W CU, Schmieder P. Structural identification of 13-demethyl-FK506 and its isomers generated by in vitro metabolism of FK506 using human liver microsomes. Helv Chim Acta 1993;76:28-34.

110. Molowa DT, Schuetz EG, Wrighton SA, Watkins PB, Kremers P, Mendez-Picon G, Parker GA, Guzelian PS. Complete cDNA sequence of a cytochrome P-450 inducible by glucocorticoids in human liver. Proc Natl Acad Sci U S A 1986;83(14):5311-5.

111. Beaune PH, Umbenhauer DR, Bork RW, Lloyd RS, Guengerich FP. Isolation and sequence determination of a cDNA clone related to human cytochrome P-450 nifedipine oxidase. Proc Natl Acad Sci U S A 1986;83(21):8064-8.

112. Wrighton SA, Ring BJ, Watkins PB, VandenBranden M. Identification of a polymorphically expressed member of the human cytochrome P-450III family. Mol Pharmacol 1989;36(1):97105.

113. Aoyama T, Yamano S, Waxman DJ, Lapenson DP, Meyer UA, Fischer V, Tyndale R, Inaba T, Kalow W, Gelboin HV, et al. Cytochrome P-450 hPCN3, a novel cytochrome P-450 IIIA gene product that is differentially expressed in adult human liver. cDNA and deduced amino acid sequence and distinct specificities of cDNA-expressed hPCN1 and hPCN3 for the metabolism of steroid hormones and cyclosporine. J Biol Chem 1989;264(18):10388-95. 
114. Schuetz JD, Molowa DT, Guzelian PS. Characterization of a cDNA encoding a new member of the glucocorticoid-responsive cytochromes P450 in human liver. Arch Biochem Biophys 1989;274(2):355-65.

115. Kitada M, Kamataki T, Itahashi K, Rikihisa T, Kanakubo Y. P-450 HFLa, a form of cytochrome P-450 purified from human fetal livers, is the 16 alpha-hydroxylase of dehydroepiandrosterone 3-sulfate. J Biol Chem 1987;262(28):13534-7.

116. Komori M, Nishio K, Fujitani T, Ohi H, Kitada M, Mima S, Itahashi K, Kamataki T. Isolation of a new human fetal liver cytochrome P450 cDNA clone: evidence for expression of a limited number of forms of cytochrome P450 in human fetal livers. Arch Biochem Biophys 1989;272(1):219-25.

117. Domanski TL, Finta C, Halpert JR, Zaphiropoulos PG. CDNA cloning and initial characterization of CYP3A43, a novel human cytochrome P450. Mol Pharmacol 2001;59(2):386-92.

118. Gellner K, Eiselt R, Hustert E, Arnold H, Koch I, Haberl M, Deglmann CJ, Burk O, Buntefuss D, Escher S, Bishop C, Koebe HG, Brinkmann U, Klenk HP, Kleine K, Meyer UA, Wojnowski L. Genomic organization of the human CYP3A locus: identification of a new, inducible CYP3A gene. Pharmacogenetics 2001;11(2):111-21.

119. Westlind A, Malmebo S, Johansson I, Otter C, Andersson TB, Ingelman-Sundberg M, Oscarson M. Cloning and tissue distribution of a novel human cytochrome p450 of the CYP3A subfamily, CYP3A43. Biochem Biophys Res Commun 2001;281(5):1349-55.

120. Christians U, Braun F, Schmidt M, Kosian N, Schiebel HM, Ernst L, Winkler M, Kruse C, Linck A, Sewing KF. Specific and sensitive measurement of FK506 and its metabolites in blood and urine of liver-graft recipients. Clin Chem 1992;38(10):2025-32.

121. Gonschior AK, Christians U, Winkler M, Linck A, Baumann J, Sewing KF. Tacrolimus (FK506) metabolite patterns in blood from liver and kidney transplant patients. Clin Chem 1996;42(9):1426-32.

122. Nelson DR, Koymans L, Kamataki T, Stegeman JJ, Feyereisen R, Waxman DJ, Waterman MR, Gotoh O, Coon MJ, Estabrook RW, Gunsalus IC, Nebert DW. P450 superfamily: update on new sequences, gene mapping, accession numbers and nomenclature. Pharmacogenetics 1996;6(1):1-42.

123. Inoue K, Inazawa J, Nakagawa H, Shimada $T$, Yamazaki H, Guengerich FP, Abe T. Assignment of the human cytochrome P-450 nifedipine oxidase gene (CYP3A4) to chromosome 7 at band q22.1 by fluorescence in situ hybridization. Jpn J Hum Genet 1992;37(2):133-8.

124. Gonzalez FJ, Schmid BJ, Umeno M, McBride OW, Hardwick JP, Meyer UA, Gelboin HV, Idle JR. Human P450PCN1: sequence, chromosome localization, and direct evidence through cDNA expression that P450PCN1 is nifedipine oxidase. DNA 1988;7(2):79-86.

125. DeVane CL, Nemeroff CB. 2002 guide to psychtropic drug interactions. Primary Psychiatry 2002;9:28-57.

126. Zhang QY, Dunbar D, Ostrowska A, Zeisloft S, Yang J, Kaminsky LS. Characterization of human small intestinal cytochromes P-450. Drug Metab Dispos 1999;27(7):804-9.

127. Tanaka E. Gender-related differences in pharmacokinetics and their clinical significance. J Clin Pharm Ther 1999;24(5):339-46.

128. Olesen OV, Linnet K. Metabolism of the tricyclic antidepressant amitriptyline by cDNAexpressed human cytochrome P450 enzymes. Pharmacology 1997;55(5):235-43.

129. von Moltke LL, Greenblatt DJ, Duan SX, Harmatz JS, Wright CE, Shader RI. Inhibition of terfenadine metabolism in vitro by azole antifungal agents and by selective serotonin reuptake inhibitor antidepressants: relation to pharmacokinetic interactions in vivo. J Clin Psychopharmacol 1996;16(2):104-12.

130. Boxenbaum $\mathrm{H}$. Cytochrome P450 $3 \mathrm{~A} 4$ in vivo ketoconazole competitive inhibition: determination of $\mathrm{Ki}$ and dangers associated with high clearance drugs in general. J Pharm Pharm Sci 1999;2(2):47-52.

131. Sutton D, Butler AM, Nadin L, Murray M. Role of CYP3A4 in human hepatic diltiazem Ndemethylation: inhibition of CYP3A4 activity by oxidized diltiazem metabolites. J Pharmacol Exp Ther 1997;282(1):294-300. 
132. Pai MP, Graci DM, Amsden GW. Macrolide drug interactions: an update. Ann Pharmacother 2000;34(4):495-513.

133. Venkatakrishnan K, von Moltke LL, Duan SX, Fleishaker JC, Shader RI, Greenblatt DJ. Kinetic characterization and identification of the enzymes responsible for the hepatic biotransformation of adinazolam and $\mathrm{N}$-desmethyladinazolam in man. J Pharm Pharmacol 1998;50(3):265-74

134. McLellan RA, Drobitch RK, Monshouwer M, Renton KW. Fluoroquinolone antibiotics inhibit cytochrome P450-mediated microsomal drug metabolism in rat and human. Drug Metab Dispos 1996;24(10):1134-8.

135. Rubinstein E, Prokocimer $\mathrm{P}$, Talbot GH. Safety and tolerability of quinupristin/dalfopristin: administration guidelines. J Antimicrob Chemother 1999;44 Suppl A:37-46.

136. Iribarne C, Berthou F, Carlhant D, Dreano Y, Picart D, Lohezic F, Riche C. Inhibition of methadone and buprenorphine N-dealkylations by three HIV-1 protease inhibitors. Drug Metab Dispos 1998;26(3):257-60.

137. He K, lyer KR, Hayes RN, Sinz MW, Woolf TF, Hollenberg PF. Inactivation of cytochrome P450 3A4 by bergamottin, a component of grapefruit juice. Chem Res Toxicol 1998;11(4):252-9.

138. Fuhr U. Drug interactions with grapefruit juice. Extent, probable mechanism and clinical relevance. Drug Saf 1998;18(4):251-72.

139. Wang EJ, Casciano CN, Clement RP, Johnson WW. Inhibition of P-glycoprotein transport function by grapefruit juice psoralen. Pharm Res 2001;18(4):432-8.

140. Levy RH. Cytochrome P450 isozymes and antiepileptic drug interactions. Epilepsia 1995;36 Suppl 5:S8-13.

141. Ketter TA, Frye MA, Cora-Locatelli G, Kimbrell TA, Post RM. Metabolism and excretion of mood stabilizers and new anticonvulsants. Cell Mol Neurobiol 1999;19(4):511-32.

142. Anderson GD. A mechanistic approach to antiepileptic drug interactions. Ann Pharmacother 1998;32(5):554-63.

143. Strayhorn VA, Baciewicz AM, Self TH. Update on rifampin drug interactions, III. Arch Intern Med 1997;157(21):2453-8.

144. Barry M, Gibbons S, Back D, Mulcahy F. Protease inhibitors in patients with HIV disease. Clinically important pharmacokinetic considerations. Clin Pharmacokinet 1997;32(3):194-209.

145. Tseng AL, Foisy MM. Management of drug interactions in patients with HIV. Ann Pharmacother 1997;31(9):1040-58.

146. Caspi A. Troglitazone. Pharmacy and Therapeutics 1997;22:198-205.

147. Pichard L, Fabre I, Daujat M, Domergue J, Joyeux H, Maurel P. Effect of corticosteroids on the expression of cytochromes $\mathrm{P} 450$ and on cyclosporin A oxidase activity in primary cultures of human hepatocytes. Mol Pharmacol 1992;41(6):1047-55.

148. Moore LB, Goodwin B, Jones SA, Wisely GB, Serabjit-Singh CJ, Willson TM, Collins JL, Kliewer SA. St. John's wort induces hepatic drug metabolism through activation of the pregnane X receptor. Proc Natl Acad Sci U S A 2000;97(13):7500-2.

149. Roby CA, Anderson GD, Kantor E, Dryer DA, Burstein AH. St John's Wort: effect on CYP3A4 activity. Clin Pharmacol Ther 2000;67(5):451-7.

150. Hennessy M, Kelleher D, Spiers JP, Barry M, Kavanagh P, Back D, Mulcahy F, Feely J. St Johns wort increases expression of P-glycoprotein: implications for drug interactions. $\mathrm{Br} \mathrm{J}$ Clin Pharmacol 2002;53(1):75-82.

151. Markowitz JS, Donovan JL, DeVane CL, Taylor RM, Ruan Y, Wang JS, Chavin KD. Effect of St John's wort on drug metabolism by induction of cytochrome P450 3A4 enzyme. Jama 2003;290(11):1500-4.

152. Barone GW, Gurley BJ, Ketel BL, Lightfoot ML, Abul-Ezz SR. Drug interaction between St. John's wort and cyclosporine. Ann Pharmacother 2000;34(9):1013-6.

153. Karliova M, Treichel U, Malago M, Frilling A, Gerken G, Broelsch CE. Interaction of Hypericum perforatum (St. John's wort) with cyclosporin A metabolism in a patient after liver transplantation. J Hepatol 2000;33(5):853-5.

154. Ruschitzka F, Meier PJ, Turina M, Luscher TF, Noll G. Acute heart transplant rejection due to Saint John's wort. Lancet 2000;355(9203):548-9. 
155. Johne A, Brockmoller J, Bauer S, Maurer A, Langheinrich M, Roots I. Pharmacokinetic interaction of digoxin with an herbal extract from St John's wort (Hypericum perforatum). Clin Pharmacol Ther 1999;66(4):338-45.

156. Tang W, Stearns RA. Heterotropic cooperativity of cytochrome P450 3A4 and potential drugdrug interactions. Curr Drug Metab 2001;2(2):185-98.

157. Lin YS, Dowling AL, Quigley SD, Farin FM, Zhang J, Lamba J, Schuetz EG, Thummel KE. Co-regulation of CYP3A4 and CYP3A5 and contribution to hepatic and intestinal midazolam metabolism. Mol Pharmacol 2002;62(1):162-72.

158. Rebbeck TR, Jaffe JM, Walker AH, Wein AJ, Malkowicz SB. Modification of clinical presentation of prostate tumors by a novel genetic variant in CYP3A4. J Natl Cancer Inst 1998;90(16):1225-9.

159. Sata F, Sapone A, Elizondo G, Stocker P, Miller VP, Zheng W, Raunio H, Crespi CL, Gonzalez FJ. CYP3A4 allelic variants with amino acid substitutions in exons 7 and 12: evidence for an allelic variant with altered catalytic activity. Clin Pharmacol Ther 2000;67(1):48-56.

160. Ando Y, Tateishi T, Sekido Y, Yamamoto T, Satoh T, Hasegawa Y, Kobayashi S, Katsumata $\mathrm{Y}$, Shimokata K, Saito H. Re: Modification of clinical presentation of prostate tumors by a novel genetic variant in CYP3A4. J Natl Cancer Inst 1999;91(18):1587-90.

161. Ball SE, Scatina J, Kao J, Ferron GM, Fruncillo R, Mayer P, Weinryb I, Guida M, Hopkins PJ, Warner N, Hall J. Population distribution and effects on drug metabolism of a genetic variant in the 5' promoter region of CYP3A4. Clin Pharmacol Ther 1999;66(3):288-94.

162. Paris PL, Kupelian PA, Hall JM, Williams TL, Levin H, Klein EA, Casey G, Witte JS. Association between a CYP3A4 genetic variant and clinical presentation in African-American prostate cancer patients. Cancer Epidemiol Biomarkers Prev 1999;8(10):901-5.

163. van Schaik RH, van der Heiden IP, van den Anker JN, Lindemans J. CYP3A5 variant allele frequencies in Dutch Caucasians. Clin Chem 2002;48(10):1668-71.

164. Westlind A, Lofberg L, Tindberg N, Andersson TB, Ingelman-Sundberg M. Interindividual differences in hepatic expression of CYP3A4: relationship to genetic polymorphism in the 5'upstream regulatory region. Biochem Biophys Res Commun 1999;259(1):201-5.

165. Tayeb MT, Clark C, Ameyaw MM, Haites NE, Evans DA, Tariq M, Mobarek A, Ofori-Adjei D, McLeod HL. CYP3A4 promoter variant in Saudi, Ghanaian and Scottish Caucasian populations. Pharmacogenetics 2000;10(8):753-6.

166. Tayeb MT, Clark C, Sharp L, Haites NE, Rooney PH, Murray GI, Payne SN, McLeod HL. CYP3A4 promoter variant is associated with prostate cancer risk in men with benign prostate hyperplasia. Oncol Rep 2002;9(3):653-5.

167. Wandel C, Witte JS, Hall JM, Stein CM, Wood AJ, Wilkinson GR. CYP3A activity in African American and European American men: population differences and functional effect of the CYP3A4*1B5'-promoter region polymorphism. Clin Pharmacol Ther 2000;68(1):82-91.

168. Patki KC, von Moltke LL, Harmatz JS, Hesse LM, Court MH, Greenblatt DJ. Effect of age on in vitro triazolam biotransformation in male human liver microsomes. J Pharmacol Exp Ther 2004;308(3):874-9.

169. Spurr NK, Gough AC, Stevenson K, Wolf CR. The human cytochrome P450 CYP3 locus: assignment to chromosome 7q22-qter. Hum Genet 1989;81(2):171-4.

170. Paine MF, Khalighi M, Fisher JM, Shen DD, Kunze KL, Marsh CL, Perkins JD, Thummel KE. Characterization of interintestinal and intraintestinal variations in human CYP3A-dependent metabolism. J Pharmacol Exp Ther 1997;283(3):1552-62.

171. Gervot L, Carriere V, Costet P. CYP3A5 is the major cytochrome P450 3A expressed in the human colon and colonic cell lines. Environ Toxicol Pharmacol 1996;2(4):381-8.

172. Kivisto KT, Fritz P, Linder A, Friedel G, Beaune P, Kroemer HK. Immunohistochemical localization of cytochrome P450 3A in human pulmonary carcinomas and normal bronchial tissue. Histochem Cell Biol 1995;103(1):25-9.

173. Lechevrel M, Casson AG, Wolf CR, Hardie LJ, Flinterman MB, Montesano R, Wild CP. Characterization of cytochrome P450 expression in human oesophageal mucosa. Carcinogenesis 1999;20(2):243-8. 
174. Haehner BD, Gorski JC, Vandenbranden M, Wrighton SA, Janardan SK, Watkins PB, Hall SD. Bimodal distribution of renal cytochrome P450 3A activity in humans. Mol Pharmacol 1996;50(1):52-9.

175. Schuetz EG, Schuetz JD, Grogan WM, Naray-Fejes-Toth A, Fejes-Toth G, Raucy J, Guzelian $\mathrm{P}$, Gionela K, Watlington CO. Expression of cytochrome P450 3A in amphibian, rat, and human kidney. Arch Biochem Biophys 1992;294(1):206-14.

176. Koch I, Weil R, Wolbold R, Brockmoller J, Hustert E, Burk O, Nuessler A, Neuhaus P, Eichelbaum M, Zanger U, Wojnowski L. Interindividual variability and tissue-specificity in the expression of cytochrome P450 3A mRNA. Drug Metab Dispos 2002;30(10):1108-14.

177. Murray GI, Pritchard S, Melvin WT, Burke MD. Cytochrome P450 CYP3A5 in the human anterior pituitary gland. FEBS Lett 1995;364(1):79-82.

178. Huang Z, Fasco MJ, Figge HL, Keyomarsi K, Kaminsky LS. Expression of cytochromes P450 in human breast tissue and tumors. Drug Metab Dispos 1996;24(8):899-905.

179. Yamakoshi Y, Kishimoto T, Sugimura K, Kawashima H. Human prostate CYP3A5: identification of a unique 5'-untranslated sequence and characterization of purified recombinant protein. Biochem Biophys Res Commun 1999;260(3):676-81.

180. Janardan SK, Lown KS, Schmiedlin-Ren P, Thummel KE, Watkins PB. Selective expression of CYP3A5 and not CYP3A4 in human blood. Pharmacogenetics 1996;6(5):379-85.

181. Rendic S. Summary of information on human CYP enzymes: human P450 metabolism data. Drug Metab Rev 2002;34(1-2):83-448.

182. McConn DJ, 2nd, Lin YS, Allen K, Kunze KL, Thummel KE. Differences in the inhibition of cytochromes P450 3A4 and 3A5 by metabolite-inhibitor complex-forming drugs. Drug Metab Dispos 2004;32(10):1083-91.

183. Xie HG, Wood AJ, Kim RB, Stein CM, Wilkinson GR. Genetic variability in CYP3A5 and its possible consequences. Pharmacogenomics 2004;5(3):243-72.

184. Lee SJ, Usmani KA, Chanas B, Ghanayem B, Xi T, Hodgson E, Mohrenweiser HW, Goldstein JA. Genetic findings and functional studies of human CYP3A5 single nucleotide polymorphisms in different ethnic groups. Pharmacogenetics 2003;13(8):461-72.

185. Kuehl P, Zhang J, Lin Y, Lamba J, Assem M, Schuetz J, Watkins PB, Daly A, Wrighton SA, Hall SD, Maurel P, Relling M, Brimer C, Yasuda K, Venkataramanan R, Strom S, Thummel K, Boguski MS, Schuetz E. Sequence diversity in CYP3A promoters and characterization of the genetic basis of polymorphic CYP3A5 expression. Nat Genet 2001;27(4):383-91.

186. Hustert E, Haberl M, Burk O, Wolbold R, He YQ, Klein K, Nuessler AC, Neuhaus P, Klattig J, Eiselt R, Koch I, Zibat A, Brockmoller J, Halpert JR, Zanger UM, Wojnowski L. The genetic determinants of the CYP3A5 polymorphism. Pharmacogenetics 2001;11(9):773-9.

187. Chou FC, Tzeng SJ, Huang JD. Genetic polymorphism of cytochrome P450 3 A5 in Chinese. Drug Metab Dispos 2001;29(9):1205-9.

188. Saeki M, Saito Y, Nakamura T, Murayama N, Kim SR, Ozawa S, Komamura K, Ueno K, Kamakura S, Nakajima T, Saito H, Kitamura Y, Kamatani N, Sawada J. Single nucleotide polymorphisms and haplotype frequencies of CYP3A5 in a Japanese population. Hum Mutat 2003;21(6):653.

189. King BP, Leathart JB, Mutch E, Williams FM, Daly AK. CYP3A5 phenotype-genotype correlations in a British population. Br J Clin Pharmacol 2003;55(6):625-9.

190. Dally H, Edler L, Jager B, Schmezer P, Spiegelhalder B, Dienemann H, Drings $P$, Schulz V, Kayser $\mathrm{K}$, Bartsch $\mathrm{H}$, Risch $\mathrm{A}$. The CYP3A4*1B allele increases risk for small cell lung cancer: effect of gender and smoking dose. Pharmacogenetics 2003;13(10):607-18.

191. Balram C, Zhou Q, Cheung YB, Lee EJ. CYP3A5*3 and *6 single nucleotide polymorphisms in three distinct Asian populations. Eur J Clin Pharmacol 2003;59(2):123-6.

192. Hiratsuka M, Takekuma Y, Endo N, Narahara K, Hamdy SI, Kishikawa Y, Matsuura M, Agatsuma Y, Inoue T, Mizugaki M. Allele and genotype frequencies of CYP2B6 and CYP3A5 in the Japanese population. Eur J Clin Pharmacol 2002;58(6):417-21.

193. Fukuen S, Fukuda T, Maune H, Ikenaga Y, Yamamoto I, Inaba T, Azuma J. Novel detection assay by PCR-RFLP and frequency of the CYP3A5 SNPs, CYP3A5*3 and *6, in a Japanese population. Pharmacogenetics 2002;12(4):331-4. 
194. Fukudo M, Yano I, Masuda S, Goto M, Uesugi M, Katsura T, Ogura Y, Oike F, Takada Y, Egawa $\mathrm{H}$, Uemoto $\mathrm{S}$, Inui K. Population pharmacokinetic and pharmacogenomic analysis of tacrolimus in pediatric living-donor liver transplant recipients. Clin Pharmacol Ther 2006;80(4):331-45.

195. Fredericks S, Moreton M, Reboux S, Carter ND, Goldberg L, Holt DW, MacPhee IA. Multidrug resistance gene-1 (MDR-1) haplotypes have a minor influence on tacrolimus dose requirements. Transplantation 2006;82(5):705-8.

196. Roy JN, Barama A, Poirier C, Vinet B, Roger M. Cyp3A4, Cyp3A5, and MDR-1 genetic influences on tacrolimus pharmacokinetics in renal transplant recipients. Pharmacogenet Genomics 2006;16(9):659-65.

197. Uesugi M, Masuda S, Katsura T, Oike F, Takada Y, Inui K. Effect of intestinal CYP3A5 on postoperative tacrolimus trough levels in living-donor liver transplant recipients. Pharmacogenet Genomics 2006;16(2):119-27.

198. Yu S, Wu L, Jin J, Yan S, Jiang G, Xie H, Zheng S. Influence of CYP3A5 gene polymorphisms of donor rather than recipient to tacrolimus individual dose requirement in liver transplantation. Transplantation 2006;81(1):46-51.

199. Macphee IA, Fredericks S, Mohamed M, Moreton M, Carter ND, Johnston A, Goldberg L, Holt DW. Tacrolimus pharmacogenetics: the CYP3A5*1 allele predicts low dose-normalized tacrolimus blood concentrations in whites and South Asians. Transplantation 2005;79(4):499502.

200. Thervet E, Anglicheau D, King B, Schlageter MH, Cassinat B, Beaune P, Legendre C, Daly AK. Impact of cytochrome p450 3A5 genetic polymorphism on tacrolimus doses and concentration-to-dose ratio in renal transplant recipients. Transplantation 2003;76(8):1233-5.

201. Cheung CY, Op den Buijsch RA, Wong KM, Chan HW, Chau KF, Li CS, Leung KT, Kwan TH, de Vrie JE, Wijnen PA, van Dieijen-Visser MP, Bekers O. Influence of different allelic variants of the CYP3A and ABCB1 genes on the tacrolimus pharmacokinetic profile of Chinese renal transplant recipients. Pharmacogenomics 2006;7(4):563-74.

202. Haufroid V, Wallemacq P, VanKerckhove V, Elens L, De Meyer M, Eddour DC, Malaise J, Lison D, Mourad M. CYP3A5 and ABCB1 polymorphisms and tacrolimus pharmacokinetics in renal transplant candidates: guidelines from an experimental study. Am J Transplant 2006;6(11):2706-13.

203. Zhao Y, Song M, Guan D, Bi S, Meng J, Li Q, Wang W. Genetic polymorphisms of CYP3A5 genes and concentration of the cyclosporine and tacrolimus. Transplant Proc 2005;37(1):17881.

204. Mai I, Stormer E, Bauer S, Kruger H, Budde K, Roots I. Impact of St John's wort treatment on the pharmacokinetics of tacrolimus and mycophenolic acid in renal transplant patients. Nephrol Dial Transplant 2003;18(4):819-22.

205. MacPhee IA, Fredericks S, Tai T, Syrris P, Carter ND, Johnston A, Goldberg L, Holt DW. The influence of pharmacogenetics on the time to achieve target tacrolimus concentrations after kidney transplantation. Am J Transplant 2004;4(6):914-9.

206. Kreutz R, Zurcher H, Kain S, Martus P, Offermann G, Beige J. The effect of variable CYP3A5 expression on cyclosporine dosing, blood pressure and long-term graft survival in renal transplant patients. Pharmacogenetics 2004;14(10):665-71.

207. Hesselink DA, van Gelder T, van Schaik RH, Balk AH, van der Heiden IP, van Dam T, van der Werf M, Weimar W, Mathot RA. Population pharmacokinetics of cyclosporine in kidney and heart transplant recipients and the influence of ethnicity and genetic polymorphisms in the MDR-1, CYP3A4, and CYP3A5 genes. Clin Pharmacol Ther 2004;76(6):545-56.

208. Anglicheau D, Thervet E, Etienne I, Hurault De Ligny B, Le Meur Y, Touchard G, Buchler M, Laurent-Puig P, Tregouet D, Beaune P, Daly A, Legendre C, Marquet P. CYP3A5 and MDR1 genetic polymorphisms and cyclosporine pharmacokinetics after renal transplantation. Clin Pharmacol Ther 2004;75(5):422-33.

209. Azarpira N, Aghdaie MH, Behzad-Behbahanie A, Geramizadeh B, Behzadi S, Malekhoseinie SA, Raisjalal GH, Rahsaz M, Pourgholami A, Sagheb F. Association between cyclosporine concentration and genetic polymorphisms of CYP3A5 and MDR1 during the early stage after renal transplantation. Exp Clin Transplant 2006;4(1):416-9. 
210. Chu XM, Hao HP, Wang GJ, Guo LQ, Min PQ. Influence of CYP3A5 genetic polymorphism on cyclosporine $A$ metabolism and elimination in Chinese renal transplant recipients. Acta Pharmacol Sin 2006;27(11):1504-8.

211. Yates CR, Zhang W, Song P, Li S, Gaber AO, Kotb M, Honaker MR, Alloway RR, Meibohm $B$. The effect of CYP3A5 and MDR1 polymorphic expression on cyclosporine oral disposition in renal transplant patients. J Clin Pharmacol 2003;43(6):555-64.

212. Eng HS, Mohamed Z, Calne R, Lang CC, Mohd MA, Seet WT, Tan SY. The influence of CYP3A gene polymorphisms on cyclosporine dose requirement in renal allograft recipients. Kidney Int 2006;69(10):1858-64.

213. Min DI, Ellingrod VL, Marsh S, McLeod H. CYP3A5 polymorphism and the ethnic differences in cyclosporine pharmacokinetics in healthy subjects. Ther Drug Monit 2004;26(5):524-8.

214. Djebli N, Rousseau A, Hoizey G, Rerolle JP, Toupance O, Le Meur Y, Marquet P. Sirolimus population pharmacokinetic/pharmacogenetic analysis and bayesian modelling in kidney transplant recipients. Clin Pharmacokinet 2006;45(11):1135-48.

215. Le Meur Y, Djebli N, Szelag JC, Hoizey G, Toupance O, Rerolle JP, Marquet P. CYP3A5*3 influences sirolimus oral clearance in de novo and stable renal transplant recipients. Clin Pharmacol Ther 2006;80(1):51-60.

216. Anglicheau D, Le Corre D, Lechaton S, Laurent-Puig P, Kreis H, Beaune P, Legendre C, Thervet $\mathrm{E}$. Consequences of genetic polymorphisms for sirolimus requirements after renal transplant in patients on primary sirolimus therapy. Am J Transplant 2005;5(3):595-603.

217. Hu YF, Qiu W, Liu ZQ, Zhu LJ, Tu JH, Wang D, Li Z, He J, Zhong GP, Zhou G, Zhou HH. Effects of genetic polymorphisms of cyp3a4, cyp3a5 and mdr1 on cyclosporine pharmacokinetics after renal transplantation. Clin Exp Pharmacol Physiol 2006;33(11):10938.

218. Kamdem LK, Streit F, Zanger UM, Brockmoller J, Oellerich M, Armstrong VW, Wojnowski L. Contribution of CYP3A5 to the in vitro hepatic clearance of tacrolimus. Clin Chem 2005;51(8):1374-81.

219. Dai $Y$, Iwanaga K, Lin YS, Hebert MF, Davis CL, Huang W, Kharasch ED, Thummel KE. In vitro metabolism of cyclosporine A by human kidney CYP3A5. Biochem Pharmacol 2004;68(9):1889-902.

220. Kuypers DR, Claes K, Evenepoel P, Maes B, Coosemans W, Pirenne J, Vanrenterghem Y. Time-related clinical determinants of long-term tacrolimus pharmacokinetics in combination therapy with mycophenolic acid and corticosteroids: a prospective study in one hundred de novo renal transplant recipients. Clin Pharmacokinet 2004;43(11):741-62.

221. Staatz CE, Tett SE. Clinical pharmacokinetics and pharmacodynamics of tacrolimus in solid organ transplantation. Clin Pharmacokinet 2004;43(10):623-53.

222. Itoh S, Yanagimoto T, Tagawa S, Hashimoto H, Kitamura R, Nakajima Y, Okochi T, Fujimoto S, Uchino J, Kamataki T. Genomic organization of human fetal specific P-450IIIA7 (cytochrome P-450HFLa)-related gene(s) and interaction of transcriptional regulatory factor with its DNA element in the 5' flanking region. Biochim Biophys Acta 1992;1130(2):133-8.

223. Shimada T, Yamazaki H, Mimura M, Wakamiya N, Ueng YF, Guengerich FP, Inui Y. Characterization of microsomal cytochrome P450 enzymes involved in the oxidation of xenobiotic chemicals in human fetal liver and adult lungs. Drug Metab Dispos 1996;24(5):515-22.

224. Burk O, Tegude H, Koch I, Hustert E, Wolbold R, Glaeser H, Klein K, Fromm MF, Nuessler AK, Neuhaus P, Zanger UM, Eichelbaum M, Wojnowski L. Molecular mechanisms of polymorphic CYP3A7 expression in adult human liver and intestine. J Biol Chem 2002;277(27):24280-8.

225. Schuetz JD, Kauma S, Guzelian PS. Identification of the fetal liver cytochrome CYP3A7 in human endometrium and placenta. J Clin Invest 1993;92(2):1018-24.

226. Sarkar MA, Vadlamuri V, Ghosh S, Glover DD. Expression and cyclic variability of CYP3A4 and CYP3A7 isoforms in human endometrium and cervix during the menstrual cycle. Drug Metab Dispos 2003;31(1):1-6. 
227. Marill J, Cresteil T, Lanotte M, Chabot GG. Identification of human cytochrome P450s involved in the formation of all-trans-retinoic acid principal metabolites. Mol Pharmacol 2000;58(6):1341-8.

228. Chen H, Fantel AG, Juchau MR. Catalysis of the 4-hydroxylation of retinoic acids by cyp3a7 in human fetal hepatic tissues. Drug Metab Dispos 2000;28(9):1051-7.

229. Clagett-Dame M, DeLuca HF. The role of vitamin A in mammalian reproduction and embryonic development. Annu Rev Nutr 2002;22:347-81.

230. Matsunaga T, Maruyama M, Harada E, Katsuyama Y, Sugihara N, Ise H, Negishi N, Ikeda U, Ohmori S. Expression and induction of CYP3As in human fetal hepatocytes. Biochem Biophys Res Commun 2004;318(2):428-34.

231. Hashimoto K, Uchiumi T, Konno T, Ebihara T, Nakamura T, Wada M, Sakisaka S, Maniwa F, Amachi T, Ueda K, Kuwano M. Trafficking and functional defects by mutations of the ATPbinding domains in MRP2 in patients with Dubin-Johnson syndrome. Hepatology 2002;36(5):1236-45.

232. Firdaous I, Verbeeck RK, Hassoun A, Langrehr JM, Wallemacq PE. Excretion of tacrolimus glucuronides in human bile. Eur J Drug Metab Pharmacokinet 1997;22(3):217-21.

233. Strassburg CP, Barut A, Obermayer-Straub P, Li Q, Nguyen N, Tukey RH, Manns MP. Identification of cyclosporine $A$ and tacrolimus glucuronidation in human liver and the gastrointestinal tract by a differentially expressed UDP-glucuronosyltransferase: UGT2B7. J Hepatol 2001;34(6):865-72.

234. Guillemette C. Pharmacogenomics of human UDP-glucuronosyltransferase enzymes. Pharmacogenomics J 2003;3(3):136-58.

235. Radominska-Pandya A, Little JM, Czernik PJ. Human UDP-glucuronosyltransferase $2 \mathrm{~B} 7$. Curr Drug Metab 2001;2(3):283-98.

236. King CD, Rios GR, Green MD, Tephly TR. UDP-glucuronosyltransferases. Curr Drug Metab 2000;1(2):143-61.

237. Meech R, Mackenzie PI. Structure and function of uridine diphosphate glucuronosyltransferases. Clin Exp Pharmacol Physiol 1997;24(12):907-15.

238. Tukey RH, Strassburg CP. Genetic multiplicity of the human UDP-glucuronosyltransferases and regulation in the gastrointestinal tract. Mol Pharmacol 2001;59(3):405-14.

239. Christians U, Braun F, Kosian N, Schmidt M, Schiebel HM, Ernst L, Kruse C, Winkler M, Holze I, Linck A, et al. High performance liquid chromatography/mass spectrometry of FK 506 and its metabolites in blood, bile, and urine of liver grafted patients. Transplant Proc 1991;23(6):2741-4.

240. Christians U, Kruse C, Kownatzki R, Schiebel HM, Schwinzer R, Sattler M, Schottmann R, Linck A, Almeida VM, Braun F, et al. Measurement of FK 506 by HPLC and isolation and characterization of its metabolites. Transplant Proc 1991;23(1 Pt 2):940-1.

241. Lehmann JM, McKee DD, Watson MA, Willson TM, Moore JT, Kliewer SA. The human orphan nuclear receptor PXR is activated by compounds that regulate CYP3A4 gene expression and cause drug interactions. J Clin Invest 1998;102(5):1016-23.

242. Blumberg B, Sabbagh W, Jr., Juguilon H, Bolado J, Jr., van Meter CM, Ong ES, Evans RM. SXR, a novel steroid and xenobiotic-sensing nuclear receptor. Genes Dev 1998;12(20):3195205.

243. Bertilsson G, Heidrich J, Svensson K, Asman M, Jendeberg L, Sydow-Backman M, Ohlsson $\mathrm{R}$, Postlind $\mathrm{H}$, Blomquist $\mathrm{P}$, Berkenstam $\mathrm{A}$. Identification of a human nuclear receptor defines a new signaling pathway for CYP3A induction. Proc Natl Acad Sci U S A 1998;95(21):1220813.

244. Synold TW, Dussault I, Forman BM. The orphan nuclear receptor SXR coordinately regulates drug metabolism and efflux. Nat Med 2001;7(5):584-90.

245. Geick A, Eichelbaum M, Burk O. Nuclear receptor response elements mediate induction of intestinal MDR1 by rifampin. J Biol Chem 2001;276(18):14581-7.

246. Moore JT, Kliewer SA. Use of the nuclear receptor PXR to predict drug interactions. Toxicology 2000;153(1-3):1-10.

247. Kliewer SA, Goodwin B, Willson TM. The nuclear pregnane $X$ receptor: a key regulator of xenobiotic metabolism. Endocr Rev 2002;23(5):687-702. 
248. Baes M, Gulick T, Choi HS, Martinoli MG, Simha D, Moore DD. A new orphan member of the nuclear hormone receptor superfamily that interacts with a subset of retinoic acid response elements. Mol Cell Biol 1994;14(3):1544-52.

249. Giguere V. Orphan nuclear receptors: from gene to function. Endocr Rev 1999;20(5):689725.

250. Corcos L, Lagadic-Gossmann D. Gene induction by Phenobarbital: an update on an old question that receives key novel answers. Pharmacol Toxicol 2001;89(3):113-22.

251. Pascussi JM, Gerbal-Chaloin S, Drocourt L, Maurel P, Vilarem MJ. The expression of CYP2B6, CYP2C9 and CYP3A4 genes: a tangle of networks of nuclear and steroid receptors. Biochim Biophys Acta 2003;1619(3):243-53.

252. Wei $P$, Zhang J, Dowhan DH, Han Y, Moore DD. Specific and overlapping functions of the nuclear hormone receptors CAR and PXR in xenobiotic response. Pharmacogenomics J 2002;2(2):117-26.

253. Chang TK, Bandiera SM, Chen J. Constitutive androstane receptor and pregnane $X$ receptor gene expression in human liver: interindividual variability and correlation with CYP2B6 mRNA levels. Drug Metab Dispos 2003;31(1):7-10.

254. Sugatani J, Kojima H, Ueda A, Kakizaki S, Yoshinari K, Gong QH, Owens IS, Negishi M, Sueyoshi T. The phenobarbital response enhancer module in the human bilirubin UDPglucuronosyltransferase UGT1A1 gene and regulation by the nuclear receptor CAR. Hepatology 2001;33(5):1232-8.

255. Sueyoshi T, Kawamoto T, Zelko I, Honkakoski P, Negishi M. The repressed nuclear receptor CAR responds to phenobarbital in activating the human CYP2B6 gene. J Biol Chem 1999;274(10):6043-6.

256. Chen Y, Ferguson SS, Negishi M, Goldstein JA. Identification of constitutive androstane receptor and glucocorticoid receptor binding sites in the CYP2C19 promoter. Mol Pharmacol 2003;64(2):316-24.

257. Pratt WB, Toft DO. Steroid receptor interactions with heat shock protein and immunophilin chaperones. Endocr Rev 1997;18(3):306-60.

258. Webster JC, Cidlowski JA. Mechanisms of Glucocorticoid-receptor-mediated Repression of Gene Expression. Trends Endocrinol Metab 1999;10(10):396-402.

259. Reichardt HM, Kaestner KH, Tuckermann J, Kretz O, Wessely O, Bock R, Gass P, Schmid W, Herrlich P, Angel P, Schutz G. DNA binding of the glucocorticoid receptor is not essential for survival. Cell 1998;93(4):531-41.

260. De Bosscher K, Vanden Berghe W, Haegeman G. Mechanisms of anti-inflammatory action and of immunosuppression by glucocorticoids: negative interference of activated glucocorticoid receptor with transcription factors. J Neuroimmunol 2000;109(1):16-22.

261. Berrebi D, Bruscoli S, Cohen N, Foussat A, Migliorati G, Bouchet-Delbos L, Maillot MC, Portier A, Couderc J, Galanaud P, Peuchmaur M, Riccardi C, Emilie D. Synthesis of glucocorticoid-induced leucine zipper (GILZ) by macrophages: an anti-inflammatory and immunosuppressive mechanism shared by glucocorticoids and IL-10. Blood 2003;101(2):72938.

262. Gerbal-Chaloin S, Pascussi JM, Pichard-Garcia L, Daujat M, Waechter F, Fabre JM, Carrere $\mathrm{N}$, Maurel P. Induction of CYP2C genes in human hepatocytes in primary culture. Drug Metab Dispos 2001;29(3):242-51.

263. Dvorak Z, Modriansky M, Pichard-Garcia L, Balaguer P, Vilarem MJ, Ulrichova J, Maurel P, Pascussi JM. Colchicine down-regulates cytochrome P450 2B6, 2C8, 2C9, and 3A4 in human hepatocytes by affecting their glucocorticoid receptor-mediated regulation. Mol Pharmacol 2003;64(1):160-9.

264. Gerbal-Chaloin S, Daujat M, Pascussi JM, Pichard-Garcia L, Vilarem MJ, Maurel P. Transcriptional regulation of CYP2C9 gene. Role of glucocorticoid receptor and constitutive androstane receptor. J Biol Chem 2002;277(1):209-17.

265. Gibson GG, Plant NJ, Swales KE, Ayrton A, El-Sankary W. Receptor-dependent transcriptional activation of cytochrome P4503A genes: induction mechanisms, species differences and interindividual variation in man. Xenobiotica 2002;32(3):165-206. 
266. Shishido S, Asanuma H, Tajima E, Honda M, Nakai H. Pharmacokinetics of tacrolimus in pediatric renal transplant recipients. Transplant Proc 2001;33(1-2):1066-8.

267. Mehta P, Beltz S, Kedar A, Graham-Pole J, Wingard JR. Increased clearance of tacrolimus in children: need for higher doses and earlier initiation prior to bone marrow transplantation. Bone Marrow Transplant 1999;24(12):1323-7.

268. Moreno M, Manzanares C, Castellano F, Medina E, Urruzuno P, Camarena C, Manzanares J, Jara $P$. Monitoring of tacrolimus as rescue therapy in pediatric liver transplantation. Ther Drug Monit 1998;20(4):376-9.

269. McDiarmid SV, Colonna JO, 2nd, Shaked A, Vargas J, Ament ME, Busuttil RW. Differences in oral FK506 dose requirements between adult and pediatric liver transplant patients. Transplantation 1993;55(6):1328-32.

270. Uemoto S, Tanaka K, Honda K, Tokunaga Y, Sano K, Katoh H, Yamamoto E, Takada Y, Ozawa K. Experience with FK506 in living-related liver transplantation. Transplantation 1993;55(2):288-92.

271. MacFarlane GD, Venkataramanan R, McDiarmid SV, Pirsch JD, Scheller DG, Ersfeld DL, Fitzsimmons WE. Therapeutic drug monitoring of tacrolimus in pediatric liver transplant patients. Pediatr Transplant 2001;5(2):119-24.

272. Mittal N, Thompson JF, Kato T, Tzakis AG. Tacrolimus and diarrhea: pathogenesis of altered metabolism. Pediatr Transplant 2001;5(2):75-9.

273. Wrighton SA, Brian WR, Sari MA, Iwasaki M, Guengerich FP, Raucy JL, Molowa DT, Vandenbranden $M$. Studies on the expression and metabolic capabilities of human liver cytochrome P450IIIA5 (HLp3). Mol Pharmacol 1990;38(2):207-13.

274. Felipe CR, Silva HT, Machado PG, Garcia R, da Silva Moreira SR, Pestana JO. The impact of ethnic miscegenation on tacrolimus clinical pharmacokinetics and therapeutic drug monitoring. Clin Transplant 2002;16(4):262-72.

275. Uber PA, Mehra MR, Scott RL, Prasad AK, Park MH. Ethnic disparities in the pharmacologic characteristics of tacrolimus in heart transplantation. Transplant Proc 2001;33(1-2):1581-2.

276. Undre NA, Schafer A. Factors affecting the pharmacokinetics of tacrolimus in the first year after renal transplantation. European Tacrolimus Multicentre Renal Study Group. Transplant Proc 1998;30(4):1261-3.

277. Kuzuya T, Ogura Y, Motegi Y, Moriyama N, Nabeshima T. Interference of hematocrit in the tacrolimus II microparticle enzyme immunoassay. Ther Drug Monit 2002;24(4):507-11.

278. Brown NW, Gonde CE, Adams JE, Tredger JM. Low hematocrit and serum albumin concentrations underlie the overestimation of tacrolimus concentrations by microparticle enzyme immunoassay versus liquid chromatography-tandem mass spectrometry. Clin Chem 2005;51(3):586-92.

279. Huang ML, Venkataramanan R, Burckart GJ, Ptachcinski RJ, Van Thiel DH, Starzl TE. Drugbinding proteins in liver transplant patients. J Clin Pharmacol 1988;28(6):505-6.

280. Ghoshal AK, Soldin SJ. IMx tacrolimus II assay: is it reliable at low blood concentrations? A comparison with tandem MS/MS. Clin Biochem 2002;35(5):389-92.

281. Beaulieu M, Levesque E, Hum DW, Belanger A. Isolation and characterization of a human orphan UDP-glucuronosyltransferase, UGT2B11. Biochem Biophys Res Commun 1998;248(1):44-50.

282. Christiaans M, van Duijnhoven E, Beysens T, Undre N, Schafer A, van Hooff J. Effect of breakfast on the oral bioavailability of tacrolimus and changes in pharmacokinetics at different times posttransplant in renal transplant recipients. Transplant Proc 1998;30(4):1271-3.

283. Jain AB, Abu-Elmagd K, Abdallah H, Warty V, Fung J, Todo S, Starzl TE, Venkataramanan R. Pharmacokinetics of FK506 in liver transplant recipients after continuous intravenous infusion. J Clin Pharmacol 1993;33(7):606-11.

284. Satomura K, Ozaki N, Okajima H, Egawa H, Uemoto S, Inomata Y, Tanaka K, Yamaoka Y, Hashida T, Yasuhara M, Inui K. Pharmacokinetics of FK 506 in living-related liver transplantation. Transplant Proc 1996;28(2):1005.

285. Boswell GW, Bekersky I, Fay J, Wingard J, Antin J, Weisdorf D, Maher R, Fitzsimmons W, Nash R. Tacrolimus pharmacokinetics in BMT patients. Bone Marrow Transplant 1998;21(1):23-8. 
286. Jain AB, Venkataramanan R, Cadoff E, Fung JJ, Todo S, Krajack A, Starzl TE. Effect of hepatic dysfunction and T tube clamping on FK 506 pharmacokinetics and trough concentrations. Transplant Proc 1990;22(1):57-9.

287. McMaster P, Mirza DF, Ismail T, Vennarecci G, Patapis $P$, Mayer AD. Therapeutic drug monitoring of tacrolimus in clinical transplantation. Ther Drug Monit 1995;17(6):602-5.

288. Christians U, Jacobsen W, Benet LZ, Lampen A. Mechanisms of clinically relevant drug interactions associated with tacrolimus. Clin Pharmacokinet 2002;41(11):813-51.

289. Bekersky I, Dressler D, Alak A, Boswell GW, Mekki QA. Comparative tacrolimus pharmacokinetics: normal versus mildly hepatically impaired subjects. J Clin Pharmacol 2001;41(6):628-35.

290. Abu-Elmagd KM, Fung JJ, Alessiani M, Jain A, Takaya S, Venkataramanan R, Warty VS, Shannon W, Todo S, Tzakis A, et al. Strategy of FK 506 therapy in liver transplant patients: effect of graft function. Transplant Proc 1991;23(6):2771-4.

291. Abu-Elmagd KM, Fung J, Draviam R, Shannon W, Jain A, Alessiani M, Takaya S, Venkataramanan R, Warty VS, Tzakis A, et al. Four-hour versus 24-hour intravenous infusion of FK 506 in liver transplantation. Transplant Proc 1991;23(6):2767-70.

292. Pou L, Brunet M, Andres I, Rodamilans M, Lopez R, Corbella J. Influence of posttransplant time on dose and concentration of tacrolimus in liver transplant patients. Transpl Int 1998;11 Suppl 1:S270-1.

293. Manzanares C, Moreno M, Castellanos F, Cubas A, Herrero JC, Morales-Ruiz E, Segura J, Andres A, Morales JM. Influence of hepatitis C virus infection on FK 506 blood levels in renal transplant patients. Transplant Proc 1998;30(4):1264-5.

294. van den Berg AP, Haagsma EB, Gouw AS, Slooff MJ, Jansen PL. Recurrent HCV infection reduces the requirement for tacrolimus after liver transplantation. Transplant Proc 2001;33(12):1467.

295. Horina JH, Wirnsberger GH, Kenner L, Holzer H, Krejs GJ. Increased susceptibility for CsAinduced hepatotoxicity in kidney graft recipients with chronic viral hepatitis $\mathrm{C}$. Transplantation 1993;56(5):1091-4.

296. Teperman L, Morgan GR, Diflo T. Tacrolimus dose is donor age dependent [abstract]. 24th Annual Scientific Meeting of the American Society of Transplantation Surgeons 1998 May 1315 Chicago.

297. Taber DJ, Dupuis RE, Fann AL, Andreoni KA, Gerber DA, Fair JH, Johnson MW, Shrestha R. Tacrolimus dosing requirements and concentrations in adult living donor liver transplant recipients. Liver Transpl 2002;8(3):219-23.

298. Trotter JF, Stolpman N, Wachs M, Bak T, Kugelmas M, Kam I, Everson GT. Living donor liver transplant recipients achieve relatively higher immunosuppressant blood levels than cadaveric recipients. Liver Transpl 2002;8(3):212-8.

299. Troisi R, Militerno G, Hoste E, Decruyenaere J, Colpaert K, Monsieurs K, Colle I, Van Vlierberghe $\mathrm{H}$, de Hemptinne $\mathrm{B}$. Are reduced tacrolimus dosages needed in the early postoperative period following living donor liver transplantation in adults? Transplant Proc 2002;34(5):1531-2.

300. Harihara Y, Sano K, Makuuchi M, Kawarasaki H, Takayama T, Kubota K, Ito M, Mizuta K, Yoshino H, Hirata M, Kita Y, Hisatomi S, Kusaka K, Miura Y, Hashizume K. Correlation between graft size and necessary tacrolimus dose after living-related liver transplantation. Transplant Proc 2000;32(7):2166-7.

301. Sugawara Y, Makuuchi M, Kaneko J, Ohkubo T, Imamura H, Kawarasaki H. Correlation between optimal tacrolimus doses and the graft weight in living donor liver transplantation. Clin Transplant 2002;16(2):102-6.

302. Kawasaki S, Makuuchi M, Ishizone S, Matsunami H, Terada M, Kawarazaki H. Liver regeneration in recipients and donors after transplantation. Lancet 1992;339(8793):580-1.

303. Inomata Y, Kiuchi T, Kim I, Uemoto S, Egawa H, Asonuma K, Fujita S, Hayashi M, Tanaka K. Auxiliary partial orthotopic living donor liver transplantation as an aid for small-for-size grafts in larger recipients. Transplantation 1999;67(10):1314-9.

304. Sewing KF. Pharmacokinetics, dosing principles, and blood level monitoring of FK506. Transplant Proc 1994;26(6):3267-9. 
305. van Duijnhoven EM, Christiaans MH, Boots JM, van Hooff JP. Evidence that fasting does not significantly affect trough levels of tacrolimus in stable renal transplant recipients. Transplant Proc 2002;34(5):1723-5.

306. Pond S. Pharmacokinetic basis for drug treatment. In: Benet LZ MN, Gambertoglio JG, editor. Pharmacokinetic drug interactions. New York: Raven Press; 1984. p. 195-220.

307. Wilkinson GR. Drug metabolism and variability among patients in drug response. N Engl J Med 2005;352(21):2211-21.

308. Formea CM, Evans CG, Karlix JL. Altered cytochrome p450 metabolism of calcineurin inhibitors: case report and review of the literature. Pharmacotherapy 2005;25(7):1021-9.

309. Nalli N, Stewart-Teixeira L, Dipchand Al. Amiodarone-sirolimus/tacrolimus interaction in a pediatric heart transplant patient. Pediatr Transplant 2006;10(6):736-9.

310. Mannel M. Drug interactions with St John's wort : mechanisms and clinical implications. Drug Saf 2004;27(11):773-97.

311. Hu Z, Yang X, Ho PC, Chan SY, Heng PW, Chan E, Duan W, Koh HL, Zhou S. Herb-drug interactions: a literature review. Drugs 2005;65(9):1239-82.

312. Mahalati K, Kahan BD. Pharmacological surrogates of allograft outcome. Ann Transplant 2000;5(2):14-23.

313. Braun F, Schutz E, Peters B, Talaulicar R, Grupp C, Undre N, Schafer A, Armstrong VW, Oellerich M, Ringe B. Pharmacokinetics of tacrolimus primary immunosuppression in kidney transplant recipients. Transplant Proc 2001;33(3):2127-8.

314. Backman L, Nicar M, Levy M, Distant D, Eisenstein C, Renard T, Goldstein R, Husberg B, Gonwa T, Klintmalm G. Whole blood and plasma levels of FK 506 after liver transplantation: correlation with toxicity. Transplant Proc 1994;26(3):1804.

315. Kershner RP, Fitzsimmons WE. Relationship of FK506 whole blood concentrations and efficacy and toxicity after liver and kidney transplantation. Transplantation 1996;62(7):920-6.

316. Takahara S, Kokado $Y$, Kameoka H, Takano $Y$, Jiang $H$, Moutabarrik A, Ishibashi M, Okuyama A, Sonoda T. Monitoring of FK 506 blood levels in kidney transplant recipients. Transplant Proc 1994;26(4):2106-8.

317. Winkler M, Ringe B, Rodeck B, Melter M, Stoll K, Baumann J, Wonigeit K, Pichlmayr R. The use of plasma levels for FK 506 dosing in liver-grafted patients. Transpl Int 1994;7(5):329-33.

318. Armendariz Y, Pou L, Cantarell C, Lopez R, Perello M, Capdevila L. Evaluation of a limited sampling strategy to estimate area under the curve of tacrolimus in adult renal transplant patients. Ther Drug Monit 2005;27(4):431-4.

319. Balbontin FG, Kiberd B, Squires J, Singh D, Fraser A, Belitsky P, Lawen J. Tacrolimus monitoring by simplified sparse sampling under the concentration time curve. Transplant Proc 2003;35(7):2445-8.

320. Scholten EM, Cremers SC, Schoemaker RC, Rowshani AT, van Kan EJ, den Hartigh J, Paul LC, de Fijter JW. AUC-guided dosing of tacrolimus prevents progressive systemic overexposure in renal transplant recipients. Kidney Int 2005;67(6):2440-7.

321. Wong KM, Shek CC, Chau KF, Li CS. Abbreviated tacrolimus area-under-the-curve monitoring for renal transplant recipients. Am J Kidney Dis 2000;35(4):660-6.

322. Stolk LM, Van Duijnhoven EM, Christiaans MH, van Hooff JP. Trough levels of tacrolimus. Ther Drug Monit 2002;24(4):573; author reply -4 .

323. Pisitkun T, Eiam-Ong S, Chusil S, Praditpornsilpa K, Pansin P, Tungsanga K. The roles of C4 and AUC0-4 in monitoring of tacrolimus in stable kidney transplant patients. Transplant Proc 2002;34(8):3173-5.

324. Ku YM, Min DI. An abbreviated area-under-the-curve monitoring for tacrolimus in patients with liver transplants. Ther Drug Monit 1998;20(2):219-23.

325. Aumente Rubio MD, Arizon del Prado JM, Lopez Malo de Molina MD, Cardenas Aranzana M, Segura Saint-Gerons J, Lopez Granados A, Rodriguez Esteban E, Mesa Rubio D, Romo Penas E, Segura Saint-Gerons C. Clinical pharmacokinetics of tacrolimus in heart transplantation: new strategies of monitoring. Transplant Proc 2003;35(5):1988-91.

326. Sgrosso JL, Araujo GL, Vazquez MC. Tacrolimus pharmacokinetics in heart transplant. Transplant Proc 2002;34(1):142-3. 
327. Ragette R, Kamler M, Weinreich G, Teschler H, Jakob H. Tacrolimus pharmacokinetics in lung transplantation: new strategies for monitoring. J Heart Lung Transplant 2005;24(9):13159.

328. Eur J Clin Pharmacol

328. Hebert MF, Fisher RM, Marsh CL, Dressler D, Bekersky I. Effects of rifampin on tacrolimus pharmacokinetics in healthy volunteers. J Clin Pharmacol 1999;39(1):91-6.

329. Tamura K, Kobayashi M, Hashimoto K, Kojima K, Nagase K, Iwasaki K, Kaizu T, Tanaka H, Niwa M. A highly sensitive method to assay FK-506 levels in plasma. Transplant Proc 1987;19(5 Suppl 6):23-9.

330. Wallemacq PE, Firdaous I, Hassoun A. Improvement and assessment of enzyme-linked immunosorbent assay to detect low FK506 concentrations in plasma or whole blood within 6 hours. Clin Chem 1993;39(6):1045-9.

331. Kobayashi M, Tamura K, Katayama N, Nakamura K, Nagase K, Hane K, Tutumi T, Niwa M, Tanaka H, Iwasaki K, et al. FK 506 assay past and present--characteristics of FK 506 ELISA. Transplant Proc 1991;23(6):2725-9.

332. Grenier FC, Luczkiw J, Bergmann M, Lunetta S, Morrison M, Blonski D, Shoemaker K, Kobayashi M. A whole blood FK 506 assay for the IMx analyzer. Transplant Proc 1991;23(6):2748-9.

333. Winkler M, Christians U, Baumann J, Gonschior AK, Wonigeit K, Pichlmayr R. Evaluation of the Pro-Trac tacrolimus monoclonal whole-blood enzyme-linked immunosorbent assay for monitoring of tacrolimus levels in patients after kidney, heart, and liver transplantation. Ther Drug Monit 1996;18(6):640-6.

334. Cannon RD, Wong SH, Hariharan S, Adams MB, Johnson CP, Roza AM, Pearson ML, Werner CL. Clinical efficacy of the Abbott Tacrolimus II assay for the IMx. Ann Clin Lab Sci 1999;29(4):299-302.

335. Murthy JN, Chen Y, Warty VS, Venkataramanan R, Donnelly JG, Zeevi A, Soldin SJ. Radioreceptor assay for quantifying FK-506 immunosuppressant in whole blood. Clin Chem 1992;38(7):1307-10.

336. Zeevi A, Eiras G, Burckart G, Jain A, Kragack A, Venkataramanan R, Todo S, Fung J, Starzl TE, Duquesnoy RJ. Bioassay of plasma specimens from liver transplant patients on FK 506 immunosuppression. Transplant Proc 1990;22(1):60-3.

337. D'Ambrosio R, Girzaitis N, Jusko WJ. Multicenter comparison of tacrolimus (FK 506) whole blood concentrations as measured by the Abbott IMX analyzer and enzyme immunoassay with methylene chloride extraction. Ther Drug Monit 1994;16(3):287-92.

338. Matsunami H, Tada A, Makuuchi M, Lynch SV, Strong RW. New technique for measuring tacrolimus concentrations in blood. Am J Hosp Pharm 1994;51(1):123.

339. Mayer AD, Dmitrewski J, Squifflet JP, Besse T, Grabensee B, Klein B, Eigler FW, Heemann U, Pichlmayr R, Behrend M, Vanrenterghem Y, Donck J, van Hooff J, Christiaans M, Morales JM, Andres A, Johnson RW, Short C, Buchholz B, Rehmert N, Land W, Schleibner S, Forsythe JL, Talbot $\mathrm{D}$, Pohanka $\mathrm{E}$, et al. Multicenter randomized trial comparing tacrolimus (FK506) and cyclosporine in the prevention of renal allograft rejection: a report of the European Tacrolimus Multicenter Renal Study Group. Transplantation 1997;64(3):436-43.

340. Pirsch JD, Miller J, Deierhoi MH, Vincenti F, Filo RS. A comparison of tacrolimus (FK506) and cyclosporine for immunosuppression after cadaveric renal transplantation. FK506 Kidney Transplant Study Group. Transplantation 1997;63(7):977-83.

341. Williams R, Neuhaus P, Bismuth H, McMaster P, Pichlmayr R, Calne R, Otto G, Groth C. Two-year data from the European multicentre tacrolimus (FK506) liver study. Transpl Int 1996;9 Suppl 1:S144-50.

342. Busuttil RW, Klintmalm GB, Lake JR, Miller CM, Porayko M. General guidelines for the use of tacrolimus in adult liver transplant patients. Transplantation 1996;61(5):845-7.

343. Randomised trial comparing tacrolimus (FK506) and cyclosporin in prevention of liver allograft rejection. European FK506 Multicentre Liver Study Group. Lancet 1994;344(8920):423-8. 
344. Bowles MJ, Waters JB, Lechler RI, Williams G. Do cyclosporin profiles provide useful information in the management of renal transplant recipients? Nephrol Dial Transplant 1996;11(8):1597-602.

345. Mor EYA, Chodoff L. New immunosuppressive agents for maintenance therapy in organ transplantation: focus on adverse effects. Biodrugs 1997;16(4):242-57.

346. Henry ML. Cyclosporine and tacrolimus (FK506): a comparison of efficacy and safety profiles. Clin Transplant 1999;13(3):209-20.

347. Chang C. Neurological complications of critical illness and transplantation. Curr Opin Crit Care 1999;5(2):112-18.

348. Mueller AR, Platz KP, Christe W, Bechstein WO, Blumhardt G, Neuhaus P. Severe neurotoxicity after liver transplantation: association between FK 506 therapy and hepatitis C virus disease. Transplant Proc 1994;26(6):3131-2.

349. Jindal RM, Sidner RA, Milgrom ML. Post-transplant diabetes mellitus. The role of immunosuppression. Drug Saf 1997;16(4):242-57.

350. Bonomini Vftl-STSg. Low rejection rates with tacrolimus-based dual and triple regimens following renal transplantation [abstract]. J Am Soc Nephrol 1999;10(720A).

351. Fung JJ, Todo S, Tzakis A, Demetris A, Jain A, Abu-Elmaged K, Alessiani M, Starzl TE. Conversion of liver allograft recipients from cyclosporine to FK 506-based immunosuppression: benefits and pitfalls. Transplant Proc 1991;23(1 Pt 1):14-21.

352. Peters DH, Fitton A, Plosker GL, Faulds D. Tacrolimus. A review of its pharmacology, and therapeutic potential in hepatic and renal transplantation. Drugs 1993;46(4):746-94.

353. Mayer AD. Four-year follow-up of the European Tacrolimus Multicenter Renal Study. Transplant Proc 1999;31(7A):27S-8S.

354. Fagiuoli S, Gasbarrini A, Azzarone A, Francavilla A, Van Thiel DH. FK 506: a new immunosuppressive agent for organ transplantation. Pharmacology, mechanism of action and clinical applications. Ital J Gastroenterol 1992;24(6):355-60.

355. Li PK, Nicholls MG, Lai KN. The complications of newer transplant antirejection drugs: treatment with cyclosporin A, OKT3, and FK506. Adverse Drug React Acute Poisoning Rev 1990;9(3):123-55.

356. McCauley J, Fung J, Jain A, Todo S, Starzl TE. The effects of FK 506 on renal function after liver transplantation. Transplant Proc 1990;22(1):17-20.

357. Niederstadt C, Steinhoff J, Erbsloh-Moller B, Renner F, Sack K, Rob PM. Effect of FK506 on magnesium homeostasis after renal transplantation. Transplant Proc 1997;29(7):3161-2.

358. Spencer CM, Goa KL, Gillis JC. Tacrolimus. An update of its pharmacology and clinical efficacy in the management of organ transplantation. Drugs 1997;54(6):925-75.

359. Tzakis AG, Fung JJ, Todo S, Reyes J, Green M, Starzl TE. Use of FK 506 in pediatric patients. Transplant Proc 1991;23(1 Pt 2):924-7.

360. Tzakis AG, Reyes J, Todo S, Nour B, Shapiro R, Jordan M, McCauley J, Armitage J, Fung JJ, Starzl TE. Two-year experience with FK 506 in pediatric patients. Transplant Proc 1993;25(1 Pt 1):619-21.

361. Cacciarelli TV, Esquivel CO, Cox KL, Hayashi M, Berquist WE, Concepcion W, So SK. Oral tacrolimus (FK506) induction therapy in pediatric orthotopic liver transplantation. Transplantation 1996;61(8):1188-92.

362. Sokal EM, Antunes H, Beguin C, Bodeus M, Wallemacq P, de Ville de Goyet J, Reding R, Janssen M, Buts JP, Otte JB. Early signs and risk factors for the increased incidence of Epstein-Barr virus-related posttransplant lymphoproliferative diseases in pediatric liver transplant recipients treated with tacrolimus. Transplantation 1997;64(10):1438-42.

363. Shapiro R, Scantlebury VP, Jordan ML, Vivas C, Ellis D, Lombardozzi-Lane S, Gilboa N, Gritsch HA, Irish W, McCauley J, Fung JJ, Hakala TR, Simmons RL, Starzl TE. Pediatric renal transplantation under tacrolimus-based immunosuppression. Transplantation 1999;67(2):299-303.

364. Jain A, Reyes J, Kashyap R, Rohal S, Cacclarelli T, McMichael J, Rakela J, Starzl TE, Fung JJ. Liver transplantation under tacrolimus in infants, children, adults, and seniors: long-term results, survival, and adverse events in 1000 consecutive patients. Transplant Proc 1998;30(4):1403-4. 
365. Inomata $\mathrm{Y}$, Tanaka K, Egawa $\mathrm{H}$, Uemoto S, Ozaki N, Okajima H, Satomura K, Kiuchi T, Yamaoka Y, Hashida T. The evolution of immunosuppression with FK506 in pediatric livingrelated liver transplantation. Transplantation 1996;61(2):247-52.

366. Newell KA, Alonso EM, Whitington PF, Bruce DS, Millis JM, Piper JB, Woodle ES, Kelly SM, Koeppen H, Hart J, Rubin CM, Thistlethwaite JR, Jr. Posttransplant lymphoproliferative disease in pediatric liver transplantation. Interplay between primary Epstein-Barr virus infection and immunosuppression. Transplantation 1996;62(3):370-5.

367. Paolillo J, Wagner K, Boyle GE. Post-transplant diabetes mellitus in paediatric thoracic organ recipients receiving tacrolimus-based immunosuppression [abstract]. Transplantation 1999;67(7):S230.

368. Moxey-Mims MM, Kay C, Light JA, Kher KK. Increased incidence of insulin-dependent diabetes mellitus in pediatric renal transplant patients receiving tacrolimus (FK506). Transplantation 1998;65(5):617-9.

369. Wacher V, Salphati L, Benet, LZ. Active secretion and enterocytic drug metabolism barriers to drug absorption. Adv Drug Deliv Rev 1996;20:99-112.

370. Soldner A, Benet LZ, Mutschler E, Christians U. Active transport of the angiotensin-II antagonist losartan and its main metabolite EXP 3174 across MDCK-MDR1 and caco-2 cell monolayers. Br J Pharmacol 2000;129(6):1235-43. 


\section{Chapter 3}

\section{Comparison of DNA isolation kits to extract DNA from whole blood samples}

Robert A.M. Op den Buijsch, Johan E. de Vries, Joop ten Kate, Petal A.H.M. Wijnen, Snježana Rothkrantz-Kos, Marja P. van Dieijen-Visser, Otto Bekers 


\section{Abstract}

\section{Background and aim}

Genomic deoxyribonucleic acid (DNA) from white blood cells (WBCs) is widely used for polymerase chain reaction (PCR). Although kits for DNA isolation are in common use, there is scarce information about their performance and the PCR quality of the genomic DNA obtained. Hence, three different kits, QIAamp blood mini kit, High Pure PCR Template Preparation Kit and the Puregene DNA isolation kit were evaluated on these aspects.

\section{Materials and methods}

Genomic DNA was isolated from whole blood samples with WBC counts ranging from 0.5 to $20 \times 10^{9} \mathrm{WBC} / \mathrm{l}$. The WBC count was used to calculate the amount of genomic DNA. The actual amount of genomic DNA isolated, was determined spectrophotometrically. The DNA extraction efficiency was obtained by dividing the actual amount of DNA by the calculated amount yielded. PCR quality was analysed by measuring Cycle threshold $\left(C_{t}\right)$ values with a quantitative real-time PCR $\beta$-globin assay.

\section{Results}

The extraction efficiency of the three DNA isolation kits was $20 \%$ to $40 \%$. Spectrophotometrically determined DNA concentrations correlated inversely with $C_{t}$ values, regardless of the DNA isolation kit applied, whereas the strongest correlation was obtained for the Puregene DNA isolation kit. WBC counts also correlated inversely with $C_{t}$ values and here the strongest correlation was found for the QIAamp blood mini kit.

\section{Conclusion}

The overall performance of the DNA isolation kits was quite comparable (DNA recoveries of $20-40 \%$ ), albeit the QIAamp blood mini kit yielded the most reproducible extraction efficiencies and lowest $C_{t}$ values within every WBC count category. 


\section{Introduction}

White blood cells (WBCs) are easily obtained and therefore a common source of genomic deoxyribonucleic acid (DNA), which is the starting material for a variety of molecular biological techniques. One of the most important applications is the use of genomic DNA in polymerase chain reaction (PCR), for either polymorphism analysis or quantitative analysis with fluorescent real-time PCR. In the latter, the number of genome copies present at the start of the PCR is related to the Cycle threshold $\left(C_{t}\right)$ values ${ }^{1,2}$. DNA isolation kits are commonly used for the isolation of genomic DNA from WBCs. However, it is not known whether the performance of DNA isolation kits is influenced by the number of WBCs present. Neither, has been investigated whether the PCR quality of genomic DNA depends on the DNA isolation kit used. To answer these questions three different DNA isolation kits are tested. The QIAamp blood mini kit (Qiagen, Leusden, the Netherlands) and the High Pure PCR Template Preparation Kit (Roche Diagnostics $\mathrm{GmbH}$, Mannheim, Germany) rely on the preparation of a chaotropic mixture, in which DNA binds to a column and is subsequently eluted. The principle of DNA isolation with the Puregene DNA isolation kit (Puregene, Landgraaf, the Netherlands) is based on a salting out method. The WBC count was used as the gold standard to calculate the exact amount of genomic DNA in a given volume. The diploid genome of one WBC equals the amount of $6.6 \mathrm{pg} \mathrm{DNA}^{2}$. The calculated amount of DNA is set as the $100 \%$ score. The actual amount of genomic DNA isolated was measured spectrophotometrically. Dividing the actual amount of genomic DNA isolated, by the calculated amount of genomic DNA, yields the extraction efficiency. The $C_{t}$ value was used as a rough indicator for the PCR quality of genomic DNA, provided that an equal number of genome copies is present at the start of the $P C R^{1,2}$. Genomic DNA with the best PCR quality should result in the lowest $C_{t}$ value. $A$ quantitative real-time PCR $\beta$-globin assay was used in this study to compare the PCR quality of genomic DNA, obtained with the different DNA isolation kits $^{2,3}$.

\section{Materials and methods}

\section{Sample collection}

Thirty ethylene diamine tetra-acetic acid (EDTA) anticoagulated blood samples with known WBC counts were collected from anonymized patients referred to the haematology department for routine investigations. These samples were categorized in six different WBC categories each category consisting of five samples. The range of WBC counts was set at $0.5 \times 10^{9} \mathrm{WBC} / \mathrm{l}$, being the lowest number of WBC counts that could be counted reliably. The highest level was set at $20 \times 10^{9} \mathrm{WBC} / \mathrm{l}$, being twice the number of the upper limit of a normal WBC count. Four intermediate categories of 2.0, 5.0, 10 and $15 \times 10^{9} \mathrm{WBC} / \mathrm{l}$ were formed. Each sample was divided into three equal 
aliquots of $300 \mu \mathrm{l}$ whole blood. Until DNA isolation was performed all blood samples were stored at $-20^{\circ} \mathrm{C}$. WBC counts were performed on a Beckman Coulter GenS (Beckman Coulter Inc., Fullerton, CA, USA).

\section{DNA isolation procedures}

DNA isolation was performed with the QIAamp blood mini kit (Qiagen, Leusden, the Netherlands), the High Pure PCR Template Preparation Kit (Roche Diagnostics $\mathrm{GmbH}$ Mannheim, Germany) and the Puregene DNA isolation Kit (Biozyme, Landgraaf, the Netherlands), all according to the manufacturers' protocols. Isolated genomic DNA was quantified spectrophotometrically by measuring absorptions at 260,280 and $320 \mathrm{~nm}^{4-7}$ with the Ultrospec 2000 (Pharmacia Biotech, Roosendaal, the Netherlands). Absorption at $320 \mathrm{~nm}\left(A^{320}\right)$ gives information about the presence of e.g. phenolic substances, whereas the ratio of the absorptions at $260 \mathrm{~nm}$ versus $280 \mathrm{~nm}\left(A^{260 / 280}\right)$ provides information about impurities due to proteins or RNA.

\section{Quantitative real-time PCR $\beta$-globine TaqMan ${ }^{\circledR}$ assay}

A quantitative real-time PCR $\beta$-globin TaqMan ${ }^{\circledR}$ assay, described by Lo et al. for the ABI Prism 7700 , was used to obtain $C_{t}$ values ${ }^{2}$. This quantitative real-time PCR TaqMan ${ }^{\circledR}$ assay was adapted for use on the LightCycler ${ }^{\circledR}$ (Roche Diagnostics by Almere, the Netherlands). The fluorescence signal from the liberated FAM reporter group was measured at the end of the extension step $\left(72^{\circ} \mathrm{C}\right)$ in channel 1 . The $2^{\text {nd }}$ derivative method was used to calculate $C_{t}$ values from the sigmoid real-time PCR curves. The PCR mixture contained $7.0 \mu \mathrm{l}$ sterile water, $4.0 \mathrm{mM} \mathrm{MgCl}_{2}, 2.0 \mu \mathrm{l}$ LC Faststart DNA Master Hybridization Probes (Roche Diagnostics, $\mathrm{GmbH}$, Mannheim, Germany), $0.2 \mu \mathrm{M}$ of the dual labelled FAM/TAMRA TaqMan ${ }^{\circledR}$ probe BGFT13 (Eurogentec, Seraing, Belgium) and $0.70 \mu \mathrm{M}$ of both primers BGLOBF13 and BGLOBR13 (Eurogentec, Seraing, Belgium). After adding $1.0 \mu \mathrm{l}$ genomic DNA to the PCR mixture, the total volume was $20 \mu \mathrm{l}$. The PCR protocol included the following steps a) denaturation for 10 minutes at $95^{\circ} \mathrm{C}$ b) 45 cycles at $95^{\circ} \mathrm{C}$ for 10 seconds, $60^{\circ} \mathrm{C}$ for 30 seconds and $72^{\circ} \mathrm{C}$ for 5 seconds. The temperature transition rates were programmed at $20^{\circ} \mathrm{C} /$ second for all three temperatures. $C_{t}$ values of thirty DNA samples, isolated with the same DNA isolation kit, were determined within one PCR run.

\section{Statistical methods}

Statistical analysis was performed using SPSS 10.0 for Windows (SPSS, Chicago, IL, USA). As initial distributions of the variables extraction efficiencies and $C_{t}$ values were positively skewed. When appropriate, parametric tests were performed, otherwise non parametric statistics were used. To explore the influence of the WBC count $(6$ different levels from 0.5 to $\left.20 \times 10^{9} \mathrm{WBC} / \mathrm{l}\right)$ on the extraction efficiency, the analysis was performed on the dataset where the outliers with extraction efficiency $<1.3 \%$ and 
$>104 \%$ were omitted from the analysis (three for the Puregene method, two for the Roche method). As the data were thereafter readily normalized, univariate ANOVA was performed. The correlation between $C_{t}$ values and DNA concentrations based on either WBC counts or UVspectrophotometry was determined with the non parametric Spearman rank correlation. The Spearman correlation coefficient $\left(r_{s}\right)$ indicates the degree of association between either DNA concentrations and the $C_{t}$ values $\left(r_{s(U V)}\right)$ or WBC counts and $\mathrm{C}_{\mathrm{t}}$ values $\left(\mathrm{r}_{\mathrm{s}}(\mathrm{WBC})\right.$ ).

\section{Results}

Following the manufacturers' protocols, the end volume for the genomic DNA solution was $200 \mu \mathrm{l}$ for the Roche, $100 \mu \mathrm{l}$ for the Qiagen and the Puregene DNA isolation kit. DNA extraction efficiencies appeared to be similar for all three DNA isolation kits in all WBC count categories, except in the lowest category (Figure 3.1). In this category the chaotropic isolation methods (Qiagen and Roche) seemed to exceed the salting out based method (Puregene). Background $A^{320}$ readings \pm standard deviation (SD) showed different optical density (OD) values over the complete range for each DNA isolation kit, but were higher for the chaotropic isolation methods than for the salting out isolation method, with respectively $0.20 \pm 0.12$ and $0.08 \pm 0.06$ for the Roche and Qiagen, and $0.02 \pm 0.02$ for the Puregene DNA isolation kit. The background corrected $A^{260 / 280}$ ratio of genomic DNA of the WBC count categories of $5.0 \times 10^{9} \mathrm{WBC} / \mathrm{l}$ and higher, varied from 1.8 to 1.9. Only the two lowest WBC count categories had a different background corrected $A^{260 / 280}$ ratio. Genomic DNA, isolated with the chaotropic isolation methods, showed in this area lower ratios than genomic DNA, isolated with the salting out method, 1.7 and 1.8 for the Qiagen and Roche DNA isolation kits, respectively, and 2.0 for the Puregene DNA isolation kit (Table 3.1). To explore the influence of the WBC counts on the extraction efficiency, the univariate ANOVA analysis was performed including all WBC count categories for each DNA isolation kit. The results were respectively $F=13.4, P<0.0001$ for Qiagen, $F=20.8, P<0.0001$ for Roche and $\mathrm{F}=1.67, P=0.186$ for Puregene. This indicates that the mean value of at least one WBC level was significantly different as compared to other WBC levels for the Qiagen and Roche DNA isolation kit. The correlations of different DNA isolation methods (taking all WBC count levels into account) with the WBC count were as follows: $r=-0.596$, $P=0.001$ for Qiagen, $r=-0.782, P<0.0001$ for Roche and $r=0.153, P=0.445$ for Puregene. We speculated that two factors might be attributable to these findings. The first one was large variation in the extraction efficiency results in the group with WBC count of $0.5 \times 10^{9} \mathrm{WBC} / \mathrm{l}$. The second one might be that extraction efficiency is dependent on the WBC count. Therefore, the analysis was performed once more, thereby omitting WBC count group of $0.5 \times 10^{9} \mathrm{WBC} / \mathrm{l}$. The results of univariate ANOVA were respectively $\mathrm{F}=1.33, P=0.293$ for Qiagen, $\mathrm{F}=22.1, P<0.0001$ for Roche and $\mathrm{F}=1.87, P=0.162$ for Puregene. Only for the Roche DNA isolation kit at least one 
WBC level was significantly different as compared to other WBC levels. The correlations of different DNA isolation methods (omitting WBC count level of $0.5 \times 10^{9} \mathrm{WBC} / \mathrm{l}$ ) with the WBC count were as follows: $r=-0.398, P=0.05$ for Qiagen, $r=-0.844, P<0.0001$ for Roche and $r=0.326, P=0.138$ for Puregene. In the tenfold range of WBC counts, the extraction efficiency varies roughly from $20 \%$ to $40 \%$. In the lowest WBC count category, the extraction efficiency is higher for the chaotropic isolation methods than for the salting out isolation method (Figure 3.1). The real-time PCR curves are shown in Figure 3.2.

A

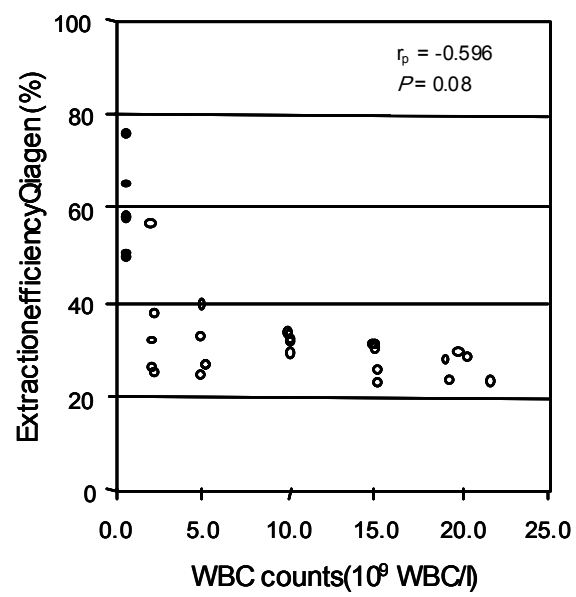

B

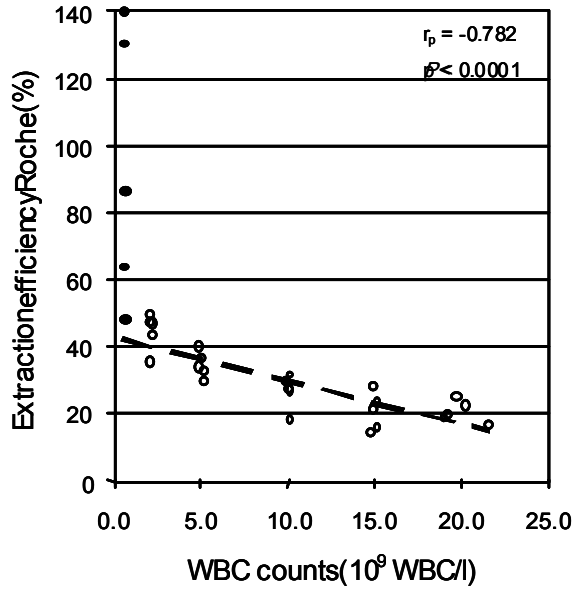

C

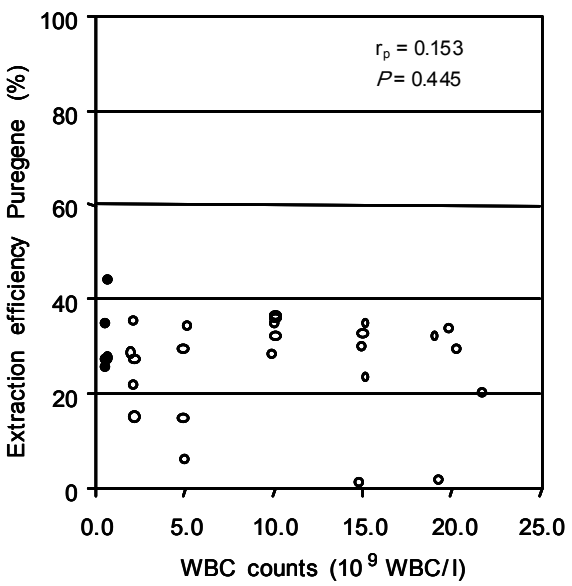

Figure 3.1 White blood cell (WBC) counts versus extraction efficiency of (A) Qiagen, (B) Roche and (C) Puregene with a WBC range of \pm 0.5 to $\pm 20 \times 10^{9} \mathrm{WBC} / \mathrm{l}$. The WBC count category of $0.5 \times 10^{9} \mathrm{WBC} / \mathrm{l}$ is excluded before calculating the $r_{p}$ and $p$ values of all DNA isolation kits. The closed circles in Figure 3.1B are not included in the trend line. 
Table 3.1 

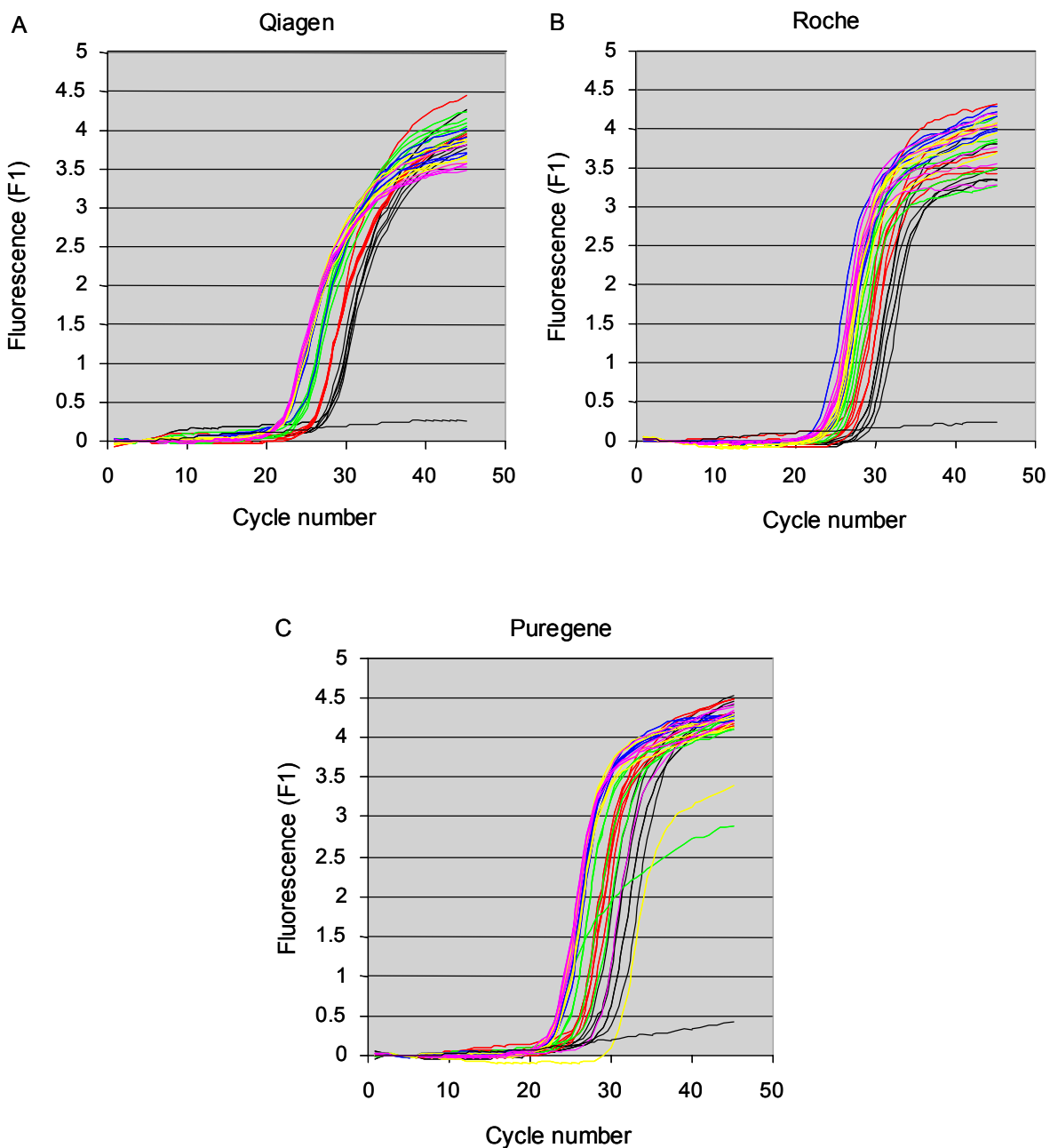

Figure 3.2 Real-time PCR amplification curves of three different DNA isolation kits (A) Qiagen, (B) Roche and (C) Puregene.

The median $C_{t}$ values calculated from these curves seemed to be equal for the three DNA isolation kits in the lower three WBC count categories. Albeit that the median $C_{t}$ value was somewhat lower for the Qiagen DNA isolation kit with the smallest $C_{t}$ value interval ranges (Table 3.1). The median $C_{t}$ values in the three higher WBC count categories seemed to be the lowest for the Qiagen DNA isolation kit, with also the narrowest $\mathrm{C}_{t}$ value interval ranges (Table 3.1). It was one and two $\mathrm{Ct}$ units lower than the median $C_{t}$ values of the Puregene and the Roche DNA isolation kits, respectively. The variability of the $C_{t}$ values within one WBC count category is lower for the 
chaotropic isolation methods than for the salting out method (Table 3.1). For all the DNA isolation kits it was found that increased concentrations of genomic DNA was paralleled by decreased $C_{t}$ values. Likewise, increased WBC counts were related with a decrease in $C_{t}$ values. However, there seem to be subtle differences in the strength of these associations between the DNA isolation kits. This is apparent from the $r_{s}$ values obtained with the non parametric Spearman rank correlation (Figure 3.3).
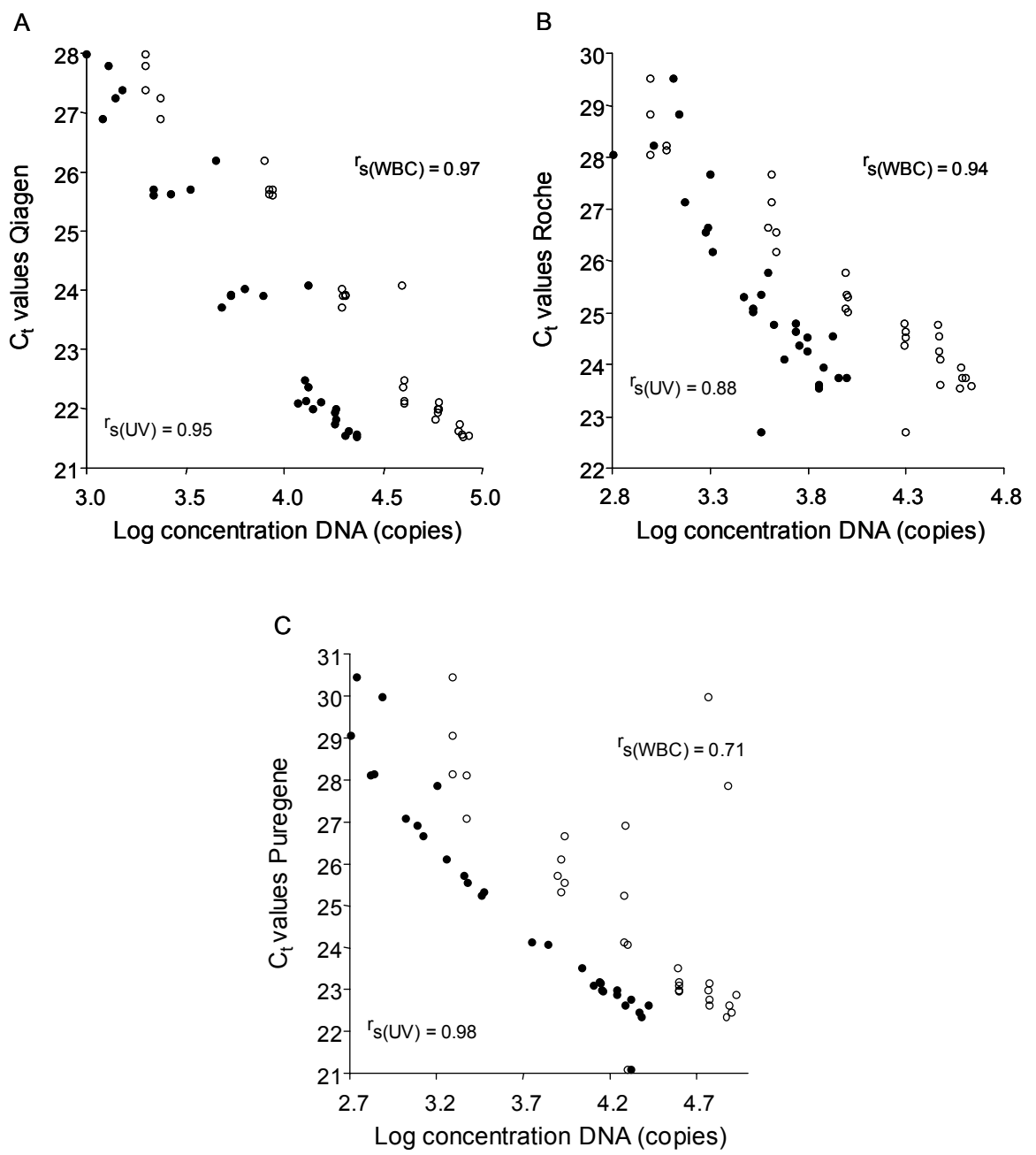

Figure 3.3 Log concentration DNA versus $C_{t}$ values. The Spearman correlation coefficients $\left(r_{s}\right)$ indicate the correlation between the log concentrations DNA in copies versus the $C_{t}$ values of respectively (A) Qiagen, (B) Roche and (C) Puregene. The closed circles indicate the samples of which the DNA concentration is determined UVspectrophotometrically $\left(r_{s(U v)}\right)$. The open circles indicate the samples of which the DNA concentration is determined by counting white blood cells $\left(r_{s(\mathrm{WBC})}\right)$. 
The $r_{s(U V)}$ value for the association of the concentration of genomic DNA with the $C_{t}$ value was the highest for the Puregene and the lowest for the Roche DNA isolation kit, 0.98 and 0.88 , respectively. The $r_{s}(\mathrm{WBC})$ value for the association of the WBC counts with the $C_{t}$ value was the highest for the Qiagen and the lowest for the Puregene DNA isolation kit, 0.97 and 0.71 , respectively. The $C_{t}$ values of the Qiagen DNA isolation kit correlated very well with the concentration of genomic DNA as well as with the WBC counts. Also, the $C_{t}$ values of the Roche DNA isolation kit correlated well with the concentration of genomic DNA as well as with the WBC counts. In contrast, the $C_{t}$ values of the Puregene DNA isolation kit correlated very well with the concentration of genomic DNA but relatively poorly with the WBC counts.

\section{Discussion}

WBC counts generate unambiguous data about the amount of genomic DNA present in a given volume of anticoagulated whole blood samples. Hence, the efficiency of a genomic DNA isolation with a DNA isolation kit can be determined unequivocally from the number of WBCs. In this study three different DNA isolation kits were compared, using samples containing low as well as high WBC counts, divided into six different WBC count categories. We showed that the different DNA isolation kits were comparable with regard to the total amount of genomic DNA that can be isolated. This is determined spectrophotometrically ${ }^{4-7}$. However, the background $A^{320}$ readings are substantially higher in the chaotropic isolation methods than in the salting out method, this is especially prominent in the lowest WBC count category. OD readings for samples with low concentrations of genomic DNA, obtained with the chaotropic DNA isolation kits, might therefore overestimate the actual genomic DNA present. Only in the lowest WBC count category there is a marked difference in the calculated extraction efficiencies between the salting out and the chaotropic DNA isolation methods. The salting out method showed an extraction efficiency of about $40 \%$, whereas the extraction efficiency of the chaotropic method was much higher. However, the high background in genomic DNA isolated with the chaotropic method might lead to an overestimation of the actual amount of genomic DNA present, and hence, to an exaggerated extraction efficiency. Turning to $2.0 \times 10^{9} \mathrm{WBC} / \mathrm{l}$ and higher, there is a remarkable constancy in the extraction efficiency. In a tenfold increase of WBC counts, there is a decrease from $40 \%$ to $20 \%$ in the extraction efficiency. This is observed for all the DNA isolation kits examined. It seems therefore that extraction efficiency depends on neither the method of DNA isolation nor the WBC count (Qiagen and Puregene), given that the WBC count is $2.0 \times 10^{9} \mathrm{WBC} / \mathrm{l}$ or higher. The PCR quality of the genomic DNA is evaluated by comparison of $C_{t}$ values, obtained with a quantitative real-time PCR TaqMan ${ }^{\circledR}$ assay for the $\beta$-globin gene. Provided that the same copy number is present at the start of the PCR, genomic DNA with consistently the lowest $C_{t}$ value, offers the best PCR quality. Although the $C_{t}$ values are almost identical within a WBC 
count category, the median $\mathrm{C}_{t}$ value of genomic DNA isolated with the Qiagen kit seems to be consistently lower than the $C_{t}$ values obtained with genomic DNA isolated with the other DNA isolation kits. The Qiagen kit also yields genomic DNA with the narrowest $C_{t}$ value interval ranges (Table 3.1). The largest $C_{t}$ value interval ranges are observed with genomic DNA isolated with the salting out method. Most likely, this is related to the fact that three samples in three different WBC count categories yielded a very low extraction efficiency. In general, $C_{t}$ values are inversely related to DNA concentrations. Because the DNA concentration in a whole blood sample is largely determined by the number of WBCs, one should also find an inverse relation between $C_{t}$ values and WBC counts. Actually, the association found between $C_{t}$ values and WBC counts for the chaotropic isolation methods is better than the association between $C_{t}$ values and genomic DNA concentration, as measured with UV spectrophotometry. For the salting out method this association is the other way around and most likely, due to the very low extraction efficiency of three samples in three highest WBC count categories, which impairs the association of the $C_{t}$ values with WBC counts, but not the association of $C_{t}$ values with genomic DNA concentration, as measured with UVspectrophotometry. It implies that WBC counts could be used to predict the yield of genomic DNA if a chaotropic DNA isolation is used in addition of an UVspectrophotometric measurement. This would be worthwhile considering if samples with a low WBC count are used.

In conclusion, the use of WBC counts to calculate the amount of genomic DNA in a given volume allowed us to establish that the extraction efficiency ranges roughly from $20 \%$ to $40 \%$, independent of the DNA isolation kit used and the number of WBCs present (Qiagen and Puregene). Using $C_{t}$ values as a measure for the PCR quality of genomic DNA, it was found that the Qiagen blood mini kit seemed to yield the best quality of genomic DNA for PCR in the three highest WBC count categories. 


\section{References}

1. de Kok JB, Hendriks JC, van Solinge WW, Willems HL, Mensink EJ, Swinkels DW. Use of real-time quantitative PCR to compare DNA isolation methods. Clin Chem 1998;44: 2201-4.

2. Lo YM, Tein MS, Lau TK, Haines CJ, Leung TN, Poon PM, Wainscoat JS, Johnson PJ, Chang AM, Hjelm NM. Quantitative analysis of fetal DNA in maternal plasma and serum: implications for noninvasive prenatal diagnosis. Am J Hum Genet 1998;62:768-75.

3. Klaassen $\mathrm{CH}$, Jeunink MA, Prinsen CF, Ruers TJ, Tan AC, Strobbe LJ, Thunnissen FB. Quantification of human DNA in feces as a diagnostic test for the presence of colorectal cancer. Clin Chem 2003;49:1185-7.

4. Ausubel FM BR, Kingston RE, Moore DD, Seidman JG, Smith JA, Struhl K. Current protocols in molecular biology. New York: Wiley; 1998.

5. Sambrook J FE, Maniatis T. Molecular cloning: a laboratory manual. New York: Cold Spring Harbor Press; 1989.

6. Munro HN, Fleck A. Recent developments in the measurement of nucleic acids in biological materials. A supplementary review. Analyst 1966;91:78-88.

7. Volkin E, Cohn WE. Estimation of nucleic acids. Methods Biochem Anal 1954;1:287-305. 


\section{Chapter 4}

Genotyping of the pregnane X receptor A11156C polymorphism with locked nucleic acid containing fluorogenic probes

Robert A.M. Op den Buijsch, Johan E. de Vries, Wil J.G. Loots, Olfert Landt, Petal A.H.M. Wijnen, Marja P. van Dieijen-Visser, Otto Bekers The Pharmacogenomics Journal 2005;5:72-74 


\section{Abstract}

Background and aim

The discriminative power of oligonucleotide probes to differentiate between two alleles of a biallelic gene locus is an important aspect in polymorphism analysis.

Materials and methods

This study investigates the enhancement of discriminative power in a fluorescence resonance energy transfer (FRET) assay by incorporation of a locked nucleic acid (LNA) at the polymorphic site applied on genotyping of the pregnane $X$ receptor (PXR) A11156C polymorphism. Fifty individuals were genotyped for this PXR A11156C polymorphism. Polymerase chain reaction (PCR) products of the different PXR 11156 allelic variants were sequenced to validate the results of this FRET assay.

\section{Results}

It follows that incorporation of the LNA significantly improved the genotyping of the PXR A11156C polymorphism. Especially, heterozygotes could be discriminated clearly by showing two melting peaks, whereas the probes without a LNA were not able to separate melting peaks in the melting curve analysis.

Conclusion

A LNA within a sensor probe may improve the discriminating power of FRET assays significantly. 


\section{Introduction}

The introduction of molecular technologies that combine the polymerase chain reaction (PCR) with the use of fluorescent hybridisation probes significantly reduced the risk of contamination, since no post PCR steps are involved. Although these techniques have been successfully used for the identification of a huge variety of single nucleotide polymorphisms (SNPs) ${ }^{1,2}$, there are target sequences in which the discriminating power of deoxyribonucleic acid (DNA) probes is not sufficient to differentiate between the two alleles of a biallelic gene locus. The nuclear pregnane $X$ receptor (PXR), (also known as SXR, PAR, PRR and NR1/2) is an important component of the body's adaptive defensive mechanism against toxic substances including drugs. Ligand activated PXR is involved in the transcriptional activation of multiple drug resistance gene 1 (MDR1) and cytochrome P450 3A4 (CYP3A4). Both are main regulators in the uptake and transformation of many orally prescribed medicines. Hence, knowledge with regard to known PXR polymorphisms, which influence the expression of MDR1 and/or CYP3A4, is therefore relevant to understand the interindividual responses towards drugs ${ }^{3-5}$. One of the putative relevant polymorphisms is PXR A11156C because it has been shown that the presence of the $11156 \mathrm{C}$ allele is associated with a decreased expression of MDR1 mRNA in intestinal villi cells derived from gut biopsies ${ }^{4}$. In order to determine the genotype of the PXR A11156C polymorphism we developed a real-time PCR fluorescence resonance energy transfer (FRET) assay. Although homozygotes could be discriminated unequivocally, separate melting peaks could not be obtained in putative heterozygote genotypes. To improve the discriminative power of the sensor probe two routes were followed. The first was to shorten the sensor probe and the second route was to modify the sensor probe with a locked nucleic acid (LNA) on the polymorphic position $^{6-13}$. This last mentioned possibility is based on some recently published reports, which documented the high discriminative power of fluorogenic probes containing LNA to differentiate between matched and mismatched duplexes in several techniques, but not yet applied in FRET assays ${ }^{14-16}$. However, FRET assays have become a major technique in the field of polymorphism analysis. It is therefore worthwhile to examine the usefulness of LNA in FRET assays. The present study describes a real-time PCR FRET assay on the LightCycler in which three different sensor probes, of which one contains a LNA, are compared for their ability to differentiate between matched and mismatched duplexes.

\section{Materials and methods}

Ethylene diamine tetra-acetic acid (EDTA) whole blood samples of 50 anonymized patients referred for routine haematologic laboratory investigation were collected. The whole blood samples were stored at $-20^{\circ} \mathrm{C}$ until DNA isolation, with a QIAamp blood mini kit (Qiagen, Leusden, the Netherlands) according to the manufacturers' 
instructions, was performed. To obtain the different allelic variants of the PXR A11156C polymorphism a real-time PCR FRET assay consisted of a primerset, an anchor probe and the sensor probe Sen $[A]$ is used. The PCR primers were chosen to specifically target the human PXR gene. The primerset and the different fluorogenic probes used were designed and synthesised by TIB MOLBIOL (Berlin, Germany). The primers F22: 5'-CAA TCA gTT AAC ACA CCg gAg-'3 (sense; 81370-391) and R22: 5'-TTT TAT gTT CTT ACg CCg gAg T-'3 (anti-sense; 81766-745) were used to amplify a $397 \mathrm{bp}$ fragment from the human PXR gene which covers the A11156C polymorphism in the 3'-untranslated region (3'-UTR) area (Genbank acces no: AF280107). Detection was carried out using the anchor probe 56Anchor: 5'-TTT Tgg gAA ATg TAg CCC Tgg gT-'3 (sense; 81553-575), which was labelled at the 5'-end with LCRed640 and phosphorylated at the 3'-end to block extension, and combined with one of the three sensor probes shown in Table 4.1.

Table 4.1 Melting curve analysis obtained by genotyping fifty individuals with three different sensor probes.

\begin{tabular}{|c|c|c|c|c|}
\hline Name $^{a}$ & Sequence sensor probe ${ }^{b}$ & $\begin{array}{c}\operatorname{Tm}_{[\mathrm{AA}]}{ }^{\mathrm{C}} \\
\left({ }^{\circ} \mathrm{C}\right)\end{array}$ & $\begin{array}{c}\operatorname{Tm}_{[\mathrm{C}]}{ }^{d} \\
\left({ }^{\circ} \mathrm{C}\right)\end{array}$ & $\begin{array}{c}\Delta \operatorname{Tm}_{[\mathrm{A}] /[\mathrm{C}]}{ }^{\mathrm{e}} \\
\left({ }^{\circ} \mathrm{C}\right)\end{array}$ \\
\hline Sen $[A]$ & Agg CAT TCC ACA CCT AAg AAC TA-F & $62.4 \pm 0.18$ & 59.3 & $\mathrm{Nd}$ \\
\hline Sen $[A] s$ & САТ TCC ACA CCT AAg AAC TA-F & $57.2 \pm 0.08$ & 53.1 & $\mathrm{Nd}$ \\
\hline Sen $[A] s L$ & CAT TCC ACA CCT AAg AAC TA-F & $58.7 \pm 0.08$ & 51.9 & $7.5 \pm 0.10$ \\
\hline
\end{tabular}

a "s" is the short variant of the sensor probe; "L" short variant with a locked nucleic acid (LNA) on the polymorphic site; ${ }^{b}$ Probe position in human PXR sequence AF280107 is sense between $81529-551 \mathrm{bp}$; the polymorphic nucleotide is underlined and expressed in bold; $\mathrm{F}$ is the position of the labelled fluorescein; ${ }^{\circ}$ The mean melting temperature $(\mathrm{Tm}) \pm$ standard deviation (SD) of 33 homozygote PXR $11156[\mathrm{~A}] /[\mathrm{A}] ;{ }^{d}$ The melting temperature $(\mathrm{Tm})$ of a homozygote PXR 11156 $[C] /[C] ;{ }^{~}$ The mean melting temperature difference $(\Delta T m) \pm S D$ of 16 samples with the PXR 11156 $[\mathrm{A}] /[\mathrm{C}]$ genotype; $\mathrm{Nd}$ is not discriminable.

PCR and melting curve analysis were performed on the LightCycler (Roche Diagnostics, Almere, the Netherlands). The PCR mixture contained $3.0 \mathrm{mM} \mathrm{MgCl} 2,2.0 \mu \mathrm{LC}$ Faststart DNA Master Hybridization Probes Mix (Roche Diagnostics $\mathrm{GmbH}$, Mannheim, Germany), $0.50 \mu \mathrm{M}$ of each primer, $0.20 \mu \mathrm{M}$ of the anchor probe and $0.20 \mu \mathrm{M}$ of the sensor probe. After adding 2.0 $\mu$ l containing 50-100 ng genomic DNA to the PCR mixture the total volume was $20 \mu \mathrm{l}$. The PCR protocol included the following steps: a) denaturation for ten minutes at $95^{\circ} \mathrm{C}$ b) 45 cycles at $95^{\circ} \mathrm{C}$ for ten seconds; $55^{\circ} \mathrm{C}$ for ten seconds and $72^{\circ} \mathrm{C}$ for 16 seconds. After amplification was completed, a melting curve was recorded by cooling to $45^{\circ} \mathrm{C}$ at a ramp rate of $20^{\circ} \mathrm{C} /$ second, holding at $40^{\circ} \mathrm{C}$ for one minute and then heating slowly to $70^{\circ} \mathrm{C}$ at $0.2^{\circ} \mathrm{C} /$ second. The derivative melting curves are read in channel 2 of the LightCycler for the detection of the PXR fragment. The PCR products were sequenced according to a direct sequence procedure performed with the capillairy sequencer $\mathrm{ABI} 3100^{\circledR}$ (Applied Biosystems, Fostercity, USA) using the Bridge version 1.1 sequence kit. 


\section{Results and discussion}

Fifty individuals were genotyped for the PXR A11156C polymorphism by a real-time PCR FRET assay using the sensor probes illustrated in Table 4.1. Since sensor probe Sen $[A]$ is complementary to the PXR 11156 [A] allele, melting of the PCR product homozygous for this $11156[\mathrm{~A}]$ allele produced a melting peak at $62.4 \pm 0.18^{\circ} \mathrm{C}$, whereas for a PCR product homozygous for the PXR $11156[\mathrm{C}]$ allele the melting peak was obtained at $59.3^{\circ} \mathrm{C}$. In accordance with the melting temperatures obtained, 33 samples were genotyped as PXR $11156[A] /[A]$ and one sample was genotyped as PXR $11156[\mathrm{C}] /[\mathrm{C}]$. A heterozygous sample contains both types of targets and should therefore generate both peaks. However, the real-time PCR FRET assay using the sensor probe Sen $[A]$ produced for 16 samples one unspecific melting peak around 60.0 $\pm 0.66^{\circ} \mathrm{C}$ (see Figure $4.1 \mathrm{~A}$ ), which in our hands under no conditions could be resolved into two separated peaks. Most likely, these samples are heterozygous for the PXR A11156C polymorphism. Hence, the allele frequency for the $11156[\mathrm{~A}]$ polymorphism is $84 \%$ and for the 11156 [C] $16 \%$ which is in line with the other study ${ }^{4}$. The PCR products of three different PXR 11156 allelic variants were sequenced to confirm the results obtained by the real-time PCR FRET assays. The results provided by the sequence analysis matched exactly with the genotypes as classified by the melting peaks. The discriminating power of SNP detection by FRET probes is based on the difference in melting behaviour of mismatches versus perfect matches to the target probe. The greater the difference between the melting temperature $(\mathrm{Tm})$ of the matched versus mismatched duplexes $(\Delta \mathrm{Tm})$, the better is the discriminating potential of the sensor probes in the FRET assay. This $\Delta \mathrm{Tm}$ is dependent upon the length of the sensor probe, the type of mismatch and the neighbouring nucleotides. The longer the sensor probe, the smaller the effect of a single-base mismatch on overall duplex stability, hence the $\Delta \mathrm{Tm}$ between match and mismatch duplexes decreases. Therefore to improve the melting curve analysis the sensor probe was shortened by three nucleotides which resulted in Sen $[A] s$. The Tm of both homozygotes was lowered as to be expected. The difference between the $\mathrm{Tm}$ of both homozygotes was 4.1 , which is $1^{\circ} \mathrm{C}$ more than obtained with Sen [A] (Table 4.1). However the melting curve analysis of heterozygotes did not yield two separate melting peaks, this is illustrated in Figure 4.1B. The differential stability of a match versus mismatch duplex is the main limitation of the use of FRET probes for detection of SNPs. Fluorogenic probes containing LNAs have shown strong affinity for their complementary targets. The main structural feature of these probes is the presence of an additional methylene bridge linking the 2'-hydroxyl group of a RNA monomer to the 4'-carbon of the ribose ring. The presence of this bridge "locks" the sugar ring in one fixed conformation (3'-endo), which is the conformation observed for the ribose ring in RNA or DNA hybrids. Based on NMR studies of LNA/DNA duplexes, it has been concluded that the main factor contributing to the extraordinary high stability of LNA containing duplexes is a local change of the phosphate backbone geometry that favours a much higher degree of base stacking ${ }^{6-13}$. Thus, the 
Sen $[A] s$ was modified with a LNA on the polymorphic site, resulting in Sen $[A] s L$. The melting curve analysis showed an increment in the temperature of the melting peaks of homozygotes $11156[\mathrm{~A}] /[\mathrm{A}]$. This could be attributed to the improved binding of the LNA probe. The melting peak for the homozygote $11156[\mathrm{C}] /[\mathrm{C}]$ seemed to be somewhat lowered. Figure 4.1C shows these melting curves. The heterozygotes now yielded two separated peaks for with a $\Delta \mathrm{Tm}$ of $7.5^{\circ} \mathrm{C}$ (Table 4.1). From the present study it is obvious that by introducing a LNA on the polymorphic location in a sensor probe the discriminative power of a real-time PCR FRET assay may increase enormously. Therefore, we conclude that the incorporation of a LNA in the sensor probe of a FRET assay is an additional tool to improve further the analysis of SNPs.
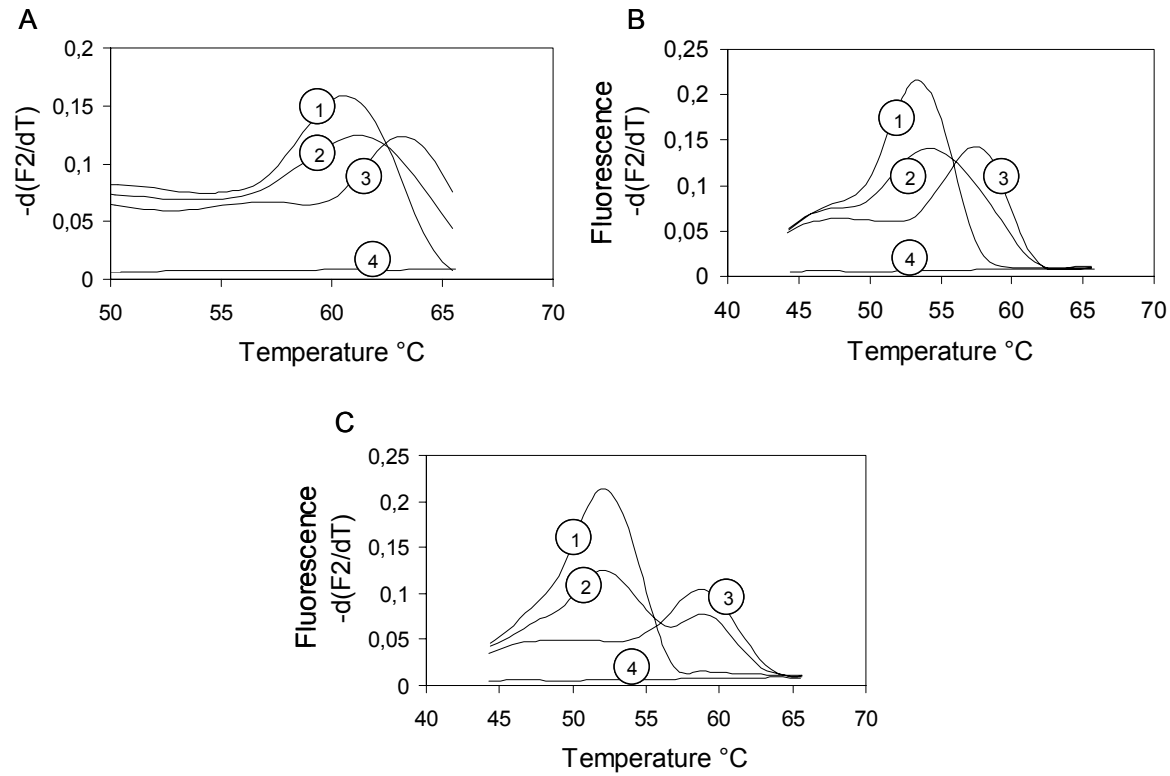

Figure 4.1 Genotyping of the A11156C polymorphism of the PXR gene with allele specific fluorescent probes using (A) Sen [A], (B) Sen [A]s and (C) Sen [A]sL by derivative melting curve plots. Representative derivative melting curves are plotted for the sample homozygous for the (1) 11156 [C] allele; (2) a heterozygous sample; (3) a homozygous sample for the $11156[\mathrm{~A}]$ allele; (4) a no template control. 


\section{References}

1. Schutz E, von Ahsen N, Oellerich M. Genotyping of eight thiopurine methyltransferase mutations: three-color multiplexing, "two-color/shared" anchor, and fluorescence-quenching hybridization probe assays based on thermodynamic nearest-neighbor probe design. Clin Chem 2000;46:1728-37.

2. Hersberger M, Marti-Jaun J, Rentsch K, Hanseler E. Rapid detection of the CYP2D6*3, CYP2D6*4, and CYP2D6*6 alleles by tetra-primer PCR and of the CYP2D6*5 allele by multiplex long PCR. Clin Chem 2000;46:1072-7.

3. Xie W, Evans RM. Orphan nuclear receptors: the exotics of xenobiotics. J Biol Chem 2001;276:37739-42.

4. Zhang J, Kuehl P, Green ED, Touchman JW, Watkins PB, Daly A, Hall SD, Maurel P, Relling M, Brimer C, Yasuda K, Wrighton SA, Hancock M, Kim RB, Strom S, Thummel K, Russell CG, Hudson JR Jr, Schuetz EG, Boguski MS. The human pregnane $X$ receptor: genomic structure and identification and functional characterization of natural allelic variants. Pharmacogenetics 2001;11:555-72.

5. Synold TW, Dussault I, Forman BM. The orphan nuclear receptor SXR coordinately regulates drug metabolism and efflux. Nat Med 2001;7:584-90.

6. Demidov VV. PNA and LNA throw light on DNA. Trends Biotechnol 2003;21:4-7.

7. Kurreck J, Wyszko E, Gillen C, Erdmann VA. Design of antisense oligonucleotides stabilized by locked nucleic acids. Nucleic Acids Res 2002;30:1911-8.

8. Latorra D, Campbell K, Wolter A, Hurley JM. Enhanced allele-specific PCR discrimination in SNP genotyping using 3' locked nucleic acid (LNA) primers. Hum Mutat 2003;22:79-85.

9. Mouritzen P, Nielsen AT, Pfundheller HM, Choleva Y, Kongsbak L, Moller S. Single nucleotide polymorphism genotyping using locked nucleic acid (LNA). Expert Rev Mol Diagn 2003;3:27-38.

10. Petersen $M$, Wengel J. LNA: a versatile tool for therapeutics and genomics. Trends Biotechnol 2003;21:74-81.

11. Simeonov A, Nikiforov TT. Single nucleotide polymorphism genotyping using short, fluorescently labeled locked nucleic acid (LNA) probes and fluorescence polarization detection. Nucleic Acids Res 2002;30:e91.

12. Ugozzoli LA, Latorra D, Pucket R, Arar K, Hamby K. Real-time genotyping with oligonucleotide probes containing locked nucleic acids. Anal Biochem 2004;324:143-52.

13. Latorra D, Arar K, Hurley JM. Design considerations and effects of LNA in PCR primers. Mol Cell Probes 2003;17:253-9.

14. Jacobsen N, Bentzen J, Meldgaard M, Jakobsen MH, Fenger M, Kauppinen S, Skouv J. LNAenhanced detection of single nucleotide polymorphisms in the apolipoprotein E. Nucleic Acids Res 2002;30:e100.

15. Jacobsen N, Fenger M, Bentzen J, Rasmussen SL, Jakobsen MH, Fenstholt J, Skouv J. Genotyping of the apolipoprotein B R3500Q mutation using immobilized locked nucleic acid capture probes. Clin Chem 2002;48:657-60.

16. Orum $\mathrm{H}$, Jakobsen $\mathrm{MH}$, Koch $\mathrm{T}$, Vuust $\mathrm{J}$, Borre MB. Detection of the factor V Leiden mutation by direct allele-specific hybridization of PCR amplicons to photoimmobilized locked nucleic acids. Clin Chem 1999;45:1898-905. 


\section{Chapter 5}

Rapid genotyping of the organic anion transporter polypeptide 1B1 polymorphisms A388G and T521C with real-time polymerase chain reaction fluorescence resonance energy transfer assays

Robert A.M. Op den Buijsch, Otto Bekers, Petal A.H.M. Wijnen, Marja P. van Dieijen-Visser, Johan E. de Vries 


\section{Abstract}

Background and aim

The organic anion transporting polypeptide 1B1 (OATP1B1) polymorphisms A388G and T521C of the solute carrier organic anion-transporter family member 1B1 gene (SLCO1B1), previously known as OATP-C, have potential impact on the drug metabolism.

\section{Materials and methods}

In order to set up a fast and consistent assay for these polymorphisms, we developed for both OATP1B1 polymorphisms rapid speed polymerase chain reaction (PCR) fluorescence resonance energy transfer (FRET) assays on the LightCycler.

\section{Results}

A locked nucleic acid (LNA) on the polymorphic location within the sensor probe was necessary to discriminate both alleles of the OATP1B1 T521C polymorphism. To confirm the reliability of both real-time PCR FRET assays, these new methods were validated by genotyping 120 samples using a PCR restriction fragment length polymorphism (RFLP) assay and an allele-specific PCR.

\section{Conclusion}

The results of the real-time PCR FRET assays were completely in line with the conventional PCR methods, indicating that the real-time PCR FRET assays are appropriate for clinical settings. 


\section{Introduction}

The solute carrier organic anion-transporter (SLCO) family, also known as the organic anion-transporting polypeptides (OATP), represent a family of proteins responsible for the membrane transport of a large number of endogenous and xenobiotic compounds. Within this family, OATP1B1, OATP2B1 and OATP1B3 have now been established as the major OATPs located at the basolateral membrane of human hepatocytes. OATP1B1, also known as liver specific transporter-1 (LST-1), OATP-C or OATP2, is involved in the hepatocellular uptake of a variety of endogenous and foreign chemicals $^{1-4}$. Different groups have identified a number of single nucleotide polymorphisms (SNPs) in the SLCO1B1 gene ${ }^{5,6}$. In vitro experiments showed that some OATP1B1 allelic variants exhibit a markedly reduced uptake of the OATP1B1 substrates estrone sulfate and estradiol $17 \beta$-D-glucuronide ${ }^{5,7,8}$. Several SNPs introduce amino acid changes in the OATP1B1 protein that result either in altered transport activity or affect the substrate specificity of this protein, as has for instance been shown for the substrates $E_{2} 17 \beta G$ and cholyltaurine ${ }^{5,8,9}$. More recently, several publications reported the OATP1B1*1b (388G), OATP1B1*5 (521C) and OATP1B1*15 (388G and 521C) variant alleles, which have relatively high allele frequencies in different ethnic populations and are associated with significantly altered pharmacokinetics of pravastatin, irinotecan and its active metabolite $\mathrm{SN}-38^{10-13}$. Until now these OATP1B1 alleles have been genotyped with either a PCR restriction fragment length polymorphism (RFLP) assay (A388G) or with an allele-specific PCR assay (T521C) ${ }^{5,6}$. In order to perform large epidemiological studies or for routine clinical use, a rapid genotype method is preferred. Therefore, the present study describes real-time PCR fluorescence resonance energy transfer (FRET) assays, which are able to genotype these OATP1B1 polymorphisms in considerably less hands on time and with less contamination risk. The results are compared with both a PCR RFLP assay and with an allele-specific PCR assay.

\section{Materials and methods}

\section{Study design}

For the present study genomic deoxyribonucleic acid (DNA) was isolated from 120 anonymized samples originating from a healthy Caucasian population volunteers which consisted of 73 males and 47 females with a median age of 37 years (19-94 years). DNA was isolated from $200 \mu \mathrm{l}$ ethylene diamine tetra-acetic acid (EDTA) anticoagulated blood with a High Pure PCR Template Preparation Kit (Roche Diagnostics $\mathrm{GmbH}$, Mannheim, Germany) or a QIAamp blood mini kit (Qiagen, Leusden, the Netherlands) according to the manufacturers' instructions. Genotyping for the OATP1B1 A388G and T521C polymorphisms was performed using real-time PCR FRET assays 
on the LightCycler (Roche Diagnostics, Almere, the Netherlands). A PCR RFLP for the A388G polymorphism and an allele-specific PCR for the T521C polymorphism were used to confirm the results obtained by the real-time PCR FRET assays ${ }^{6}$. The digested and allele-specific PCR products were electrophoresed on a $3 \%$ MetaPhor $^{\circledR}$ agarose gel containing $0.3 \mathrm{mg} / \mathrm{l}$ ethidium bromide at $75 \mathrm{~V}$ for 1 hour and 30 minutes, respectively, and examined under ultraviolet illumination. FRET genotyping was also validated by sequencing a homozygote allelic variant sample, a heterozygote sample and a wild type sample of both OATP1B1 polymorphisms. The PCR products were sequenced according to a direct sequence procedure performed with the capillary sequencer $A B I$ $3100^{\circledR}$ (Applied Biosystems, Fostercity, USA) using the Bridge version 1.1 sequence kit (Applied Biosystems, Fostercity, USA).

\section{Genotyping for OATP1B1 T521C polymorphism}

The primers F27: 5'-gTA gAC AAA ggg AAAgTg ATC ATA-'3 (sense; 80677-700) and R27: 5'-gTT AAA TTT gTAATAgAAATg C-'3 (anti-sense; 80936-915) were used to amplify a 260 bp part from the SLCO1B1 gene which covers the T521C polymorphism in exon 5 (Genbank acces no: AC022335). Detection was carried out using the anchor probe OATPCA27: 5'-TAA TAT gCT TCg Tgg AAT Agg ggA gAC TC-'3 (anti-sense; 80823-795) which was labelled at the 5'-end with LCRed 640 and phosphorylated the 3'-end to block extension and the sensor probe OATPCP27L: 5'-Tgg ATATAT gㅁg TTCATg g-'3 (anti-sense; 80843-825) which is complementary to the OATP1B1 521C polymorphism. This 3'-fluorescein-labelled sensor probe, in which the polymorphic locked nucleic acid (LNA) is underlined, binds with a distance of one base 5 ' to the detection probe ${ }^{14,15}$. The PCR mixture contained $5.9 \mu$ sterile water; $3.0 \mathrm{mM} \mathrm{MgCl}$; $2.0 \mu \mathrm{l}$ LC Faststart DNA Master Hybridization Probes (Roche Diagnostics $\mathrm{GmbH}$, Mannheim, Germany); $0.50 \mu \mathrm{M}$ of each primer and $0.225 \mu \mathrm{M}$ of both anchor and sensor probe (TIB MOLBIOL, Berlin, Germany). After adding $2.0 \mu \mathrm{l}$ containing 50-100 ng genomic DNA to the PCR mixture the total volume is $20 \mu \mathrm{l}$. The PCR protocol included the following steps: a) denaturation for ten minutes at $95^{\circ} \mathrm{C}$ b) 55 cycles at $95^{\circ} \mathrm{C}$ for five seconds; $51^{\circ} \mathrm{C}$ for ten seconds and $72^{\circ} \mathrm{C}$ for 20 seconds. After amplification was completed, a melting curve was recorded by heating to $95^{\circ} \mathrm{C}\left(20^{\circ} \mathrm{C} /\right.$ second), holding at $95^{\circ} \mathrm{C}$ for 20 seconds then cooling to $40^{\circ} \mathrm{C}\left(20^{\circ} \mathrm{C} /\right.$ second $)$, holding at $40^{\circ} \mathrm{C}$ for 20 seconds and then heating slowly to $85^{\circ} \mathrm{C}$ at $0.2^{\circ} \mathrm{C} / \mathrm{s}$.

\section{Genotyping for OATP1B1 A388G polymorphism}

The primers F28: 5'-CTC Agg TgA TgC TCT ATT gAg TgA -'3 (sense; 82564-587) and R28: 5'-ggA AAT TgA CAg AAA gTA CTC Tgg T-'3 (anti-sense; 82809-785) were used to amplify a $246 \mathrm{bp}$ part from the SLCO1B1 gene which covers the A388G polymorphism in exon 4 (Genbank acces no: AC022335). Detection was carried out using the anchor probe OATPCA28: 5'-TAC CTg TAA CTg TAA gAA CAT CAC TgA ATT AAA CAT TTT gC-'3 (sense; 82664-704) which was labelled at the 5'-end 
with LCRed640 and phosphorylated at the 3'-end to block extension and the sensor probe OATPCP28: 5'-TTT CTg ATg AAT IgA TAT TAg TTT CTT TAg A-'3 (sense; 82632-662) which is complementary to the OATP1B1 388A polymorphism. This 3 -fluorescein-labelled sensor probe, in which the polymorphic nucleotide is underlined, binds with a distance of one base 5' to the detection probe. The PCR mixture contained $6.4 \mu \mathrm{l}$ sterile water; $3.0 \mathrm{mM} \mathrm{MgCl} 2 ; 2.0 \mu \mathrm{l}$ LC Faststart DNA Master Hybridization Probes, $0.50 \mu \mathrm{M}$ of each primer and $0.20 \mu \mathrm{M}$ of both anchor and sensor probe. After adding $2.0 \mu$ l containing 50-100 ng genomic DNA to the PCR mixture the total volume is $20 \mu \mathrm{l}$. The PCR protocol included the following steps: a) denaturation for ten minutes at $95^{\circ} \mathrm{C}$ b) 45 cycles at $95^{\circ} \mathrm{C}$ for ten seconds; $55^{\circ} \mathrm{C}$ for ten seconds and $72^{\circ} \mathrm{C}$ for ten seconds. After amplification was completed, a melting curve was recorded by heating to $95^{\circ} \mathrm{C}\left(20^{\circ} \mathrm{C} /\right.$ second $)$, holding at $95^{\circ} \mathrm{C}$ for 30 seconds, subsequently cooling to $60^{\circ} \mathrm{C}$ $\left(0.5^{\circ} \mathrm{C} /\right.$ second $)$, holding at $60^{\circ} \mathrm{C}$ for 30 seconds and finally cooling to $45^{\circ} \mathrm{C}$ for 0 second $\left(20^{\circ} \mathrm{C} /\right.$ second) and then heating slowly to $75^{\circ} \mathrm{C}$ at $0.2^{\circ} \mathrm{C} /$ second. During the slow heating procedure of the melting curves, fluorescence was measured continuously to monitor the dissociation of the fluorophore-labelled detection probe. The fluorescence signals were then converted to melting peaks by plotting the negative derivative of the fluorescence with respect to temperature versus temperature (- $\mathrm{d}(\mathrm{F} 2 / \mathrm{dT}$ versus $\mathrm{T})$.

\section{Results}

During the optimalisation of the real-time PCR FRET assay for the OATP1B1 T521C polymorphism, several FRET designs have been tried. For the OATP1B1 T521C assay we used the same primers as Tirona et al. for their allele-specific PCR ${ }^{5}$. However, discrimination of the different allelic variants of the OATP1B1 T521C polymorphism was not possible using standard FRET probes. The modified FRET T521C assay applied a sensor probe in which the cytosine on the polymorphic location is substituted by an analogues locked nucleic acid (LNA). Due to their more rigid sugar moiety, LNA bases have a higher binding affinity to their complementary nucleic acids ${ }^{15}$. Hence, shorter sensor probes can be used which makes a better allelic discrimination possible ${ }^{14}$. Because the binding affinity of a well-designed LNA probe is remarkably decreased if hybrids contain one mismatched basepair (bp). For the OATP1B1 T521C polymorphism, the mean melting point \pm standard deviation (SD) of the sensor probes was $52.2 \pm 0.29^{\circ} \mathrm{C}(\mathrm{n}=82)$ when hybridized to the OATP1B1 521TT polymorphism and $59.1^{\circ} \mathrm{C}(\mathrm{n}=3)$ when hybridized to the OATP1B1 521CC polymorphism. The mean difference \pm SD between two melting temperatures of 35 heterozygous samples of the OATP1B1 T521C polymorphism was $7.6 \pm 0.19^{\circ} \mathrm{C}$ (Figure $5.1 \mathrm{~A}$ ). 
A

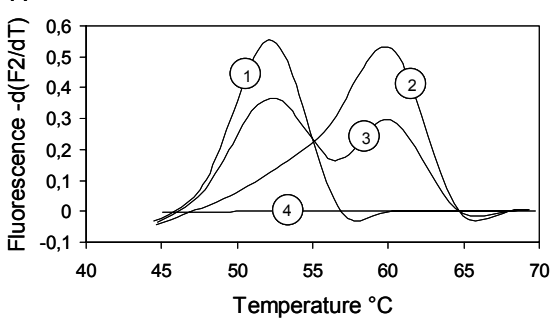

$\mathrm{B}$

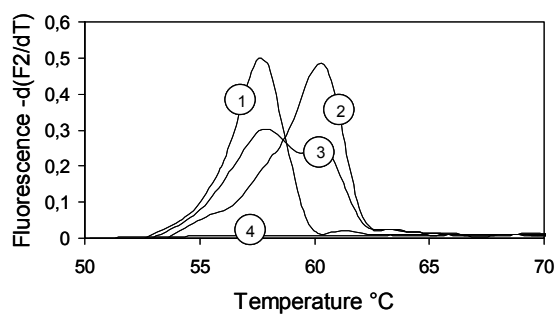

Figure 5.1 Genotyping of the OATP1B1 A388G and T521C polymorphisms with allele specific fluorescent probes by derivative melting curve plots. The $-\mathrm{d}(\mathrm{F} 2 / \mathrm{dT})$ derivative melting curves are read in channel 2 for the detection of both OATP1B1 fragments.

A. The derivative melting curve is plotted for a sample homozygous for the 521T allele (1; $\left.\mathrm{Tm} 52.1^{\circ} \mathrm{C}\right)$; a sample homozygous for the $521 \mathrm{C}$ allele $\left(2 ; \mathrm{Tm} 59.4^{\circ} \mathrm{C}\right)$ and a heterozygous sample $\left(3 ; \mathrm{Tm} 52.3^{\circ} \mathrm{C}\right.$ and $\left.60.0^{\circ} \mathrm{C}\right)$.

B. The derivative melting curve is plotted for a sample homozygous for the $388 \mathrm{G}$ allele (1; $\mathrm{Tm} 57.6^{\circ} \mathrm{C}$ ); a sample homozygous for the $388 \mathrm{~A}$ allele $\left(2 ; \mathrm{Tm} 60.0^{\circ} \mathrm{C}\right.$ ) and a heterozygous sample $\left(3 ; \mathrm{Tm} 57.9^{\circ} \mathrm{C}\right.$ and $\left.60.4^{\circ} \mathrm{C}\right)$. Melting analysis of a no template control was also performed for both assays (4).

Although we tried to optimise several FRET designs for the OATP1B1 A388G polymorphism, including the use of a LNA in the sensor probe, the discrimination between the melting peaks of heterozygous samples is still limited. Tirona et al. used primers for the OATP1B1 A388G assay which have a melting temperature (Tm) that is too low for application in this real-time PCR FRET assay ${ }^{5}$. Because this whole sequence area is very $A / T$ rich, unusual long sensor and anchor probes were necessary to obtain a sufficient high probe $\mathrm{Tm}^{16}$. For the OATP1B1 A388G polymorphism, the mean melting point \pm SD of the sensor probes was $59.5 \pm 0.14^{\circ} \mathrm{C}(n=43)$ when hybridised to the OATP1B1 388AA genotype and $57.3 \pm 0.14^{\circ} \mathrm{C}(\mathrm{n}=16)$ when hybridised to the OATP1B1 388GG genotype. This is close, hence 61 heterozygotes do not demonstrate two separated melting peaks. Yet, as is shown in Figure 5.1B, they can be discriminated from either wild type or variant homozygotes. In total, after genotyping 120 individuals in five different PCR runs for both polymorphisms, the frequency of the OATP1B1 521TT genotype is $68 \%$, for the $521 \mathrm{CT}$ genotype $29 \%$ and for the OATP1B1 $521 \mathrm{CC}$ genotype $3 \%$. In addition, the frequency of the OATP1B1 388AA genotype is $36 \%$, for the 388AG genotype $51 \%$ and for the OATP1B1 388GG genotype 13\%. The allele frequencies of the volunteers examined is $17 \%(521 \mathrm{C})$ and $39 \%$ (388G) which is in line with those published in other studies $5,6,10$. To evaluate the reliability of the real-time PCR FRET assays on the LightCycler the 120 samples were also genotyped for the OATP1B1 A388G polymorphism with the PCR RFLP assay using Taql (Roche Diagnostics GmbH, Basel, Switzerland) and for the T521C polymorphism using an allele-specific $P C R^{6}$. The A388G substitution introduces a restriction enzyme cleavage site for Taql. Accordingly, 
after digestion with Taql, the fragments of the 388A allele were 90 and $72 \mathrm{bp}$, whereas the amplicon of the $388 \mathrm{G}$ allele is digested into 90,49 and $23 \mathrm{bp}$ fragments. Individuals carrying both 388 alleles yield 90, 72, 49 and 23 bp fragments. An allele-specific PCR was used for the confirmation of the T521C polymorphism. Depending on the presence of a 521T or C allele a $142 \mathrm{bp}$ fragment appears after electrophoresis of the PCR products. The PCR products and fragments obtained by allele-specific PCR and PCR RFLP were of the expected sizes and the genotypes determined by both methods matched completely with the genotypes determined with the real-time PCR FRET assays. Furthermore, sequence analysis confirmed the results obtained by both realtime PCR FRET assays, the PCR RFLP and the allele-specific PCR.

\section{Highlights}

- Recently, several studies found a correlation between OATP1B1 388G and OATP1B1 521C allelic variants and blood levels of several drugs and/or their metabolites. Individuals carrying one of both OATP1B1 521C alleles eventually in combination with OATP1B1 388G showed significantly higher blood levels.

- Nowadays, genotyping of these polymorphisms is still performed by an allelespecific PCR or a PCR RFLP method which are conventional genotyping methods that are time consuming and with a high contamination risk in contrast to the realtime PCR methods.

- In this study we describe two real-time PCR FRET assays on the LightCycler for genotyping the OATP1B1 A388G and T521C allelic variants. The results of both conventional PCR RFLP and allele-specific PCR methods are compared with the results of the real-time PCR FRET assays. The real-time PCR FRET assays are also validated by sequencing a homozygote allelic variant sample, a heterozygote sample and a wild type sample of both OATP1B1 polymorphisms.

- The locked nucleic acid (LNA) on the polymorphic location used in the sensor probe of the FRET assay makes discrimination of the OATP1B1 $521 \mathrm{C}$ allelic variants possible. Therefore, implementation of a LNA on a polymorphic location in a sensor probe can contribute to applications for FRET probes in real-time PCR assays for polymorphism detection.

- Given the potential impact of functional OATP1B1 polymorphisms on drug metabolism, reliable and fast assays are clearly needed. Therefore, the overall goal of this study is to provide a fast and consistent genotyping method for the OATP1B1 A388G and T521C polymorphisms which can be used in epidemiological studies or routine clinical settings. 


\section{Outlook and conclusions}

Since new polymorphisms are being discovered in a high speed, the need for fast and reliable genotyping methods becomes clear. Especially, polymorphisms in genes which have a significant effect on several drug blood levels and with a high allelic frequency, are of special interest. Recently, two functional OATP1B1 polymorphisms were discovered, which have apparently a cumulative effect on pravastatin blood levels. Genotyping 120 volunteers for these OATP1B1 polymorphisms with both real-time PCR FRET assays indicates complete concordance with the genotyping obtained by the PCR RFLP assay for OATP1B1 A388G and the allele-specific PCR assay for OATP1B1 T521C. Based on these results, we conclude that genotyping of the OATP1B1 A388G and T521C polymorphism with a real-time PCR FRET assay on the LightCycler is a very reliable, robust and reproducible technique. 


\section{References}

1. Tirona RG, Kim RB. Pharmacogenomics of organic anion-transporting polypeptides (OATP). Adv Drug Deliv Rev 2002;54:1343-52.

2. Hagenbuch B, Meier PJ. The superfamily of organic anion transporting polypeptides. Biochim Biophys Acta 2003;1609:1-18.

3. Kim RB. Organic anion-transporting polypeptide (OATP) transporter family and drug disposition. Eur J Clin Invest 2003;33 S2:1-5.

4. Hagenbuch B, Meier PJ. Organic anion transporting polypeptides of the OATP/ SLC21 family: phylogenetic classification as OATP/ SLCO superfamily, new nomenclature and molecular/functional properties. Pflugers Arch 2004;447:653-65.

5. Tirona RG, Leake BF, Merino G, Kim RB. Polymorphisms in OATP-C: identification of multiple allelic variants associated with altered transport activity among European- and African-Americans. J Biol Chem 2001;276:35669-75.

6. Nozawa T, Nakajima M, Tamai I, Noda K, Nezu J, Sai Y, Tsuji A, Yokoi T. Genetic polymorphisms of human organic anion transporters OATP-C (SLC21A6) and OATP-B (SLC21A9): allele frequencies in the Japanese population and functional analysis. J Pharmacol Exp Ther 2002;302:804-13.

7. Iwai M, Suzuki H, leiri I, Otsubo K, Sugiyama Y. Functional analysis of single nucleotide polymorphisms of hepatic organic anion transporter OATP1B1 (OATP-C). Pharmacogenetics 2004;14:749-57.

8. Michalski C, Cui Y, Nies AT, Nuessler AK, Neuhaus P, Zanger UM, Klein K, Eichelbaum M, Keppler D, Konig J. A naturally occurring mutation in the SLC21A6 gene causing impaired membrane localization of the hepatocyte uptake transporter. J Biol Chem 2002;277:4305863.

9. Ishikawa T, Tsuji A, Inui K, Sai $Y$, Anzai N, Wada M, Endou H, Sumino Y. The genetic polymorphism of drug transporters: functional analysis approaches. Pharmacogenomics 2004;5:67-99.

10. Nishizato $Y$, leiri I, Suzuki H, Kimura M, Kawabata K, Hirota T, Takane H, Irie S, Kusuhara H, Urasaki Y, Urae A, Higuchi S, Otsubo K, Sugiyama Y. Polymorphisms of OATP-C (SLC21A6) and OAT3 (SLC22A8) genes: consequences for pravastatin pharmacokinetics. Clin Pharmacol Ther 2003;73:554-65.

11. Niemi M, Schaeffeler E, Lang T, Fromm MF, Neuvonen M, Kyrklund C, Backman JT, Kerb R, Schwab M, Neuvonen PJ, Eichelbaum M, Kivisto KT. High plasma pravastatin concentrations are associated with single nucleotide polymorphisms and haplotypes of organic anion transporting polypeptide-C (OATP-C, SLCO1B1). Pharmacogenetics 2004;14:429-40.

12. Mwinyi J, Johne A, Bauer S, Roots I, Gerloff T. Evidence for inverse effects of OATP-C (SLC21A6) 5 and $1 \mathrm{~b}$ haplotypes on pravastatin kinetics. Clin Pharmacol Ther 2004;75: 415-21.

13. Nozawa T, Minami H, Sugiura S, Tsuji A, Tamai I. Role of Organic Anion Transporter Oatp1b1 (Oatp-C) in Hepatic Uptake of Irinotecan and Its Active Metabolite Sn-38: In Vitro Evidence and Effect of Single Nucleotide Polymorphisms. Drug Metab Dispos 2004.

14. Op den Buijsch RA, de Vries JE, Loots WJ Landt O, Wijnen PA, van Dieijen-Visser MP, Bekers O. Genotyping of the PXR A11156C polymorphism with locked nucleic acid containing fluorogenic probes. Pharmacogenomics J 2005;5:72-4.

15. Braasch DA, Corey DR. Locked nucleic acid (LNA): fine-tuning the recognition of DNA and RNA. Chem Biol 2001;8:1-7.

16. https://www.tib-molbiol.com/de/lightcycler/design/index.html. 


\section{Chapter 6}

\section{Evaluation of limited sampling strategies for tacrolimus}

Robert A.M. Op den Buijsch, Afke van de Plas, Leo M.L. Stolk, Maarten H.L. Christiaans, Johannes P. van Hooff, Nas A. Undre, Marja P. van Dieijen-Visser, Otto Bekers

Eur J Clin Pharmacol, in press 


\section{Abstract}

Background and aim

In literature, a great diversity of limited sampling strategies (LSS) have been recommended for tacrolimus monitoring, although proper validation is limited. The question is if these LSS might be useful for AUC prediction of other patient populations.

Materials and methods

The performance of 24 of these LSS in 37 renal transplant patients with known AUC's has been evaluated and the results were also compared with the predictability of the trough concentrations, $\mathrm{C}_{0}$ and $\mathrm{C}_{12}$. Criterion was an absolute prediction error (APE\%) that differs less than $15 \%$ from the complete $\mathrm{AUC}_{0-12}$.

Results

Thirteen of the $18(72 \%)$ LSS based on regression analysis were capable of predicting at least $90 \%$ of the 37 individual $A U_{0-12}$ within an APE of $15 \%$. Predictions based on $\mathrm{C}_{0}, \mathrm{C}_{12}$ and Bayesian fitting were lower than $90 \%: 62 \%$ and $66.8 \%$, respectively.

\section{Conclusion}

The present study indicates that implementation of LSS based on regression analysis could produce satisfactory predictions although careful evaluation is mandatory. 


\section{Introduction}

The calcineurin inhibitor tacrolimus, used widely after organ transplantation, has a narrow therapeutic index and highly variable pharmacokinetic characteristics. Close monitoring of the drug concentration is required to achieve an optimal efficiency by minimizing the risk of subtherapeutic and toxic blood concentrations. Efficacy and side effects of tacrolimus are highly correlated with the area under the time tacrolimus concentration curve $\left(\mathrm{AUC}_{0-12}\right)^{1}$. Elevated tacrolimus concentrations may lead to severe side effects such as nephrotoxicity, neurotoxicity and hyperglycaemia ${ }^{2-4}$ while subtherapeutic tacrolimus concentrations increase the risk of transplant rejection enormously ${ }^{5-7}$. The most exact way to monitor the total tacrolimus exposure is by creating 12 hour pharmacokinetic profiles, which implicates that the tacrolimus concentration should be measured on at least six different time points. The $\mathrm{AUC}_{0-12}$ can then be calculated according to the trapezoidal rule using the tacrolimus concentrations measured at different time points. Since recording a complete 12 hour pharmacokinetic profile for every patient is not feasible in clinical practice, traditionally many transplant centres use tacrolimus trough $\left(\mathrm{C}_{0}\right)$ concentrations to estimate the tacrolimus exposure. Although tacrolimus $\mathrm{C}_{0}$ concentrations are generally considered to be a good indication of the total systemic drug exposure ${ }^{1,8}$, its usefulness in differentiating graft rejection episodes from nephrotoxicity has been questioned ${ }^{6,9-11}$. Recently, the correlation between individual tacrolimus concentrations and $\mathrm{AUC}_{0-12}$ has been studied in kidney $^{12-18}$, liver $^{19}$, heart ${ }^{20,21}$ and lung ${ }^{22}$ transplant recipients. In these studies, a poor association was found between the tacrolimus $C_{0}$ concentrations and the $A_{U} C_{0-12}$, while tacrolimus concentrations measured at other time points showed much better correlations with the $\mathrm{AUC}_{0-12}$. Additionally, strategies have been developed that consisted of a limited number of sampling time points within a short time post dose, the so called limited sampling strategies. Several two and three time point sampling strategies showed a high correlation with the $\mathrm{AUC}_{0-12}$ in the published studies and were able to predict the $A \cup C_{0-12}$ more accurately than the $C_{0}$ concentration alone ${ }^{12,15,16,18,20,22}$. Based on the number of published studies regarding limited sampling strategies for tacrolimus, there seems to be a growing interest for non $\mathrm{C}_{0}$ concentration measurements as an indicator of between patient variability and as a guide for dose adjustments. Most of these studies recommend different limited sampling strategies but these strategies have not been validated with a separate population. Ting et al. ${ }^{23}$ recently reported that validation of the different limited sampling strategies with an independent transplant population is without doubt an absolute prerequisite. The question is if limited sampling strategies, described in literature could be used for the own population. Different limited sampling strategies have been selected for an evaluation in this study based on their predictive performances claimed in previous studies and their number of sample points (two or three) within a short time post dose ( $\leq$ 4 hours). Evaluation of these limited sampling strategies was performed by evaluating the predictive value of 24 different limited sampling strategies from literature and also 
the trough concentrations $\mathrm{C}_{0}$ and $\mathrm{C}_{12}$, determined in our own population. Parameters used for the strategy comparison was the associated determination coefficient $\left(R^{2}\right)$ between the $A \cup C_{\text {predicted }}\left(A \cup C_{\text {pred }}\right)$ from the limited sampling strategy and the actual 12 hour AUC $\left(A \cup C_{\text {actual }}\right)$ calculated by the trapezoidal rule, the percentage of prediction error (PE\%) and the percentage of absolute prediction error (APE\%) was determined using our own well-characterised late posttransplant patient group of 37 patients.

\section{Materials and methods}

\section{Patient populations}

In total 37 Caucasian renal transplant recipients of whom in the past, for a clinical trial, a 12 hour time tacrolimus concentration curve was performed, were included in this study. The transplant recipients underwent a renal transplantation at least one year ago. Patients taking medication known to interact with tacrolimus, suffered from gastrointestinal or liver disease, pre-transplantation diabetes mellitus or other disorders that could have altered the absorption of tacrolimus were excluded for this study as is illustrated in Table 6.1. Prior to the blood sample collection, there was no tacrolimus dose change for at least one week. After overnight fasting the blood samples were collected immediately pre $\left(\mathrm{C}_{0}\right)$ and $0.5\left(\mathrm{C}_{0.5}\right), 1\left(\mathrm{C}_{1}\right), 2\left(\mathrm{C}_{2}\right), 3\left(\mathrm{C}_{3}\right), 4\left(\mathrm{C}_{4}\right), 5\left(\mathrm{C}_{5}\right), 7.5$ $\left(C_{7.5}\right)$ and $12\left(C_{12}\right)$ hours after the morning tacrolimus administration. Patients were not allowed to take food until one hour after ingesting the tacrolimus dose and were advised to avoid grapefruit juice to prevent alterations in the tacrolimus metabolism. Demographic as well as clinical data were determined at the time of recording the 12 hour time tacrolimus concentration curve. Figure 6.1 shows the mean pharmacokinetic profile of the renal transplant recipients. The study was performed in accordance to the Declaration of Helsinki and its amendments. The protocol was approved by the local Medical Ethics Committee and written informed consent for participation in this study was obtained from all patients.

\section{Determination of tacrolimus concentrations}

The tacrolimus blood concentrations were determined in ethylene diamine tetra-acetic acid (EDTA) whole blood, using a method based on high pressure liquid chromatography (HLPC) tandem mass spectrometry (MS/MS). The assay is linear from 1 to $300 \mu \mathrm{g} / \mathrm{l}$. Intra-assay precision and accuracy was $3.4 \%, 2.2 \%, 3.0 \%$ and $102 \%$, $94 \%$ and $94 \%$ respectively at 3.04, 6.23 and $13.0 \mu \mathrm{g} / \mathrm{l}(\mathrm{n}=6)$. Inter-assay precision and accuracy were $8.2 \%, 5.2 \%, 4.6 \%$ and $102 \%, 94 \%$ and $93 \%(n=9)$ respectively. Limit of quantification was $1.0 \mu \mathrm{g} / \mathrm{l}$. The laboratory participates in an International Tacrolimus Proficiency Testing Scheme. 
Table 6.1 Demographic characteristics of the two renal transplant recipients groups.

\begin{tabular}{|c|c|c|}
\hline \multicolumn{2}{|c|}{ Demographic characteristics } & Patients $(n=37)$ \\
\hline \multicolumn{2}{|c|}{ Gender (male/female) } & $24 / 13$ \\
\hline \multicolumn{2}{|l|}{ Age (years, mean $\pm S D$ ) } & $51.3 \pm 10.9$ \\
\hline \multicolumn{2}{|l|}{ Length $(\mathrm{cm}$, mean $\pm \mathrm{SD})$} & $174 \pm 8.4$ \\
\hline \multicolumn{2}{|c|}{ Weight $(\mathrm{kg}$, mean $\pm \mathrm{SD})$} & $77.4 \pm 13.5$ \\
\hline \multicolumn{2}{|c|}{ Body Mass Index $\left(\mathrm{kg} / \mathrm{m}^{2}\right.$, mean $\left.\pm \mathrm{SD}\right)$} & $25.6 \pm 3.42$ \\
\hline \multirow{8}{*}{ Primary kidney disease } & Glomerulonephritis & 1 \\
\hline & Chronic pyelonephritis & 2 \\
\hline & IgA nephropathy & 4 \\
\hline & Hypertensive nephropathy & 7 \\
\hline & Diabetes Mellitus nephropathy & 0 \\
\hline & Polycystic kidney disease & 8 \\
\hline & Unknown & 4 \\
\hline & Other & 11 \\
\hline \multirow[t]{3}{*}{ Transplantation number } & First & 30 \\
\hline & Second & 6 \\
\hline & Third or more & 1 \\
\hline \multicolumn{2}{|l|}{ Tacrolimus mono therapy } & 29 \\
\hline \multicolumn{2}{|c|}{ Tacrolimus dose (mg/kg/day, mean \pm SD) } & $0.054 \pm 0.029$ \\
\hline \multicolumn{2}{|c|}{$\mathrm{C}_{0}(\mathrm{ng} / \mathrm{mL}$, mean $\pm \mathrm{SD})$} & $6.59 \pm 1.39$ \\
\hline \multicolumn{2}{|c|}{$\mathrm{AUC}_{0-12}(\mathrm{ng} \times \mathrm{hr} / \mathrm{ml}$, mean $\pm \mathrm{SD})$} & $122.5 \pm 31.1$ \\
\hline \multicolumn{2}{|c|}{$\mathrm{C}_{\max }(\mathrm{ng} / \mathrm{ml}$, mean $\pm \mathrm{SD})$} & $20.9 \pm 6.5$ \\
\hline \multicolumn{2}{|c|}{$\mathrm{T}_{\max }(\mathrm{hr}$, mean $\pm \mathrm{SD})$} & $1.24 \pm 0.43$ \\
\hline \multicolumn{2}{|c|}{ Use of azothioprine, $\mathrm{MMF}^{\mathrm{a}}$, rapamycine, steroids } & $3 / 4 / 0 / 0$ \\
\hline \multicolumn{2}{|c|}{ Time since transplantation (days, mean, (range)) } & $1542(453-4128)$ \\
\hline \multicolumn{2}{|c|}{ Haemoglobin $(\mathrm{mmol} / \mathrm{l}$, mean $\pm \mathrm{SD})$} & $8.52 \pm 0.83$ \\
\hline \multicolumn{2}{|c|}{ Haematocrit fraction (mean \pm SD) } & $0.41 \pm 0.04$ \\
\hline \multicolumn{2}{|c|}{ ALAT (U/I, mean \pm SD) } & $24 \pm 13$ \\
\hline \multicolumn{2}{|c|}{ ASAT (U/l, mean \pm SD) } & $17 \pm 10$ \\
\hline \multicolumn{2}{|c|}{ Serum albumin ( $g / l$, mean $\pm S D$, ) } & $37.0 \pm 3.84$ \\
\hline \multicolumn{2}{|c|}{ Serum creatinine $(\mu \mathrm{mol} / /$, mean $\pm S D)$} & $128 \pm 29$ \\
\hline \multicolumn{2}{|c|}{ Creatinine Clearance (Cockcroft - Gault; ml/min, mean \pm SD) } & $58.4 \pm 26.6$ \\
\hline
\end{tabular}

${ }^{a}$ mycophenolate mofetil

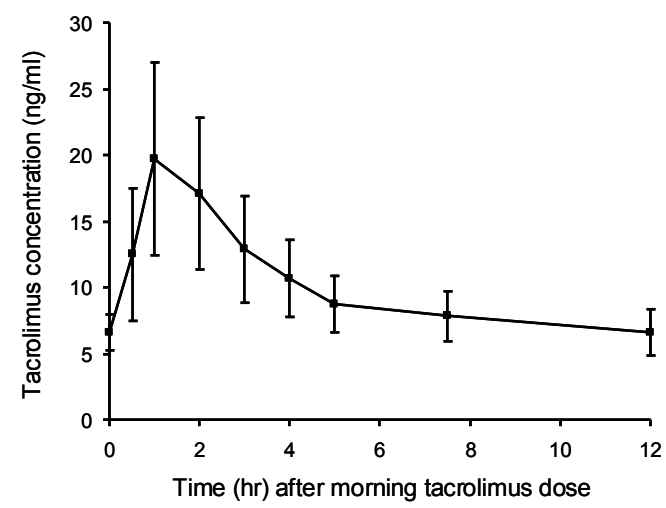

Figure 6.1 Mean ( \pm SD) whole blood concentrations of tacrolimus in 37 renal transplant recipients. 


\section{Pharmacokinetical and statistical analysis}

The area under the time tacrolimus concentration curve $\left(\mathrm{AUC}_{0-12}\right)$ was calculated from the time versus tacrolimus concentration plot using the linear trapezoidal rule in MWPharm 3.50 (Mediware, Groningen, the Netherlands). The predicted $\mathrm{AUC}_{0-12}$ $\left(A \cup C_{\text {pred }}\right)$, calculated with 24 limited sampling strategies, were validated by determining the predictive performance as described by Sheiner and Beal ${ }^{24}$. The percentage of the prediction error (PE (\%)) and the percentage of the absolute prediction error (APE (\%)) are parameters often used for the validation in the studies that describe limited sampling strategies $^{12,14-16,18,20,22}$. In our opinion, a suitable limited sampling strategy for tacrolimus should consist of two or three time concentration points within a short time post dose ( $\leq 4$ hour) and is able to predict at least $90 \%$ of $A U C_{0-12}$ within an APE (\%) of $15 \%$. Given the high pharmacokinetic variability, an APE (\%) of less than $15 \%$ was considered clinically acceptable ${ }^{16,25,26}$. Finally, a strategy based on the tacrolimus $\mathrm{C}_{0}$ and $\mathrm{C}_{12}$ concentrations is developed for our own renal transplant patient population and compared with the different limited sampling strategies that already have been published.

Prediction bias was measured by a percentage of the prediction error (PE (\%)) using the following formula:

$\operatorname{PE}(\%)=100 \times\left(A U C_{\text {pred }}-A C_{\text {actual }}\right) / A C_{\text {actual }}$

Prediction precision was measured by the percentage of the absolute prediction error (APE (\%)) using the following formula:

$\operatorname{APE}(\%)=100 \times\left|\left(\mathrm{AUC}_{\text {pred }}-\mathrm{AUC}_{\text {actual }}\right)\right| / \mathrm{AUC}_{\text {actual }}$

The variance in the strength of association between the $A \cup C_{\text {pred }}$ and the $A \cup C_{\text {actual }}$ was reflected by the linear regression coefficient of multiple determination $\left(R^{2}\right)$. All values are expressed as mean \pm SD. All statistical analyses were performed with use of SPSS 12.0 software for windows (Chicago, IL, USA).

\section{Results}

\section{Evaluation of predictive performances of the limited sampling strategies}

Table 6.2 shows an overview of the studies describing the limited sampling strategies evaluated in the present study. The regression equations and the $R^{2}$ found by the investigators of the limited sampling strategies evaluated are summarised in Table 6.3. 
Table 6.2 Overview of the characteristics of the transplant patients included in the studies that described limited sampling strategies.

\begin{tabular}{|c|c|c|c|c|c|c|}
\hline Study & $\begin{array}{c}\text { Transplanted } \\
\text { Organ }\end{array}$ & $\begin{array}{c}\text { Number of } \\
\text { patients }^{\mathrm{a}}\end{array}$ & $\begin{array}{l}\text { Number } \\
\text { of } \\
\text { AUC }_{0-12} \\
\text { curves for } \\
\text { validation } \\
\left(\mathrm{I}^{\mathrm{b}} / \mathrm{NI}^{\mathrm{C}}\right)\end{array}$ & $\begin{array}{l}\text { Analytical } \\
\text { method }^{d}\end{array}$ & $\begin{array}{c}\text { Time since } \\
\text { transplantation }^{\mathrm{e}}\end{array}$ & $\begin{array}{l}\text { Inclusion } \\
\text { criteria }^{f}\end{array}$ \\
\hline${\text { Wong et } a l^{16}}^{16}$ & Kidney & 18 & $0 / 18$ & IMx II & 2.5 years & 1,2 \\
\hline Aumente Rubio et al. ${ }^{20}$ & Heart & 22 & $0 / 25$ & $\mathrm{IMx}$ & $<1$ year & --- \\
\hline Pisitkun et al. $^{18}$ & Kidney & 15 & $0 / 15$ & IMx II & 8.7 months & $1,2,3$ \\
\hline Armendariz et al. ${ }^{12}$ & Kidney & 22 & $13 / 14$ & $\mathrm{IMx}$ & Unknown & --- \\
\hline Scholten et al. ${ }^{15}$ & Kidney & 43 & $64 / 20$ & IMx & Differs ${ }^{g}$ & 2 \\
\hline${\text { Ragette et } a l^{22}}^{22}$ & Lung & 15 & $0 / 31$ & $\mathrm{IMx}$ & 7.3 months & --- \\
\hline
\end{tabular}

${ }^{a}$ number of transplant patients used in the included study for both developing and validating the limited sampling strategies. ${ }^{b}$ number of $\mathrm{AUC}_{0-12}$ used for developing the limited sampling strategies described in this study. ${ }^{\mathrm{C}}$ number of independent (I) and dependent (NI) $\mathrm{AUC}_{0-12}$ used in the study to validate the created limited sampling strategies. ${ }^{d}$ the analytical method used to determine the whole blood tacrolimus concentration. ${ }^{\mathrm{e}}$ the mean time after transplantation. ${ }^{f}$ the inclusion criteria used for the transplant patients in the different studies. 1. tacrolimus is administrated when patients were in the fasting state. 2. patients have been selected for using no interfering medication with tacrolimus. 3. patients have been selected with a normal liver function test. 9 Twenty-two pharmacokinetic profiles were obtained within two weeks after transplantation, 11 pharmacokinetic profiles were obtained between two and six weeks after transplantation and 51 pharmacokinetic profile were obtained between 6 and 52 weeks after transplantation.

Table 6.3 Overview limited sampling strategies and their reported correlation coefficient $\left(R^{2}\right)$ with the complete tacrolimus $\mathrm{AUC}_{0-12}$.

\begin{tabular}{|c|c|c|c|c|}
\hline Equation & Time points & Regression equations & $R^{2}$ & Ref \\
\hline 1. & $\mathrm{C}_{0}$ & $14.550+16.387 \times \mathrm{C}_{0}$ & 0.54 & \\
\hline 2. & $\mathrm{C}_{12}$ & $15.892+17.852 \times \mathrm{C}_{12}$ & 0.79 & \\
\hline 3. ${ }^{a}$ & $\mathrm{C}_{0}, \mathrm{C}_{2}, \mathrm{C}_{4}$ & $13.3+1.2 \times \mathrm{C}_{0}+2.4 \times \mathrm{C}_{2}+5.6 \times \mathrm{C}_{4}$ & 0.93 & 16 \\
\hline $4 .^{a}$ & $\mathrm{C}_{2}, \mathrm{C}_{4}$ & $16.2+2.4 \times \mathrm{C}_{2}+5.9 \times \mathrm{C}_{4}$ & 0.93 & 16 \\
\hline 5. ${ }^{a}$ & $\mathrm{C}_{0}, \mathrm{C}_{2}, \mathrm{C}_{4}$ & $0.98+4.17 \times \mathrm{C}_{0}+2.29 \times \mathrm{C}_{2}+5.3 \times \mathrm{C}_{4}$ & 0.97 & 20 \\
\hline 6. & $\mathrm{C}_{0}, \mathrm{C}_{4}$ & $3.75+5.52 \times \mathrm{C}_{0}+6.97 \times \mathrm{C}_{4}$ & 0.95 & 20 \\
\hline 7. & $\mathrm{C}_{0}, \mathrm{C}_{1}, \mathrm{C}_{2}$ & $-5.496+7.189 \times \mathrm{C}_{0}+2.357 \times \mathrm{C}_{1}+2.131 \times \mathrm{C}_{2}$ & 0.93 & 18 \\
\hline 8. $^{a}$ & $\mathrm{C}_{0}, \mathrm{C}_{1}, \mathrm{C}_{4}$ & $3.85+3.688 \times \mathrm{C}_{0}+1.355 \times \mathrm{C}_{1}+6.649 \times \mathrm{C}_{4}$ & 0.97 & 18 \\
\hline 9. ${ }^{a}$ & $\mathrm{C}_{0}, \mathrm{C}_{2}, \mathrm{C}_{4}$ & $-6.103+2.383 \times \mathrm{C}_{0}+1.911 \times \mathrm{C}_{2}+7.582 \times \mathrm{C}_{4}$ & 0.97 & 18 \\
\hline $10 .^{a}$ & $\mathrm{C}_{1}, \mathrm{C}_{2}, \mathrm{C}_{4}$ & $1.304+0.465 \times \mathrm{C}_{1}+1.636 \times \mathrm{C}_{2}+8.256 \times \mathrm{C}_{4}$ & 0.96 & 18 \\
\hline 11. & $\mathrm{C}_{0}, \mathrm{C}_{1}$ & $9.345+8.408 \times \mathrm{C}_{0}+3.23 \times \mathrm{C}_{1}$ & 0.91 & 18 \\
\hline $12 .^{\mathrm{a}}$ & $\mathrm{C}_{0}, \mathrm{C}_{4}$ & $8.231+2.316 \times \mathrm{C}_{0}+9.636 \times \mathrm{C}_{4}$ & 0.95 & 18 \\
\hline $13 .^{a}$ & $\mathrm{C}_{1}, \mathrm{C}_{4}$ & $13.114+0.873 \times \mathrm{C}_{1}+9.291 \times \mathrm{C}_{4}$ & 0.95 & 18 \\
\hline $14 .^{a}$ & $\mathrm{C}_{2}, \mathrm{C}_{4}$ & $-0.192+1.888 \times \mathrm{C}_{2}+8.783 \times \mathrm{C}_{4}$ & 0.96 & 18 \\
\hline $15 .^{a}$ & $\mathrm{C}_{0}, \mathrm{C}_{1}, \mathrm{C}_{4}{ }^{*}$ & $4.5 \times \mathrm{C}_{0}+2 \times \mathrm{C}_{1}+5.5 \times \mathrm{C}_{4}$ & 0.97 & 18 \\
\hline $16 .^{a}$ & $\mathrm{C}_{0}, \mathrm{C}_{2}, \mathrm{C}_{4}$ & $5 \times C_{0}+2 \times C_{2}+5 \times C_{4}$ & 0.96 & 18 \\
\hline 17. & $\mathrm{C}_{0}, \mathrm{C}_{1}, \mathrm{C}_{4}$ & $8.90+4.0 \times \mathrm{C}_{0}+1.77 \times \mathrm{C}_{1}+5.47 \times \mathrm{C}_{4}$ & 0.97 & 12 \\
\hline 18. & $\mathrm{C}_{0}, \mathrm{C}_{1}, \mathrm{C}_{3}$ & Bayesian estimation of the actual $\mathrm{AUC}_{0-12}$ & 0.97 & 15 \\
\hline 19. & $\mathrm{C}_{0}, \mathrm{C}_{2}, \mathrm{C}_{3}$ & Bayesian estimation of the actual $\mathrm{AUC}_{0-12}$ & 0.96 & 15 \\
\hline 20. & $\mathrm{C}_{0}, \mathrm{C}_{2}, \mathrm{C}_{4}$ & Bayesian estimation of the actual $\mathrm{AUC}_{0-12}$ & 0.97 & 15 \\
\hline 21. & $\mathrm{C}_{0}, \mathrm{C}_{2}$ & Bayesian estimation of the actual $\mathrm{AUC}_{0-12}$ & 0.94 & 15 \\
\hline 22. & $\mathrm{C}_{0}, \mathrm{C}_{3}$ & Bayesian estimation of the actual $\mathrm{AUC}_{0-12}$ & 0.96 & 15 \\
\hline 23. & $\mathrm{C}_{0}, \mathrm{C}_{4}$ & Bayesian estimation of the actual $\mathrm{AUC}_{0-12}$ & 0.95 & 15 \\
\hline $24 .^{a}$ & $\mathrm{C}_{0}, \mathrm{C}_{2}, \mathrm{C}_{4}$ & $5.87+4.50 \times \mathrm{C}_{0}+1.05 \times \mathrm{C}_{2}+5.87 \times \mathrm{C}_{4}$ & 0.98 & 22 \\
\hline 25. & $\mathrm{C}_{0}, \mathrm{C}_{4}$ & $1.16+4.41 \times \mathrm{C}_{0}+7.71 \times \mathrm{C}_{4}$ & 0.96 & 22 \\
\hline $26 .^{a}$ & $\mathrm{C}_{2}, \mathrm{C}_{4}$ & $24.36+0.97 \times \mathrm{C}_{2}+7.94 \times \mathrm{C}_{4}$ & 0.94 & 22 \\
\hline
\end{tabular}

Limited sample strategies derived from the linear trapezoidal rule and the actual $\mathrm{AUC}_{0-12 .}{ }^{\mathrm{a}}{ }^{\mathrm{L}}$ imited sampling strategies that are able to predict $90 \%$ of complete $\mathrm{AUC}_{0-12}$ of the renal transplant recipients within the absolute prediction error (APE\%) of $15 \%$. 
Table 6.4 describes the $R^{2}$ that represents the association between $\mathrm{AUC}_{\text {pred }}$ and $\mathrm{AUC}_{\text {actual }}$ and the calculated PE (\%) and APE (\%) of the 24 evaluated limited sampling strategies for our 37 pharmacokinetic profiles. Additionally, all but three of the LSS examined gave a better prediction of the complete $\mathrm{AUC}_{0-12}$ in comparison with trough concentrations $\mathrm{C}_{0}$ and $\mathrm{C}_{12}$ (mean $62 \%$ ). Predictivity of all six limited sampling strategies based on Bayesian fitting was $<90 \%$ (mean $66.8 \%$ ).

Table 6.4 Evaluation of predictive performance of limited sampling strategies to estimate the complete $\mathrm{AUC}_{0-12}$ in the 37 renal transplant recipients.

\begin{tabular}{|c|c|c|c|c|c|}
\hline Equation & Time points & $R^{2}$ & Mean PE (\%) & Mean APE (\%) & $\pm 15 \%^{a}$ \\
\hline 23. & $\mathrm{C}_{0}, \mathrm{C}_{4}{ }^{\mathrm{C}}$ & 0.760 & $-14.9 \pm 13.8(-46.0-33.2)$ & $17.9 \pm 9.43(1.12-46.0)$ & $13(35 \%)$ \\
\hline 22. & $\mathrm{C}_{0}, \mathrm{C}_{3}{ }^{\mathrm{c}}$ & 0.779 & $-11.5 \pm 14.0(-41.9-33.1)$ & $15.7 \pm 8.83(2.0-41.9)$ & $21(57 \%)$ \\
\hline 1. & $\mathrm{C}_{0}$ & 0.536 & $2.11 \pm 14.8(-27.1-24.4)$ & $12.3 \pm 8.22(0.7-27.1)$ & $22(59 \%)$ \\
\hline 11. & $\mathrm{C}_{0}, \mathrm{C}_{1}$ & 0.703 & $6.58 \pm 14.8(-26.5-43.7)$ & $12.6 \pm 10.1(0.1-43.7)$ & $24(65 \%)$ \\
\hline 2. & $\mathrm{C}_{12}$ & 0.80 & $9.56 \pm 11.6(-12.7-29.9)$ & $12.0 \pm 8.97(0.3-29.9)$ & $24(65 \%)$ \\
\hline 19. & $\mathrm{C}_{0}, \mathrm{C}_{2}, \mathrm{C}_{3}{ }^{\mathrm{c}}$ & 0.502 & $-4.44 \pm 17.4(-45.3-50.6)$ & $13.7 \pm 11.4(0.4-50.6)$ & $25(68 \%)$ \\
\hline 20. & $\mathrm{C}_{0}, \mathrm{C}_{2}, \mathrm{C}_{4}{ }^{\mathrm{c}}$ & 0.537 & $-5.1 \pm 16.3(-43.1-50.3)$ & $12.9 \pm 10.4(0.2-50.3)$ & $28(76 \%)$ \\
\hline 18. & $\mathrm{C}_{0}, \mathrm{C}_{1}, \mathrm{C}_{3}{ }^{\mathrm{c}}$ & 0.525 & $9.95 \pm 19.4 \quad(-29.7-88.8)$ & $13.1 \pm 17.4(0.4-88.8)$ & $30(81 \%)$ \\
\hline 25. & $\mathrm{C}_{0}, \mathrm{C}_{4}$ & 0.911 & $-7.83 \pm 6.36 \quad(-21.3-2.4)$ & $8.08 \pm 6.02(0.1-21.3)$ & $30(81 \%)$ \\
\hline 7. & $\mathrm{C}_{0}, \mathrm{C}_{1}, \mathrm{C}_{2}$ & 0.869 & $2.35 \pm 9.96 \quad(-17.2-27.3)$ & $8.03 \pm 6.22(0.0-27.3)$ & $31(84 \%)$ \\
\hline 6. & $\mathrm{C}_{0}, \mathrm{C}_{4}$ & 0.896 & $-5.97 \pm 6.71(-20.1-4.7)$ & $6.63 \pm 6.04(0.6-20.1)$ & $31(84 \%)$ \\
\hline 21. & $\mathrm{C}_{0}, \mathrm{C}_{2}^{\mathrm{b}}$ & 0.802 & $-3.69 \pm 10.2(-19.6-18.6)$ & $9.10 \pm 5.67 \quad(0.4-19.6)$ & $31(84 \%)$ \\
\hline 17. & $\mathrm{C}_{0}, \mathrm{C}_{1}, \mathrm{C}_{4}$ & 0.943 & $5.91 \pm 7.06(-8.8-26.3)$ & $7.02 \pm 5.93(0.2-26.3)$ & $33(89 \%)$ \\
\hline 15. & $\mathrm{C}_{0}, \mathrm{C}_{1}, \mathrm{C}_{4}^{\mathrm{b}}$ & 0.934 & $5.00 \pm 7.28 \quad(-9.8-25.8)$ & $6.81 \pm 5.57 \quad(0.2-25.8)$ & $34(92 \%)$ \\
\hline 14. & $\mathrm{C}_{2}, \mathrm{C}_{4}$ & 0.964 & $2.28 \pm 6.58(-17.1-16.1)$ & $5.45 \pm 4.24(0.7-17.1)$ & $35(95 \%)$ \\
\hline 24. & $\mathrm{C}_{0}, \mathrm{C}_{2}, \mathrm{C}_{4}$ & 0.941 & $-4.81 \pm 5.26(-17.3-2.8)$ & $5.32 \pm 4.73(0.1-17.3)$ & $35(95 \%)$ \\
\hline 13. & $\mathrm{C}_{1}, \mathrm{C}_{4}$ & 0.973 & $6.30 \pm 4.84(-5.9-17.8)$ & $6.68 \pm 4.28(0.3-17.8)$ & $36(97 \%)$ \\
\hline 8. & $\mathrm{C}_{0}, \mathrm{C}_{1}, \mathrm{C}_{4}$ & 0.967 & $3.37 \pm 5.21 \quad(-5.2-17.7)$ & $4.87 \pm 3.80(0.2-17.7)$ & $36(97 \%)$ \\
\hline 9. & $\mathrm{C}_{0}, \mathrm{C}_{2}, \mathrm{C}_{4}$ & 0.962 & $0.10 \pm 6.37(-16.7-14.7)$ & $4.71 \pm 4.22(0.3-16.7)$ & $36(97 \%)$ \\
\hline 26. & $\mathrm{C}_{2}, \mathrm{C}_{4}$ & 0.959 & $3.38 \pm 5.24(-7.6-15.5)$ & $5.20 \pm 3.37(0.0-15.5)$ & $36(97 \%)$ \\
\hline 10. & $\mathrm{C}_{1}, \mathrm{C}_{2}, \mathrm{C}_{4}$ & 0.976 & $3.07 \pm 5.40(-14.9-13.2)$ & $4.99 \pm 3.64 \quad(0.1-14.9)$ & $37(100 \%)$ \\
\hline 16. & $\mathrm{C}_{0}, \mathrm{C}_{2}, \mathrm{C}_{4}{ }^{\mathrm{b}}$ & 0.953 & $-1.58 \pm 5.29(-14.9-10.1)$ & $4.00 \pm 3.75(0.0-14.9)$ & $37(100 \%)$ \\
\hline 12. & $\mathrm{C}_{0}, \mathrm{C}_{4}$ & 0.930 & $3.55 \pm 6.30(-9.8-14.3)$ & $6.29 \pm 3.46(0.1-14.3)$ & $37(100 \%)$ \\
\hline 4. & $\mathrm{C}_{2}, \mathrm{C}_{4}$ & 0.963 & $-1.66 \pm 4.99(-12.0-14.3)$ & $4.13 \pm 3.20(0.2-14.3)$ & $37(100 \%)$ \\
\hline 5. & $\mathrm{C}_{0}, \mathrm{C}_{2}, \mathrm{C}_{4}$ & 0.959 & $1.33 \pm 5.24(-11.8-14.0)$ & $4.22 \pm 3.32(0.5-14.0)$ & $37(100 \%)$ \\
\hline 3. & $\mathrm{C}_{0}, \mathrm{C}_{2}, \mathrm{C}_{4}$ & 0.965 & $-0.20 \pm 4.79(-10.4-13.7)$ & $3.64 \pm 3.06(0.2-13.7)$ & $37(100 \%)$ \\
\hline
\end{tabular}

${ }^{a}$ Number and percentage of calculated $\mathrm{AUC}_{0-12}$ with a prediction error within $15 \% ;{ }^{\mathrm{b}}$ Limited sample strategies derived from the linear trapezoidal rule and the actual $\mathrm{AUC}_{0-12} ;{ }^{\mathrm{C}}$ Bayesian estimation of the actual $\mathrm{AUC}_{0-12}$ 


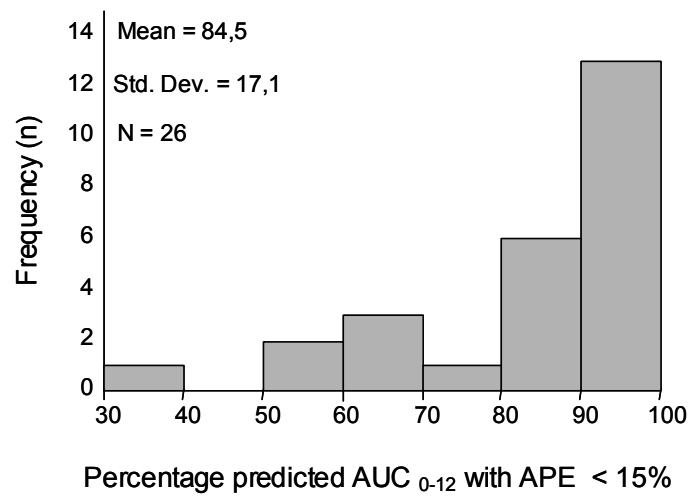

Figure 6.2 An overview of the predictive performances of the limited sampling strategies published using 37 different pharmacokinetic profiles recorded in 37 different renal transplant recipients. The mean prediction error $(\mathrm{PE} \%)<15 \%$ is plotted versus the frequency of the limited sampling strategies examined.

\section{Discussion}

Our results indicate like several other studies ${ }^{12,14-16,18,20,22}$ that trough concentrations $\mathrm{C}_{0}$ and $\mathrm{C}_{12}$ have a lower predictive value for the complete 12 hour AUC than most limited sampling strategies already published. Bayesian estimation of the $A \cup C_{\text {actual }}$ using different two or three time point strategies is not able to predict the $\mathrm{AUC}_{\text {actual }}$ reliably in the renal transplant recipient group examined. The Bayesian estimation strategies showed for at least $16 \%$ of the complete AUC $0-12$ an APE of more than $15 \%$. Two or three time points in the early phase ( $\leq 4$ hour) post dose seems not to be sufficient for a Bayesian estimation strategy to fit correctly most of the $\mathrm{AUC}_{0-12}$ and thus predict the complete $A \cup C_{0-12}$ reliably. The differences in variability and shape between the curves of late posttransplant recipients combined with just two or three sample points may have caused the large differences found between the $A \cup C_{\text {pred }}$ calculated according to the Bayesian estimation strategy and the complete $A \cup C_{\text {actual. }}$ Ting et al. ${ }^{23}$ recently suggests that limited sampling strategies should only be applied on transplant patient populations that are comparable with the transplant patient population that has been used to develop the limited sampling strategy. However, the renal transplant patient group examined in the present study is not exactly comparable with the transplant patient populations in which the equations for the limited sampling strategies are developed. For example: Aumente Rubio et $a l^{20}$ and Ragette et al. ${ }^{22}$ used respectively heart and lung transplant recipients to develop and validate their limited sampling strategies. Despite these limited sampling strategies being developed with the pharmacokinetic 
profiles of patients who underwent a different kind of transplantation, equation 5, 24 and 26 are able to predict at least $90 \%$ of the $A U_{0-12}$ within an APE (\%) of $15 \%$ which suggests that these limited sampling strategies are more robust than is expected by Ting et al. ${ }^{23}$. In conclusion, the present study indicates that limited sampling strategies from literature based on regression analysis, could produce satisfactory predictions with own patients, although careful evaluation of its reliability is mandatory. 


\section{References}

1. Mahalati K, Kahan BD. Pharmacological surrogates of allograft outcome. Ann Transplant 2000;5:14-23.

2. Winkler M, Christians U. A risk-benefit assessment of tacrolimus in transplantation. Drug Saf 1995;12:348-57.

3. McMaster P, Mirza DF, Ismail T, Vennarecci G, Patapis P, Mayer AD. Therapeutic drug monitoring of tacrolimus in clinical transplantation. Ther Drug Monit 1995;17:602-605.

4. Staatz CE, Tett SE. Clinical pharmacokinetics and pharmacodynamics of tacrolimus in solid organ transplantation. Clin Pharmacokinet 2004;43:623-53.

5. Laskow DA, Vincenti F, Neylan JF, Mendez R, Matas AJ. An open-label, concentrationranging trial of FK506 in primary kidney transplantation: a report of the United States Multicenter FK506 Kidney Transplant Group. Transplantation 1996;62:900-5.

6. Kershner RP, Fitzsimmons WE. Relationship of FK506 whole blood concentrations and efficacy and toxicity after liver and kidney transplantation. Transplantation.1996;62:920-926.

7. Undre NA, van Hooff J, Christiaans M Vanrenterghem Y, Donck J, Heeman U, Kohnle M, Zanker B, Land W, Morales JM, Andres A, Schafer A, Stevenson P. Low systemic exposure to tacrolimus correlates with acute rejection. Transplant Proc 1999;31:296-8.

8. Braun F, Schutz E, Peters B, Talaulicar R, Grupp C, Undre N, Schafer A, Armstrong VW, Oellerich M, Ringe B. Pharmacokinetics of tacrolimus primary immunosuppression in kidney transplant recipients. Transplant Proc 2001;33:2127-8.

9. Backman L, Nicar M, Levy M, Distant D, Eisenstein C, Renard T, Goldstein R, Husberg B, Gonwa T, Klintmalm G. Whole blood and plasma levels of FK 506 after liver transplantation: correlation with toxicity. Transplant Proc 1994;26:1804.

10. Takahara S, Kokado $\mathrm{Y}$, Kameoka H, Takano $\mathrm{Y}$, Jiang $\mathrm{H}$, Moutabarrik A, Ishibashi M, Okuyama A, Sonoda T. Monitoring of FK 506 blood levels in kidney transplant recipients. Transplant Proc 1994;26:2106-8.

11. Winkler M, Ringe B, Rodeck B, Melter M, Stoll K, Baumann J, Wonigeit K, Pichlmayr R. The use of plasma levels for FK 506 dosing in liver-grafted patients. Transpl Int.1994;7:329-33.

12. Armendariz Y, Pou L, Cantarell C, Lopez R, Perello M, Capdevila L. Evaluation of a limited sampling strategy to estimate area under the curve of tacrolimus in adult renal transplant patients. Ther Drug Monit 2005;27:431-4.

13. Balbontin FG, Kiberd B, Squires J, Singh D, Fraser A, Belitsky P, Lawen J. Tacrolimus monitoring by simplified sparse sampling under the concentration time curve. Transplant Proc 2003;35:2445-8.

14. Kuypers DR, Claes K, Evenepoel P, Maes B, Coosemans W, Pirenne J, Vanrenterghem Y. Time-related clinical determinants of long-term tacrolimus pharmacokinetics in combination therapy with mycophenolic acid and corticosteroids: a prospective study in one hundred de novo renal transplant recipients. Clin Pharmacokinet.2004;43:741-62.

15. Scholten EM, Cremers SC, Schoemaker RC, Rowshani AT, van Kan EJ, den Hartigh J, Paul LC, de Fijter JW. AUC-guided dosing of tacrolimus prevents progressive systemic overexposure in renal transplant recipients. Kidney Int 2005;67:2440-7.

16. Wong KM, Shek CC, Chau KF, Li CS. Abbreviated tacrolimus area-under-the-curve monitoring for renal transplant recipients. Am J Kidney Dis 2000;35:660-6.

17. Stolk LM, van Duijnhoven EM, Christiaans MH, van Hooff JP. Trough levels of tacrolimus. Ther Drug Monit.2002;24:573; author reply 573-4.

18. Pisitkun T, Eiam-Ong S, Chusil S, Praditpornsilpa K, Pansin P, Tungsanga K. The roles of C4 and AUCO-4 in monitoring of tacrolimus in stable kidney transplant patients. Transplant Proc 2002;34:3173-5.

19. Ku YM, Min DI. An abbreviated area-under-the-curve monitoring for tacrolimus in patients with liver transplants. Ther Drug Monit 1998;20:219-23. 
20. Aumente Rubio MD, Arizon del Prado JM, Lopez Malo de Molina MD, Cardenas Aranzana M, Segura Saint-Gerons J, Lopez Granados A, Rodriguez Esteban E, Mesa Rubio D, Romo Penas E, Segura Saint-Gerons C. Clinical pharmacokinetics of tacrolimus in heart transplantation: new strategies of monitoring. Transplant Proc 2003;35:1988-91.

21. Sgrosso JL, Araujo GL, Vazquez MC. Tacrolimus pharmacokinetics in heart transplant. Transplant Proc 2002;34:142-3.

22. Ragette R, Kamler M, Weinreich G, Teschler H, Jakob H. Tacrolimus pharmacokinetics in lung transplantation: new strategies for monitoring. J Heart Lung Transplant 2005;24:1315-9.

23. Ting LS, Villeneuve E, Ensom MH. Beyond cyclosporine: a systematic review of limited sampling strategies for other immunosuppressants. Ther Drug Monit 2006;28:419-30.

24. Sheiner LB, Beal SL. Some suggestions for measuring predictive performance. J Pharmacokinet Biopharm 1981;9:503-12.

25. Meier-Kriesche HU, Kaplan B, Brannan P, Kahan BD, Portman RJ. A limited sampling strategy for the estimation of eight-hour neoral areas under the curve in renal transplantation. Ther Drug Monit 1998;20:401-7.

26. David OJ, Johnston A. Limited sampling strategies for estimating cyclosporin area under the concentration-time curve: review of current algorithms. Ther Drug Monit 2001;23:100-14.

27. Bowles MJ, Waters JB, Lechler RI, Williams G. Do cyclosporin profiles provide useful information in the management of renal transplant recipients? Nephrol Dial Transplant 1996;11:1597-602.

28. Staatz CE, Taylor PJ, Tett SE. Comparison of an ELISA and an LC/MS/MS method for measuring tacrolimus concentrations and making dosage decisions in transplant recipients. Ther Drug Monit 2002;24:607-15.

29. Braun F, Lorf T, Schutz E, Christians U, Grupp C, Sattler B, Canelo R, Sewing KF, Armstrong VW, Oellerich M, Ringe B. Clinical relevance of monitoring tacrolimus: comparison of microparticle enzyme immunoassay, enzyme-linked immunosorbent assay, and liquid chromatography mass spectrometry in renal transplant recipients converted from cyclosporine to tacrolimus. Transplant Proc 1996;28:3175-6.

30. Borrows R, Chusney G, Loucaidou M, Singh S, James A, Stichbury J, Van Tromp J, Cairns T, Griffith M, Hakim N, McLean A, Palmer A, Papalois V, Taube D. Tacrolimus monitoring in renal transplantation: a comparison between high-performance liquid chromatography and immunoassay. Transplant Proc 2005;37:1733-5.

31. Brown NW, Gonde CE, Adams JE, Tredger JM. Low hematocrit and serum albumin concentrations underlie the overestimation of tacrolimus concentrations by microparticle enzyme immunoassay versus liquid chromatography-tandem mass spectrometry. Clin Chem 2005;51:586-92.

32. Ghoshal AK, Soldin SJ. IMx tacrolimus II assay: is it reliable at low blood concentrations? A comparison with tandem MS/MS. Clin Biochem 2002;35:389-92.

33. Proost $\mathrm{JH}$. Adaptive control of drug dosage regimens using maximum a posteriori probability Bayesian fitting. Int J Clin Pharmacol Ther 1995;33:531-6. 


\section{Chapter}

Influence of different allelic variants of the

cytochrome 3A and adenosine triphosphate-

binding cassette B1 gene on the tacrolimus

pharmacokinetic profile of Chinese renal

transplant recipients

Chi Yuen Cheung, Robert A.M. Op den Buijsch, Kim Ming Wong, Hoi Wong Chan, Ka Foon Chau, Chun Sang Li, Kay Tai Leung, Tze Hoi Kwan, Johan E. de Vries, Petal A.H.M. Wijnen, Marja P. van Dieijen-Visser; Otto Bekers

Pharmacogenomics 2006; 7:563-574 


\section{Abstract}

\section{Background and aim}

Tacrolimus has a narrow therapeutic window and a wide interindividual variation in its pharmacokinetics. Cytochrome P450 3A (CYP3A) and the adenosine triphosphatebinding cassette $B 1$ (ABCB1) gene encoding protein, multidrug resistance-1 (MDR1) or P-glycoprotein play an important role in the tacrolimus disposition. Therefore this study evaluates whether CYP3A and $A B C B 1$ polymorphisms are associated with the area under the time tacrolimus concentration curve $\left(\mathrm{AUC}_{0-12}\right)$ calculated using a two time point sample strategy.

\section{Materials and methods}

The CYP3A and ABCB1 genotypes are determined by real-time polymerase chain reaction (PCR) fluorescence resonance energy transfer (FRET) assays in 103 Chinese renal transplant recipients and consequently related to their dose-normalized $A C_{0-12}$ $\left(\right.$ dnAUC $\left._{0-12}\right)$.

\section{Results}

A significant allele-dependent effect (Kruskal Wallis; $P<0.001$ ) is observed between the CYP3A5 3 polymorphism and the $\mathrm{dnAUC}_{0-12}$. Multiple regression analysis showed that the CYP3A5*3 polymorphism is the most significant independent variable and explained $35 \%$ of the dose requirement variability in relation to tacrolimus use. Regarding the ABCB1 G2677T/A and C3435T polymorphisms, a trend is observed between the different genotypes and the $\operatorname{dnAUC}_{0-12}$.

\section{Conclusion}

The CYP $3 A 5^{\star} 3$ polymorphism may be an important factor in determining the dose requirement for tacrolimus and genotyping can help determine the initial daily dose needed by individual patients for adequate immunosuppression. 


\section{Introduction}

The calcineurin inhibitor tacrolimus that is used worldwide for primary immunosuppression following renal transplantation has a narrow therapeutic index, which makes close therapeutic drug monitoring necessary to prevent both subtherapeutic blood levels as well as toxic blood levels. Subtherapeutic tacrolimus blood levels increase the risk of transplant rejection ${ }^{1-3}$, while toxic tacrolimus blood levels may lead to severe side effects such as nephrotoxicity and neurotoxicity ${ }^{4-6}$. The high interindividual variability in tacrolimus pharmacokinetics complicates the realization of this narrow therapeutic index ${ }^{7,8}$. Although tacrolimus trough $\left(\mathrm{C}_{0}\right)$ levels have been shown to provide a reliable indication of the total drug exposure ${ }^{9}$, their usefulness in differentiating graft rejection episodes from nephrotoxicity has been questioned ${ }^{2,10}$. A more accurate estimation of the tacrolimus exposure by making 12 hour pharmacokinetic profiles may lead to a lower incidence of acute rejection like in the case of cyclosporine ${ }^{11,12}$. Since obtaining complete 12 hour pharmacokinetic profiles for every renal transplant patient is not feasible in clinical practice, parameters have been examined that strongly correlate with the 12 hour pharmacokinetic profile. Recent studies showed higher correlations with the 12 hour pharmacokinetic profiles of tacrolimus when a limited sampling point sample strategy is used instead of $\mathrm{C}_{0}$ levels alone ${ }^{13-17}$. Additionally, the two time point sample strategy used in the present study is able to calculate reliable the area under the time tacrolimus concentration curve or $\mathrm{AUC}_{0-12}$ in renal transplant patient groups ${ }^{15,17}$. The cytochrome P450 (CYP) 3A isoenzymes mainly represented by CYP3A4 and CYP3A5 have been identified as the major enzymes responsible for the disposition of tacrolimus ${ }^{18}$. Although a number of CYP3A4 polymorphisms have been identified (website Human Cytochrome P450 (CYP) Allele Nomenclature Committee ${ }^{101}$ ), these are rare and therefore do not contribute significantly to CYP3A4 expression variability. The single nucleotide polymorphism (SNP) CYP3A5 $6986 \mathrm{G}$ or ${ }^{*} 3$ displays a sequence variability in intron 3 that creates a cryptic splice site and encodes an aberrantly spliced mRNA with a premature stop codon, leading to the absence of protein expression. This CYP $3 A 5^{\star} 3$ polymorphism occurred homozygously in $90 \%$ of the Caucasians, $73 \%$ of the Chinese and in $30 \%$ of the African-American population ${ }^{19-21}$. Although several studies ${ }^{22-31}$ have described the association between the CYP3A5*3 polymorphism and tacrolimus $\mathrm{C}_{0}$ levels, the present study examines the associations with the CYP3A polymorphisms using a more accurate approach to determine the tacrolimus exposure in renal transplant patients. Tacrolimus is also a substrate for the adenosine triphosphatebinding cassette $B 1$ ( $A B C B 1$ ) gene encoding protein multidrug resistance-1 (MDR1) or P-glycoprotein. ABCB1 is an ATP-dependent efflux pump that contributes to the protection of the body from environmental toxins and drugs like tacrolimus by limiting their absorption from the gut lumen or increasing their biliary and urinary excretion ${ }^{32}$. Three partly linked polymorphisms in the ABCB1 gene located on exons 12, 21 and 26 have been studied widely and these polymorphisms account for the major haplotypes 
encountered in Caucasians. Whereas two of these ABCB1 polymorphisms, C1236T and C3435T, result in silent mutations, the ABCB1 G2677T/A polymorphism in exon 21 is non-synonymous and results in an amino acid exchange (Ala893Ser/Thr). A number of studies already have reported that there seems to be no association between the ABCB1 polymorphisms and tacrolimus dose-normalized trough $\left(\mathrm{dnC}_{0}\right)$ levels ${ }^{25-27,30,31,33}$ or the dose-normalized area under the time tacrolimus concentration curve $\left(\text { dnAUC }_{0-12}\right)^{34,35}$. However, some studies found a correlation between individual ABCB1 polymorphisms $^{23,24,36}$ or the ABCB1 $1236 \mathrm{C}-2677 \mathrm{G}-3435 \mathrm{C}$ haplotype ${ }^{37}$ and a higher tacrolimus dose. The present study evaluates in Chinese renal transplant recipients the impact of CYP3A and $A B C B 1$ polymorphisms on the dnAUC $C_{0-12}$ which is calculated according to a two time point sampling strategy. Furthermore, we described two new real-time polymerase chain reaction (PCR) fluorescence resonance energy transfer (FRET) assays to determine the genotype for the CYP3A5 A6986G and ABCB1 C1236T polymorphism.

\section{Patients and methods}

\section{Study population}

A total of 103 Chinese renal transplant recipients who received tacrolimus as part of the immunosuppressive therapy and had regular follow-up in Queen Elizabeth Hospital or Tuen Mun Hospital in Hong Kong were included in this retrospective study. There was no change in the daily tacrolimus dose for at least two weeks. Patients were advised to avoid St. John's wort and grapefruit juice which may affect the tacrolimus concentration. None of the patients included were taking medication known to have interaction with tacrolimus, such as calcium channel blockers, anti-epileptics, anti-mycotics and macrolide antibiotics. Additionally, patients who suffered from gastrointestinal disease, liver disease or other disorders that may alter the absorption of tacrolimus were excluded. Apart from tacrolimus and steroids, these patients were normally put on azathioprine, however some patients preferred to use mycophenolic acid on advice of their private physician. The dosage of azathioprine was $1.5 \mathrm{mg} / \mathrm{kg} /$ day while the dosage of mycophenolic acid was 0.5 gram twice daily. The initial tacrolimus dosage, administrated twice daily, was $0.3 \mathrm{mg} / \mathrm{kg} /$ day for all patients. The daily tacrolimus dose was then adjusted according to the $\mathrm{AUC}_{0-12}$ value, which was kept at around 100$150 \mathrm{ng} \times \mathrm{hr} / \mathrm{ml}$ in the first 3 months. After three months the target $\mathrm{AUC}_{0-12}$ value was decreased to around $80-100 \mathrm{ng} \times \mathrm{hr} / \mathrm{ml}$ for long term maintenance. These $\mathrm{AUC}_{0-12}$ values were based on our previous pilot study ${ }^{15}$ and the experiences obtained in our transplantation centers. The steroid regimen for the first month was $30 \mathrm{mg} / \mathrm{day}$ of oral prednisolone, progressively tapered by $2.5 \mathrm{mg}$ every two weeks until a daily maintenance dose of $5 \mathrm{mg}$. Demographic as well as clinical data were collected the time of the tacrolimus blood sample collection. 


\section{Tacrolimus concentration determination}

Tacrolimus blood concentrations were determined 2 (C2) and 4 (C4) hours after the morning tacrolimus administration in ethylene diamine tetra-acetic acid (EDTA) whole blood using a semi-automated microparticle enzyme immunoassay (MEIA) on an Imx II clinical analyser (Abbott Laboratories, Abbott Park, IL, USA). The Imx II does not crossreact enormously with the most important tacrolimus metabolite produced by CYP3A5, 13-O-demethyl tacrolimus, which has a minor immunosuppressive effect. Furthermore, a few metabolites show significant cross reactivity with the antibody but were present at low concentrations compared to tacrolimus ${ }^{27}$. The two tacrolimus blood concentrations determined were used to calculate the $\mathrm{AUC}_{0-12}$ according to the equation based strategy as described by our group ${ }^{15}: \mathrm{AUC}_{0-12}=16.2+2.4 \times \mathrm{C} 2+5.9 \times \mathrm{C} 4$. The dnAUC $0-12$ was calculated by dividing the $\mathrm{AUC}_{0-12}$ by the corresponding 24 hour dose on a milligrams per kilogram basis.

\section{Ethics}

The study was performed in accordance to the Declaration of Helsinki and its amendments. The protocol was approved by the Medical Ethics Committee of the Queen Elizabeth Hospital in Hong Kong and written informed consent for participation in this study was obtained from all patients.

\section{DNA isolation}

Genomic DNA was extracted from 103 Chinese renal transplant recipients by using $200 \mu$ I EDTA anti-coagulated blood for isolation with a QIAamp blood mini kit (Qiagen, Leusden, the Netherlands) according to the manufacturers' instructions.

\section{Genotyping of CYP3A and ABCB1 gene polymorphisms}

Real-time PCR FRET assays were used for genotyping the CYP3A4 A-392G, CYP3AP1 G-44A, ABCB1 G2677T/A and C3435T polymorphisms with the same primers and probes as described in the original publications ${ }^{38-41}$. The real-time PCR FRET assays for the CYP3A5 A6986G and ABCB1 C1236T polymorphisms were designed, optimised and validated in our laboratory. The presence of the expected polymorphisms was confirmed by sequencing the different allelic variants of CYP3A5 and ABCB1 according to a direct sequence procedure on a capillary sequencer $A B I$ Prism $3100^{\circledR}$ using the Bridge version 1.1 sequence kit (both products from Applied Biosystems, Fostercity, USA). Genotyping for the CYP3A5 A6986G polymorphism was performed using the primers F16: 5'-TTT gCC TCT TTg TAC TTC TTC ATC-'3 (sense; 172835-858) and R16: 5'- Tag TTg TAC gAC ACA Cag CAA CC-'3 (anti-sense; 173335-313) to amplify a 501 bp part from the CYP3A5 gene which covers the A6986G polymorphism in intron 3 (Genbank acces no: AF280107). Detection was carried out using the anchor probe CYP316R640: 5'-CCC TgT TTg gAC CAC ATT ACC CTT-'3 (sense; 173214-237) which 
was labelled at the $5^{\prime}$ end with LCRed 640 and phosphorylated at the 3 '- end to block extension and the sensor probe CYP3A5A16: 5'-gAg CTC TTT TgT CTT TCA ATA TCT CT-3 (sense; 173187-212) which is complementary to the CYP3A5 6986A or *1 allele with the polymorphic nucleotide indicated underlined. This 3'-fluorescein labelled anchor probe binds with a distance of one base 5' to the detection probe. The PCR mixture contained $3.3 \mu \mathrm{l}$ sterile water; $2.0 \mathrm{mmol} / \mathrm{l} \mathrm{MgCl} 2 ; 1.0 \mu \mathrm{l}$ LC Faststart DNA Master Hybridisation Probes (Roche Diagnostics $\mathrm{GmbH}$, Mannheim, Germany), $0.60 \mu \mathrm{mol} / \mathrm{l}$ of each primer, and $0.20 \mu \mathrm{mol} / / \mathrm{l}$ of both anchor and sensor probe (TIB MOLBIOL, Berlin, Germany). After adding 1.0 $\mu$ l containing 50-100 ng genomic DNA to the PCR mixture, the total volume is $10 \mu \mathrm{l}$. The PCR protocol included the following steps: a) denaturation for ten minutes at $95^{\circ} \mathrm{C} \mathrm{b}$ ) 45 cycles at $95^{\circ} \mathrm{C}$ for ten seconds; $55^{\circ} \mathrm{C}$ for ten seconds and $72^{\circ} \mathrm{C}$ for 20 seconds (all $20^{\circ} \mathrm{C} /$ second). After amplification was completed, a melting curve was recorded by cooling to $45^{\circ} \mathrm{C}\left(20^{\circ} \mathrm{C} /\right.$ second $)$ holding at $45^{\circ} \mathrm{C}$ for two minutes and then heating slowly to $75^{\circ} \mathrm{C}$ at $0.1^{\circ} \mathrm{C} /$ second. Moreover, genotyping for the ABCB1 C1236T polymorphism is performed using the primers F35: 5'-gTT CCT ATA TCC TgT gTC TgT gAA T-'3 (sense; 208-32) and R35: 5'-AgT CTA gCT CgC ATg ggT CAT C-'3 (anti-sense; 448-27) to amplify a 241 bp part from the ABCB1 gene which covers the C1236T polymorphism in exon 12 (Genbank access no: M29432). Detection of the ABCB1 C1236T polymorphism was carried out using the anchor probe A35: 5'-gCC ACC gTC TgC CCA CTC TgC AC-3 (anti-sense; 343-321) which is labelled at the 3'end with fluorescence and binds with a distance of one base 5' to the sensor probe. This 5' LCRed640 labelled sensor probe P35: TTC Agg TTC AgA CCC TTC AAg (antisense; 319-299) which is phosphorylated at the 3 ' end to block extension from the anchor probe and is complementary to the ABCB1 1236T polymorphism which is indicated underlined. The PCR mixture for the ABCB1 C1236T polymorphism contained: $2.95 \mu \mathrm{l}$ sterile water; $2.0 \mathrm{mmol} / \mathrm{l} \mathrm{MgCl} 2 ; 1.0 \mu \mathrm{l}$ LC Faststart DNA Master Hybridization Probes; (Roche Diagnostics $\mathrm{GmbH}$, Mannheim, Germany) $0.5 \mu \mathrm{M}$ of each primer and $0.225 \mu \mathrm{mol} / \mathrm{l}$ of both sensor and anchor probe (TIB MOLBIOL, Berlin, Germany). After adding 1.0 $\mu$ l containing 50-100 ng genomic DNA to the PCR mixture, the total volume was $10 \mu \mathrm{l}$. The PCR protocol included the following steps: denaturation for 10 minutes at $95^{\circ} \mathrm{C} ; 45$ cycles at $95^{\circ} \mathrm{C}$ for 5 seconds, $55^{\circ} \mathrm{C}$ for 10 seconds and $72^{\circ} \mathrm{C}$ for 20 seconds (all $20^{\circ} \mathrm{C} /$ second). After amplification was completed, a melting curve was recorded by heating to $95^{\circ} \mathrm{C}\left(20^{\circ} \mathrm{C} /\right.$ second $)$ holding at $95^{\circ} \mathrm{C}$ for 20 seconds; subsequently cooling to $40^{\circ} \mathrm{C}\left(20^{\circ} \mathrm{C} /\right.$ second $)$ holding at $40^{\circ} \mathrm{C}$ for 20 seconds and then heating slowly to $85^{\circ} \mathrm{C}$ at $0.2^{\circ} \mathrm{C} /$ second. All PCR and melting curve analysis were performed on the LightCycler (Roche Diagnostics, Almere, the Netherlands).

\section{Statistical analysis}

Statistical analysis of the data was performed with use of SPSS 12.0 software for windows (Chicago, IL, USA). To examine the population homogeneity of the patients, the genotype frequencies of the CYP $3 A$ and $A B C B 1$ polymorphisms were tested against 
Hardy-Weinberg equilibrium by the Pearson's goodness-of-fit test. For analysis of the $\mathrm{dnAUC}_{0-12}(\mathrm{ng} \times \mathrm{hr} / \mathrm{ml}$ per $\mathrm{mg} / \mathrm{kg})$ and the daily tacrolimus dose $(\mathrm{mg} / \mathrm{kg} / \mathrm{day})$, two groups were compared using the non parametric Mann-Whitney test while the non parameteric Kruskal Wallis test was used to compare several groups. Stepwise multiple regression analyses was used to calculate the relative contribution of several genetic and nongenetic factors on the variability in the daily tacrolimus dose requirement. The genetic factors examined are the CYP $3 A 5^{\star} 3$ polymorphism and three ABCB1 polymorphisms while the non-genetic factors examined are gender, age, serum creatinine concentration, time since transplantation and steroid dosing. $P$ values less than 0.05 were considered statistically significant. All values are expressed as median and range unless stated otherwise.

\section{Results}

\section{Demographic characteristics of patients}

Table 7.1 illustrates the characteristics of the 103 Chinese renal transplant patients that fulfilled the inclusion criteria and were enrolled in our study.

\section{Real-time PCR FRET assays for CYP3A5 A6986G and ABCB1 C1236T genotyping}

The melting point of the sensor probe covering the CYP3A5 A6986G polymorphism was $57^{\circ} \mathrm{C}$ when hybridised to the CYP3A5 $6986 \mathrm{G} / \mathrm{G}$ or ${ }^{*} 3 /{ }^{*} 3$ genotype and $62^{\circ} \mathrm{C}$ when hybridised to the CYP3A5 6986A/A or ${ }^{*} 1 /{ }^{*} 1$ genotype. A heterozygous sample contained both type of targets and thus generated both peaks (Figure 7.1A). In addition, for the $A B C B 1 \mathrm{C} 1236 \mathrm{~T}$ polymorphism, the melting point of the sensor probe was $56.5^{\circ} \mathrm{C}$ when hybridised to the $A B C B 11236 C C$ genotype and $62^{\circ} \mathrm{C}$ when hybridised to the ABCB1 1236TT genotype. A heterozygote sample for the ABCB1 C1236T polymorphism showed both melting peaks (Figure 7.1B). The presence of the expected polymorphisms was confirmed by sequencing these different allelic variants of CYP3A5 and $A B C B 1$ gene. The resulting characterised heterozygote samples were used as controls in each run performed. 
Table 7.1 Demographic characteristics of the renal transplant recipients

\begin{tabular}{|c|c|}
\hline Demographic characteristics & \\
\hline Gender (male/female) & $58 / 45$ \\
\hline Age (years, mean $\pm S D$, (range)) & $43.1 \pm 11.1(21-77)$ \\
\hline Weight $(\mathrm{kg}$, mean $\pm \mathrm{SD}$, (range) & $62.5 \pm 11.4(37.4-87.8)$ \\
\hline Primary kidney disease & \\
\hline Glomerulonephritis & 57 \\
\hline Chronic pyelonephritis & 1 \\
\hline Diabetic nephropathy & 10 \\
\hline Hypertensive nephropathy & 9 \\
\hline Polycystic kidney disease & 2 \\
\hline Obstructive Uropathy & 3 \\
\hline Unknown & 18 \\
\hline Other & 3 \\
\hline Transplantation number & \\
\hline First & 97 \\
\hline Second & 6 \\
\hline Tacrolimus dose (mg/kg body weight/day, mean $\pm \mathrm{SD}$, (range)) & $0.067 \pm 0.032(0.01-0.18)$ \\
\hline Tacrolimus conc. 2 hour post dose ( $\mathrm{ng} / \mathrm{ml}$, mean $\pm \mathrm{SD}$, (range) & $13.5 \pm 4.30(5.7-29.4)$ \\
\hline Tacrolimus conc. 4 hour post dose ( $\mathrm{ng} / \mathrm{ml}$, mean $\pm \mathrm{SD}$, (range)) & $8.7 \pm 2.60(2.3-16.4)$ \\
\hline $\mathrm{AUC}_{0-12}(\mathrm{ng} \times \mathrm{hr} / \mathrm{ml}$, mean, (range)) & $100.3(47.8-183.5)$ \\
\hline $\operatorname{DnAUC}_{0-12}(\mathrm{ng} \times \mathrm{hr} / \mathrm{ml}$ per $\mathrm{mg} / \mathrm{kg}$ body weight, mean, (range) $)$ & $1940(300-11125)$ \\
\hline Use of azathiopurine/mycophenolate mofetil & $78 / 25$ \\
\hline Current steroid dose (mg, mean \pm SD, (range)) & $6.98 \pm 2.37(4-25)$ \\
\hline Time since transplantation (days, mean, (range)) & $977(133-4982)$ \\
\hline Haemoglobin $(\mathrm{mmol} / /$, mean \pm SD, (range)) & $12.8 \pm 2.0(8.5-19)$ \\
\hline Haematocrit fraction (mean $\pm \mathrm{SD}$, (range)) & $0.38 \pm 0.058(0.25-0.57)$ \\
\hline $\operatorname{ALAT}(\mathrm{U} / \mathrm{l}$, mean $\pm \mathrm{SD}$, (range)) & $22 \pm 18(8-147)$ \\
\hline Serum albumin (g/l, mean $\pm \mathrm{SD}$, (range)) & $43 \pm 3.2(34-50)$ \\
\hline Serum creatinine $(\mu \mathrm{mol} / \mathrm{l}$, mean $\pm \mathrm{SD}$, (range) $)$ & $156 \pm 76(62-462)$ \\
\hline
\end{tabular}

A

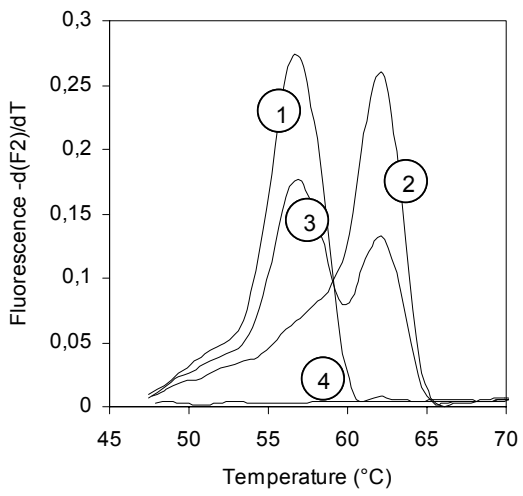

B

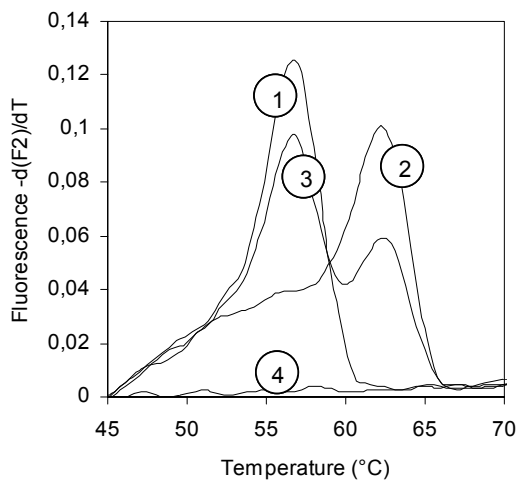

Figure 7.1 Genotyping of CYP3A5 A6986G and ABCB1 C1236T with allele specific fluorescent probes by derivative melting curve plots. The derivative melting curves are read in channel 2 for the detection of the CYP3A5 and the ABCB1 fragments.

$A$. The derivative melting curve is plotted for a sample homozygous for the CYP3A5 $6986 \mathrm{G}$ or *3 allele $\left(1 ; \mathrm{Tm} 57^{\circ} \mathrm{C}\right)$; a sample homozygous for the CYP3A5 $6986 \mathrm{~A}$ or *1 allele $\left(2 ; \mathrm{Tm} 62^{\circ} \mathrm{C}\right)$ and a heterozygous sample $\left(3 ; \operatorname{Tm} 57^{\circ} \mathrm{C}\right.$ and $\left.62^{\circ} \mathrm{C}\right)$. B. The derivative melting curve is plotted for a sample homozygous for the ABCB1 1236C allele $\left(1 ; \mathrm{Tm} 56.5^{\circ} \mathrm{C}\right)$; a sample homozygous for the $\mathrm{ABCB} 11236 \mathrm{~T}$ allele $\left(2 ; \mathrm{Tm} 62^{\circ} \mathrm{C}\right)$ and a heterozygous sample $\left(3 ; \operatorname{Tm} 56.5^{\circ} \mathrm{C}\right.$ and $\left.62^{\circ} \mathrm{C}\right)$. Melting analysis of a no template control was also performed for both assays (4). 


\section{The allele distribution of the different CYP3A and ABCB1 polymorphisms}

Table 7.2 shows both the different genotypes and the allele frequencies of the CYP3A and $A B C B 1$ polymorphisms. In our population, we found no homozygous or heterozygous variant allele for the CYP3A4*1B polymorphism, which confirmed its very low frequency in the Chinese population. The allele frequencies found for the CYP3A5, CYP3AP1 and ABCB1 polymorphisms are in line with the literature ${ }^{20,22,25}$. The distribution of all polymorphisms examined is not significantly different from that predicted with the Hardy-Weinberg equilibrium (each $P>0.05$ ). The genetic linkage of CYP3AP1 G-44A with CYP3A5 A6986G as already described by previous studies ${ }^{42,43}$, was also confirmed in our study.

Table 7.2 Allelic distribution of CYP3A, CYP3AP1 and ABCB1 variants in 103 Chinese renal transplant recipients

\begin{tabular}{lcccccc}
\hline SNP & $\mathrm{wt} / \mathrm{wt}$ & $\mathrm{wt} / \mathrm{m}$ & $\mathrm{m} / \mathrm{m}$ & \multicolumn{3}{c}{ Allele frequency (\%) } \\
\hline CYP3A4 & & & & $\mathrm{A}$ & $\mathrm{G}$ \\
A-392G & $103(100 \%)$ & $0(0 \%)$ & $0(0 \%)$ & 100 & 0 & \\
CYP3A5 & & & & $\mathrm{A}$ & $\mathrm{G}$ & \\
A6986G & $10(10 \%)$ & $38(37 \%)$ & $55(53 \%)$ & 28 & 72 & \\
CYP3AP1 & & & & $\mathrm{G}$ & $\mathrm{A}$ & \\
G-44A & $9(9 \%)$ & $40(39 \%)$ & $54(52 \%)$ & 28 & 72 & \\
ABCB1, exon 12 & & & & $\mathrm{C}$ & $\mathrm{T}$ & \\
C1236T & $8(8 \%)$ & $52(50 \%)$ & $43(42 \%)$ & 33 & 67 & $\mathrm{~A}$ \\
ABCB1, exon 21 & & $\mathrm{GT}: 32(31 \%)$ & $\mathrm{TT}: 19(19 \%)$ & $\mathrm{G}$ & $\mathrm{T}$ & 13 \\
G2677T/A & $26(25 \%)$ & $\mathrm{GA}: 16(15 \%)$ & $\mathrm{TA}: 10(10 \%)$ & 48 & 39 & 13 \\
ABCB1, exon 26 & & & & $\mathrm{C}$ & $\mathrm{T}$ & \\
C3435T & $46(45 \%)$ & $43(42 \%)$ & $14(13 \%)$ & 66 & 34 & \\
\hline
\end{tabular}

\section{Effect of CYP3A and ABCB1 polymorphisms on tacrolimus dose requirements and pharmacokinetic profiles}

Table 7.3 shows a significant decrease in the dnAUC $C_{0-12}$ which strongly depends on whether the patients were carrier of none, one or two CYP3A5*1 alleles $(2143,1228$ and $920 \mathrm{ng} \times \mathrm{hr} / \mathrm{ml}$ per $\mathrm{mg} / \mathrm{kg}$; Kruskal Wallis, $P<0.001$ ), respectively. Consequently, the daily tacrolimus dose was $80 \%$ higher in homozygous carriers of a CYP3A5*1 allele compared to homozygous carriers of the CYP3A5*3 allele $(0.09 \mathrm{mg} / \mathrm{kg} /$ day versus 0.05 $\mathrm{mg} / \mathrm{kg} /$ day; Kruskal Wallis, $P<0.001)$. This allele-dependent effect of the CYP3A5 3 polymorphism is also illustrated in Figure 7.2. Additionally, a significant correlation is found between the allelic variants of the CYP3AP1 G-44A polymorphism and both the $\mathrm{dnAUC}_{0-12}$ and the daily tacrolimus dose. Likely, this is caused by a very high linkage $(>98 \%$ ) between CYP3A5*3 and CYP3AP1 -44A (only two patients differed in genotype) in our study. 
A

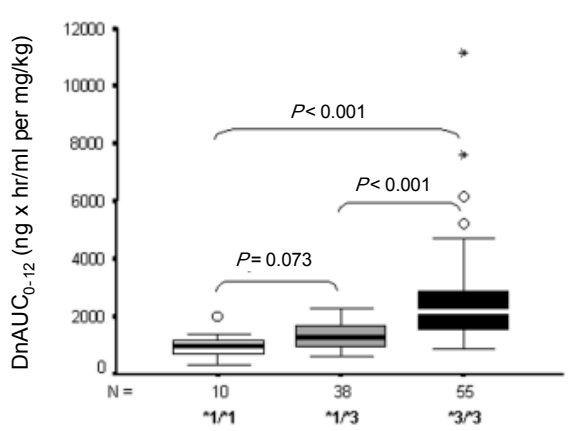

CYP3A5 A6986G polymorphism

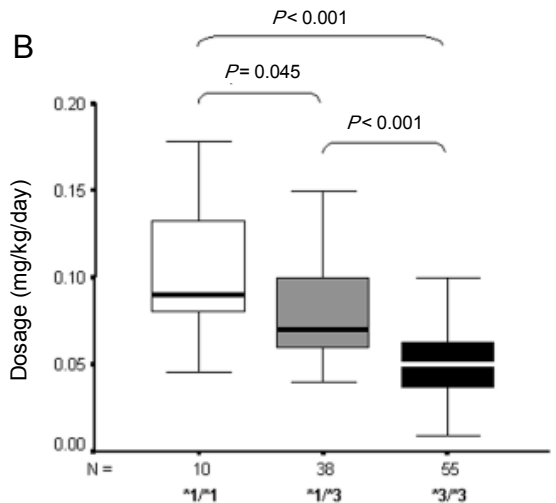

CYP3A5 A6986G polymorphism

Figure 7.2 Influence of the CYP3A5 A6986G genotype on the pharmacological parameters recorded in 103 renal transplant recipients. A. The boxplot of the dose-normalized (dn)AUC $\mathrm{C}_{0-12}$ ( $\mathrm{ng} \times \mathrm{hr} / \mathrm{ml}$ per $\mathrm{mg} / \mathrm{kg}$ body weight) clustered according to CYP3A5 A6986G genotype. B. The boxplot of the distribution of the daily tacrolimus dose (mg/kg body weight) clustered according to CYP3A5 A6986G genotype. $P$ values for the pairwise comparisons of each genotype are given. Open circles indicate an outlier value at more than 1.5 boxlengths above the box, while asterics indicate an extreme value at more than 3 box lengths above the box.

Regarding the $A B C B 1$ polymorphisms, we examined both the individual $A B C B 1$ polymorphisms and the $A B C B 1$ haplotypes present in the renal transplant patients. Table 7.3 shows the genetic effect of the three individual ABCB1 polymorphisms on both the dnAUC 0 -12 and the daily tacrolimus dose. Individuals carrying the 2677TT or 3435TT genotype showed no significant difference in the $\mathrm{dnAUC}_{0-12}$ compared to individuals carrying the $2677 \mathrm{GG}$ or $3435 \mathrm{CC}$ genotype. However, as is shown in Table 7.3 , individuals carrying the $2677 \mathrm{TT}$ or $3435 \mathrm{TT}$ genotype required a significantly higher daily tacrolimus dose than individuals carrying the $2677 \mathrm{GG}$ or $3435 \mathrm{CC}$ genotype $(0.066$ $\mathrm{mg} / \mathrm{kg} /$ day versus $0.053 \mathrm{mg} / \mathrm{kg} /$ day and $0.073 \mathrm{mg} / \mathrm{kg} /$ day versus $0.051 \mathrm{mg} / \mathrm{kg} / \mathrm{day}$; Mann-Whitney, $P=0.033$ and $P=0.044$ ), respectively. In contrast to ABCB1 G2677T/A and $\mathrm{C} 3435 \mathrm{~T}$, the allelic variants of the ABCB1 C1236T polymorphism showed no significant difference on the $\mathrm{dnAUC}_{0-12}$ and the daily tacrolimus dose. Additionally, we analysed the correlation between the $\mathrm{ABCB} 1$ haplotypes and the $\mathrm{dnAUC}_{0-12}$ as well as the daily tacrolimus dose. 
Table 7.3 Influence of CYP3A, CYP3AP1 and ABCB1 genotypes on the daily tacrolimus dose and the dose-normalized (Dn)AUC $\mathrm{A}_{0-12}$.

\begin{tabular}{|c|c|c|c|}
\hline Genotype & Allelic status (n) & $\begin{array}{c}\text { Dose } \\
\text { (mg/kg/day) }\end{array}$ & $\begin{array}{c}\mathrm{DnAUC}_{0-12} \\
(\mathrm{ng} \times \mathrm{hr} / \mathrm{ml} \\
\text { per } \mathrm{mg} / \mathrm{kg})\end{array}$ \\
\hline CYP3A5 & *1/*1 (10) & $0.090(0.05-0.18)^{a}$ & $920(300-1981)^{a}$ \\
\hline \multirow[t]{2}{*}{ A6986G } & *1/*3 (38) & $0.070(0.04-0.15)^{\mathrm{a}}$ & $1228(589-2266)^{a}$ \\
\hline & *3/*3 (55) & $0.050(0.01-0.10)^{\mathrm{a}}$ & $2143(827-11125)^{\mathrm{a}}$ \\
\hline CYP3AP1 & $\mathrm{G} / \mathrm{G}(9)$ & $0.090(0.05-0.18)^{a}$ & $929(300-1981)^{a}$ \\
\hline \multirow[t]{2}{*}{ G-44A } & $\mathrm{A} / \mathrm{G}(40)$ & $0.070(0.04-0.15)^{a}$ & $1298(589-2265)^{a}$ \\
\hline & A/A (54) & $0.050(0.01-0.10)^{\mathrm{a}}$ & $2156(827-11125)^{a}$ \\
\hline ABCB1 & $\mathrm{C} / \mathrm{C} \quad(8)$ & $0.060(0.03-0.15)$ & $1484(875-5166)$ \\
\hline \multirow[t]{2}{*}{ C1236T } & $\mathrm{C} / \mathrm{T}(52)$ & $0.060(0.01-0.18)$ & $1494(300-11125)$ \\
\hline & $\mathrm{T} / \mathrm{T}(43)$ & $0.063(0.01-0.15)$ & $1651(589-7579)$ \\
\hline ABCB1 & $\mathrm{G} / \mathrm{G}(26)$ & $0.053(0.03-0.09)^{b}$ & 1887 (891-6166) \\
\hline \multirow[t]{4}{*}{ G2677T/A } & $\mathrm{G} / \mathrm{T}(32)$ & $0.070(0.01-0.18)$ & 1365 (300-7579) \\
\hline & $\mathrm{G} / \mathrm{A}(16)$ & $0.050(0.01-0.15)$ & $1864(676-11125)$ \\
\hline & T/A (10) & $0.056(0.05-0.13)$ & $1765(805-2870)$ \\
\hline & $\mathrm{T} / \mathrm{T}(19)$ & $0.066(0.02-0.15)^{b}$ & 1473 (589-4532) \\
\hline ABCB1 & $\mathrm{C} / \mathrm{C}(46)$ & $0.052(0.01-0.15)^{\mathrm{b}}$ & $1882(676-11125)$ \\
\hline \multirow{2}{*}{ C3435T } & $\mathrm{C} / \mathrm{T}(43)$ & $0.063(0.03-0.18)$ & $1466(300-6166)$ \\
\hline & $\mathrm{T} / \mathrm{T}(14)$ & $0.073(0.02-0.15)^{b}$ & $1332(589-4532)$ \\
\hline CYP3A5 - ABCB1 & ${ }^{*} 3 /{ }^{*} 3-G G(17)$ & $0.048(0.03-0.08)$ & $2097(1056-6166)$ \\
\hline \multirow[t]{8}{*}{ A6986G - G2677T/A } & ${ }^{*} 3 /{ }^{*} 3-$ GA/GT/TA (26) & $0.050(0.01-0.10)$ & $2369(827-11125)$ \\
\hline & ${ }^{*} 3 /{ }^{*} 3-\mathrm{TT}(12)$ & $0.063(0.02-0.09)$ & $1694(1237-4532)$ \\
\hline & ${ }^{*} 1 /{ }^{*} 3-\mathrm{GG}(8)$ & $0.068(0.04-0.09)$ & $1346(913-2168)$ \\
\hline & ${ }^{*} 1 /{ }^{*} 3-\mathrm{GA} / \mathrm{GT} / \mathrm{TA}(24)$ & $0.073(0.05-0.15)^{\mathrm{c}}$ & $1271(691-1973)^{c}$ \\
\hline & $* 1 / * 3-\mathrm{TT}(6)$ & $0.104(0.05-0.15)^{\mathrm{c}}$ & $788(589-2266)^{c}$ \\
\hline & $* 1 / * 1-G G(1)$ & 0.0787 & 891 \\
\hline & ${ }^{*} 1 /{ }^{*} 1-\mathrm{GA} / \mathrm{GT} / \mathrm{TA}(8)$ & $0.110(0.05-0.18)^{\mathrm{c}}$ & $878(300-1981)^{c}$ \\
\hline & ${ }^{*} 1 /{ }^{*} 1-\mathrm{TT}(1)$ & 0.0800 & $1106^{\star}$ \\
\hline & ${ }^{*} 3 / * 3-\operatorname{CC}(28)$ & $0.046(0.01-0.08)$ & $2120(1056-11125)$ \\
\hline \multirow[t]{8}{*}{ A6986G - C3435T } & ${ }^{*} 3 /{ }^{*} 3-\mathrm{CT}(21)$ & $0.059(0.03-0.10)$ & 2179 (827-6166) \\
\hline & ${ }^{*} 3 /{ }^{*} 3-\mathrm{TT}(6)$ & $0.055(0.02-0.09)$ & $1845(1322-4532)$ \\
\hline & $* 1 / * 3-\operatorname{CC}(15)$ & $0.069(0.04-0.15)^{c}$ & $1106(870-2168)^{\mathrm{c}}$ \\
\hline & ${ }^{*} 1 /{ }^{*} 3-\mathrm{CT}(16)$ & $0.073(0.05-0.13)^{\mathrm{c}}$ & $1271(691-1882)^{c}$ \\
\hline & ${ }^{*} 1 /{ }^{*} 3-\mathrm{TT}(7)$ & $0.098(0.05-0.15)^{c}$ & $841(589-2266)^{c}$ \\
\hline & $* 1 / * 1-\mathrm{CC}(3)$ & $0.090(0.08-0.13)^{\mathrm{c}}$ & $891(676-950)^{c}$ \\
\hline & $* 1 /{ }^{*} 1-\mathrm{CT}(6)$ & $0.11(0.05-0.18)^{c}$ & $977(300-1981)^{\mathrm{C}}$ \\
\hline & $* 1 / * 1-\mathrm{TT}(1)$ & 0.800 & 1106 \\
\hline
\end{tabular}

Values are indicated as median (range), ${ }^{\mathrm{a}} P<0.001$ (Kruskal Wallis); ${ }^{\mathrm{b}} P<0.05$ (Mann-Whitney), ${ }^{\mathrm{c}} P<0.05$ (Bonferroni), when the designated CYP3A5 - ABCB1 genotype combination is compared to the reference genotype combination, which is CYP3A5 - ABCB1 G2677T/A *3/*3 - GG and CYP3A5-ABCB1 C3435T *3/*3-CC, respectively.

Table 7.4 illustrates that in contrast to the two individual $A B C B 1$ polymorphisms, no significant difference or trend was observed between the ABCB1 haplotypes and the $\mathrm{dnAUC}_{0-12}$ as well as the daily tacrolimus dose. Moreover, using stepwise multiple regression analysis to examine the relative contribution of the non-genetic and genetic factors to the daily tacrolimus dose variability, the CYP3A5*3 polymorphism appears to be the most significant independent variable when considering the daily tacrolimus dose 
as a dependent variable. The CYP3A5*3 polymorphism can explain $35.3 \%(P<0.001)$ of the variation in the daily tacrolimus dose observed in the renal transplant recipient population. Furthermore, gender $(9.9 \% ; P<0.001)$ and the ABCB1 C3435T polymorphism $(3.7 \% ; P<0.009)$ have a significant contribution in the variation of the daily tacrolimus dose. The two ABCB1 polymorphisms C1236T and G2677T/A, ABCB1 haplotypes and the non-genetic factors: age, serum creatinine concentration, time since transplantation and steroid dosing have no significant contribution on the variation of the daily tacrolimus dose.

Table 7.4 ABCB1 haplotypes in correlation to tacrolimus dose and dose-normalized (Dn)AUC $\mathrm{C}_{0-12}$

\begin{tabular}{cccccll}
\hline C1236T & G2677T/A & C3435T & $n$ & $\begin{array}{c}\text { Frequency } \\
(\%)\end{array}$ & $\begin{array}{c}\text { Dose } \\
(\mathrm{mg} / \mathrm{kg} / \mathrm{day})\end{array}$ & $\begin{array}{c}\text { DnAUC } 0-12 \\
(\mathrm{ng} \times \mathrm{hr} / \mathrm{ml} \\
\text { er } \mathrm{mg} / \mathrm{kg})\end{array}$ \\
\hline CC & GG & CC & 4 & 3.9 & $0.064(0.03-0.08)$ & $1484(1301-5166)$ \\
CC & GA & CC & 4 & 3.9 & $0.054(0.03-0.15)$ & $1862(875-3948)$ \\
CT & GG & CC & 11 & 10.7 & $0.070(0.03-0.09)$ & $1073(891-4002)$ \\
CT & GG & CT & 2 & 1.9 & 0.034 & 4519 \\
CT & GT & CC & 2 & 1.9 & 0.067 & 1650 \\
CT & GT & CT & 15 & 14.6 & $0.070(0.03-0.18)$ & $1227(300-4702)$ \\
CT & GT & TT & 2 & 1.9 & 0.056 & 2156 \\
CT & GA & CC & 11 & 10.7 & $0.050(0.01-0.13)$ & $1846(676-11125)$ \\
CT & TA & CC & 1 & 1.0 & 0.050 & 1918 \\
CT & TA & CT & 8 & 7.8 & $0.056(0.05-0.13)$ & $1765(805-2870)$ \\
TT & GG & CC & 9 & 8.7 & $0.050(0.03-0.08)$ & $1919(1438-3717)$ \\
TT & GT & CC & 2 & 1.9 & 0.021 & 4814 \\
TT & GT & CT & 11 & 10.7 & $0.080(0.05-0.10)$ & $1325(837-2309)$ \\
TT & GA & CC & 1 & 1.0 & 0.039 & 2933 \\
TT & TA & CC & 1 & 1.0 & 0.072 & 1106 \\
TT & TT & CT & 7 & 6.7 & $0.063(0.05-0.08)$ & $1685(1237-2626)$ \\
TT & TT & TT & 12 & 11.7 & $0.075(0.02-0.15)$ & $1277(589-4532)$ \\
\hline
\end{tabular}

Figure 7.3 suggests that a combined analysis of the CYP3A5*3 and ABCB1 G2677T/A or $\mathrm{ABCB} 1 \mathrm{C} 3435 \mathrm{~T}$ polymorphism may be helpful to identify those individuals that require a strong aberrant daily tacrolimus dose, although the contribution of the individual $\mathrm{ABCB} 1$ polymorphisms on the daily tacrolimus dose variation is not significant or minor compared to the CYP3A5*3 polymorphism. 

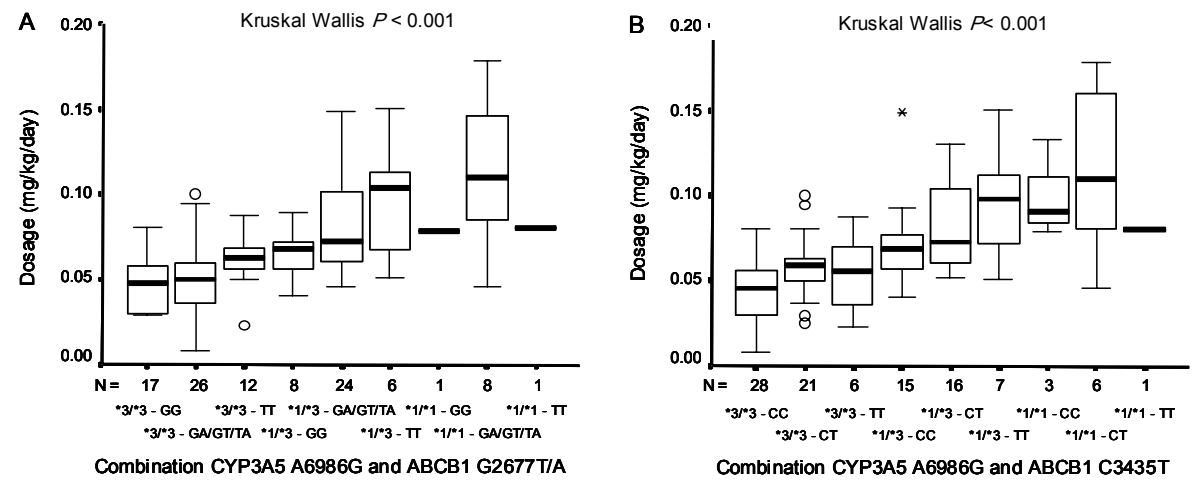

Figure 7.3 The boxplot of the distribution of the daily tacrolimus dose $(\mathrm{mg} / \mathrm{kg})$ clustered according to the combination of CYP3A5 A6986G and ABCB1 G2677T/A genotypes. B. The boxplot of the distribution of the daily tacrolimus dose ( $\mathrm{mg} / \mathrm{kg}$ body weight) clustered according to the combination of CYP3A5 A6986G and ABCB1 C3435T genotypes. A $P$ value is given for comparison of several groups of both CYP3A5 and ABCB1 genotype combinations. Open circles indicate an outlier value at more than 1.5 boxlengths below/above the box, while asterics indicate an extreme value at more than 3 box lengths above the box.

\section{Discussion}

Although most centres still use $\mathrm{C}_{0}$ levels for monitoring tacrolimus there are conflicting data about the correlation with the systemic tacrolimus exposure. Several studies reported a reasonable squared correlation between $C_{0}$ levels and $A C_{0-12}$ of tacrolimus ${ }^{44-46}$, while other studies found very poor correlations ${ }^{13-16,47,48}$. Recently, Scholten et al. ${ }^{17}$ reported a reduction of the $95 \%$ prediction interval by $50 \%$, when a two point sampling strategy was used consisting of a $\mathrm{C}_{0}$ level and a second sample obtained between two and four hour post dose. Moreover, Scholten et al. ${ }^{17}$ evaluated the predictive performance of the two time point sample strategy used in the present study and confirmed its suitability. It is known that several non-genetic factors can modulate the post-operative CYP3A phenotype, especially in the early period after transplantation $^{49}$. Therefore, it is important to demonstrate with close drug monitoring of tacrolimus that steady state blood concentrations have been achieved in order to examine the genotype-phenotype associations more accurately. Therapeutic drug monitoring of tacrolimus can be performed accurately using complete $\mathrm{AUC}_{0-12}$ or an $\mathrm{AUC}_{0-12}$ calculated by a limited sampling strategy. In the present study a limited sampling strategy is used to calculate the $A_{U C} C_{0-12}$ in 103 Chinese renal transplant recipients. To the best of our knowledge, two recent studies ${ }^{34,35}$ previously examined, in Japanese renal transplant recipients, the association between the CYP $3 A 5^{\star} 3$ and the $A B C B 1$ C3435T polymorphism and the pharmacokinetic parameters; $(\mathrm{dn}) \mathrm{C}_{0}$, 
$(\mathrm{dn}) \mathrm{AUC}_{0-12},(\mathrm{dn}) \mathrm{C}_{\max }, \mathrm{T}_{\max }$ and $\mathrm{t}_{1 / 2}$. Although several studies found a significant effect of CYP3A5 3 polymorphism ${ }^{22-24,26-31,35}$ on tacrolimus levels or dosages, the number homozygous carriers of the CYP3A5*1 polymorphism was limited in these studies. Recently, Zhang et al. ${ }^{25}$ correlated the different genotypes of the CYP3A5*3 and ABCB1 C3435T polymorphism of 118 Chinese renal transplant recipients with their corresponding $\mathrm{C}_{0}$ levels and daily tacrolimus dosages respectively, 1 week, 1 month and 3 months after transplantation. Our findings showed in line with the results of Zhang et $a l^{25}$ a strong significant genetic effect between the CYP3A $5^{\star} 3$ polymorphism and both the dnAUC $\mathrm{C}_{0-12}$ and the daily tacrolimus dose. After a mean time of 2.5 years post transplantation, carriers of the CYP $3 A^{*} 3$ polymorphism still require a remarkable lower daily tacrolimus dose compared to carriers of the CYP3A5*1 polymorphism. An estimation of the contribution of the different CYP3A and $A B C B 1$ polymorphisms in the variation of the daily tacrolimus dose is performed by Haufroid et al. ${ }^{27}$. They found that the CYP $3 A 5^{*} 3$ polymorphism is with a relative contribution of $38 \%$ the most significant independent variable when considering the daily tacrolimus dose as dependent variable, which is in line with the findings observed in the present study. The significant contribution of the gender in the variation of the daily tacrolimus dose is also found by Kuypers et al. ${ }^{14}$ although they examined the influence of several non-genetic variables within the first year after transplantation. However, no significant contribution is observed for the time since transplantation in the variation of the daily tacrolimus dose in contrast to the findings observed by Haufroid et al. ${ }^{27}$. Despite the ABCB1 G2677T/A and C3435T polymorphisms showed a significant genetic effect after correlating these $A B C B 1$ polymorphisms with the daily tacrolimus dose, no significant contribution is found using multiple regression analysis for the two individual $A B C B 1$ polymorphisms or $A B C B 1$ haplotype. Our findings seem therefore in contrast to several other studies which reported that carriers of the $3435 \mathrm{CC}$ allele $23,24,36$ and $1236 \mathrm{C}-2677 \mathrm{G}-3435 \mathrm{C}$ or 2677GG-3435CC haplotype required a higher daily tacrolimus dose ${ }^{37}$. However, the significant genetic effect for ABCB1 polymorphisms or haplotypes found in these studies is like in our study not as pronounced as it is for the CYP3A5*3 polymorphism. The minor influence of the $A B C B 1$ polymorphisms compared to the CYP $3 A 5^{\star} 3$ polymorphism on the tacrolimus pharmacokinetics combined with the differences regarding pharmacokinetic parameter used $\left(\mathrm{C}_{0}\right.$ or $\left.A \mathrm{AC}_{0-12}\right)$, the genetic (single SNP versus haplotype) analyses that were performed, the number of transplant patients included, and the difference in inclusion criteria for the transplant recipients may explain the differences in genotype-phenotype associations found by these studies. Also after combining the CYP3A5*3 polymorphism with the ABCB1 G2677T/A or C3435T polymorphism, the extra part of the variation in $\operatorname{dnAUC}_{0-12}$ and daily tacrolimus dose that can be clarified above the CYP3A5*3 polymorphism is marginal. 


\section{Highlights}

- The calcineurin inhibitor tacrolimus, an immunosuppressant used in transplantation therapy, has unpredictable drug levels and therefore requires close therapeutic drug monitoring in order to minimize the risk of under- or overimmunosuppression.

- Tacrolimus is metabolized by the cytochrome P450 3A (CYP3A) iso-enzymes, which is quantitatively the most important metabolic route of tacrolimus. Additionally, tacrolimus is also a substrate for the adenosine triphosphate-binding cassette B1 (ABCB1) gene encoding protein multidrug resistance-1 (MDR1) or P-glycoprotein.

- The present study used a two time point sampling strategy to calculate the area under the time tacrolimus concentration curve $\left(A_{U} C_{0-12}\right)$ and correlated these dosenormalized $\mathrm{AUC}_{0-12}$ with the corresponding CYP3A and $\mathrm{ABCB} 1$ genotypes in 103 Chinese renal transplant recipients.

- $\quad$ Several single nucleotide polymorphisms (SNPs) recently identified in CYP3A and $A B C B 1$ gene may elucidate the interindividual differences in the tacrolimus pharmacokinetics.

- The CYP3A5*3 allele, which results in the absence of the functional CYP3A5 protein, has been strongly associated with a higher dnAUC $\mathrm{C}_{0-12}$ and consequently a lower daily tacrolimus dose. The different genotypes of the ABCB1 G2677T/A and C3435T SNPs showed a weaker association with the $\mathrm{dnAUC}_{0-12}$ as well as the daily tacrolimus dose.

- Multiple regression analysis demonstrates that the CYP3A5*3 allele is the most important independent variable among several genetic and non-genetic variables examined in the renal transplant recipients.

- Knowing the impact of the CYP3A5*3 allele on the tacrolimus disposition, genotyping prior transplantation may help to assess the initial daily dose needed by individual patients for adequate immunosuppression.

\section{Outlook and conclusion}

Tacrolimus has a narrow therapeutic index which requires close monitoring of the drug concentration in order to achieve an optimal efficiency and minimizing the risks of acute rejection and drug overdose. The polymorphisms present in CYP3A and ABCB1 can explain their variability in expression and activity and thus clarify the interindividual differences in the tacrolimus pharmacokinetics. The majority of studies that examined the CYP3A and ABCB1 genotype-phenotype association were based on tacrolimus $\mathrm{C}_{0}$ levels, despite the fact that an $\mathrm{AUC}_{0-12}$ is the best way to determine the tacrolimus exposure. To the best of our knowledge only two studies reported an association between the CYP3A5*3 polymorphism and both the different pharmacokinetic parameters of tacrolimus and the daily tacrolimus dose. Furthermore, several studies 
reported an association between $\mathrm{CYP} \mathrm{A} 5^{*} 3$ polymorphism and the tacrolimus $\mathrm{C}_{0}$ levels obtained within the early period after transplantation. However, non-genetic parameters have then also a large impact on the tacrolimus concentration in this period. The present study calculated an $\mathrm{AUC}_{0-12}$ according to a two time point sampling strategy for 103 Chinese renal transplant patients with a wide time interval starting on at least three months posttransplantation. Our results clearly point out that the CYP $3 A 5^{\star} 3$ polymorphism is strongly allele-dependent associated with both the $\operatorname{dnAUC}_{0-12}$ and the daily tacrolimus dose in renal transplant recipients. A weaker significant association is found for the ABCB1 G2677T/A and ABCB1 C3435T polymorphisms. Multiple regression analysis demonstrates that the CYP3A5*3 polymorphism is the most important independent variable among several genetic and non-genetic variables examined in the renal transplant recipients. Therefore, CYP3A5 genotyping prior transplantation may contribute to determine the initial tacrolimus dose required for individual patients. 


\section{References}

1. Laskow, DA, Vincenti F, Neylan JF, Mendez R, Matas AJ. An open-label, concentrationranging trial of FK506 in primary kidney transplantation: a report of the United States Multicenter FK506 Kidney Transplant Group. Transplantation 1996;62:900-5.

2. Kershner, RP, Fitzsimmons WE. Relationship of FK506 whole blood concentrations and efficacy and toxicity after liver and kidney transplantation. Transplantation 1996;62:920-6.

3. Undre NA, van Hooff J, Christiaans M Vanrenterghem $Y$, Donck J, Heeman U, Kohnle M, Zanker B, Land W, Morales JM, Andres A, Schafer A, Stevenson P. Low systemic exposure to tacrolimus correlates with acute rejection. Transplant Proc.1999;31:296-8.

4. Winkler, M, Christians U. A risk-benefit assessment of tacrolimus in transplantation. Drug Saf 1995;12:348-57.

5. McMaster, P, Mirza DF, Ismail T, Vennarecci G, Patapis P, MayerAD. Therapeutic drug monitoring of tacrolimus in clinical transplantation. Ther Drug Monit 1995;17:602-5.

6. Staatz CE, Tett SE. Clinical pharmacokinetics and pharmacodynamics of tacrolimus in solid organ transplantation. Clin Pharmacokinet 2004;43:623-53.

-• Excellent review regarding the clinical pharmacokinetics of tacrolimus.

7. Spencer CM, Goa KL, Gillis JC. Tacrolimus. An update of its pharmacology and clinical efficacy in the management of organ transplantation. Drugs 1997;54:925-75.

8. Venkataramanan R, Swaminathan A, Prasad T, Jain A, Zuckerman S, Warty V, McMichael J, Lever J, Burckart G, Starzl T. Clinical pharmacokinetics of tacrolimus. Clin Pharmacokinet 1995;29:404-30.

9. Shaw LM, Holt DW, Keown P, Venkataramanan R, Yatscoff RW. Current opinions on therapeutic drug monitoring of immunosuppressive drugs. Clin Ther 1999;21:1632-52; discussion 1631.

10. Backman L, Nicar M, Levy M, Distant D, Eisenstein C, Renard T, Goldstein R, Husberg B, Gonwa T, Klintmalm G. Whole blood and plasma levels of FK 506 after liver transplantation: correlation with toxicity. Transplant Proc 1994;26:1804.

11. Lindholm A, Kahan BD. Influence of cyclosporine pharmacokinetics, trough concentrations, and AUC monitoring on outcome after kidney transplantation. Clin Pharmacol Ther 1993;54: 205-18.

12. Primmett DR, Levine M, Kovarik JM, Mueller EA, Keown PA. Cyclosporine monitoring in patients with renal transplants: two- or three-point methods that estimate area under the curve are superior to trough levels in predicting drug exposure. Ther Drug Monit 1998;20:27683.

13. Armendariz Y, Pou L, Cantarell C, Lopez R, Perello M, Capdevila L. Evaluation of a limited sampling strategy to estimate area under the curve of tacrolimus in adult renal transplant patients. Ther Drug Monit 2005;27:431-4.

14. Kuypers DR, Claes K, Evenepoel P, Maes B, Coosemans W, Pirenne J, Vanrenterghem Y. Time-related clinical determinants of long-term tacrolimus pharmacokinetics in combination therapy with mycophenolic acid and corticosteroids: a prospective study in one hundred de novo renal transplant recipients. Clin Pharmacokinet 2004;43:741-62.

15. Wong KM, Shek CC, Chau KF, Li CS. Abbreviated tacrolimus area-under-the-curve monitoring for renal transplant recipients. Am J Kidney Dis 2000;35:660-6.

- Study describing a two time point sample strategy that is able to predict reliable the AUCO12 in renal transplant recipients.

16. Ragette R, Kamler M, Weinreich $\mathrm{G}$, Teschler $\mathrm{H}$,Jakob $\mathrm{H}$. Tacrolimus pharmacokinetics in lung transplantation: new strategies for monitoring. J Heart Lung Transplant 2005;24:1315-9.

17. Scholten EM, Cremers SC, Schoemaker RC, Rowshani AT, van Kan EJ, den Hartigh J, Paul LC, de Fijter JW. AUC-guided dosing of tacrolimus prevents progressive systemic overexposure in renal transplant recipients. Kidney Int 2005;67:2440-7.

18. Sattler M, Guengerich FP, Yun CH, Christians U, Sewing KF. Cytochrome P-450 3A enzymes are responsible for biotransformation of FK506 and rapamycin in man and rat. Drug Metab Dispos 1992;20:753-61. 
19. Hustert E, Haberl M, Burk O, Wolbold R, He YQ, Klein K, Nuessler AC, Neuhaus P, Klattig J, Eiselt R, Koch I, Zibat A, Brockmoller J, Halpert JR, Zanger UM, Wojnowski L. The genetic determinants of the CYP3A5 polymorphism. Pharmacogenetics 2001;11:773-9.

20. Xie HG, Wood AJ, Kim RB, Stein CM, Wilkinson GR. Genetic variability in CYP3A5 and its possible consequences. Pharmacogenomics 2004;5:243-72.

-• Excellent review regarding the CYP3A5 iso-enzyme.

21. van Schaik RH, van der Heiden IP, van den Anker JN, Lindemans J. CYP3A5 variant allele frequencies in Dutch Caucasians. Clin Chem 2002;48:1668-71.

22. Zhao Y, Song M, Guan D, Bi S, Meng J, Li Q, Wang W. Genetic polymorphisms of CYP3A5 genes and concentration of the cyclosporine and tacrolimus. Transplant Proc 2005;37:17881.

23. Zheng H, Webber S, Zeevi A, Schuetz E, Zhang J, Bowman P, Boyle G, Law Y, Miller S, Lamba J, Burckart GJ. Tacrolimus dosing in pediatric heart transplant patients is related to CYP3A5 and MDR1 gene polymorphisms. Am J Transplant 2003;3:477-83.

24. Zheng H, Zeevi A, Schuetz E, Lamba J, McCurry K, Griffith BP, Webber S, Ristich J, Dauber J, lacono A, Grgurich W, Zaldonis D, McDade K, Zhang J, Burckart GJ. Tacrolimus dosing in adult lung transplant patients is related to cytochrome P4503A5 gene polymorphism. J Clin Pharmacol 2004:44:135-40.

25. Zhang X, Liu ZH, Zheng JM, Chen ZH, Tang Z, Chen JS, Li LS. Influence of CYP3A5 and MDR1 polymorphisms on tacrolimus concentration in the early stage after renal transplantation. Clin Transplant 2005;19:638-43.

- Study describing the association in a Chinese renal transplant recipient population between the CYP3A5*3 and MDR1 C3435T polymorphisms and both the tacrolimus $\mathrm{C} 0$ level and the daily tacrolimus dose 1 week, 1 month and 3 months after transplantation.

26. Hesselink DA, van Schaik RH, van der Heiden IP, van der Werf M, Gregoor PJ, Lindemans J, Weimar W, van Gelder T. Genetic polymorphisms of the CYP3A4, CYP3A5, and MDR-1 genes and pharmacokinetics of the calcineurin inhibitors cyclosporine and tacrolimus. Clin Pharmacol Ther 2003;74:245-54.

27. Haufroid V, Mourad M, Van Kerckhove V, Wawrzyniak J, De Meyer M, Eddour DC, Malaise J, Lison D, Squifflet JP, Wallemacq P. The effect of CYP3A5 and MDR1 (ABCB1) polymorphisms on cyclosporine and tacrolimus dose requirements and trough blood levels in stable renal transplant patients. Pharmacogenetics 2004;14:147-54.

28. Thervet E, Anglicheau D, King B, Schlageter MH, Cassinat B, Beaune P, Legendre C, Daly AK. Impact of cytochrome p450 3A5 genetic polymorphism on tacrolimus doses and concentration-to-dose ratio in renal transplant recipients. Transplantation 2003;76:1233-5.

29. MacPhee IA, Fredericks S, Mohamed M, Moreton M, Carter ND, Johnston A, Goldberg L, Holt DW. Tacrolimus pharmacogenetics: the CYP3A5*1 allele predicts low dose-normalized tacrolimus blood concentrations in whites and South Asians. Transplantation 2005;79:499502.

30. Goto M, Masuda S, Kiuchi T, Ogura Y, Oike F, Okuda M, Tanaka K, Inui K. CYP3A5*1carrying graft liver reduces the concentration/oral dose ratio of tacrolimus in recipients of living-donor liver transplantation. Pharmacogenetics 2004;14:471-8.

31. Mai I, Perloff ES, Bauer S, Goldammer M, Johne A, Filler G, Budde K, Roots I. MDR1 haplotypes derived from exons 21 and 26 do not affect the steady-state pharmacokinetics of tacrolimus in renal transplant patients. Br J Clin Pharmacol 2004;58:548-53.

32. Schwab M, Eichelbaum M, Fromm MF. Genetic polymorphisms of the human MDR1 drug transporter. Annu Rev Pharmacol Toxicol 2003;43:285-307.

33. Hebert MF, Dowling AL, Gierwatowski C, Lin YS, Edwards KL, Davis CL, Marsh CL, Schuetz EG, Thummel KE. Association between ABCB1 (multidrug resistance transporter) genotype and post-liver transplantation renal dysfunction in patients receiving calcineurin inhibitors. Pharmacogenetics 2003;13:661-74.

34. Tada H, Tsuchiya N, Satoh S, Kagaya H, Li Z, Sato K, Miura M, Suzuki T, Kato T, Habuchi T. Impact of CYP3A5 and MDR1(ABCB1) C3435T polymorphisms on the pharmacokinetics of tacrolimus in renal transplant recipients. Transplant Proc 2005;37:1730-2. 
35. Tsuchiya N, Satoh S, Tada H, Li Z, Ohyama C, Sato K, Suzuki T, Habuchi T, Kato T. Influence of CYP3A5 and MDR1 (ABCB1) polymorphisms on the pharmacokinetics of tacrolimus in renal transplant recipients. Transplantation 2004;78:1182-7.

- First study that demonstrated in Japanese renal transplant recipients an association between the CYP3A5*3 polymorphism and the pharmacokinetic parameters such as $(\mathrm{dnC})$, dn(AUC0-12), dnCmax, Tmax, and t1/2.

36. MacPhee IA, Fredericks S, Tai T, Syrris P, Carter ND, Johnston A, Goldberg L, Holt DW. Tacrolimus pharmacogenetics: polymorphisms associated with expression of cytochrome p4503A5 and P-glycoprotein correlate with dose requirement. Transplantation 2002;74:14869.

- Study that first described the association between the pseudogene CYP3AP1 G-44A polymorphism and the tacrolimus $\mathrm{CO}$ levels and tacrolimus dose. Additionally, a multi-genetic approach was first used by this research group.

37. Anglicheau D, Verstuyft C, Laurent-Puig P, Becquemont L, Schlageter MH, Cassinat B, Beaune $\mathrm{P}$, Legendre $\mathrm{C}$, Thervet $\mathrm{E}$. Association of the multidrug resistance-1 gene singlenucleotide polymorphisms with the tacrolimus dose requirements in renal transplant recipients. J Am Soc Nephrol 2003;14:1889-96.

38. Dally H, Bartsch H, Jager B, Edler L, Schmezer P, Spiegelhalder B, Dienemann H, Drings $P$, Kayser K, Schulz V, Risch A. Genotype relationships in the CYP3A locus in Caucasians. Cancer Lett 2004;207:95-9.

39. Arjomand-Nahad F, Diefenbach K, Landt O, Gaikovitch E, Roots I. Genotyping of the triallelic variant G2677T/A in MDR1 using LightCycler with locked-nucleic-acid-modified hybridization probes. Anal Biochem 2004;334:201-3.

40. Nauck M, Stein U, von Karger S, Marz W, Wieland H. Rapid detection of the C3435T polymorphism of multidrug resistance gene 1 using fluorogenic hybridization probes. Clin Chem 2000;46:1995-7.

41. von Ahsen N, Richter M, Grupp C, Ringe B, Oellerich M, Armstrong VW. No influence of the MDR-1 C3435T polymorphism or a CYP3A4 promoter polymorphism (CYP3A4-V allele) on dose-adjusted cyclosporin A trough concentrations or rejection incidence in stable renal transplant recipients. Clin Chem 2001;47:1048-52.

42. Kuehl P, Zhang J, Lin Y, Lamba J, Assem M, Schuetz J, Watkins PB, Daly A, Wrighton SA, Hall SD, Maurel P, Relling M, Brimer C, Yasuda K, Venkataramanan R, Strom S, Thummel K, Boguski MS, Schuetz E. Sequence diversity in CYP3A promoters and characterization of the genetic basis of polymorphic CYP3A5 expression. Nat Genet 2001;27:383-91.

43. Paulussen A, Lavrijsen K, Bohets $H$, Hendrickx J, Verhasselt P, Luyten W, Konings $F$, Armstrong $M$. Two linked mutations in transcriptional regulatory elements of the CYP3A5 gene constitute the major genetic determinant of polymorphic activity in humans. Pharmacogenetics 2000;10:415-24.

44. Jorgensen K, Povlsen J, Madsen S, Madsen M, Hansen H, Pedersen A, Heinsvig EM, Poulsen J. C2 (2-h) levels are not superior to trough levels as estimates of the area under the curve in tacrolimus-treated renal-transplant patients. Nephrol Dial Transplant 2002;17:148790.

45. Kimikawa M, Kamoya K, Toma H, Teraoka S. Effective oral administration of tacrolimus in renal transplant recipients. Clin Transplant 2001;15:324-9.

46. Braun F, Schutz E, Peters B, Talaulicar R, Grupp C, Undre N, Schafer A, Armstrong VW, Oellerich M, Ringe B. Pharmacokinetics of tacrolimus primary immunosuppression in kidney transplant recipients. Transplant Proc 2001;33:2127-8.

47. Pisitkun T, Eiam-Ong S, Chusil S, Praditpornsilpa K, Pansin P,Tungsanga K. The roles of C4 and AUC0-4 in monitoring of tacrolimus in stable kidney transplant patients. Transplant Proc 2002;34:3173-5.

48. Stolk LM, Van Duijnhoven EM, Christiaans MH, van Hooff JP. Trough levels of tacrolimus. Ther Drug Monit 2002;24:573; author reply 573-4.

49. Thummel KE. A genetic test for immunosuppressant dose selection? Pharmacogenetics 2004;14:145-6.

101. http://www.imm.ki.se/CYPalleles/default.htm. 
118 


\section{Chapter}

Tacrolimus pharmacokinetics and pharmacogenetics: influence of adenosine triphosphate-binding cassette B1 (ABCB1) and cytochrome (CYP) 3A polymorphisms

Robert A.M. Op den Buijsch, Maarten H.L. Christiaans, Leo M.L. Stolk, Johan E. de Vries, Chi Yuen Cheung, Nas A. Undre, Johannes P. van Hooff, Marja P. van Dieijen-Visser, Otto Bekers

Fundamental \& Clinical Pharmacology, 2007;21:427-35 
Abstract

Background and aim

Tacrolimus, an immunosuppressant used after organ transplantation, has a narrow therapeutic range and its pharmacokinetic variability complicates its daily dose assessment. P-glycoprotein (P-gp), encoded by the adenosine triphosphate-binding cassette B1 (ABCB1) and the cytochrome (CYP) 3A4 and 3A5 enzymes appear to play a role in the tacrolimus metabolism.

Materials and methods

In the present study, two different renal transplant recipients groups are used to examine the influence of $A B C B 1$ and CYP3A polymorphisms on the daily tacrolimus dose and several pharmacokinetic parameters. In total 63 Caucasian renal transplant recipients divided into 26 early and 37 late posttransplant recipients were genotyped for ABCB1 and CYP3A polymorphisms. The pharmacokinetic parameters of tacrolimus were determined for all renal transplant recipients and correlated with their corresponding genotypes.

\section{Results}

A significant difference in allele frequencies of the CYP3A4*1B $(P=0.028)$ and CYP3A5*1 $(P=0.022)$ alleles was observed between the early and late posttransplant recipient group. Significant higher dose-normalized trough levels $\left(\mathrm{dnC}_{0}\right)$, dosenormalized area under the curve $\left(\mathrm{dnAUC}_{0-12}\right)$, and dose-normalized maximum concentration $\left(\mathrm{dnC}_{\max }\right)$ were observed for carriers of the CYP3A5*3 variant allele in the two renal transplant patient groups. Except for the daily tacrolimus dose $(P=0.025)$ no significant differences were observed for carriers of the CYP3A4*1B variant allele. Neither the individual $A B C B 1$ polymorphisms nor the $A B C B 1$ haplotypes were associated with any pharmacokinetic parameter.

\section{Conclusion}

We noticed that a complete pharmacokinetic profile is more frequently requested for renal transplant recipients carrying a CYP $3 A 5^{*} 1$ allele suggesting that these patients have more difficulties in achieving and maintaining tacrolimus concentrations compared to homozygous carriers of the CYP $3 \mathrm{~A}^{\star} 3$ variant allele. Additionally, patients carrying a CYP3A5*1 allele require a twofold higher tacrolimus dose compared to homozygous carriers of the CYP3A5*3 variant allele to maintain the target dnAUC 0 -12. Therefore, genotyping for the CYP3A5*3 variant allele can contribute to a better and more individualized immunosuppressive therapy in transplant patients. 


\section{Introduction}

The immunosuppressant tacrolimus is used worldwide in transplant patients although its narrow therapeutic window and high pharmacokinetic variability complicate the establishment of a dosage regime ${ }^{1,2}$. Therefore, close therapeutic drug monitoring for tacrolimus is required to prevent the risk of subtherapeutic or toxic blood concentrations. Subtherapeutic tacrolimus blood concentrations increase the risk of transplant rejection enormously $^{3-5}$, while high tacrolimus blood concentrations may lead to severe side effects such as nephrotoxicity, neurotoxicity and hyperglycemia ${ }^{6-8}$. Tacrolimus is like numerous other clinically used drugs, a substrate for P-glycoprotein ( $P$-gp) and cytochrome P450 3A (CYP3A) enzymes. P-gp is encoded by the adenosine triphosphate (ATP)-binding cassette $B 1$ (ABCB1) gene and co-expressed with the CYP3A enzymes in the liver and intestines. CYP3A4 and CYP3A5 are the most important members of the CYP3A subfamily ${ }^{9,10}$. The differences in expression levels and activity of $A B C B 1$ and CYP3A may explain the interindividual variations in the tacrolimus pharmacokinetics. P-gp is an ATP-dependent membranous transporter that contributes to the protection of the body from environmental toxins and drugs like tacrolimus by limiting their absorption from the intestine and promoting the efflux into bile and urine ${ }^{11}$. Three partly linked polymorphisms in the ABCB1 gene located on exons 12, 21 and 26 have been studied extensively. Two of these ABCB1 polymorphisms, C1236T and $\mathrm{C} 3435 \mathrm{~T}$, result in silent mutations while the ABCB1 G2677T/A polymorphism in exon 21 is non-synonymous and results in an amino acid exchange (Ala893Ser/Thr). A number of studies found no association between the $A B C B 1$ genotypes and tacrolimus trough $\left(C_{0}\right)$ concentrations $^{12-17}$ or the pharmacokinetic parameters: area under the time tacrolimus concentration curve $\left(A \cup C_{0-12}\right)$, the maximum concentration $\left(\mathrm{C}_{\max }\right)$, the time that the maximum concentration is reached $\left(T_{\max }\right)$ and the half-life time $\left(t_{1 / 2}\right)^{18,19}$. However, some other studies found an association between the tacrolimus $\mathrm{C}_{0}$ concentrations, the daily tacrolimus dose and individual $A B C B 1$ polymorphisms ${ }^{20,21}$ or the $A B C B 1$ haplotypes ${ }^{22}$. Homozygotes for the CYP3A4*1B and CYP3A5*3 variant allele carry at position -392 an $A$ and at position 6986 a G, respectively. Moreover, homozygotes for the CYP3A4*1B variant allele show an altered CYP3A4 enzyme activity while homozygotes for the CYP3A5*3 variant allele show no CYP3A5 enzyme activity. A number of studies already demonstrated the impact of the CYP3A5*3 variant allele on tacrolimus $C_{0}$ concentrations ${ }^{12-17,23-25}$, the pharmacokinetic parameters: $\mathrm{AUC}_{0-12}, \mathrm{C}_{\max }, \mathrm{T}_{\max }, \mathrm{t}_{1 / 2}{ }^{18,19}$ and the daily tacrolimus dose in different transplant patient groups. However, the influence of CYP3A4*1B and ABCB1 $\mathrm{C} 1236 \mathrm{~T}$ variant alleles on these pharmacokinetic parameters of tacrolimus has never been examined. In the present study, a complete 12 hour pharmacokinetic profile is recorded for all transplant patients and the influence of several clinical and genetic parameters is determined on the variation in pharmacokinetic parameters of tacrolimus in an early and a late posttransplant recipient group. Additionally, the association will be examined between the CYP3A4 A-392G, CYP3A5 A6986G, CYP3AP1 G-44A 
polymorphisms and the three ABCB1 polymorphisms C1236T, G2677T/A, C3435T on the pharmacokinetic parameters in the same renal transplant recipient groups.

\section{Patients and methods}

\section{Study population}

In total 63 Caucasian renal transplant recipients of whom a complete 12 hour time tacrolimus concentration curve was performed were divided over two different groups. Table 8.1 illustrates that most pharmacokinetic profiles of the patients included in group I were recorded within 6 weeks after transplantation, while group II included patients that underwent a renal transplantation at least 1 year ago. Moreover, in group I eight patients used calcium channel blockers which are known to interact with tacrolimus, whereas patients included in group II used no medication known to interfere with tacrolimus. In addition, patients that suffer from gastrointestinal, liver disease or other disorders that may alter the absorption of tacrolimus were disqualified for inclusion in both groups. Prior to the blood sample collection, there had been no tacrolimus dose change for at least three days in the two groups. After overnight fasting the blood samples were collected immediately pre $\left(\mathrm{C}_{0}\right)$ and $0.5\left(\mathrm{C}_{0.5}\right), 1\left(\mathrm{C}_{1}\right), 2\left(\mathrm{C}_{2}\right), 3\left(\mathrm{C}_{3}\right), 4\left(\mathrm{C}_{4}\right)$, $5\left(\mathrm{C}_{5}\right), 7.5\left(\mathrm{C}_{7.5}\right)$ and $12\left(\mathrm{C}_{12}\right)$ hours after the morning tacrolimus administration. Patients were not allowed to take food until 1 hour after ingesting the tacrolimus dose and were advised to avoid grapefruit juice after transplantation to prevent alterations in the tacrolimus metabolism. Demographic as well as clinical data were determined at the time of recording the 12 hour time tacrolimus concentration curve.

\section{Ethics}

The study was performed in accordance to the Declaration of Helsinki and its amendments. The protocol was approved by the local Medical Ethics Committee and written informed consent for participation in this study was obtained from all patients.

\section{Tacrolimus concentration determinations}

The tacrolimus blood concentrations were determined in ethylene diamine tetra-acetic acid (EDTA) whole blood, using a microparticle enzyme immunoassay with a monoclonal antibody (IMx II assay; Abbott Laboratories, Abbott Park, IL, USA) for group I and a method based on high pressure liquid chromotography (HPLC) tandem mass spectrometry (MS/MS) for group II. The laboratories in which the tacrolimus concentrations have been determined participate in the International Tacrolimus Proficiency Testing Scheme. 
Table 8.1 Demographic characteristics of the two renal transplant recipients groups.

\begin{tabular}{|c|c|c|}
\hline Demographic characteristics & Group I & Group II \\
\hline Gender (male/female) & $18 / 8$ & $24 / 13$ \\
\hline Age (years, mean \pm SD) & $43.0 \pm 13.2$ & $51.3 \pm 10.9$ \\
\hline Body Mass Index $\left(\mathrm{kg} / \mathrm{m}^{2}\right.$, mean $\left.\pm \mathrm{SD}\right)$ & $23.3 \pm 4.40$ & $25.6 \pm 3.42$ \\
\hline \multicolumn{3}{|l|}{ Primary kidney disease } \\
\hline Glomerulonephritis & 4 & 1 \\
\hline Chronic pyelonephritis & 2 & 2 \\
\hline IgA nephropathy & 3 & 4 \\
\hline Hypertensive nephropathy & 4 & 7 \\
\hline Diabetes Mellitus nephropathy & 4 & 0 \\
\hline Polycystic kidney disease & 1 & 8 \\
\hline Unknown & 1 & 4 \\
\hline Other & 7 & 11 \\
\hline \multicolumn{3}{|l|}{ Transplantation number } \\
\hline First & 20 & 30 \\
\hline Second & 5 & 6 \\
\hline Third or more & 1 & 1 \\
\hline Tacrolimus mono therapy & 1 & 29 \\
\hline Tacrolimus dose (mg/kg/day, mean \pm SD) & $0.39 \pm 0.231$ & $0.054 \pm 0.029$ \\
\hline $\mathrm{C}_{0}(\mathrm{ng} / \mathrm{ml}$, mean $\pm \mathrm{SD})$ & $16.8 \pm 5.83$ & $6.59 \pm 1.39$ \\
\hline $\mathrm{AUC}_{0-12}(\mathrm{ng} \times \mathrm{hr} / \mathrm{ml}$, mean $\pm \mathrm{SD})$ & $305.0 \pm 96.8$ & $122.5 \pm 31.1$ \\
\hline $\mathrm{C}_{\max }(\mathrm{ng} / \mathrm{ml}$, mean $\pm \mathrm{SD})$ & $56.3 \pm 21.3$ & $20.9 \pm 6.5$ \\
\hline $\mathrm{T}_{\max }(\mathrm{hr}$, mean $\pm \mathrm{SD})$ & $1.46 \pm 1.33$ & $1.24 \pm 0.43$ \\
\hline Use of azothiopurine, $\mathrm{MMF}^{\mathrm{a}}$, rapamycine, steroids & $11 / 3 / 4 / 26$ & $3 / 4 / 0 / 0$ \\
\hline \multicolumn{3}{|l|}{ Current steroid dose (mg, dose, no. patients) } \\
\hline 0 mg/day & 3 & 37 \\
\hline $5 \mathrm{mg} / \mathrm{day}$ & 2 & 0 \\
\hline 8 mg/day & 2 & 0 \\
\hline $10 \mathrm{mg} / \mathrm{day}$ & 10 & 0 \\
\hline 15 mg/day & 4 & 0 \\
\hline 20 mg/day & 3 & 0 \\
\hline$>20 \mathrm{mg} / \mathrm{day}$ & 2 & 0 \\
\hline Time since transplantation (days, median, (range)) & $16(3-74)$ & $1465(453-4128)$ \\
\hline Haemoglobin (mmol/l, mean \pm SD; ref. ${ }^{\lambda} 8.2-11.0$, , $7.3-9.7$ ) & $5.43 \pm 1.08$ & $8.52 \pm 0.83$ \\
\hline Haematocrit (mean \pm SD; ref. ô 0.41-0.52, ㅇ 0.36-0.48) & $0.25 \pm 0.07$ & $0.41 \pm 0.04$ \\
\hline ALAT (U/I, mean \pm SD; ref. $\left.\sigma^{\lambda<45, ~}+<35\right)$ & $34 \pm 34$ & $24 \pm 13$ \\
\hline Serum albumin (g/l, mean \pm SD; ref. 34-45) & $30.7 \pm 3.86$ & $37.0 \pm 3.84$ \\
\hline Serum creatinine ( $\mu \mathrm{mol} / \mathrm{l}$, mean $\pm \mathrm{SD}$; ref. $\widehat{\lambda} 71-110$, q 53-97) & $331 \pm 293$ & $128 \pm 29$ \\
\hline Creatinine clearance $^{b}(\mathrm{ml} / \mathrm{min}$, mean \pm SD; ref. 90-140) & $37.5 \pm 28.4$ & $58.0 \pm 26.6$ \\
\hline
\end{tabular}

ref. are the reference values applied in the clinical chemistry and haematology laboratory of the University Hospital Maastricht. $\delta^{\lambda}$ male, $\rho$ female, ${ }^{a}$ MMF is mycophenolate mofetil, ${ }^{b}$ The creatinine clearance is determined with the Cockcroft-Gault equation.

The tacrolimus $\mathrm{C}_{0}$ concentration and the peak tacrolimus blood concentration $\left(\mathrm{C}_{\max }\right)$ during the assessed time interval were determined directly from the time versus tacrolimus blood concentration data. Additionally, the area under the time tacrolimus concentration curve $\left(\mathrm{AUC}_{0-12}\right)$ was calculated from the time versus tacrolimus concentration plot using the linear trapezoidal rule in MWPharm 3.50 (Mediware, Groningen, the Netherlands). Dose-normalized (Dn) $C_{0}$, dose-normalized (dn)AUC $\mathrm{C}_{0-12}$ 
and dose-normalized $(\mathrm{dn}) \mathrm{C}_{\max }$ were calculated by dividing the $\mathrm{C}_{0}, \mathrm{AUC}_{0-12}$ and $\mathrm{C}_{\max }$, respectively, by the corresponding morning dose on a milligram per kilogram basis.

\section{DNA isolation}

Genomic DNA isolation was performed on 63 renal transplant recipients by using $200 \mu \mathrm{l}$ EDTA anti-coagulated blood for isolation with a QIAamp blood mini kit (Qiagen, Leusden, the Netherlands) according to the manufacturers' instructions.

\section{Genotyping of ABCB1 and CYP3A gene polymorphisms}

Real-time polymerase chain reaction (PCR) fluorescence resonance energy transfer (FRET) assays were used for genotyping, ABCB1 G2677T/A, ABCB1 C3435T, CYP3A4 A-392G and CYP3AP1 G-44A using the same primers and probes compared to the original publications ${ }^{26-29}$. Regarding the ABCB1 C1236T and CYP3A5 A6986G polymorphisms real-time PCR FRET assays were used as we described earlier ${ }^{30}$. For each polymorphism, heterozygote samples were sequenced according to a direct sequence procedure on a capillary sequencer $\mathrm{ABI}$ Prism $3100^{\circledR}$ using the Bridge version 1.1 sequence kit (both products from Applied Biosystems, Fostercity, USA) and used in every real-time PCR FRET assay run as control sample.

\section{Statistical analysis}

Statistical analysis of the data was performed with use of the statistical software SPSS 11.0 for windows (Chicago, IL, USA). Correlations between pharmacokinetic parameters and clinical variables were evaluated using stepwise multiple regression analysis. To examine the population homogeneity of the patients, the genotype frequencies of the ABCB1 and CYP3A polymorphisms were tested against Hardy-Weinberg equilibrium by the Pearson's goodness-of-fit test ${ }^{31}$. Allele frequencies of the early and late posttransplant recipient group were compared using the $\chi^{2}$ test. For analysis of the daily tacrolimus dose $\left(\mathrm{mg} / \mathrm{kg} /\right.$ day), $\mathrm{dnC}_{0}(\mathrm{ng} / \mathrm{ml}$ per $\mathrm{mg} / \mathrm{kg})$, dnAUC ${ }_{0-12}(\mathrm{ng} \times \mathrm{hr} / \mathrm{ml}$ per $\mathrm{mg} / \mathrm{kg})$, and $\mathrm{dnC}_{\max }(\mathrm{ng} / \mathrm{ml}$ per $\mathrm{mg} / \mathrm{kg})$, groups were compared using non parametric statistical tests. To compare two groups we used the Mann-Whitney test, and to compare several groups the Kruskal Wallis test. $P$ values less than 0.05 were considered statistically significant. All values are expressed as median and range unless stated otherwise. 


\section{Results}

\section{Influence of clinical and genetic parameters on the variation in pharmacokinetic tacrolimus parameters}

The characteristics of the early posttransplant (group I) as well as the late posttransplant (group II) recipients that were enrolled in our study are shown in Table 8.1.

Tabel 8.2 Influence of independent clinical and genetic parameters on the pharmacokinetic parameters of an early (group I) and a late (group II) posttransplant recipient group.

\begin{tabular}{|c|c|c|c|c|}
\hline Group & Dependent parameter & Independent parameter & Partial $r^{2}$ & ${ }^{a} P$ value \\
\hline I & Tacrolimus dose & $\begin{array}{l}\text { CYP3A5 A6986G polymorphism } \\
\text { Model } r^{2}: 0.531\end{array}$ & 0.531 & $<0.001$ \\
\hline \multirow[t]{2}{*}{ I } & \multirow[t]{2}{*}{$\mathrm{DnC}_{0}$} & Time since transplantation & 0.613 & $<0.001$ \\
\hline & & $\begin{array}{l}\text { Haemoglobin } \\
\text { Model } r^{2}: 0.692\end{array}$ & 0.079 & $<0.001$ \\
\hline \multirow[t]{2}{*}{ I } & \multirow[t]{2}{*}{ DnAUC $_{0-12}$} & Time since transplantation & 0.528 & $<0.001$ \\
\hline & & $\begin{array}{l}\text { Haemoglobin } \\
\text { Model } r^{2}: 0.620\end{array}$ & 0.092 & $<0.001$ \\
\hline \multirow[t]{2}{*}{ I } & \multirow[t]{2}{*}{$\mathrm{DnC}_{\max }$} & Time since transplantation & 0.405 & $<0.001$ \\
\hline & & $\begin{array}{l}\text { Haemoglobin } \\
\text { Model } r^{2}: 0.635\end{array}$ & 0.230 & $<0.001$ \\
\hline II & Tacrolimus dose & $\begin{array}{l}\text { CYP3A5 A6986G polymorphism } \\
\text { Model } r^{2}: 0.354\end{array}$ & 0.354 & $<0.001$ \\
\hline \multirow[t]{4}{*}{ II } & \multirow[t]{4}{*}{$\mathrm{DnC}_{0}$} & CYP3A5 A6986G polymorphism & 0.175 & 0.010 \\
\hline & & Body mass index (BMI) & 0.157 & 0.001 \\
\hline & & Gender & 0.086 & $<0.001$ \\
\hline & & Model $r^{2}: 0.418$ & & \\
\hline \multirow[t]{2}{*}{ II } & \multirow[t]{2}{*}{ DnAUC $_{0-12}$} & CYP3A5 A6986G polymorphism & 0.190 & 0.007 \\
\hline & & $\begin{array}{l}\text { Body mass index (BMI) } \\
\text { Model } r^{2}: 0.335\end{array}$ & 0.145 & 0.001 \\
\hline \multirow[t]{4}{*}{ II } & \multirow[t]{4}{*}{$\mathrm{DnC}_{\max }$} & CYP3A5 A6986G polymorphism & 0.226 & 0.003 \\
\hline & & Body mass index (BMI) & 0.109 & 0.001 \\
\hline & & Serum Albumin & 0.077 & $<0.001$ \\
\hline & & Model $r^{2}: 0.412$ & & \\
\hline
\end{tabular}

$P$ value belonging to the partial $r^{2}$. $\mathrm{DnC}_{0}$, dose-normalized trough level, $\mathrm{dnAUC}_{0-12}$, dose-normalized area under the curve, $\mathrm{DnC}_{\max }$ dose-normalized maximum concentration. Tested independent parameters were gender, age, body mass index (BMI), haemoglobin, haematocrit, ALAT, serum albumin, serum creatinine, creatinine clearance (Cockcroft-Gault), CYP3A4 A-392G, CYP3A5 A6986G, ABCB1 C1236T, G2677T/A, C3435T.

The influence of different clinical (gender, age, body mass index (BMI), haemoglobin, haematocrit, ALAT, serum albumin, serum creatinine, creatinine clearance) and genetic (CYP3A4 A-392G, CYP3A5 A6986G, ABCB1 C1236T, G2677T/A, C3435T) parameters is examined on the variation in the tacrolimus pharmacokinetic parameters in all posttransplant recipients. Table 8.2 illustrates the influence of independent clinical and genetic parameters on the variability of pharmacokinetic tacrolimus parameters. In the 
early posttransplant recipient group the time since transplantation and the haemoglobin concentration correlate significantly with $\mathrm{dnC}_{0}, \mathrm{dnAUC}_{0-12}$ and $\mathrm{dnC}_{\max }$ whereas the CYP3A5 A6986G polymorphism and the body mass index (BMI) have a significant contribution on the variability of $\mathrm{dnC}_{0}, \mathrm{dnAUC}_{0-12}$ and $\mathrm{dnC}_{\max }$ in the late posttransplant recipient group. The clinical and genetic parameters: age, haematocrit, ALAT, serum creatinine, creatinine clearance and the polymorphisms CYP3A4 A-392G, ABCB1 C1236T, ABCB1 G2677T/A and ABCB1 C3435T show no significant correlation with any of the pharmacokinetic parameters in both renal transplant recipient groups.

\section{Allele distribution of the different ABCB1 and CYP3A polymorphisms}

Table 8.3 and 8.4 show the genotype frequencies of the different CYP3A and CYP3AP1 polymorphisms that were determined for the 26 early and 37 late posttransplant recipients. The genotype frequencies of the two renal transplant recipient groups were not significantly different from that predicted by the Hardy-Weinberg equation.

Table 8.3 Influence of ABCB1, CYP3A and CYP3AP1 allelic variants on the pharmacokinetic tacrolimus parameters of the early posttransplant recipients.

\begin{tabular}{lcccccc}
\hline Genotype & $\begin{array}{r}\mathrm{N} \\
\text { No }\end{array}$ & $\begin{array}{c}\text { Allelic } \\
\text { status }\end{array}$ & Dose & DnC $_{0}$ & DnAUC $_{0-12}$ & DnC $_{\max }$ \\
\hline CYP3A4 & 21 & ${ }^{*} 1 \mathrm{~A}^{*} 1 \mathrm{~A}$ & $0.28(0.04-0.80)^{\mathrm{a}}$ & $90(40-1329)$ & $1782(824-15721)$ & $383(89-1535)$ \\
A-392G & 5 & ${ }^{*} 1 \mathrm{~A}^{*} 1 \mathrm{~B}$ & $0.50(0.43-0.79)^{\mathrm{a}}$ & $59(32-107)$ & $1275(922-1796)$ & $216(184-338)$ \\
& 0 & ${ }^{*} 1 \mathrm{~B} /{ }^{*} 1 \mathrm{~B}$ & ---- & ---- & ---- & - \\
CYP3A5 & 1 & ${ }^{*} 1 /^{*} 1$ & 0.78 & 32 & 922 & 184 \\
A6986G & 9 & ${ }^{*} 1 /^{*} 3$ & $0.50(0.35-0.80)^{\mathrm{a}}$ & $59(40-107)^{\mathrm{a}}$ & $1220(824-1796)^{\mathrm{a}}$ & $216(89-380)^{\mathrm{a}}$ \\
& 16 & ${ }^{*} 3 /^{*} 3$ & $0.25(0.04-0.59)^{\mathrm{a}}$ & $118(45-1329)^{\mathrm{a}}$ & $1975(839-15721)^{\mathrm{a}}$ & $435(90-1535)^{\mathrm{a}}$ \\
CYP3AP1 & 1 & $\mathrm{G} / \mathrm{G}$ & 0.78 & 32 & 922 & 184 \\
G-44A & 10 & $\mathrm{G} / \mathrm{A}$ & $0.49(0.12-0.80)^{\mathrm{a}}$ & $60(40-107)^{\mathrm{a}}$ & $1248(824-1796)^{\mathrm{a}}$ & $236(89-381)^{\mathrm{a}}$ \\
& 15 & $\mathrm{~A} / \mathrm{A}$ & $0.25(0.04-0.59)^{\mathrm{a}}$ & $123(45-1329)^{\mathrm{a}}$ & $2030(839-15721)^{\mathrm{a}}$ & $454(90-1535)^{\mathrm{a}}$ \\
\hline
\end{tabular}

Tacrolimus dose (mg/kg/day), $\mathrm{dnC}_{0}$, dose-normalized trough concentration ( $\mathrm{ng} / \mathrm{ml} \mathrm{per} \mathrm{mg} / \mathrm{kg}$ ), $\mathrm{dnAUC}_{0-12}(\mathrm{ng} \times \mathrm{hr} / \mathrm{ml}$ per $\mathrm{mg} / \mathrm{kg})$ dose-normalized area under the curve, $\mathrm{dnC}_{\max }$ dose-normalized maximum concentration ( $\mathrm{ng} / \mathrm{ml}$ per $\mathrm{mg} / \mathrm{kg}$ ). Values are indicated as median and (range), ${ }^{a} P<0.05$; (Mann-Whitney).

\section{Effect of ABCB1 and CYP3A polymorphisms on the daily tacrolimus dose and the pharmacokinetic parameters}

As is demonstrated in Table 8.5 and Table 8.6, we found that neither the individual $A B C B 1$ polymorphisms nor the $A B C B 1$ haplotypes are associated with the daily tacrolimus dose and the pharmacokinetic parameters; $\mathrm{dnC}_{0}, \mathrm{dnAUC}_{0-12}$ and $\mathrm{dnC}_{\max }$.

Table 8.3 shows a trend between the heterozygote carriers of the CYP3A4*1B variant allele in both the daily tacrolimus dose and the pharmacokinetic tacrolimus parameters compared to the homozygote carriers of the CYP3A4*1A allele. However, except for the daily tacrolimus dose (0.28 versus $0.50 \mathrm{mg} / \mathrm{kg} / \mathrm{day}$; Mann-Whitney, $P=0.025)$ no 
significant differences are found between the pharmacokinetic parameters for tacrolimus and the different CYP3A4 A-392G genotypes in the early posttransplant recipient group.

Table 8.4 Influence of ABCB1, CYP3A and CYP3AP1 allelic variants on the pharmacokinetic tacrolimus parameters of the late posttransplant recipients.

\begin{tabular}{|c|c|c|c|c|c|c|}
\hline Genotype & $\begin{array}{l}\mathrm{N} \\
\text { No }\end{array}$ & $\begin{array}{l}\text { Allelic } \\
\text { status }\end{array}$ & Dose & $\mathrm{DnC}_{0}$ & $\operatorname{DnAUC}_{0-12}$ & $\mathrm{DnC}_{\max }$ \\
\hline CYP3A4 & 36 & $* 1 \mathrm{~A} /{ }^{*} 1 \mathrm{~A}$ & $0.05(0.02-0.14)$ & 276 (70-669) & 4642 (1355-11994) & 775 (294-1729) \\
\hline A-392G & 1 & $* 1 \mathrm{~A} /{ }^{*} 1 \mathrm{~B}$ & 0.067 & 121 & 2766 & 504 \\
\hline & 0 & *1B/*1B & ---- & ----- & ----- & ----- \\
\hline CYP3A5 & 0 & $* 1 / * 1$ & ---- & ---- & ---- & ---- \\
\hline A6986G & 5 & $* 1 / * 3$ & $0.10(0.05-0.14)^{a}$ & $87.4(70-248)^{a}$ & $1663(1355-4057)^{a}$ & $461(294-646)^{a}$ \\
\hline & 32 & ${ }^{*} 3 /{ }^{*} 3$ & $0.04(0.02-0.11)^{a}$ & $287(118-669)^{a}$ & $4808(2227-11994)^{a}$ & $814(465-1729)^{\mathrm{a}}$ \\
\hline CYP3AP1 & 0 & $\mathrm{G} / \mathrm{G}$ & ----- & ----- & ---- & ---- \\
\hline G-44A & $\begin{array}{c}8 \\
29\end{array}$ & $\begin{array}{l}G / A \\
A / A\end{array}$ & $\begin{array}{l}0.07(0.02-0.14)^{\mathrm{a}} \\
0.04(0.02-0.11)^{\mathrm{a}}\end{array}$ & $\begin{array}{c}161(70-669)^{\mathrm{a}} \\
283(118-640)^{\mathrm{a}}\end{array}$ & $\begin{array}{l}2990(1355-11994)^{a} \\
4761(2227-11504)^{a}\end{array}$ & $\begin{array}{l}544(294-1729)^{\mathrm{a}} \\
810(465-1493)^{\mathrm{a}}\end{array}$ \\
\hline
\end{tabular}

Tacrolimus dose $(\mathrm{mg} / \mathrm{kg} / \mathrm{day}), \mathrm{dnC}_{0}$, dose-normalized trough concentration $(\mathrm{ng} / \mathrm{ml} \mathrm{per} \mathrm{mg} / \mathrm{kg})$, $\mathrm{dnAUC}_{0-12}(\mathrm{ng} \times \mathrm{hr} / \mathrm{ml}$ per $\mathrm{mg} / \mathrm{kg})$ dose-normalized area under the curve, $\mathrm{dnC}_{\max }$ dose-normalized maximum concentration ( $\mathrm{ng} / \mathrm{ml}$ per $\mathrm{mg} / \mathrm{kg}$ ). Values are indicated as median and (range), ${ }^{\mathrm{a}} P<0.05$; (Mann-Whitney).

Additionally, Table 8.3 demonstrates a significant decrease in the pharmacokinetic tacrolimus parameters $\mathrm{dnC}_{0}, 118$ versus $59 \mathrm{ng} / \mathrm{ml}$ per mg/kg; dnAUC $0-121975$ versus $1220 \mathrm{ng} \times \mathrm{hr} / \mathrm{ml}$ per $\mathrm{mg} / \mathrm{kg}$; and $\mathrm{dnC}_{\max } 435$ versus $216 \mathrm{ng} / \mathrm{ml}$ per $\mathrm{mg} / \mathrm{kg}$ when renal transplant recipients were carrier of none or one CYP3A5*1 allele, respectively. Consequently, the daily tacrolimus dose is significantly higher in heterozygous carriers of the CYP3A5*3 variant allele compared to homozygous carriers of the CYP $3 A 5^{\star} 3$ variant allele ( 0.50 versus $0.25 \mathrm{mg} / \mathrm{kg} / \mathrm{day}$; Mann-Whitney, $P=0.001)$. Regarding the late posttransplant recipients included in group II, a similar genetic effect is found for CYP3A5*1 allele in association with the pharmacokinetic tacrolimus parameters and the daily tacrolimus dose, as is shown in Table 8.4. Because there is only one heterozygous carrier of the CYP3A4*1B variant allele among the late posttransplant group, no statistical analyses could be performed between the CYP3A4*1B genotypes and the pharmacokinetic tacrolimus parameters. Although we observed a significant difference in the daily tacrolimus dose as well as in the $\mathrm{dnC}_{0}, \mathrm{dnAUC_{0-12 }}$ and $\mathrm{dnC}_{\max }$ for only the CYP3A5*3 variant allele, it is not clear whether the CYP3A4*1B variant allele has, similarly as the CYP3A5*3 variant allele, an important contribution to the pharmacokinetic variability of tacrolimus. Particularly, knowing that in this study all individuals carrying a CYP3A4*1B variant allele also carry at least one CYP3A5*1 allele. To examine the influence of the CYP3A4*1B variant allele solely, we selected those renal transplant recipients in group I that were heterozygous for the CYP3A5*1 allele. One renal transplant patient was heterozygote for the CYP3A4*1B variant allele and homozygote for the CYP3A5*1 allele. Five renal transplant patients were carrier of both one CYP3A4*1B variant allele and one CYP3A5*1 allele. Additionally, another four renal 
transplant recipients were homozygous for the CYP3A4*1A allele and heterozygous for one CYP3A5*1 allele. Figure 8.1 illustrates renal transplant recipients who are heterozygous for the CYP3A4*1B and CYP3A5*3 variant allele show no significantly higher daily tacrolimus dose or lower $\mathrm{dnAUC}_{0-12}$ compared to patients that were only heterozygous for the CYP3A4*1B variant allele.

Table 8.5 ABCB1 haplotypes related to tacrolimus dose requirement and dose-normalized $\mathrm{AUC}_{0-12}$ of the early posttransplant recipients.

\begin{tabular}{|c|c|c|c|c|c|}
\hline \multicolumn{3}{|c|}{ ABCB1 haplotypes } & $\mathrm{N}$ & Dose & $\mathrm{DnAUC}_{0-12}$ \\
\hline C1236T & G2677T/A & C3435T & No & (mg/kg/day) & $(\mathrm{ng} \times \mathrm{hr} / \mathrm{ml}$ per $\mathrm{mg} / \mathrm{kg})$ \\
\hline $\mathrm{CC}$ & GG & $\mathrm{CC}$ & 3 & $0.78(0.23-0.79)$ & $1333(922-1737)$ \\
\hline $\mathrm{CC}$ & GG & CT & 3 & $0.23(0.04-0.49)$ & $2030(1275-6186)$ \\
\hline $\mathrm{CC}$ & GA & CC & 2 & $0.34(0.04-0.65)$ & $8292(864-15721)$ \\
\hline CT & GT & $\mathrm{CC}$ & 1 & 0.46 & 1097 \\
\hline CT & GT & CT & 6 & $0.30(0.22-0.59)$ & $1570(1103-3032)$ \\
\hline CT & GT & TT & 3 & $0.28(0.25-0.42)$ & $1920(1821-2066)$ \\
\hline CT & GG & $\mathrm{CC}$ & 1 & 0.54 & 839 \\
\hline CT & GG & TT & 1 & 0.35 & 1321 \\
\hline TT & TT & TT & 6 & $0.40(0.07-0.80)$ & 1789 (824-8964) \\
\hline
\end{tabular}

Values are indicated as median and (range).

Table 8.6 ABCB1 haplotypes related to tacrolimus dose requirement and dose-normalized $A \cup C_{0-12}$ of the late posttransplant recipients

\begin{tabular}{|c|c|c|c|c|c|}
\hline \multicolumn{3}{|c|}{ ABCB1 haplotypes } & $\mathrm{N}$ & Dose & $\mathrm{DnAUC}_{0-12}$ \\
\hline C1236T & G2677T/A & C3435T & No & (mg/kg/day) & $(\mathrm{ng} \times \mathrm{hr} / \mathrm{ml}$ per $\mathrm{mg} / \mathrm{kg})$ \\
\hline $\mathrm{CC}$ & GG & $\mathrm{CC}$ & 3 & $0.03(0.02-0.04)$ & 8798 (5010-9320) \\
\hline $\mathrm{CC}$ & GG & CT & 7 & $0.06(0.03-0.08)$ & 4057 (2227-5216) \\
\hline $\mathrm{CC}$ & GG & TT & 3 & $0.04(0.02-0.06)$ & 4465 (3147-6854) \\
\hline $\mathrm{CC}$ & GA & $\mathrm{CC}$ & 1 & 0.07 & 3215 \\
\hline CT & GT & $\mathrm{CC}$ & 1 & 0.07 & 3081 \\
\hline CT & GT & CT & 13 & $0.05(0.02-0.13)$ & $4761(1355-9520)$ \\
\hline CT & GT & TT & 2 & $0.09(0.04-0.14)$ & $4571(1662-7481)$ \\
\hline TT & GT & CT & 1 & 0.05 & 4511 \\
\hline TT & TT & CT & 1 & 0.02 & 11504 \\
\hline TT & TT & TT & 5 & $0.04(0.02-0.07)$ & 4718 (2766-11994) \\
\hline
\end{tabular}

Values are indicated as median and (range). 

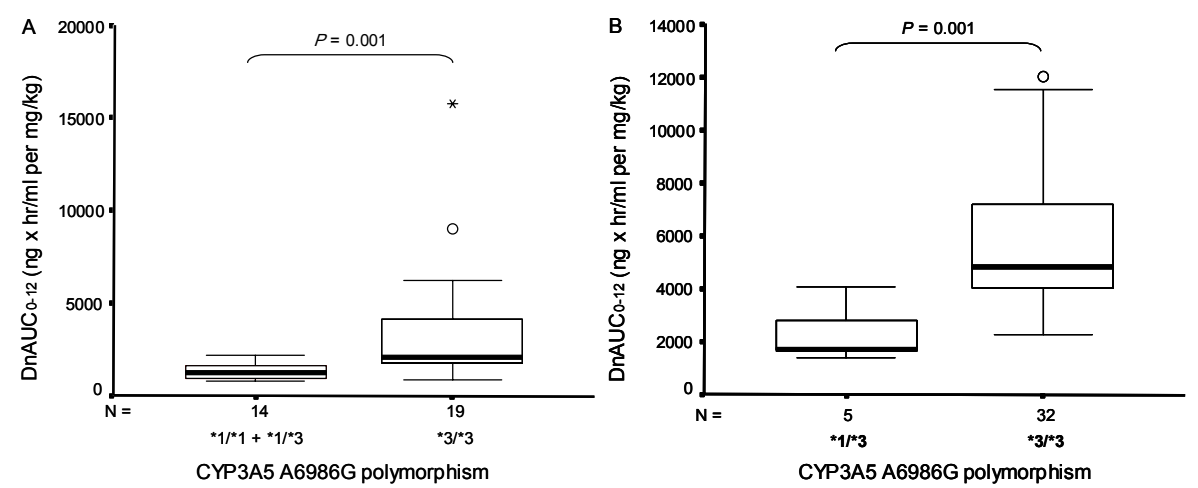

Figure 8.1 Boxplot of the distribution of $(A)$ the dose-normalized (Dn)AUC $\mathrm{C}_{0-12}(\mathrm{ng} \times \mathrm{hr} / \mathrm{ml}$ per $\mathrm{mg} / \mathrm{kg}$ ) and (B) the tacrolimus dose (mg/kg/day) clustered according to the combination of CYP3A4 A-392G and CYP3A5 A6986G genotypes. $P$ values are given for the pairwise comparisons of each genotype combination.

\section{Discussion}

In the early posttransplant recipient group the time since transplantation and the haemoglobin concentration contributes significantly to the variability of the pharmacokinetic tacrolimus parameters $\mathrm{dnC}_{0}, \mathrm{dnAU \textrm {C } _ { 0 - 1 2 }}$ and $\mathrm{dnC}_{\max }$ while in the late posttransplant recipient group the CYP3A5 A6986G polymorphism and the body mass index (BMI) have an important influence on the variability of different pharmacokinetic tacrolimus parameters. Previously, Haufroid et al. ${ }^{12}$ reported a significant contribution of the CYP3A5 A6986G polymorphism and the time since transplantation on the variation of tacrolimus $\mathrm{C}_{0}$ concentrations and the tacrolimus dose requirement. Additionally, we have also demonstrated in a stable Chinese renal transplant recipient population that the CYP3A5 A6986G polymorphism is the most significant independent variable when considering the daily tacrolimus dose as a dependent variable ${ }^{30}$. Kuypers et al. ${ }^{32}$ found higher tacrolimus peak concentrations for female renal transplant recipients compared to their male counterparts and a significantly higher tacrolimus $\mathrm{AUC}_{0-12}$ in female recipients six months after transplantation. Furthermore, Kuypers et al. ${ }^{32}$ found lower tacrolimus trough concentrations with increasing age. In the present study, a significantly higher allele frequency of the CYP3A4*1B and CYP3A5*1 allele is observed in the early renal transplant recipients compared to the late renal transplant recipients. The higher allele frequency for the CYP3A4*1B variant allele and CYP3A5*1 allele in the early renal transplant recipient group may partly clarify the difficulties in achieving and maintaining an optimal tacrolimus blood concentration. Although earlier studies ${ }^{20-22}$ reported a weak significant association between $A B C B 1$ genotypes or haplotypes with tacrolimus $\mathrm{C}_{0}$ concentrations of the transplant patients, no differences were found between either the different $A B C B 1$ polymorphisms or the $A B C B 1$ haplotypes and the 
pharmacokinetic tacrolimus parameters in the two renal transplant recipient groups. Recently, Fredericks et al. ${ }^{33}$ reported after examining 206 stable renal transplant recipients that the individual $A B C B 1$ polymorphisms and $A B C B 1$ haplotypes show a relatively minor association with the tacrolimus pharmacokinetics which implies that genotyping for $\mathrm{ABCB} 1$ polymorphisms seems to be of minor importance for predicting the daily tacrolimus dose regime. CYP3A enzymes are responsible for the most important metabolic route of tacrolimus, namely its demethylation to 13-Odemethyltacrolimus ${ }^{34-37}$. Due to the lack of CYP3A5 activity caused by the CYP3A5*3 variant allele, transplant patients who were homozygous for the CYP3A5*3 variant allele required an almost twofold lower daily tacrolimus dose and achieved even a higher $\mathrm{dnC}_{0}, \mathrm{dnAUC}_{0-12}$ and $\mathrm{dnC}_{\max }$ compared to the transplant recipients that carry at least one CYP3A5*1 allele. Although in the present study a trend is observed between the different CYP3A4 A-392G genotypes and the pharmacokinetic tacrolimus parameters, the contribution of this CYP3A4*1B variant allele seemed limited. After selecting two renal transplant recipient groups, one group with the genotype combination CYP3A4 ${ }^{*} 1 \mathrm{~A} /{ }^{*} 1 \mathrm{~A}-\mathrm{CYP} 3 \mathrm{~A} 5{ }^{*} 1 /{ }^{*} 3$ and another group with the genotype combination CYP3A4 ${ }^{*} 1 \mathrm{~A} /{ }^{*} 1 \mathrm{~B}-\mathrm{CYP} 3 \mathrm{~A} 5{ }^{*} 1 /{ }^{*} 3$, no significant differences were observed between these groups and the daily tacrolimus dose as well as the $\mathrm{dnC}_{0}, \mathrm{dnAUC}_{0-12}$ and $\mathrm{dnC}_{\max }$. This may indicate that the influence of the CYP3A4 *1B variant allele is restricted and that at least most of the genetic effect is being caused by the CYP3A5 A6986G polymorphism. These data seem to conflict with a previous study in which Hesselink et al. reported that the CYP3A4*1B variant allele has a significant influence on the daily tacrolimus dose despite they observed a $80 \%$ overlap between the CYP3A4*1B and CYP3A5*1 allele ${ }^{15}$. Although tacrolimus is a substrate of CYP3A4, our findings suggest that if there is an influence of this CYP3A4*1B polymorphism, it is probably caused by the high linkage between CYP3A4*1B and CYP3A5*1. Summarized, it appears that carriers of CYP3A5*1 allele included, in either the early or the late postransplant recipient group, show a twofold lower $\mathrm{dnC}_{0}, \mathrm{dnAUC}_{0-12}$ and $\mathrm{dnC}_{\max }$ for tacrolimus compared to homozygous carriers of a CYP $3 A 5^{\star} 3$ variant allele. Thus carriers of a CYP3A5* 1 allele require a twofold higher tacrolimus dose compared to homozygous carriers of a CYP $3 A 5 * 3$ variant allele. Therefore, we conclude that genotyping for the CYP $3 A 5^{\star} 3$ variant allele is of great value to determine the initial and maintenance oral tacrolimus dose. By doing so the risk of under- or over-immunosuppression in individual renal transplant recipients will be minimized. 


\section{References}

1. Spencer CM, Goa KL, Gillis JC. Tacrolimus. An update of its pharmacology and clinical efficacy in the management of organ transplantation. Drugs 1997;54:925-75.

2. Venkataramanan R, Swaminathan A, Prasad T, Jain A, Zuckerman S, Warty V, McMichael J, Lever J, Burckart G, Starzl T. Clinical pharmacokinetics of tacrolimus. Clin Pharmacokinet 1995:29:404-30.

3. Kershner RP, Fitzsimmons WE. Relationship of FK506 whole blood concentrations and efficacy and toxicity after liver and kidney transplantation. Transplantation 1996;62:920-6.

4. Laskow DA, Vincenti F, Neylan JF, Mendez R, Matas AJ. An open-label, concentrationranging trial of FK506 in primary kidney transplantation: a report of the United States Multicenter FK506 Kidney Transplant Group. Transplantation 1996;62:900-5.

5. Undre NA, van Hooff J, Christiaans M, Vanrenterghem $Y$, Donck J, Heeman U, Kohnle M, Zanker B, Land W, Morales JM, Andres A, Schafer A, Stevenson P. Low systemic exposure to tacrolimus correlates with acute rejection. Transplant Proc 1999;31:296-8.

6. McMaster P, Mirza DF, Ismail T, Vennarecci G, Patapis P, Mayer AD. Therapeutic drug monitoring of tacrolimus in clinical transplantation. Ther Drug Monit 1995;17:602-5.

7. Staatz CE, Tett SE. Clinical pharmacokinetics and pharmacodynamics of tacrolimus in solid organ transplantation. Clin Pharmacokinet 2004;43:623-53.

8. Winkler M, Christians U. A risk-benefit assessment of tacrolimus in transplantation. Drug Saf 1995;12:348-57.

9. Saeki T, Ueda K, Tanigawara Y, Hori R, Komano T. Human P-glycoprotein transports cyclosporin A and FK506. J Biol Chem 1993;268:6077-80.

10. Kamdem LK, Streit F, Zanger UM, Brockmoller J, Oellerich M, Armstrong VW, Wojnowski L. Contribution of CYP3A5 to the in vitro hepatic clearance of tacrolimus. Clin Chem 2005;51:1374-81.

11. Schwab M, Eichelbaum M, Fromm MF. Genetic polymorphisms of the human MDR1 drug transporter. Annu Rev Pharmacol Toxicol 2003; 43:285-307.

12. Haufroid V, Mourad M, Van Kerckhove V, Wawrzyniak J, De Meyer M, Eddour DC, Malaise J, Lison D, Squifflet JP, Wallemacq P. The effect of CYP3A5 and MDR1 (ABCB1) polymorphisms on cyclosporine and tacrolimus dose requirements and trough blood levels in stable renal transplant patients. Pharmacogenetics 2004;14:147-54.

13. Haufroid V, Wallemacq P, Vankerckhove V, Elens L, De Meyer M, Eddour DC, Malaise J, Lison D, Mourad M. CYP3A5 and ABCB1 Polymorphisms and Tacrolimus Pharmacokinetics in Renal Transplant Candidates: Guidelines from an Experimental Study. Am J Transplant 2006;6:2706-13.

14. Mai I, Perloff ES, Bauer S, Goldammer M, Johne A, Filler G, Budde K, Roots I. MDR1 haplotypes derived from exons 21 and 26 do not affect the steady-state pharmacokinetics of tacrolimus in renal transplant patients. Br J Clin Pharmacol 2004;58:548-53.

15. Hesselink DA, van Schaik RH, van der Heiden IP, van der Werf M, Gregoor PJ, Lindemans J, Weimar W, van Gelder T. Genetic polymorphisms of the CYP3A4, CYP3A5, and MDR-1 genes and pharmacokinetics of the calcineurin inhibitors cyclosporine and tacrolimus. Clin Pharmacol Ther 2003;74:245-54.

16. Mourad M, Wallemacq P, De Meyer M, Brandt D, Van Kerkhove V, Malaise J, Chaib Eddour $D$, Lison D, Haufroid V. The influence of genetic polymorphisms of cytochrome P450 3A5 and $A B C B 1$ on starting dose- and weight-standardized tacrolimus trough concentrations after kidney transplantation in relation to renal function. Clin Chem Lab Med 2006;44:1192-8.

17. Roy JN, Barama A, Poirier C, Vinet B, Roger M. Cyp3A4, Cyp3A5, and MDR-1 genetic influences on tacrolimus pharmacokinetics in renal transplant recipients. Pharmacogenet Genomics 2006;16:659-65.

18. Tsuchiya N, Satoh S, Tada H, Li Z, Ohyama C, Sato K, Suzuki T, Habuchi T, Kato T. Influence of CYP3A5 and MDR1 (ABCB1) polymorphisms on the pharmacokinetics of tacrolimus in renal transplant recipients. Transplantation 2004;78:1182-7. 
19. Tada H, Tsuchiya N, Satoh S, Kagaya H, Li Z, Sato K, Miura M, Suzuki T, Kato T, Habuchi T. Impact of CYP3A5 and MDR1(ABCB1) C3435T polymorphisms on the pharmacokinetics of tacrolimus in renal transplant recipients. Transplant Proc 2005;37:1730-2.

20. MacPhee IA, Fredericks S, Tai T, Syrris P, Carter ND, Johnston A, Goldberg L, Holt DW. Tacrolimus pharmacogenetics: polymorphisms associated with expression of cytochrome p4503A5 and P-glycoprotein correlate with dose requirement. Transplantation 2002;74: 1486-9.

21. Asano $\mathrm{T}$, Nishimoto $\mathrm{K}$, Hayakawa $\mathrm{M}$. Increased tacrolimus trough levels in association with severe diarrhea, a case report. Transplant Proc 2004;36:2096-7.

22. Anglicheau D, Verstuyft C, Laurent-Puig P, Becquemont L, Schlageter MH, Cassinat B, Beaune $P$, Legendre $C$, Thervet $E$. Association of the multidrug resistance-1 gene singlenucleotide polymorphisms with the tacrolimus dose requirements in renal transplant recipients. J Am Soc Nephrol 2003;14:1889-96.

23. MacPhee IA, Fredericks S, Mohamed M, Moreton M, Carter ND, Johnston A, Goldberg L, Holt DW. Tacrolimus pharmacogenetics: the CYP3A5*1 allele predicts low dose-normalized tacrolimus blood concentrations in whites and South Asians. Transplantation 2005;79: 499-502.

24. Zhao Y, Song M, Guan D, Bi S, Meng J, Li Q, Wang W. Genetic polymorphisms of CYP3A5 genes and concentration of the cyclosporine and tacrolimus. Transplant Proc 2005;37: $178-81$.

25. Zhang X, Liu ZH, Zheng JM, Chen ZH, Tang Z, Chen JS, Li LS. Influence of CYP3A5 and MDR1 polymorphisms on tacrolimus concentration in the early stage after renal transplantation. Clin Transplant 2005;19:638-43.

26. Dally H, Bartsch H, Jager B, Edler L, Schmezer P, Spiegelhalder B, Dienemann H, Drings $P$, Kayser K, Schulz V, Risch A. Genotype relationships in the CYP3A locus in Caucasians. Cancer Lett 2004;207:95-9.

27. Nauck M, Stein U, von Karger S, Marz W, Wieland H. Rapid detection of the C3435T polymorphism of multidrug resistance gene 1 using fluorogenic hybridization probes. Clin Chem 2000;46:1995-7.

28. von Ahsen N, Richter M, Grupp C, Ringe B, Oellerich M, Armstrong VW. No influence of the MDR-1 C3435T polymorphism or a CYP3A4 promoter polymorphism (CYP3A4-V allele) on dose-adjusted cyclosporin $A$ trough concentrations or rejection incidence in stable renal transplant recipients. Clin Chem 2001;47:1048-52.

29. Arjomand-Nahad F, Diefenbach K, Landt O, Gaikovitch E, Roots I. Genotyping of the triallelic variant G2677T/A in MDR1 using LightCycler with locked-nucleic-acid-modified hybridization probes. Anal Biochem 2004;334:201-3.

30. Cheung CY, Op den Buijsch RA, Wong KM, Chan HW, Chau KF, Li CS, Leung KT, Kwan TH, de Vrie JE, Wijnen PA, van Dieijen-Visser MP, Bekers O. Influence of different allelic variants of the CYP3A and ABCB1 genes on the tacrolimus pharmacokinetic profile of Chinese renal transplant recipients. Pharmacogenomics 2006;7:563-74.

31. Sasieni PD. From genotypes to genes: doubling the sample size. Biometrics 1997;53: 1253-61.

32. Kuypers DR, Claes K, Evenepoel P, Maes B, Coosemans W, Pirenne J, Vanrenterghem Y. Time-related clinical determinants of long-term tacrolimus pharmacokinetics in combination therapy with mycophenolic acid and corticosteroids: a prospective study in one hundred de novo renal transplant recipients. Clin Pharmacokinet 2004;43:741-62.

33. Fredericks S, Moreton M, Reboux S, Carter ND, Goldberg L, Holt DW, MacPhee IA. Multidrug Resistance Gene-1 (MDR-1) Haplotypes Have a Minor Influence on Tacrolimus Dose Requirements. Transplantation 2006;82:705-8.

34. Sattler M, Guengerich FP, Yun CH, Christians U, Sewing KF. Cytochrome P-450 3A enzymes are responsible for biotransformation of FK506 and rapamycin in man and rat. Drug Metab Dispos 1992;20:753-61.

35. Karanam BV, Vincent SH, Newton DJ, Wang RW, Chiu SH. FK 506 metabolism in human liver microsomes: investigation of the involvement of cytochrome P450 isozymes other than CYP3A4. Drug Metab Dispos 1994;22:811-4. 
36. Vincent SH, Karanam BV, Painter SK, Chiu SH. In vitro metabolism of FK-506 in rat, rabbit, and human liver microsomes: identification of a major metabolite and of cytochrome P450 3A as the major enzymes responsible for its metabolism. Arch Biochem Biophys 1992;294: 454-60.

37. Lampen A, Christians U, Guengerich FP, Watkins PB, Kolars JC, Bader A, Gonschior AK, Dralle $\mathrm{H}$, Hackbarth I, Sewing KF. Metabolism of the immunosuppressant tacrolimus in the small intestine: cytochrome P450, drug interactions, and interindividual variability. Drug Metab Dispos 1995;23:1315-24. 
134 


\section{Chapter}

\section{Cytochrome P450 (CYP3A7) *1C allelic variant is associated with the tacrolimus pharmacokinetics in renal transplant recipients}

Robert A.M. Op den Buijsch, Johan E. de Vries, Chi Yuen Cheung, Leo M.L. Stolk, Maarten H.L. Christiaans, Nas A. Undre, Petal A.H.M. Wijnen, Marja P. van Dieijen-Visser, Otto Bekers

\section{Submitted}




\section{Abstract}

Cytochrome P450 3A4/5 (CYP3A4/5) are mainly responsible for the tacrolimus metabolisation although little information is available regarding the contribution of CYP3A7. The CYP3A7*1C allele contains the proximal everted repeat 6 motif of CYP3A4 which implicates that the pregnane $x$ receptor and the constitutively activated receptor bind with a higher affinity to the CYP3A7*1C allele than to the CYP3A7*1 allele, which results in a higher expression of CYP3A7 for individuals carrying a CYP3A $7{ }^{*} 1 \mathrm{C}$ allele. An allele frequency of respectively $2.8 \%$ and $0.0 \%$ was found after genotyping 70 Caucasian and 103 Chinese renal transplant recipients for the CYP3A $7{ }^{*} 1 \mathrm{C}$ allele using a real-time polymerase chain reaction $(\mathrm{PCR})$ fluorescence resonance energy transfer (FRET) assay. Heterozygous carriers of the CYP3A7*1C allele showed no significant lower trough levels, area under the time tacrolimus concentration curve or maximum concentrations for tacrolimus compared to the carriers of the CYP3A7*1 allele. Based on these findings we conclude that the CYP3A7*1C allele is not associated with lower pharmacokinetic tacrolimus parameters. 


\section{Introduction}

Tacrolimus, a calcineurin inhibitor used in the transplantation therapy, is characterized by its variable pharmacokinetic characteristics and narrow therapeutic window. Moreover, tacrolimus is predominately metabolised into 13-O-demethyltacrolimus in the liver and the intestines by cytochrome P450 (CYP) $3 A^{1-4}$. The CYP3A subfamily composed of four genes, CYP3A4, CYP3A5, CYP3A7 and CYP3A43 and three pseudogenes CYP3AP1, CYP3AP2 and CYP3AP3, is located on chromosome $7 q 21-q 22.1^{5}$. The CYP3A concentrations and activities display interindividual variability, which can at least partly explain the variation in the trough $\left(C_{0}\right)$ levels ${ }^{6-15}$ and the other pharmacokinetic parameters of tacrolimus ${ }^{16-18}$. Although more than 30 CYP3A4 allelic variants have been reported $^{5}$, most CYP3A4 variants are single nucleotide polymorphisms (SNPS) with low allelic frequencies and many of these SNPs are population specific ${ }^{19}$. Due to their low allelic frequency, the contribution of these CYP3A4 SNPs to the interindividual variability of CYP3A4 expression is limited. In contrast to CYP3A4, a few SNPs in CYP3A5 have a major impact on the CYP3A5 expression $^{20,21}$. However, in Caucasians CYP3A5 expression appears to be mainly regulated by the $\mathrm{CYP} 3 A 5^{\star} 3$ allelic variant ${ }^{20-22}$. Individuals carrying a CYP $3 A 5^{\star} 3$ (low expressers) variant allele express a significantly lower amount CYP3A5 compared to individuals carrying a CYP3A5*1 allele (high expressers). Transplant patients categorized as low expressers achieve significantly higher pharmacokinetic parameters for tacrolimus ( $\mathrm{dnC}_{0}, \mathrm{dnAUC}_{0-12}$ and $\mathrm{dnC}_{\max }$ ) and therefore require a lower daily tacrolimus dose compared to transplant patients included in the high expresser group ${ }^{16,17}$. Although Kamden et $a l^{23}$ previously demonstrated with in vitro experiments that CYP3A7 compared to CYP3A4 and CYP3A5 plays a minor role in the tacrolimus metabolism, the role of higher CYP3A7 protein levels on the tacrolimus metabolisation in vivo is not yet been elucidated. CYP3A7 is the most abundant CYP in human liver during fetal development and the first months of postnatal age ${ }^{24}$. Moreover, CYP3A7 plays an important role in the metabolism of key steroids in the adrenals and gonads of potentially toxic and teratogenic endogenous substrates ${ }^{24-27}$ and of many drugs of abuse that reach the fetus ${ }^{28-31}$. Sim et al. ${ }^{32}$ found that the CYP3A7 protein expression is high in a fraction of the human adult livers and is associated partially with the CYP3A $7^{*} 1 \mathrm{C}$ allele. Additionally, Smit et al. ${ }^{33}$ found that the CYP3A7*1C variant allele is associated with a nearly $50 \%$ reduction of the serum dehydro-epi-androsterone sulfate (DHEAS) levels. Considering the relevance of this CYP3A7*1C allelic variant, we developed a real-time PCR fluorescence resonance energy transfer (FRET) assay for this CYP3A7 polymorphism. Moreover, since clinical studies regarding the influence of CYP3A $7{ }^{*} 1 \mathrm{C}$ polymorphism on the pharmacokinetic parameters of tacrolimus are still lacking, two Caucasian and a Chinese renal transplant recipient group are genotyped for the CYP3A7 ${ }^{*} 1 \mathrm{C}$ variant allele. Furthermore, the genotypes of the CYP3A7*1C variant allele found in the renal transplant recipient groups are correlated with their corresponding pharmacokinetic tacrolimus parameters. 


\section{Materials and methods}

\section{Study populations}

In total 70 Caucasian and 103 Chinese renal transplant recipients are included in the present study. The Caucasian renal transplant recipients are divided over two different groups of whom in the past for clinical reasons (group I) or for a clinical trial (group II) a 12 hour time tacrolimus concentration curve was performed. A two time point sampling strategy ${ }^{34}$ was used to calculate the abbreviated $\mathrm{AUC}_{0-12}$ in the Chinese renal transplant recipients (group III). Group I included early Caucasian posttransplant patients with a short median time after transplantation and large variability in the tacrolimus $\mathrm{AUC}_{0-12}$ compared to the late Caucasian posttransplant recipients of group II. Most pharmacokinetic profiles of the patients included in group I were recorded within six weeks after transplantation. All renal transplant recipients included in group II and III underwent a renal transplantation at least one year (group II) or four months (group III) ago. Moreover, eight patients in group I used a calcium channel blocker that showed interference with tacrolimus. Group II and III included no patients taking medication known to interact with tacrolimus such as calcium channel blockers, anti-epileptics, antimycotics and macrolide antibiotics. In addition, patients that suffer from gastrointestinal, liver disease, or other disorders that may alter the absorption of tacrolimus were also disqualified for inclusion. The initial tacrolimus dosage, administrated twice daily, was $0.2 \mathrm{mg} / \mathrm{kg}$ per day for patients included in group I and II and $0.3 \mathrm{mg} / \mathrm{kg}$ per day for patients included in group III. For patients in group I and II the dose requirement for tacrolimus was assessed three months after transplantation, when the target $\mathrm{C}_{0}$ concentration was between 10 to $15 \mathrm{ng} / \mathrm{ml}$ while the daily tacrolimus dose for patients in group III was adjusted according to the $A \mathrm{C}_{0-12}$ value, which was kept at around $100-150 \mathrm{ng} \times \mathrm{hr} / \mathrm{ml}$ in the first three months. After three months the target $A U_{0-12}$ value was decreased to around $80-100 \mathrm{ng} \times \mathrm{hr} / \mathrm{ml}$ for long term maintenance. Prior to the blood sample collection, there had been no tacrolimus dose change for at least three days in groups I and II and for at least two weeks in group III. After overnight fasting the blood samples were collected immediately pre $\left(\mathrm{C}_{0}\right)$ and $0.5\left(\mathrm{C}_{0.5}\right), 1\left(\mathrm{C}_{1}\right), 2\left(\mathrm{C}_{2}\right), 3\left(\mathrm{C}_{3}\right), 4\left(\mathrm{C}_{4}\right)$, $5\left(\mathrm{C}_{5}\right), 7.5\left(\mathrm{C}_{7.5}\right)$ and $12\left(\mathrm{C}_{12}\right)$ hours after the morning tacrolimus administration for group I and II while blood samples were collected at two time points $\left(C_{2}\right.$ and $\left.C_{4}\right)$ to calculate the abbreviated $\mathrm{AUC}_{0-12}$ for the patients included in group III. All patients were not allowed to take food until one hour after ingesting the tacrolimus dose and were advised to avoid grapefruit juice after transplantation to prevent alterations in the tacrolimus metabolism. Demographic as well as clinical data were determined at the time of recording the $A \cup C_{0-12}$ or the abbreviated $A_{U C} C_{0-12}$ (Table 9.1). The renal transplant recipients included in group I and II underwent a renal transplantation and a regular follow up in the University Hospital of Maastricht, the Netherlands whereas the renal transplant recipients included in group III had regular follow up in Queen Elizabeth Hospital or Tuen Mun Hospital in Hong Kong. The study was performed in accordance 
to the Declaration of Helsinki and its amendments. The protocol was approved by the local Medical Ethics Committees in the Netherlands and Hong Kong and written informed consent for participation in this study was obtained from all patients.

Table 9.1 Demographic characteristics of the three renal transplant recipients groups.

\begin{tabular}{|c|c|c|c|}
\hline Demographic characteristics & Group I & Group II & Group III \\
\hline Ethnicity & Caucasians & Caucasians & Chinese \\
\hline Gender (male/female) & $22 / 11$ & $24 / 13$ & $58 / 45$ \\
\hline Age (years, mean $\pm S D$ ) & $42.0 \pm 12.2$ & $51.3 \pm 10.9$ & $43.1 \pm 11.1$ \\
\hline Weight $(\mathrm{kg}$, mean $\pm \mathrm{SD})$ & $71.7 \pm 16.4$ & $77.4 \pm 13.5$ & $62.5 \pm 11.4$ \\
\hline \multicolumn{4}{|l|}{ Primary kidney disease } \\
\hline Glomerulonephritis & 5 & 1 & 57 \\
\hline Chronic pyelonephritis & 2 & 2 & 1 \\
\hline IgA nephropathy & 3 & 4 & 0 \\
\hline Hypertensive nephropathy & 4 & 7 & 9 \\
\hline Diabetes Mellitus nephropathy & 5 & 0 & 10 \\
\hline Polycystic kidney disease & 2 & 8 & 2 \\
\hline Obstructive Uropathy & 0 & 0 & 3 \\
\hline Unknown & 3 & 4 & 18 \\
\hline Other & 9 & 11 & 3 \\
\hline \multicolumn{4}{|l|}{ Transplantation number } \\
\hline First & 26 & 30 & 97 \\
\hline Second & 6 & 6 & 6 \\
\hline Third or more & 1 & 1 & 0 \\
\hline Tacrolimus mono therapy & 2 & 29 & 0 \\
\hline Tacrolimus dose (mg/kg/day, mean \pm SD) & $0.34 \pm 0.233$ & $0.054 \pm 0.029$ & $0.067 \pm 0.032$ \\
\hline $\mathrm{C}_{0}(\mathrm{ng} / \mathrm{ml}$, mean $\pm \mathrm{SD})$ & $14.8 \pm 6.60$ & $6.59 \pm 1.39$ & NA \\
\hline $\mathrm{AUC}_{0-12}(\mathrm{ng} \times \mathrm{hr} / \mathrm{ml}$, mean $\pm \mathrm{SD})$ & $269.7 \pm 110.9$ & $122.5 \pm 31.1$ & NA \\
\hline Abbreviated $\mathrm{AUC}_{0-12}(\mathrm{ng} \times \mathrm{hr} / \mathrm{ml}$, mean $\pm \mathrm{SD})$ & ND & ND & $100.3 \pm 24.2$ \\
\hline $\mathrm{C}_{\max }(\mathrm{ng} / \mathrm{ml}$, mean $\pm \mathrm{SD})$ & $50.2 \pm 22.8$ & $20.9 \pm 6.5$ & NA \\
\hline $\mathrm{T}_{\max }(\mathrm{hr}$, mean $\pm \mathrm{SD})$ & $1.46 \pm 1.21$ & $1.24 \pm 0.43$ & NA \\
\hline Use of $\mathrm{AZA}^{\mathrm{a}}, \mathrm{MMF}^{\mathrm{b}}$, rapamycine, steroids & $10 / 3 / 4 / 28$ & $3 / 4 / 0 / 0$ & 78/25/0/103 \\
\hline \multicolumn{4}{|l|}{ Current steroid dose (mg, dose, no. patients) } \\
\hline $0 \mathrm{mg} / \mathrm{day}$ & 5 & 37 & 0 \\
\hline 4 mg/day & 0 & 0 & 1 \\
\hline $5 \mathrm{mg} / \mathrm{day}$ & 7 & 0 & 33 \\
\hline $7.5 \mathrm{mg} / \mathrm{day}$ & 0 & 0 & 64 \\
\hline 8 mg/day & 2 & 0 & 0 \\
\hline $10 \mathrm{mg} /$ day & 10 & 0 & 3 \\
\hline $15 \mathrm{mg} /$ day & 4 & 0 & 1 \\
\hline $20 \mathrm{mg} / \mathrm{day}$ & 3 & 0 & 0 \\
\hline$>20 \mathrm{mg} / \mathrm{day}$ & 2 & 0 & 1 \\
\hline Time since Tx (days, median, (range)) & $20(3-5359)$ & $1465(453-4128)$ & $977(133-4982)$ \\
\hline Haemoglobin (mmol/l, mean \pm SD) & $6.03 \pm 1.56$ & $8.52 \pm 0.83$ & $12.8 \pm 2.0$ \\
\hline Haematocrit fraction (mean \pm SD) & $0.27 \pm 0.09$ & $0.41 \pm 0.04$ & $0.38 \pm 0.058$ \\
\hline $\operatorname{ALAT}(\mathrm{U} / \mathrm{I}$, mean $\pm \mathrm{SD})$ & $32 \pm 31$ & $24 \pm 13$ & $22 \pm 18$ \\
\hline Serum albumin (g/l, mean \pm SD, ) & $32.5 \pm 5.03$ & $37.0 \pm 3.84$ & $43 \pm 3.2$ \\
\hline Serum creatinine $(\mu \mathrm{mol} / \mathrm{l}$, median $\pm \mathrm{SD})$ & $189 \pm 268$ & $125 \pm 29$ & $156 \pm 76$ \\
\hline
\end{tabular}

${ }^{a}$ azathiopurine; ${ }^{\mathrm{b}}$ mycophenolate mofetil; ND not determined, NA not available; Abbreviated $A \cup C_{0-12}$ is the $A C_{0-12}$ calculated with the following formula: $A C_{0-12}=16.2+2.4 \times C_{2}+5.9 \times C_{4}$. 


\section{Tacrolimus concentration determination}

The tacrolimus measurements for the three groups were performed in different laboratories. For all groups the tacrolimus blood concentrations were determined in ethylene diamine tetra-acetic acid (EDTA) whole blood, using a microparticle enzyme immunoassay (MEIA) with a monoclonal antibody (IMx II assay; Abbott Laboratories, Abbott Park, IL, USA) for group I and III and a method based on high pressure liquid chromatography (LC) tandem mass spectrometry (MS/MS) for group II. All laboratories participate in the International Tacrolimus Proficiency Testing Scheme. The tacrolimus $\mathrm{C}_{0}$ concentration, the peak blood concentration $\left(\mathrm{C}_{\max }\right)$ during the assessed time interval and the time at which the highest blood concentration was observed $\left(T_{\max }\right)$ were determined directly from the time versus tacrolimus blood concentration data. Additionally, the area under the time tacrolimus concentration curve $\left(\mathrm{AUC}_{0-12}\right)$ was calculated from the time versus tacrolimus concentration plot using the linear trapezoidal rule in MWPharm 3.50 (Mediware, Groningen, the Netherlands). The two tacrolimus blood concentrations determined for the patients included in group III were used to calculate the abbreviated $\mathrm{AUC}_{0-12}$ according to the equation based strategy as described by our group ${ }^{34}: \mathrm{AUC}_{0-12}=16.2+2.4 \times \mathrm{C} 2+5.9 \times \mathrm{C} 4 . \mathrm{DnC}_{0}, \mathrm{dnAUC}_{0-12}$ and $\mathrm{dnC}_{\max }$ were calculated by dividing the $\mathrm{C}_{0}, \mathrm{AUC}_{0-12}$ and $\mathrm{C}_{\max }$ respectively by the corresponding morning dose on a milligram per kilogram basis.

\section{Real-time PCR FRET assay for CYP3A7*1C allelic variant}

Genomic DNA was isolated from 70 Caucasian and 103 Chinese renal transplant recipients by using $200 \mu \mathrm{L}$ EDTA anti coagulated blood for isolation with a Qiagen blood mini kit (Qiagen, Leusden, the Netherlands) according to the manufacturers' instructions. Genotyping for the CYP3A7*1C allelic variant was performed using a realtime PCR FRET assay on the LightCycler (Roche Diagnostics, Almere, the Netherlands). Since the different members of the CYP3A subfamily show a high sequence homology (> 90\%), the position of the primers is carefully selected. Moreover, the CYP3A $7{ }^{*} 1 \mathrm{C}$ variant allele consists of seven different polymorphisms within a 60 base pair (bp) range in the CYP3A7 promoter region, which narrows the position options of the probe that covers one of these polymorphisms. Specific primers for CYP3A7 and a sensor probe covering the T-188G polymorphism in the CYP3A7 promoter region are used in the real-time PCR FRET assay developed for the CYP3A7*1C variant allele. The primers F41: 5'-CCA TAg AgA CAA gAg gAg AgT TAA T-'3 (sense; 110611-635) and R41: 5'-gAg gCT TCT CCA CCT Cg-'3 (anti-sense; 110790-806) were used to amplify a $196 \mathrm{bp}$ part from the CYP3A7 gene which covers the T110718G polymorphism (corresponding to position -188 of the CYP3A7 promoter; Genbank acces no: AF280107) ${ }^{35}$. Detection was carried out using the anchor probe CYP3A7A41: 5'-ggg AgT CCA Agg gTT CTg gg-'3 (anti-sense; 110677-696) which was labelled at the $5^{\prime}$ end with LCRed640 and phosphorylated at the 3'-end to block extension and the

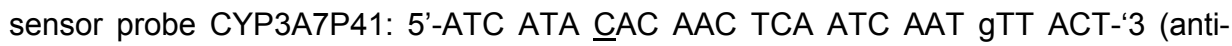


sense; $110698-724)$ which is complementary to the CYP3A7*1 allele. This 3 '-fluorescein labelled sensor probe, in which the polymorphic nucleotide is underlined, binds with a distance of one base 5' to the detection probe. The PCR mixture contained $3.2 \mu \mathrm{l}$ sterile water; 3.0 mmol// MgCl $2 ; 1.0 \mu \mathrm{l} \mathrm{LC} \mathrm{Faststart} \mathrm{DNA} \mathrm{Master} \mathrm{Hybridization} \mathrm{Probes} \mathrm{(Roche}$ Diagnostics $\mathrm{GmbH}$, Mannheim, Germany); $0.50 \mu \mathrm{mol} / \mathrm{l}$ of each primer and $0.20 \mu \mathrm{mol} / \mathrm{l}$ of both anchor and sensor probe (TIB MOLBIOL, Berlin, Germany). After adding $1.0 \mu \mathrm{l}$ genomic DNA to the PCR mixture, the total volume is $10 \mu \mathrm{l}$. The PCR protocol included the following steps: a) denaturation for ten minutes at $95^{\circ} \mathrm{C} \mathrm{b}$ ) 45 cycles at $95^{\circ} \mathrm{C}$ for 10 seconds; $55^{\circ} \mathrm{C}$ for ten seconds and $72^{\circ} \mathrm{C}$ for five seconds. After amplification was completed, a melting curve was recorded by heating to $95^{\circ} \mathrm{C}\left(20^{\circ} \mathrm{C} /\right.$ second), holding at $95^{\circ} \mathrm{C}$ for 30 seconds then cooling to $40^{\circ} \mathrm{C}\left(20^{\circ} \mathrm{C} /\right.$ second $)$, holding at $40^{\circ} \mathrm{C}$ for one minute and then heating slowly to $85^{\circ} \mathrm{C}$ at $0.2^{\circ} \mathrm{C} /$ second. During the slow heating procedure of the melting curves, fluorescence was measured continuously to monitor the dissociation of the fluorophore-labelled detection probe. The fluorescence signals were then converted to melting peaks by plotting the negative derivative of the fluorescence with respect to temperature versus temperature (-dF2/dT versus $\mathrm{T})$. The melting point of the sensor probe was $61^{\circ} \mathrm{C}$ when hybridised to the wild type CYP3A7*1 allele and $56.5^{\circ} \mathrm{C}$ when hybridised to the CYP3A7*1C variant allele. A heterozygous carrier of the CYP3A7*1C variant allele shows both melting points (Figure 9.1). The real-time PCR FRET assay for the CYP3A7*1C variant allele was validated by sequencing a heterozygote sample and a wild type sample of the CYP3A7*1C variant allele according to a direct sequence procedure performed with the capillary sequencer ABI 3100 (Applied Biosystems, Fostercity, USA) using the Bridge version 1.1 sequence kit (Applied Biosystems, Fostercity, USA).

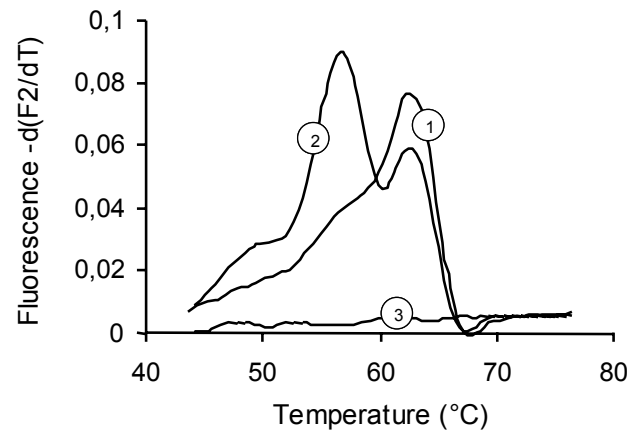

Figure 9.1 Genotyping of the CYP3A7 T-188G polymorphism with allele specific fluorescent probes by derivative melting curve plots. The derivative melting curves are read in channel 2 for the detection of the CYP3A7 fragments. The derivative melting curve is plotted for a sample homozygous for the $-188 \mathrm{G}$ allele $\left(1 ; \mathrm{Tm} 61.0^{\circ} \mathrm{C}\right)$; and a heterozygous sample $\left(2 ; \mathrm{Tm} 56.5^{\circ} \mathrm{C}\right.$ and $\left.61.0^{\circ} \mathrm{C}\right)$. Melting analysis of a no template control was also performed (3). 


\section{Statistical analysis}

Statistical analysis of the data was performed with use of the statistical software SPSS 11.0 for windows (Chicago, IL, USA). Patients' genotypes were used as categorical independent variables for analysis of continuous clinical and pharmacological variables. To examine the population homogeneity of the patients, the genotype frequencies of the CYP3A $7{ }^{*} 1 \mathrm{C}$ polymorphism were tested against Hardy-Weinberg equilibrium by the Pearson's goodness-of-fit test. For analysis of the daily tacrolimus dose ( $\mathrm{mg} / \mathrm{kg} / \mathrm{day})$, dose-normalized $(\mathrm{dn}) \mathrm{C}_{0}\left(\mathrm{ng} / \mathrm{ml}\right.$ per mg/kg), dose-normalized $(\mathrm{dn}) \mathrm{AUC}_{0-12}(\mathrm{ng} \times \mathrm{hr} / \mathrm{ml}$ per $\mathrm{mg} / \mathrm{kg}$ ), dose-normalized $(\mathrm{dn}) \mathrm{C}_{\max }\left(\mathrm{ng} / \mathrm{ml}\right.$ per $\mathrm{mg} / \mathrm{kg}$ ) and $\mathrm{T}_{\max }(\mathrm{hr})$, groups were compared using non parametric statistical tests. To compare the two groups we used the Mann-Whitney test. $P$ values less than 0.05 were considered statistically significant. All values are expressed as median and range unless stated otherwise.

\section{Results}

In total 70 Caucasian renal transplant recipients divided over 33 early (group I) and 37 late (group II) posttransplant recipients and 103 Chinese renal transplant recipients (group III) were genotyped for the CYP3A7*1C variant allele. In group I and II, respectively one and three heterozygous carriers were found for the CYP3A7*1C variant allele while no CYP3A7*1C variant allele was found in the Chinese renal transplant recipients of group III. The previous findings result in an allele frequency for the CYP3A $7{ }^{*} 1 \mathrm{C}$ variant allele of $1.5 \%, 4.1 \%$ and $0.0 \%$ in group I, II and III, respectively. The allele frequencies found in the Caucasian renal transplant recipients are in line with previous studies ${ }^{20,35}$. Since no CYP $3 A 7^{*} 1 \mathrm{C}$ variant allele was found in the 103 Chinese renal transplant recipients examined, it is likely that the frequency of this CYP3A7 polymorphism in the Chinese population is very low. Renal transplant recipient groups I and II showed no significantly different distribution of the CYP3A7*1C variant allele from that predicted by the Hardy-Weinberg equilibrium $(P>0.05)$. Moreover, no significant difference in the allele frequency for the CYP3A7*1C variant allele was found between the two Caucasian renal transplant recipient groups examined. All heterozygous carriers for the CYP3A7*1C variant allele were homozygous carrier of the CYP3A4*1A and CYP3A5*3 allele. Since one renal transplant recipient in group I was carrier of the CYP3A7*1C variant allele, a statistical analysis was only performed with the 37 Caucasian renal transplant recipients that were included in group II. Renal transplant recipients carrying a CYP3A7*1C variant allele showed no significant lower $\mathrm{dnC}_{0}$ levels (404 versus $264 \mathrm{ng} / \mathrm{ml}$ per $\mathrm{mg} / \mathrm{kg}$; Mann-Whitney $P=0.290$ ), dnAUC $\mathrm{C}_{0-12}$ (6376 versus $4539 \mathrm{ng} \times \mathrm{hr} / \mathrm{ml}$ per mg/kg; Mann-Whitney $P=0.504), \mathrm{dnC}_{\max }(1179$ versus $743 \mathrm{ng} / \mathrm{ml}$ per $\mathrm{mg} / \mathrm{kg}$; Mann-Whitney $P=0.469)$ or $\mathrm{T}_{\max }(1.00$ versus $1.00 \mathrm{hr}$; Mann-Whitney $P=0.312$ ), compared to the renal transplant recipients carrying a wild type CYP $3 A 7^{*} 1$ allele. 
Additionally, Figure 9.2 illustrates that heterozygote carriers of the CYP3A7*1C variant allele showed no difference in the 12 hour pharmacokinetic tacrolimus profile.

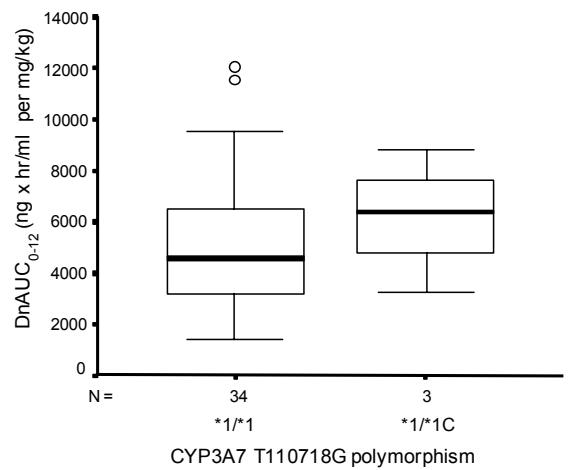

Figure 9.2 The influence of the CYP3A7 T-188G polymorphism on the 12 hour area under the time tacrolimus concentration curve $\left(\mathrm{AUC}_{0-12}\right)$ in 37 late Caucasian posttransplant patients. The boxplot of the dose-normalized $\mathrm{AUC}_{0-12}$ is clustered according to the CYP3A7 genotype. $P$ values for the pairwise comparisons of each genotype are given. The open circles indicate an outlier value at more than 1.5 box lengths above the box.

\section{Highlights}

- Tacrolimus is predominantly metabolised into 13-0-demethyltacrolimus by cytochrome P450 3A (CYP3A) iso-enzymes. Recently, a study described that the catalytic efficiency for CYP3A5 with tacrolimus is $60 \%$ higher than that for CYP3A4. The contribution of the CYP3A7*1C allele, responsible for a higher CYP3A7 expression, to the tacrolimus metabolism in transplant patients is not elucidated.

- The CYP3A7*1C variant allele consists of seven different polymorphisms located in a 60 basepair promoter region of CYP3A7. The proximal everted repeat 6 motif present in the CYP3A7*1C variant allele binds with a higher affinity the pregnane $X$ receptor and the constitutively activated receptor than the CYP3A7*1 allele, which results in a higher CYP3A7 expression for individuals carrying a CYP3A7*1C allele.

- A novel real-time PCR FRET assay on the LightCycler is described for the CYP3A7*1C allelic variant. This real-time PCR FRET assay is validated by sequencing a heterozygous sample and a homozygous wild type DNA sample.

- In total 70 Caucasian and 103 Chinese renal transplant recipients are genotyped for the CYP3A7*1C variant allele. The Caucasian renal transplant recipients were divided in 33 early and 37 late post transplant patients. The allele frequency for the CYP3A7*1C variant allele in the Caucasian and the Chinese renal transplant recipients is $2.8 \%$ and $0.0 \%$, respectively. 
- The CYP3A7*1C variant allele is not associated with any dose-normalized pharmacokinetic parameter $\left(\mathrm{C}_{0}, A \cup \mathrm{C}_{0-12}, \mathrm{C}_{\max }\right)$ recorded in the late posttransplant recipient group. Our findings indicate that a higher CYP3A7 expression has no influence on the tacrolimus metabolism.

\section{Discussion}

The initial and maintenance dosage regime of tacrolimus in transplant patients is difficult to assess due to its highly variable pharmacokinetic characteristics and narrow therapeutic range. Although several clinical studies ${ }^{16,17}$ demonstrated that the variation in the pharmacokinetic characteristics of tacrolimus may be explained by the CYP $3 A 5^{*} 3$ variant allele, there is still a large variation within the patient groups carrying a different CYP3A5 genotype for this CYP3A5*3 variant allele. Sattler et al. ${ }^{1}$ suggested that other members of the CYP3A subfamily might be involved than CYP3A4. Bader et al. ${ }^{36}$ later confirmed that CYP3A5 plays an important role in the 13-O-demethylation of tacrolimus. More recently, Kamden et al. ${ }^{23}$ demonstrated with in vitro experiments that the demethylation of tacrolimus into 13-O-demethyltacrolimus in hepatocytes is mainly performed by CYP3A4 and CYP3A5. Although Kamden et al. ${ }^{23}$ suggested that CYP3A7 played no role in the tacrolimus metabolism in vivo, clinical studies confirming these results are still lacking. Sim et $a l^{32}$ found that the CYP3A7 protein expression contributes 9 to $36 \%$ of the total CYP3A levels in $10 \%$ of 59 adult livers. Additionally, they demonstrated that the CYP3A7*1C variant allele is partly responsible for these higher CYP3A7 expression levels. The CYP3A7*1C allele contains the proximal everted repeat 6 (ER6) motif of CYP3A4 which implicates that the pregnane $X$ receptor (PXR) and the constitutively actived receptor (CAR) bind with a higher affinity to the CYP3A $7{ }^{*} 1 \mathrm{C}$ allele than to the CYP $3 A 7^{*} 1$ allele. Consequently only the promoter constructs of CYP3A7 containing this CYP3A4-ER6 motif, CYP3A7*1C, will be transactivated by PXR and CAR. Previously, Burk et $a .{ }^{35}$ reported that the presence of the ER6 motif of CYP3A4 mediates the high expression of CYP3A7 in individuals carrying a CYP3A7*1C allele. Within the late posttransplant recipient group, no significant effect on both the pharmacokinetic tacrolimus parameters and the daily tacrolimus dose was observed between carriers of the wild type CYP3A7*1 allele or the CYP3A7*1C variant allele. Previously, Kamden et al. ${ }^{23}$ demonstrated with in vitro experiments that CYP3A7 played a minor role in the tacrolimus metabolism. Our findings indicate that a higher CYP3A7 protein expression in vivo caused by the CYP3A7*1C variant allele has no significant effect on the tacrolimus metabolism. In conclusion, in the present study a reliable and reproducible real-time PCR FRET assay is described for the CYP3A7*1C variant allele. Additionally, we found that the CYP3A7*1C variant allele, responsible for higher CYP3A7 protein levels, has a (very) low frequency in a Caucasian and a Chinese renal transplant population and is not associated with the pharmacokinetic parameters of tacrolimus. 


\section{Outlook}

In the last decade pharmacogenomics has gained considerable interest among several medical disciplines. Especially, the immunosuppressive drugs cyclosporin and tacrolimus are of special importance due to their highly variable pharmacokinetic characteristics and narrow therapeutic window. Cyclosporin and tacrolimus are substrates of the cytochrome P450 3A (CYP3A) family. Although CYP3A4 and CYP3A5 both show a great affinity for cyclosporin and tacrolimus, several clinical studies demonstrated that a part of the variation in the pharmacokinetic tacrolimus parameters can be explained by a single nucleotide polymorphism (CYP3A5 A6986G) present in the CYP3A5 gene. However, even within a group transplant patients carrying the same genotype for this CYP3A5 polymorphism, there is still a large variation in the pharmacokinetic tacrolimus parameters. To achieve a better individualized immunosuppressive therapy with a lower occurrence of subtherapeutic or toxic side effects of these immunosuppressive drugs, minimizing the variation in the pharmacokinetic tacrolimus parameters is certainly a prerequisite. Therefore, future studies are necessary to examine the role of other enzymes, transporters or transcriptional regulators involved in the tacrolimus metabolism and whether polymorphisms in these genes have an important impact on the pharmacokinetic parameters and thus on the daily dose requirement. 


\section{References}

1. Sattler M, Guengerich FP, Yun CH, Christians U, Sewing KF. Cytochrome P-450 3A enzymes are responsible for biotransformation of FK506 and rapamycin in man and rat. Drug Metab Dispos 1992;20:753-61.

2. Vincent SH, Karanam BV, Painter SK, Chiu SH. In vitro metabolism of FK-506 in rat, rabbit, and human liver microsomes: identification of a major metabolite and of cytochrome P450 3A as the major enzymes responsible for its metabolism. Arch Biochem Biophys 1992;294: 454-60.

3. Lampen A, Christians U, Guengerich FP, Watkins PB, Kolars JC, Bader A, Gonschior AK, Dralle $\mathrm{H}$, Hackbarth I, Sewing KF. Metabolism of the immunosuppressant tacrolimus in the small intestine: cytochrome P450, drug interactions, and interindividual variability. Drug Metab Dispos 1995;23:1315-24.

4. Karanam BV, Vincent SH, Newton DJ, Wang RW, Chiu SH. FK 506 metabolism in human liver microsomes: investigation of the involvement of cytochrome P450 isozymes other than CYP3A4. Drug Metab Dispos 1994;22:811-4.

5. Lamba JK, Lin YS, Schuetz EG, Thummel KE. Genetic contribution to variable human CYP3A-mediated metabolism. Adv Drug Deliv Rev 2002;54:1271-94.

6. Hesselink DA, van Schaik RH, van der Heiden IP, van der Werf M, Gregoor PJ, Lindemans J, Weimar W, van Gelder T. Genetic polymorphisms of the CYP3A4, CYP3A5, and MDR-1 genes and pharmacokinetics of the calcineurin inhibitors cyclosporine and tacrolimus. Clin Pharmacol Ther 2003;74:245-54.

7. Haufroid V, Mourad M, Van Kerckhove V, Wawrzyniak J, De Meyer M, Eddour DC, Malaise J, Lison D, Squifflet JP, Wallemacq P. The effect of CYP3A5 and MDR1 (ABCB1) polymorphisms on cyclosporine and tacrolimus dose requirements and trough blood levels in stable renal transplant patients. Pharmacogenetics 2004;14:147-54.

8. Thervet E, Anglicheau D, King B, Schlageter MH, Cassinat B, Beaune P, Legendre C, Daly AK. Impact of cytochrome p450 3A5 genetic polymorphism on tacrolimus doses and concentration-to-dose ratio in renal transplant recipients. Transplantation 2003;76:1233-5.

9. MacPhee IA, Fredericks S, Mohamed M, Moreton M, Carter ND, Johnston A, Goldberg L, Holt DW. Tacrolimus pharmacogenetics: the CYP3A5*1 allele predicts low dose-normalized tacrolimus blood concentrations in whites and South Asians. Transplantation 2005;79:499-502.

10. MacPhee IA, Fredericks S, Tai T, Syrris P, Carter ND, Johnston A, Goldberg L, Holt DW. The influence of pharmacogenetics on the time to achieve target tacrolimus concentrations after kidney transplantation. Am J Transplant 2004;4:914-9.

11. Goto M, Masuda S, Kiuchi T, Ogura Y, Oike F, Okuda M, Tanaka K, Inui K. CYP3A5*1carrying graft liver reduces the concentration/oral dose ratio of tacrolimus in recipients of living-donor liver transplantation. Pharmacogenetics 2004;14:471-8.

12. Zhao Y, Song M, Guan D, Bi S, Meng J, Li Q, Wang W. Genetic polymorphisms of CYP3A5 genes and concentration of the cyclosporine and tacrolimus. Transplant Proc 2005;37:17881.

13. Zhang X, Liu ZH, Zheng JM, Chen ZH, Tang Z, Chen JS, Li LS. Influence of CYP3A5 and MDR1 polymorphisms on tacrolimus concentration in the early stage after renal transplantation. Clin Transplant 2005;19:638-43.

14. Zheng H, Webber S, Zeevi A, Schuetz E, Zhang J, Bowman P, Boyle G, Law Y, Miller S, Lamba J, Burckart GJ. Tacrolimus dosing in pediatric heart transplant patients is related to CYP3A5 and MDR1 gene polymorphisms. Am J Transplant 2003;3:477-83.

15. Zheng H, Zeevi A, Schuetz E, Lamba J, McCurry K, Griffith BP, Webber S, Ristich J, Dauber J, lacono A, Grgurich W, Zaldonis D, McDade K, Zhang J, Burckart GJ. Tacrolimus dosing in adult lung transplant patients is related to cytochrome P4503A5 gene polymorphism. J Clin Pharmacol 2004;44:135-40. 
16. Tsuchiya N, Satoh S, Tada H, Li Z, Ohyama C, Sato K, Suzuki T, Habuchi T, Kato T. Influence of CYP3A5 and MDR1 (ABCB1) polymorphisms on the pharmacokinetics of tacrolimus in renal transplant recipients. Transplantation 2004;78:1182-7.

17. Tada H, Tsuchiya N, Satoh S, Kagaya H, Li Z, Sato K, Miura M, Suzuki T, Kato T, Habuchi T. Impact of CYP3A5 and MDR1(ABCB1) C3435T polymorphisms on the pharmacokinetics of tacrolimus in renal transplant recipients. Transplant Proc 2005;37:1730-2.

18. Cheung CY, Op den Buijsch RA, Wong KM, Chan HW, Chau KF, Li CS, Leung KT, Kwan TH, de Vrie JE, Wijnen PA, van Dieijen-Visser MP, Bekers O. Influence of different allelic variants of the CYP3A and ABCB1 genes on the tacrolimus pharmacokinetic profile of Chinese renal transplant recipients. Pharmacogenomics 2006;7:563-74.

19. Lamba JK, Lin YS, Thummel K, Daly A, Watkins PB, Strom S, Zhang J, Schuetz EG. Common allelic variants of cytochrome P4503A4 and their prevalence in different populations. Pharmacogenetics 2002;12:121-32.

20. Kuehl P, Zhang J, Lin Y, Lamba J, Assem M, Schuetz J, Watkins PB, Daly A, Wrighton SA, Hall SD, Maurel P, Relling M, Brimer C, Yasuda K, Venkataramanan R, Strom S, Thummel K, Boguski MS, Schuetz E. Sequence diversity in CYP3A promoters and characterization of the genetic basis of polymorphic CYP3A5 expression. Nat Genet 2001;27:383-91.

21. Xie HG, Wood AJ, Kim RB, Stein CM, Wilkinson GR. Genetic variability in CYP3A5 and its possible consequences. Pharmacogenomics 2004;5:243-72.

22. van Schaik RH, van der Heiden IP, van den Anker JN, Lindemans J. CYP3A5 variant allele frequencies in Dutch Caucasians. Clin Chem 2002;48:1668-71.

23. Kamdem LK, Streit F, Zanger UM, Brockmoller J, Oellerich M, Armstrong VW, Wojnowski L. Contribution of CYP3A5 to the in vitro hepatic clearance of tacrolimus. Clin Chem 2005;51:1374-81.

- Study that provides an overview of the different cytochrome P450 iso-enzymes that have in vitro a role in the hepatic clearance of tacrolimus.

24. Shimada T, Yamazaki H, Mimura M, Wakamiya N, Ueng YF, Guengerich FP, Inui Y. Characterization of microsomal cytochrome P450 enzymes involved in the oxidation of xenobiotic chemicals in human fetal liver and adult lungs. Drug Metab Dispos 1996;24: 515-22.

25. Ohmori S, Nakasa H, Asanome K, Kurose Y, Ishii I, Hosokawa M, Kitada M. Differential catalytic properties in metabolism of endogenous and exogenous substrates among CYP3A enzymes expressed in COS-7 cells. Biochim Biophys Acta 1998;1380:297-304.

26. Lee AJ, Conney AH, Zhu BT. Human cytochrome P450 3A7 has a distinct high catalytic activity for the 16alpha-hydroxylation of estrone but not 17beta-estradiol. Cancer Res 2003;63:6532-6.

27. Marill J, Capron CC, Idres N, Chabot GG. Human cytochrome P450s involved in the metabolism of 9-cis- and 13-cis-retinoic acids. Biochem Pharmacol 2002;63:933-43.

28. Ladona MG, Gonzalez ML, Rane A, Peter RM, de la Torre R. Cocaine metabolism in human fetal and adult liver microsomes is related to cytochrome P450 3A expression. Life Sci 2000;68:431-43.

29. Pellinen P, Honkakoski P, Stenback F, Niemitz M, Alhava E, Pelkonen O, Lang MA, Pasanen $\mathrm{M}$. Cocaine $\mathrm{N}$-demethylation and the metabolism-related hepatotoxicity can be prevented by cytochrome P450 3A inhibitors. Eur J Pharmacol 1994;270:35-43.

30. Matsunaga T, Kishi N, Higuchi S, Watanabe K, Ohshima T, Yamamoto I. CYP3A4 is a major isoform responsible for oxidation of 7-hydroxy-Delta(8)-tetrahydrocannabinol to 7-oxodelta(8)-tetrahydrocannabinol in human liver microsomes. Drug Metab Dispos 2000;28: 1291-6.

31. Foster DJ, Somogyi AA, Bochner F. Methadone N-demethylation in human liver microsomes: lack of stereoselectivity and involvement of CYP3A4. Br J Clin Pharmacol 1999;47:403-12.

32. Sim SC, Edwards RJ, Boobis AR, Ingelman-Sundberg M. CYP3A7 protein expression is high in a fraction of adult human livers and partially associated with the CYP3A7*1C allele. Pharmacogenet Genomics 2005;15:625-31.

- Sim et al found that CYP3A7*1C variant allele may contribute $9-36 \%$ of the total CYP3A levels in the liver. 
33. Smit $P$, van Schaik RH, van der Werf M, van den Beld AW, Koper JW, Lindemans J, Pols $\mathrm{HA}$, Brinkmann AO, de Jong FH, Lamberts SW. A common polymorphism in the CYP3A7 gene is associated with a nearly $50 \%$ reduction in serum dehydroepiandrosterone sulfate levels. J Clin Endocrinol Metab 2005;90:5313-6.

- First study describing a significant reduction in serum DHEA between carriers of the CYP3A $7^{*} 1 \mathrm{C}$ variant allele compared to carriers of the wildtype CYP3A7 ${ }^{*} 1$ allele.

34. Wong KM, Shek CC, Chau KF, Li CS. Abbreviated tacrolimus area-under-the-curve monitoring for renal transplant recipients. Am J Kidney Dis 2000;35:660-6.

35. Burk O, Tegude H, Koch I, Hustert E, Wolbold R, Glaeser H, Klein K, Fromm MF, Nuessler AK, Neuhaus P, Zanger UM, Eichelbaum M, Wojnowski L. Molecular mechanisms of polymorphic CYP3A7 expression in adult human liver and intestine. J Biol Chem 2002;277:24280-8.

36. Bader A, Hansen T, Kirchner G, Allmeling C, Haverich A, Borlak JT. Primary porcine enterocyte and hepatocyte cultures to study drug oxidation reactions. $\mathrm{Br} \mathrm{J}$ Pharmacol 2000;129:331-42. 


\section{Chapter 10}

\section{Influence of allelic variants of uridine}

diphosphateglucuronosyltransferase (UGT) 2B7 on the tacrolimus exposure

Robert A.M. Op den Buijsch, Chi Yuen Cheung, Kim Ming Wong, Hoi Wong Chan, Ka Foon Chau, Chun Sang Li, Kay Tai Leung, Tze Hoi Kwan, Johan E. de Vries, Petal A.H.M. Wijnen, Marja P. van Dieijen-Visser, Otto Bekers

\section{Submitted}




\section{Abstract}

Tacrolimus is predominantly demethylated into 13-0-demethyltacrolimus although identification of tacrolimus glucuronides demonstrates that conjugation also plays a role in the tacrolimus metabolism. Uridine 5'-diphosphateglucuronosyltransferase (UGT) 2B7 is identified as the most relevant member of the UGT family responsible for tacrolimus glucuronidation. Single nucleotide polymorphisms (SNPs) in the UGT2B7 gene may have a contribution on the interindividual variation of tacrolimus blood concentrations. $A$ two time point sampling strategy is used to calculate the $\mathrm{AUC}_{0-12}$ for 103 Chinese renal transplant recipients. In the present study real-time polymerase chain reaction (PCR) fluorescence resonance energy transfer (FRET) assays were developed and used to determine the genotype of three UGT2B7 polymorphisms in Chinese renal transplant recipients. The effect of these UGT2B7 polymorphisms on both the dose-normalized area under the time tacrolimus concentration curve $\left(\mathrm{dnAUC}_{0-12}\right)$ and the daily tacrolimus dose is examined. The variant alleles of UGT2B7 polymorphisms G-79A, T-66C and C816T with an allele frequency of respectively, $0.0 \%, 5.8 \%$ and $29.6 \%$ showed no significant differences on both the dnAUC $\mathrm{C}_{0-12}$ and the daily tacrolimus dose compared to carriers of the wild type UGT2B7 alleles when the patients were categorized based on their CYP3A5 A6986G, ABCB1 G2677T/A and ABCB1 C3435T genotype. Therefore, genotyping transplant patients for these UGT2B7 polymorphisms before using tacrolimus is irrelevant. 


\section{Introduction}

Tacrolimus is usually administered orally and has a rather unpredictable and variable absorption rate. Therefore close monitoring of the tacrolimus blood levels is required to prevent both subtherapeutic and toxic blood concentrations. Although cytochrome (CYP) 3A enzyme polymorphisms and possibly also adenosine triphosphate-binding cassette B1 (ABCB1) polymorphisms clarify a considerable part of the variation in tacrolimus trough $\left(C_{0}\right)$ levels ${ }^{1-13}$, there is still a large interindividual variation in the tacrolimus $\mathrm{C}_{0}$ levels. The analysis of tacrolimus metabolites in humans has provided evidence not only for CYP3A catalysed metabolism but also for the formation of glucuronides ${ }^{14}$. Strassburg et al. ${ }^{15}$ examined the glucuronidation activities of different uridine 5'-diphosphate glucuronosyltransferase (UGT) (sub)families for both tacrolimus and cyclosporin and found that UGT2B7 showed the highest glucuronidation activity in the human gastrointestinal tract. The UGT family, a group of proteins responsible for the glucuronidation of several endogene and exogene compounds in humans, is mainly present in the liver. However, UGTs are also found throughout the gastrointestinal tract, where they are an integral part of prehepatic first-pass metabolism. In addition, UGTs also work in the kidneys, brain, placenta and in several other locations in the human body ${ }^{16-18}$. The major function of glucuronidation is to increase the polarity of the target compound, a process which facilitates their detoxification and excretion. However, glucuronidation can also result in compounds which are biologically active or demonstrate increased toxicity. After glucuronidation, intestinal bacterial $\beta$-glucuronidases break down glucuronidation products and release the unconjugated drugs via enterohepatic recirculation. This "recycling" system slowly clears conjugated compounds and releases glucuronides for re-use ${ }^{19-23}$. Although Strassburg et al. ${ }^{15}$ reported that hepatic and extrahepatic glucuronidation may influence the therapeutic efficacy of immunosuppressants, the genetic influence of known UGT2B7 polymorphisms on the pharmacokinetic parameters of immunosuppressants has never been examined. In the present study, we have developed real-time polymerase chain reaction (PCR) fluorescence resonance energy transfer (FRET) assays for three UGT2B7 polymorphisms and examined whether the interindividual variation in the tacrolimus blood levels can be explained more exactly by genotyping the transplant recipients for these UGT 2B7 polymorphisms.

\section{Materials and methods}

\section{Study populations}

A total of 103 Chinese renal transplant recipients who received tacrolimus as part of the immunosuppressive therapy and had regular follow up in the Queen Elizabeth Hospital or Tuen Mun Hospital in Hong Kong were included in this retrospective study. There 
was no change in the daily tacrolimus dose for at least two weeks. Patients who were taking medication known to have interaction with tacrolimus, such as calcium channel blockers, anti-epileptics, anti-mycotics and macrolide antibiotics were excluded from this study. Additionally, patients who suffered from gastrointestinal tract disease, liver disease or other disorders that may alter the absorption of tacrolimus were also excluded. Apart from tacrolimus and steroids, the patients were normally put on azathioprine, however some patients preferred to use mycophenolic acid on advice of their private physician. The dosage of azathioprine was $1.5 \mathrm{mg} / \mathrm{kg} / \mathrm{day}$, while the dosage of mycophenolic acid was $0.5 \mathrm{gram}$ twice daily. The initial tacrolimus dosage, administrated twice daily, was $0.3 \mathrm{mg} / \mathrm{kg}$ per day for all patients. The daily tacrolimus dose was then adjusted according to the $A_{U} C_{0-12}$ value, which was kept at around $100-150 \mathrm{ng} \times \mathrm{hr} / \mathrm{ml}$ during the first 3 months. After three months the target $\mathrm{AUC}_{0-12}$ value was decreased at around $80-100 \mathrm{ng} \times \mathrm{hr} / \mathrm{ml}$ for long term maintenance. These $\mathrm{AUC}_{0-12}$ values were based on our previous study ${ }^{24}$ and the experiences obtained in our transplantation centers. The steroid regimen for the first month was $30 \mathrm{mg} / \mathrm{day}$ of oral prednisolone, progressively tapered by $2.5 \mathrm{mg}$ every two weeks until a daily maintenance dose of $5 \mathrm{mg}$. Demographic as well as clinical data were collected at the time of the tacrolimus blood sample collection.

\section{Determination whole blood tacrolimus concentrations}

Blood samples were collected 2 (C2) and 4 (C4) hours after the morning tacrolimus administration. Tacrolimus blood concentrations were determined in ethylene diamine tetra-acetic acid (EDTA) whole blood using a semi-automated microparticle enzyme immunoassay (MEIA) on an IMx II clinical analyser (Abbott Laboratories, Abbott Park, IL, USA). The two tacrolimus blood concentrations determined were used to calculate the $\mathrm{AUC}_{0-12}$ according to the equation based strategy as described earlier: $\mathrm{AUC}_{0-12}=$ $16.2+2.4 \times \mathrm{C} 2+5.9 \times \mathrm{C}^{24}$. Dose-normalized $\mathrm{AUC}_{0-12}\left(\mathrm{dnAUC}_{0-12}\right)$ were calculated by dividing the $\mathrm{AUC}_{0-12}$ by the corresponding 24-hour dose on a milligrams per kilogram basis.

\section{DNA isolation}

Genomic DNA was extracted from 103 Chinese renal transplant recipients by using $200 \mu \mathrm{l}$ EDTA anti coagulated blood for isolation with a QIAamp blood mini kit (Qiagen, Leusden, the Netherlands) according to the manufacturers' instructions.

\section{UGT2B7 G-79A, T-66C and C816T primers and probes}

The real-time PCR fluorescence resonance energy transfer (FRET) assays were designed and optimised in our laboratory. Genotyping for the UGT2B7 G-79A and T-66C polymorphisms was performed using the primers F30: 5'-TTg CAT gTC CAT ACA AgA TCC T-'3 (sense; 1150-171) and R30: 5'-ATT TCA CAg ACA TCC Tgg TgC- 
'3 (anti-sense;1432-412) to amplify a 273 bp part from the UGT2B7 gene which covers both G-79A and T-66C polymorphisms in the promoter region of the UGT2B7 gene (Genbank acces no: AF282881). Detection of the UGT2B7 G-79A polymorphism was carried out using the anchor probe 79A30: 5'-Tgg CAA AgA gAC AAA TgA Agg TAA ATg ATC TgT TC-3' (anti-sense; 1265 - 231) which was labelled at the 5'-end with LCRed640 and phosphorylated at the 3'- end to block extension from the sensor probe 79P30: 5' CAT TAA ATC AAㅡ AgT CTg AgC ATg Tgg 3' (anti-sense; 1293-267) which is complementary to the UGT2B7 -79G polymorphism. This 3'-fluorescence-labelled sensor probe, in which the polymorphic nucleotide is underlined binds with a distance of one base 5' to the detection probe. Detection of the UGT2B7 T-66C polymorphism was carried out using the anchor probe 66A30: 5'-Agg gTT ACA TTT TAA CTT CTT ggC TAA TTT ATC TT- 3' (sense; 1283-316) which was labelled at the 5'-end with LCRed640 and phosphorylated at the 3'- end to block extension from the sensor probe

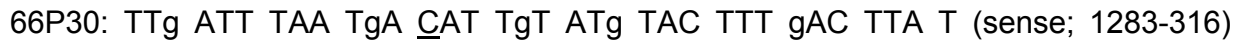
which is complementary to the UGT2B7 -66C polymorphism. This 3'-fluorescencelabelled sensor probe, in which the polymorphic nucleotide is underlined binds with a distance of one base 5' to the detection probe. The PCR mixture for both real-time PCR FRET assays contained: $3.2 \mu \mathrm{l}$ sterile water; $3.0 \mathrm{mM} \mathrm{MgCl}$; $1.0 \mu \mathrm{l}$ LC Faststart DNA Master Hybridization Probes (Roche Diagnostics $\mathrm{GmbH}$, Mannheim, Germany); $0.5 \mu \mathrm{M}$ of each primer and $0.2 \mu \mathrm{M}$ of both sensor and anchor probe (TIB MOLBIOL, Berlin, Germany). After adding 1.0 $\mu$ l containing 50-100 ng genomic DNA to the PCR mixture, the total volume was $10 \mu \mathrm{l}$. The PCR protocol included the following steps: denaturation for ten minutes at $95^{\circ} \mathrm{C} ; 45$ cycles at $95^{\circ} \mathrm{C}$ for tenseconds, $55^{\circ} \mathrm{C}$ for ten seconds and $72^{\circ} \mathrm{C}$ for 11 seconds. After amplification was completed, a melting curve was recorded by heating to $95^{\circ} \mathrm{C}\left(20^{\circ} \mathrm{C} /\right.$ second $)$ holding at $95^{\circ} \mathrm{C}$ for 30 seconds; subsequently cooling to $45^{\circ} \mathrm{C}\left(20^{\circ} \mathrm{C} /\right.$ second $)$ holding at $45^{\circ} \mathrm{C}$ for 1 minute and then heating slowly to $75^{\circ} \mathrm{C}$ at $0.2^{\circ} \mathrm{C} /$ second. Genotyping for the UGT2B7 C816T polymorphism was performed using the primers F31: 5'-ACC TTT TTT TTT TCT ATT CCT gT-'3 (sense; 1-23) and R31: 5'-CAA AAT AAA ACC AAC AAA AgT ATg-'3 (anti-sense; 204-181) to amplify a $204 \mathrm{bp}$ part from the UGT2B7 gene which covers the T815C and C816T polymorphisms in exon 1 (Genbank acces no: AF282881). Detection of the UGT2B7 C816T polymorphism was carried out using the anchor probe A31: 5'-CCA AAT gTT gAT TTT gTT ggA ggA CTC C-3' (sense; 119-146) which was labelled at the 5'-end with LCRed640 and phosphorylated at the 3' end to block extension from the sensor probe, P31: 5'-gAA TTT TCA gTT TCC ATA TCC ACT CTT-'3 which is complementary to the UGT2B7 816T polymorphism. This 3'-fluorescence-labelled sensor probe, in which the polymorphic nucleotide is underlined binds with a distance of one base 5 ' to the detection probe. The PCR mixture for the real-time PCR FRET assay contained: $3.2 \mu$ sterile water; $3.0 \mathrm{mM}$ $\mathrm{MgCl}_{2} ; 1.0 \mu \mathrm{l}$ LC Faststart DNA Master Hybridization Probes (Roche Diagnostics $\mathrm{GmbH}$, Mannheim, Germany); $0.5 \mu \mathrm{M}$ of each primer and $0.2 \mu \mathrm{M}$ of both sensor and anchor probe (TIB MOLBIOL, Berlin, Germany). After adding 1.0 $\mu$ l containing 50-100 ng genomic DNA to the PCR mixture the total volume was $10 \mu \mathrm{l}$. The PCR protocol 
included the following steps: denaturation for ten minutes at $95^{\circ} \mathrm{C}$; 45 cycles at $95^{\circ} \mathrm{C}$ for ten seconds, $55^{\circ} \mathrm{C}$ for ten seconds and $72^{\circ} \mathrm{C}$ for eight seconds. After amplification was completed, a melting curve was recorded by heating to $95^{\circ} \mathrm{C}\left(20^{\circ} \mathrm{C} /\right.$ second $)$ holding at $95^{\circ} \mathrm{C}$ for 30 seconds; subsequently cooling to $62^{\circ} \mathrm{C}\left(0.5^{\circ} \mathrm{C} /\right.$ second $)$ holding at $62^{\circ} \mathrm{C}$ for one minute and finally cooling to $45^{\circ} \mathrm{C}$ for 0 seconds $\left(20^{\circ} \mathrm{C} /\right.$ second) and then heating slowly to $80^{\circ} \mathrm{C}$ at $0.1^{\circ} \mathrm{C} /$ second. All real-time PCR and melting curve analyses were performed on a LightCycler (Roche Diagnostics, Almere, the Netherlands). Additionally, sequencing is performed on a capillary sequencer $A B I$ Prism 3100 using the Bridge version 1.1 sequence kit (Both products from Applied Biosystems, Fostercity, USA) and is used for identifying the presence of the expected UGT2B7 polymorphisms. The control samples that are sequenced are also used as controls in the different real-time PCR FRET assays.

\section{Statistical analysis}

The statistical analysis of the data was performed with use of the statistical software SPSS 11.0 for windows (Chicago, IL, USA). Patients genotypes were used as categorical independent variables for analysis of continuous clinical and pharmacological variables. To examine the population homogeneity of the patients, the genotype frequencies of the UGT2B7 polymorphisms were tested against HardyWeinberg equilibrium by the Pearson's goodness-of-fit test. For analysis of the daily dose of tacrolimus $(\mathrm{mg} / \mathrm{kg} / \mathrm{day})$ and the dnAUC $\mathrm{A}_{-12}(\mathrm{ng} \times \mathrm{hr} / \mathrm{ml}$ per $\mathrm{mg} / \mathrm{kg})$, groups were compared using non parametric statistical tests. To compare two groups we used the Mann Whitney test, and to compare several groups, the Kruskal Wallis test. $P$ values less than 0.05 were considered statistically significant. All values are expressed as median and range unless stated otherwise.

\section{Results}

\section{Real-time PCR FRET assays for the UGT2B7 G-79A, T-66C, C816T polymorphisms}

The melting point of the sensor probe for the UGT2B7 G-79A polymorphism was $59.5^{\circ} \mathrm{C}$ when hybridised to the UGT2B7 $-79 \mathrm{G}$ allele and $57.5^{\circ} \mathrm{C}$ when hybridised to the UGT2B7 $-79 \mathrm{~A}$ allele, whereas for the UGT2B7 T-66C polymorphism, the melting point of the sensor probe was $52^{\circ} \mathrm{C}$ when hybridised to the UGT2B7 $-66 \mathrm{~T}$ allele was and $59^{\circ} \mathrm{C}$ when hybridised to the UGT-66C allele. A heterozygote sample for the UGT2B7 G-79A and T-66C polymorphisms showed both melting peaks (Figure 10.1A and 10.1B). In addition, for the UGT2B7 C816T polymorphism, the melting point of the sensor probe was $62.5^{\circ} \mathrm{C}$ for the UGT2B7 $816 \mathrm{~T}$ allele and $57.5^{\circ} \mathrm{C}$ when hybridised to the UGT2B7 816C allele. A heterozygote sample for the UGT2B7 C816T polymorphism showed both 
melting peaks (Figure 10.1C). The presence of the expected polymorphisms was confirmed by sequencing the allelic variants of UGT2B7 according to a direct sequence procedure on a capillary sequencer $A B I$ Prism 3100 using the Bridge version 1.1 sequence kit (Both products from Applied Biosystems, Fostercity, USA). A heterozygote DNA sample was found for the UGT2B7 G-79A polymorphism among anonymized healthy Caucasian volunteers using a real-time PCR FRET assay for this UGT2B7 G-79A polymorphism. Additionally, this control sample was sequenced to confirm that this sample is heterozygous for the UGT2B7 G-79A polymorphism.
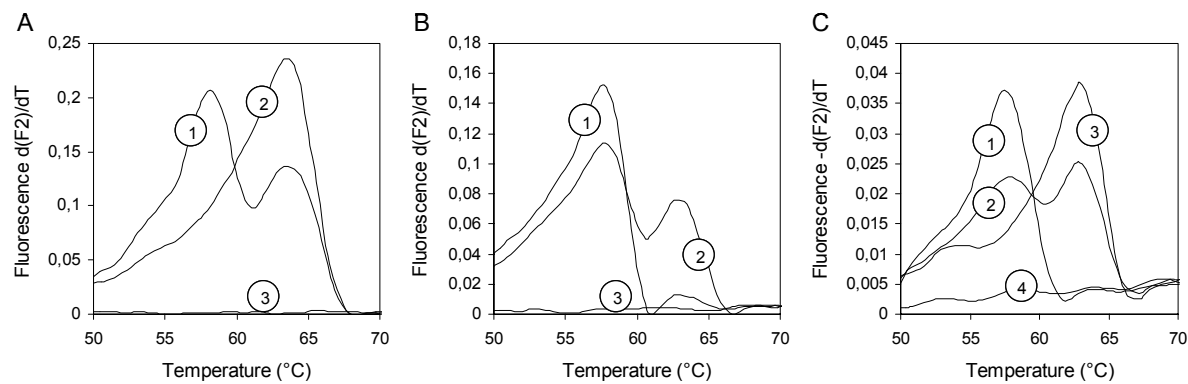

Figure 10.1 Genotyping of UGT2B7 G-79A, T-66C and C816T with allele specific fluorescent probes by derivative melting curve plots. The derivative melting curves are read in channel 2 for the detection of the two UGT2B7 fragments. A. The derivative melting curve is plotted for a sample homozygous for the UGT2B7 -79G allele $\left(1 ; \mathrm{Tm} 59.5^{\circ} \mathrm{C}\right)$ and a heterozygous sample $\left(2 ; \operatorname{Tm} 57.5^{\circ} \mathrm{C}\right.$ and $\left.59.5^{\circ} \mathrm{C}\right)$. B. The derivative melting curve is plotted for a sample homozygous for the UGT2B7 $-66 \mathrm{~T}$ allele $\left(1 ; \mathrm{Tm} 52^{\circ} \mathrm{C}\right)$ and a heterozygous sample $\left(2 ; \mathrm{Tm} 52^{\circ} \mathrm{C}\right.$ and $\left.59^{\circ} \mathrm{C}\right)$. C. The derivative melting curve is plotted for a sample homozygous for the UGT2B7 $816 \mathrm{C}$ allele $\left(1 ; \mathrm{Tm} 57.5^{\circ} \mathrm{C}\right)$; a sample homozygous for the UGT2B7 $816 \mathrm{~T}$ allele $\left(2 ; \mathrm{Tm} 62.5^{\circ} \mathrm{C}\right)$ and a heterozygous sample $\left(3 ; \mathrm{Tm} 57.5^{\circ} \mathrm{C}\right.$ and $\left.62.5^{\circ} \mathrm{C}\right)$ Melting analysis of a no template control was also performed for all assays ( 3 or 4 ).

\section{Influence of the different UGT2B7 allelic variants on the pharmacokinetic tacrolimus profiles}

Table 10.1 illustrates the demographic characteristics of 103 Chinese renal transplant recipients included in the present study. After genotyping 103 renal transplant patients, no variant allele was found for the UGT2B7 G-79A polymorphism whereas the frequency of the UGT2B7 -66TT genotype was found to be $88 \%(n=91)$ and for the UGT2B7 -66TC the frequency was 12\% ( $n=12)$. In addition, $49 \%(n=51)$ of the patients were carrier of the UGT2B7 816CC genotype while 42\% ( $n=43)$ was heterozygous carrier of the UGT2B7 816CT genotype and 9\% $(n=9)$ homozygous for the UGT2B7 816TT variant allele. The allele frequencies of the Chinese renal transplant patients examined were found to be $0.0 \%(-79 \mathrm{~A}), 5.8 \%(-66 \mathrm{C})$ and $29.6 \%(816 \mathrm{~T})$, which is not in line with those published in previous studies ${ }^{25,26}$. According to the Pearson's 
goodness-of-fit test the genotype frequencies of these UGT2B7 polymorphisms differed not significantly from the Hardy-Weinberg equilibrium $(P>0.05)$.

Table 10.1 Demographic characteristics of the renal transplant recipients.

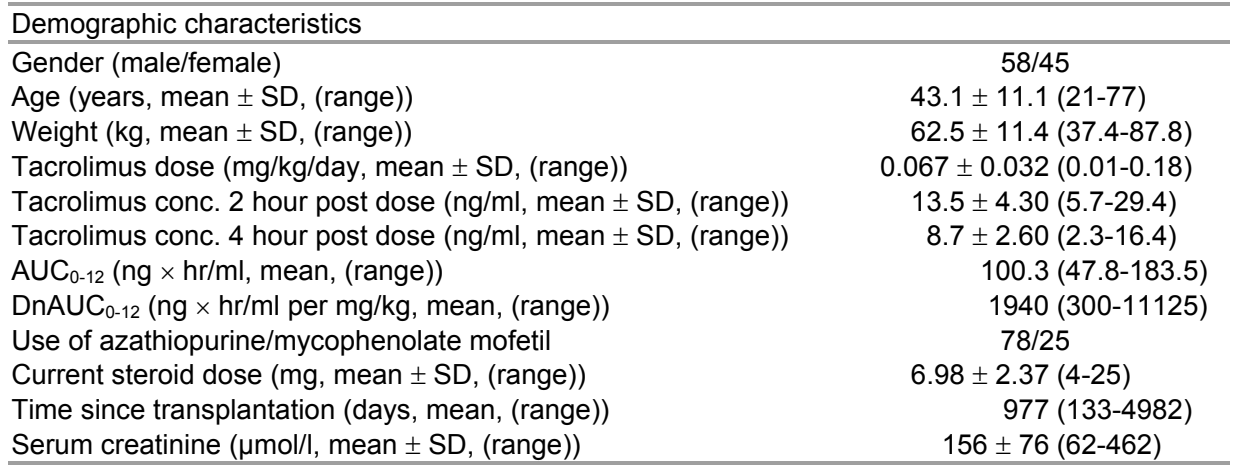

A significant higher dnAUC 0 -12 (1685 versus $1276 \mathrm{ng} \times \mathrm{hr} / \mathrm{ml}$ per mg/kg; Mann-Whitney, $P=0.026$ ) was observed for carriers of the UGT2B7 -66TT genotype compared to carriers of the UGT2B7 -66TC genotype while no significant difference (Kruskal Wallis, $P=0.817$ ) was observed between carriers of a different UGT2B7 C816T genotypes. This is illustrated in Figure 10.2A and 10.3A. However, previously we demonstrated in the same renal transplant patient group an important impact of the CYP3A5 A6986G polymorphism whereas a minor association was reported between both $A B C B 1$ polymorphisms G2677T/A and C3435T and the tacrolimus blood concentrations ${ }^{13}$. To exclude influence of one of these polymorphisms, the renal transplant recipients were based on their CYP3A5 and ABCB1 G2677T/A, C3435T genotype categorized in order to examine solely the effect of the two UGT2B7 T-66C and C816T polymorphisms on the dnAUC $\mathrm{C}_{0-12}$ and the daily tacrolimus dose. As is illustrated in Figure 10.2B - 10.2D, there is no significant influence of UGT2B7 T-66C polymorphism on the dnAUC $0-12$ of tacrolimus after categorizing the patients for respectively CYP3A5 A6986G, ABCB1 G2677T/A and ABCB1 C3435T genotype. Additionally, after categorizing the patients, Figures 10.3B - 10.3D illustrate that there is, as expected, also no significant effect of the UGT2B7 C816T polymorphism on the dnAUC $0-12$ of tacrolimus. Regarding the daily tacrolimus dose requirement similar results were obtained for both UGT2B7 polymorphisms. 
A
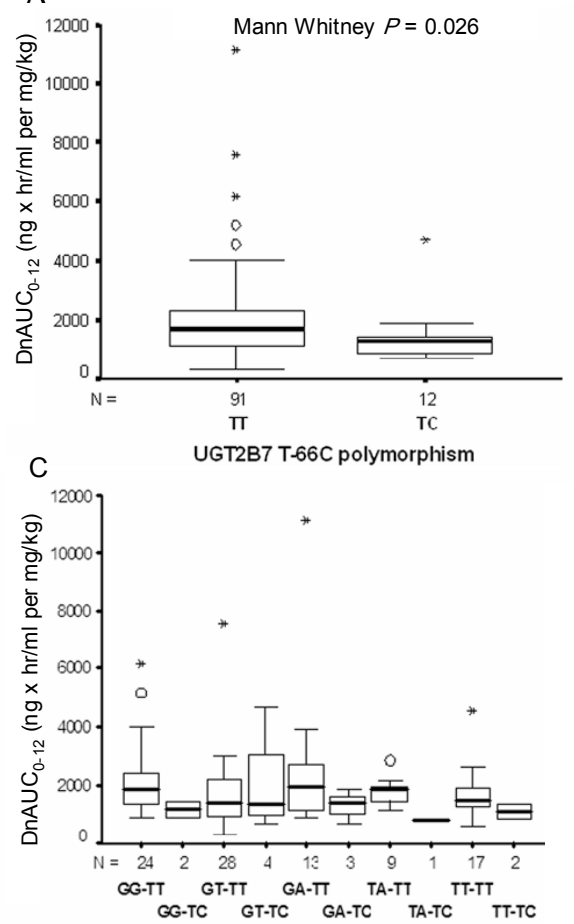

ABCB1 G2677T/A and UGT2B7 T-66C genotypes
B

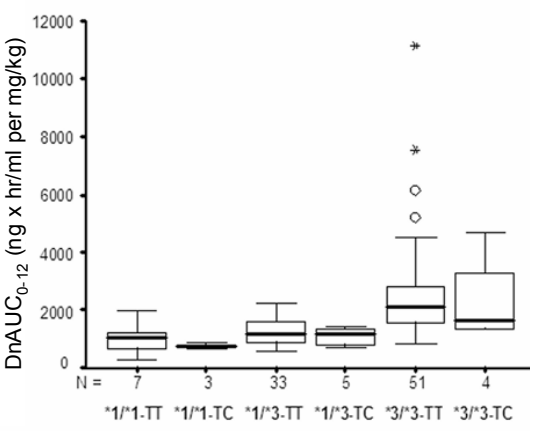

$\mathrm{D}$

CYP3A5 A6986G and UGT2B7 T-66C genotypes

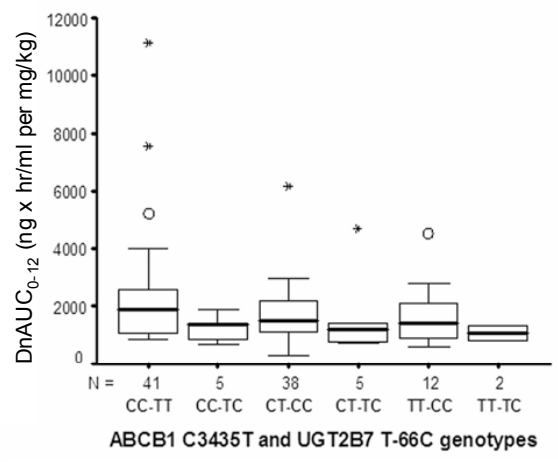

Figure 10.2 Influence of the UGT2B7 T-66C and C816T genotypes on the area under the time tacrolimus concentration curve $\left(\mathrm{AUC}_{0-12}\right)$ that were recorded in 103 stable Chinese renal transplant recipients. Figure 10.2 illustrates the boxplots of the distribution of the dose normalized $\mathrm{AUC}_{0-12}(\mathrm{ng} \times \mathrm{hr} / \mathrm{ml}$ per $\mathrm{mg} / \mathrm{kg}$ ) clustered according to the $(\mathrm{A})$ UGT2B7 T-66C genotype, (B) the combination of respectively CYP3A5 A6986G and UGT2B7 T-66C genotypes, (C) ABCB1 G2677T/A and UGT2B7 T-66C genotypes and (D) ABCB1 C3435T and UGT2B7 T-66C genotypes. Open circles indicate an outlier value at more than 1.5 box lengths above the box, while asterics indicate an extreme value at more than 3 box lengths above the box. 
A
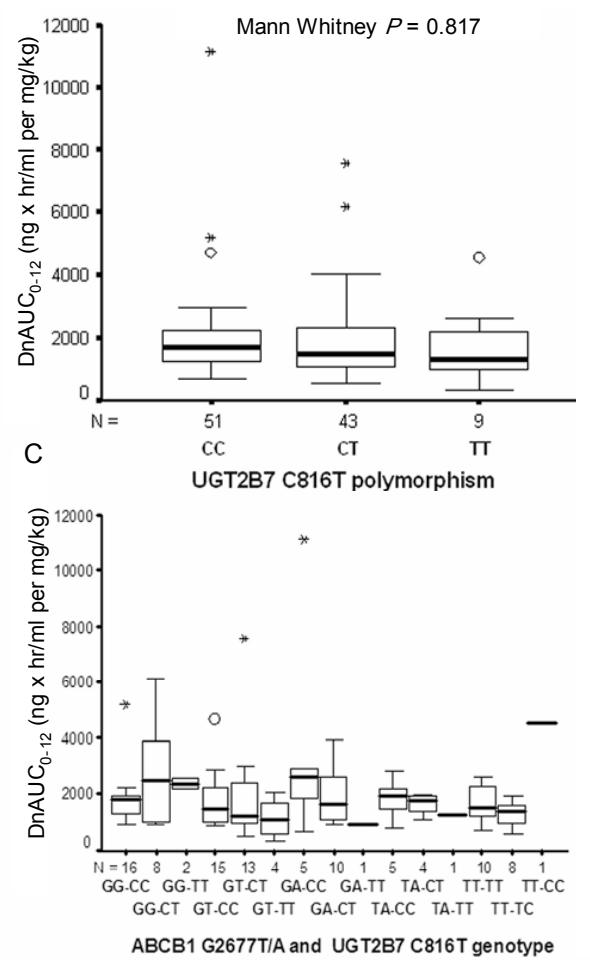

B
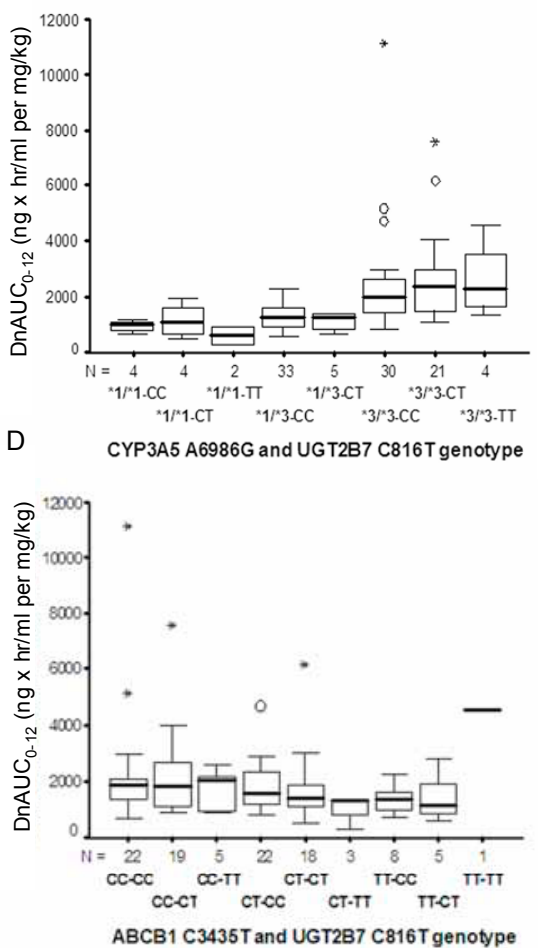

Figure 10.3 This figure illustrates the boxplots of the distributions of the $A \mathrm{CC}_{0-12}(\mathrm{ng} \times \mathrm{hr} / \mathrm{ml}$ per $\mathrm{mg} / \mathrm{kg}$ ) clustered according to the (A) UGT2B7 C816T genotype, (B) the combination of respectively CYP3A5 A6986G and UGT2B7 C816T genotypes, (C) ABCB1 G2677T/A and UGT2B7 C816T genotypes and (D) ABCB1 C3435T and UGT2B7 C816T genotypes. Open circles indicate an outlier value at more than 1.5 box lengths above the box, while asterics indicate an extreme value at more than 3 box lengths above the box.

\section{Highlights}

- Tacrolimus is predominately demethylated into 13-O-demethyltacrolimus by CYP3A iso-enzymes. However, identification of tacrolimus glucuronides demonstrate that besides demethylation also conjugation influences the tacrolimus metabolism.

- Uridine 5'-diphosphate glucuronosyltransferase (UGT) 2B7 mainly present in the liver and intestines is the major UGT isoform responsible for the glucuronidation of tacrolimus.

- $\quad$ Several single nucleotide polymorphisms (SNPs) identified in the UGT2B7 gene may besides the cytochrome $3 \mathrm{~A}$ (CYP3A) and adenosine diphosphate-binding 
cassette B1 (ABCB1) polymorphisms also explain the interindividual differences in the tacrolimus pharmacokinetics.

- A two time point sampling strategy is used to calculate the area under the time tacrolimus concentration curve $\left(\mathrm{AUC}_{0-12}\right)$ and the dose-normalised (dn) $\mathrm{AUC}_{0-12}$ are correlated with the corresponding UGT2B7 genotypes in 103 Chinese renal transplant recipients.

- After eliminating the influence of the CYP3A5 and ABCB1 polymorphisms, no significant differences were found in the $\mathrm{dnAUC}_{0-12}$ and daily tacrolimus dose between carriers of different UGT2B7 genotypes.

- Our findings indicate that SNPs in the UGT2B7 gene have no significant impact on the tacrolimus blood concentration and tacrolimus dosage. Therefore, we conclude that polymorphisms in the UGT2B7 gene have no important contribution on the interindividual variability of the tacrolimus pharmacokinetics.

\section{Discussion}

Previously, we reported a strong allele-dependent effect between the CYP3A5 A6986G polymorphism and both the $\mathrm{dnAUC}_{0-12}$ and the daily tacrolimus dose, while a less pronounced effect was found for the ABCB1 G2677T/A and C3435T polymorphisms in this Chinese renal transplant recipient population ${ }^{13}$. However, there is still variation in the tacrolimus blood concentrations among the renal transplant patients carrying the same CYP3A5 and ABCB1 genotypes. Although identification of tacrolimus ${ }^{14}$ glucuronides demonstrates that conjugation also plays a role in the metabolisation of this immunosuppressant, less information is available regarding the UDPglucuronosyltransferases (UGT) involved in the tacrolimus metabolism. Strassburg et al. ${ }^{15}$ found that UGT2B7 is the member of the UGT family that is responsible for the tacrolimus glucuronidation. Large inter-individual differences in the mRNA expression levels of $\mathrm{UGT} 2 \mathrm{~B} 7^{27}$, which could be caused to a degree by polymorphisms, may possibly explain a part of the inter-individual pharmacokinetic variation of tacrolimus. $A$ common polymorphism in the UGT2B7 gene (UGT2B7 C816T) has been found in Caucasians and Asians ${ }^{26}$. Although one study ${ }^{28}$ found no remarkable function difference between the different carriers of the UGT2B7 C816T polymorphism, another study ${ }^{29}$ recently reported that UGT2B7 816T variant allele showed significantly higher morphine-6-O-glucuronide/morphine ratios than that with the wild type UGT2B7 allele. More recently, Duguay et al. ${ }^{30}$ discovered the functional polymorphism $-79 \mathrm{~A}$ in the UGT2B7 promoter with significant impact on the promoter activity while the variation at position -66 resulted in a non-significant alteration of promoter activity compared to the wild type promoter. However, no significant difference in the ratios of morphine-6glucuronide/morphine and morphine-3-glucuronide/morphine were found between 6 heterozygous carriers of the UGT2B7 -79A variant allele and 175 wild type carriers among cancer patients receiving long term oral morphine. Although Strassburg et al. ${ }^{15}$ 
demonstrated that tacrolimus glucuronidation is performed exclusively by UGT2B7, the present study demonstrated that the UGT2B7 polymorphisms T-66C and C816T have no influence on the $\mathrm{dnAUC}_{0-12}$ of tacrolimus and the daily tacrolimus dose when categorizing patients in different groups for the CYP3A5 A6986G, ABCB1 G2677T/A and C3435T genotype. Since tacrolimus is predominately demethylated into 13-Odemethyltacrolimus it seems that tacrolimus glucuronidation plays a neglectable role in the tacrolimus metabolisation process.

\section{Outlook}

The calcineurin inhibitor tacrolimus is generally used as an immunosuppressive drug in solid organ transplantations. However, it is difficult to maintain an appropriate blood concentration of tacrolimus due to its narrow therapeutic index and significant intra- and inter-individual variety. Tacrolimus is predominantly metabolized into 13-Odemethyltacrolimus by CYP3A4 and CYP3A5 in the liver and intestines, and subsequently pumped out by P-glycoprotein, an ATP dependent efflux pump, encoded by the adenosine triphosphate-binding cassette $B 1$ (ABCB1) gene. Therefore, these proteins are considered to have a major influence on the first-pass effect in the liver and the intestines and on the variation in tacrolimus pharmacokinetics. Several studies already reported the impact of some CYP3A and ABCB1 polymorphisms on the tacrolimus trough $\left(\mathrm{C}_{0}\right)$ levels, pharmacokinetic tacrolimus parameters and the daily tacrolimus dose in transplant patients. However, identification of tacrolimus glucuronides demonstrates that conjugation also plays a role in the tacrolimus metabolism. Uridine 5'-diphosphate glucuronosyltransferase (UGT) 2B7 is the most important UGT isoform responsible for the glucuronidation of tacrolimus. Single nucleotide polymorphisms (SNPs) in the UGT2B7 gene may have an effect on the interindividual variation in the tacrolimus pharmacokinetics. In the present study we calculated an area under the time tacrolimus concentration curve $\left(\mathrm{AUC}_{0-12}\right)$ based on a two time point sample strategy for 103 Chinese renal transplant recipients and demonstrated that the UGT2B7 polymorphisms T-66C and C816T have no significant role on the variation of the dosenormalized $\mathrm{AUC}_{0-12}$ and the daily tacrolimus dose. Therefore, genotyping renal transplant patients for these UGT2B7 polymorphisms will not contribute to less variation in the tacrolimus blood concentrations and a better individualized immunosuppressive therapy. 


\section{References}

1. MacPhee IA, Fredericks S, Tai T, Syrris P, Carter ND, Johnston A, Goldberg L, Holt DW. The influence of pharmacogenetics on the time to achieve target tacrolimus concentrations after kidney transplantation. Am J Transplant 2004;4: 914-9.

2. Macphee IA, Fredericks S, Tai T, Syrris P, Carter ND, Johnston A, Goldberg L, Holt DW. Tacrolimus pharmacogenetics: polymorphisms associated with expression of cytochrome p4503A5 and P-glycoprotein correlate with dose requirement. Transplantation 2002;74:14869.

3. MacPhee IA, Fredericks S, Mohamed M, Moreton M, Carter ND, Johnston A, Goldberg L, Holt DW. Tacrolimus pharmacogenetics: the CYP3A5*1 allele predicts low dose-normalized tacrolimus blood concentrations in whites and South Asians. Transplantation 2005;79:499502.

4. Hesselink DA, van Schaik RH, van der Heiden IP, van der Werf M, Gregoor PJ, Lindemans J, Weimar W, van Gelder T. Genetic polymorphisms of the CYP3A4, CYP3A5, and MDR-1 genes and pharmacokinetics of the calcineurin inhibitors cyclosporine and tacrolimus. Clin Pharmacol Ther 2003;74:245-54.

5. Haufroid V, Mourad M, Van Kerckhove V, Wawrzyniak J, De Meyer M, Eddour DC, Malaise J, Lison D, Squifflet JP, Wallemacq P. The effect of CYP3A5 and MDR1 (ABCB1) polymorphisms on cyclosporine and tacrolimus dose requirements and trough blood levels in stable renal transplant patients. Pharmacogenetics 2004;14:147-54.

6. Thervet E, Anglicheau D, King B, Schlageter MH, Cassinat B, Beaune P, Legendre C, Daly AK. Impact of cytochrome p450 3A5 genetic polymorphism on tacrolimus doses and concentration-to-dose ratio in renal transplant recipients. Transplantation 2003;76:1233-5.

7. Tsuchiya N, Satoh S, Tada H, Li Z, Ohyama C, Sato K, Suzuki T, Habuchi T, Kato T. Influence of CYP3A5 and MDR1 (ABCB1) polymorphisms on the pharmacokinetics of tacrolimus in renal transplant recipients. Transplantation 2004;78:1182-7.

8. Goto M, Masuda S, Kiuchi T, Ogura Y, Oike F, Okuda M, Tanaka K, Inui K. CYP3A5*1carrying graft liver reduces the concentration/oral dose ratio of tacrolimus in recipients of living-donor liver transplantation. Pharmacogenetics 2004;14:471-8.

9. Zhao Y, Song M, Guan D, Bi S, Meng J, Li Q, Wang W. Genetic polymorphisms of CYP3A5 genes and concentration of the cyclosporine and tacrolimus. Transplant Proc 2005;37:17881.

10. Zheng H, Webber S, Zeevi A, Schuetz E, Zhang J, Bowman P, Boyle G, Law Y, Miller S, Lamba J, Burckart GJ. Tacrolimus dosing in pediatric heart transplant patients is related to CYP3A5 and MDR1 gene polymorphisms. Am J Transplant 2003;3:477-83.

11. Zheng H, Zeevi A, Schuetz E, Lamba J, McCurry K, Griffith BP, Webber S, Ristich J, Dauber J, lacono A, Grgurich W, Zaldonis D, McDade K, Zhang J, Burckart GJ. Tacrolimus dosing in adult lung transplant patients is related to cytochrome P4503A5 gene polymorphism. J Clin Pharmacol 2004;44:135-40.

12. Asano $\mathrm{T}$, Nishimoto $\mathrm{K}$, Hayakawa $\mathrm{M}$. Increased tacrolimus trough levels in association with severe diarrhea, a case report. Transplant Proc 2004;36:2096-7.

13. Cheung CY, Op den Buijsch RA, Wong KM, Chan HW, Chau KF, Li CS, Leung KT, Kwan TH, de Vrie JE, Wijnen PA, van Dieijen-Visser MP, Bekers O. Influence of different allelic variants of the CYP3A and ABCB1 genes on the tacrolimus pharmacokinetic profile of Chinese renal transplant recipients. Pharmacogenomics 2006;7:563-74.

14. Firdaous I, Verbeeck RK, Hassoun A, Langrehr JM, Wallemacq PE. Excretion of tacrolimus glucuronides in human bile. Eur J Drug Metab Pharmacokinet 1997;22:217-21.

- Firdaous et al identified tacrolimus glucuronides and thus demonstrated that conjugation also influenced the tacrolimus metabolism.

15. Strassburg CP, Barut A, Obermayer-Straub P, Li Q, Nguyen N, Tukey RH, Manns MP. Identification of cyclosporine $A$ and tacrolimus glucuronidation in human liver and the gastrointestinal tract by a differentially expressed UDP-glucuronosyltransferase: UGT2B7. J Hepatol 2001;34:865-72. 
- First study describing that only UGT2B7 of the different UGT isoforms is responsible for the glucuronidation of tacrolimus and ciclosporin

16. Beaulieu M, Levesque E, Hum DW, Belanger A. Isolation and characterization of a human orphan UDP-glucuronosyltransferase, UGT2B11. Biochem Biophys Res Commun 1998;248: 44-50.

17. Hum DW, Belanger A, Levesque E, Barbier O, Beaulieu M, Albert C, Vallee M, Guillemette C, Tchernof A, Turgeon D, Dubois S. Characterization of UDP-glucuronosyltransferases active on steroid hormones. J Steroid Biochem Mol Biol 1999;69:413-23.

18. Turgeon D, Carrier JS, Levesque E, Hum DW, Belanger A. Relative enzymatic activity, protein stability, and tissue distribution of human steroid-metabolizing UGT2B subfamily members. Endocrinology 2001;142:778-87.

19. Guillemette C. Pharmacogenomics of human UDP-glucuronosyltransferase enzymes. Pharmacogenomics J 2003;3:136-58.

- Excellent review article regarding the pharmacogenomics of the different UGT isoforms.

20. Radominska-Pandya A, Little JM, Czernik PJ. Human UDP-glucuronosyltransferase 2B7. Curr Drug Metab 2001;2:283-98.

21. King CD, Rios GR, Green MD, Tephly TR. UDP-glucuronosyltransferases. Curr Drug Metab 2000;1:143-61.

22. Meech R, Mackenzie PI. Structure and function of uridine diphosphate glucuronosyltransferases. Clin Exp Pharmacol Physiol 1997;24:907-15.

23. Tukey RH, Strassburg CP. Genetic multiplicity of the human UDP-glucuronosyltransferases and regulation in the gastrointestinal tract. Mol Pharmacol 2001;59:405-14.

24. Wong KM, Shek CC, Chau KF, Li CS. Abbreviated tacrolimus area-under-the-curve monitoring for renal transplant recipients. Am J Kidney Dis 2000;35:660-6.

25. Lampe JW, Bigler J, Bush AC, Potter JD. Prevalence of polymorphisms in the human UDPglucuronosyltransferase 2B family: UGT2B4(D458E), UGT2B7(H268Y), and UGT2B15(D85Y). Cancer Epidemiol Biomarkers Prev 2000;9:329-33.

26. Bhasker CR, McKinnon W, Stone A, Lo AC, Kubota T, Ishizaki T, Miners JO. Genetic polymorphism of UDP-glucuronosyltransferase 2B7 (UGT2B7) at amino acid 268: ethnic diversity of alleles and potential clinical significance. Pharmacogenetics 2000;10:679-85.

27. Congiu M, Mashford ML, Slavin JL, Desmond PV. UDP glucuronosyltransferase mRNA levels in human liver disease. Drug Metab Dispos 2002;30:129-34.

28. Holthe M, Klepstad P, Zahlsen K, Borchgrevink PC, Hagen L, Dale O, Kaasa S, Krokan HE, Skorpen F. Morphine glucuronide-to-morphine plasma ratios are unaffected by the UGT2B7 H268Y and UGT1A1*28 polymorphisms in cancer patients on chronic morphine therapy. Eur $\mathrm{J}$ Clin Pharmacol 2002;58:353-6.

- Holthe et al reported that the UGT2B7 C816T polymorphism can not account for the considerable variation in glucuronide-to-morphine ratio's in cancer patients.

29. Sawyer MB, Innocenti F, Das S, Cheng C, Ramirez J, Pantle-Fisher FH, Wright C, Badner J, Pei D, Boyett JM, Cook E Jr, Ratain MJ. A pharmacogenetic study of uridine diphosphateglucuronosyltransferase $2 \mathrm{~B} 7$ in patients receiving morphine. Clin Pharmacol Ther 2003;73:566-74.

- First study that found significantly lower morphine levels in patients carrying the UGT2B7 816TT genotype compared to the UGT2B7 816CT or 816CC genotype.

30. Duguay $\mathrm{Y}$, Baar $\mathrm{C}$, Skorpen F, Guillemette $\mathrm{C}$. A novel functional polymorphism in the uridine diphosphate-glucuronosyltransferase $2 \mathrm{~B} 7$ promoter with significant impact on promoter activity. Clin Pharmacol Ther 2004;75:223-33.

- Duguay et al first described the UGT2B7G-79A polymorphism that has a significant impact on the promoter activity. 


\section{Chapter 11}

\section{Pregnane $\mathrm{X}$ receptor (PXR) polymorphisms involved in the tacrolimus pharmacokinetics}

Robert A.M. Op den Buijsch, Chi Yuen Cheung, Yan Lun Liu,Hoi Wong Chan, Ka Foon Chau, Chun Sang Li, Kay Tai Leung, Tze Hoi Kwan, Johan E. de Vries, Petal A.H.M. Wijnen, Marja P. van Dieijen-Visser, Otto Bekers

\section{Submitted}




\section{Abstract}

Cytochrome P450 (CYP) 3A4/5 are responsible for metabolizing tacrolimus while the P-glycoprotein pump (ABCB1) modulates its bioavailability. Differences in gene expression can not be fully explained by CYP3A4/5 and/or ABCB1 polymorphisms. The pregnane $X$ receptor (PXR) is a transcriptional regulator of the CYP450 and the ABCB1 expression. Real-time PCR FRET assays determine the genotypes of four PXR polymorphisms in 103 Chinese renal transplant recipients to examine its influence on dose-normalized $\mathrm{AUC}_{0-12}\left(\mathrm{dnAUC}_{0-12}\right)$. Individuals carrying a variant allele for PXR polymorphisms A7635G, C8055T, A11156C and T11193C, associated with increased expression of CYP3A4 or $\mathrm{ABCB} 1$, had lower dnAUC 0 -12 for tacrolimus compared to individuals carrying the wild type variant for these PXR polymorphisms (respectively, Mann-Whitney; $P=0.038, P=0.088, P=0.038$ and $P=0.038$ ). These PXR polymorphisms are associated with a trend towards a lower $\operatorname{dnAUC}_{0-12}$ of tacrolimus which confirms a role of PXR in the CYP3A and ABCB1 expression and thereby on the tacrolimus metabolism. 


\section{Introduction}

Tacrolimus has a narrow therapeutic index which requires close monitoring of the drug concentration to achieve an optimal efficiency and minimizing the risks of acute rejection and drug overdose. The polymorphisms present in the cytochrome P450 3A5 (CYP3A5) iso-enzyme and adenosine triphosphate-binding cassette gene B1 (ABCB1) can partly explain their variability in expression and activity and thus clarify to a certain extend the interindividual differences in the tacrolimus pharmacokinetics. However, cytochrome P450 3A4 (CYP3A4) expression shows a large interindividual variation that can not be explained solely by polymorphisms identified in this gene ${ }^{1}$. The pregnane $X$ receptor $(\mathrm{PXR})^{2}$ also known as $\mathrm{SXR}^{3}, \mathrm{hPAR}^{4}$ or NR1/2 has been identified as a transcriptional regulator of $\mathrm{CYP} 3 A 4^{2,4}$ and $\mathrm{ABCB} 1^{5,6}$. PXR binds as a heterodimer with the 9-cis retinoic acid receptor (RXR; NR2B) to previously characterized xenobiotic response elements in CYP3A gene promoters, and importantly, PXR is activated by the spectrum of chemicals that are known to induce CYP3A gene expression ${ }^{7,8}$. Single nucleotide polymorphisms (SNPs) in the PXR gene can influence the PXR activity and thereby the CYP3A4 and ABCB1 expression. Zhang et al. ${ }^{9}$ identified 38 different polymorphisms in the PXR gene and determined their allelic frequency in a Caucasian $(n=75)$ and African-American $(n=11)$ population. Two other studies also screened the PXR gene for polymorphisms and determined their allele frequency in a Caucasian population ${ }^{10,11}$. The polymorphisms A7635G and C8055T located in correspondingly intron 5 and intron 6 of the PXR gene have a high allelic frequency in two different Caucasian populations. Bosch et al. ${ }^{10}$ reported that $32 \%$ and $15 \%$ of the Caucasians were carrier of, respectively, PXR $7635 \mathrm{G}$ and $8055 \mathrm{~T}$ variant alleles while Zhang et al. ${ }^{9}$ found that $35 \%$ and $16 \%$ of the Caucasians was carrier of correspondingly PXR $7635 \mathrm{G}$ and $8055 \mathrm{~T}$ variant alleles. In addition, Zhang et al. ${ }^{9}$ observed that $16 \%$ of the Caucasians was carrier of the $11156 \mathrm{C}$ or $11193 \mathrm{C}$ variant allele which is located in the 3'-untranslated region of the PXR gene. The PXR polymorphisms A7635G and C8055T have been shown to have a higher magnitude of induction of the intestinal CYP3A4 by rifampicin while the homozygous carriers of the PXR $11156 \mathrm{C}$ or $11193 \mathrm{C}$ variant alleles had lower P-glycoprotein levels in gut biopsies compared to those with homozygous 11156A and 11193T alleles $^{9}$. In the present study, a 12-hour area under the time concentration curve $\left(A_{U} C_{0-12}\right)$ calculated with a two time point sample strategy is correlated with the corresponding PXR genotypes for 103 Chinese renal transplant patients to elucidate whether these PXR polymorphisms can contribute to a decrease within the interindividual variability of the tacrolimus pharmacokinetics. 


\section{Patients and methods}

\section{Study population}

A total of 103 Chinese renal transplant recipients who received tacrolimus as part of the immunosuppressive therapy and had regular follow up in the Queen Elizabeth Hospital or Tuen Mun Hospital in Hong Kong were included in this retrospective study. There was no change in the daily tacrolimus dose for at least two weeks. Patients who were taking medication known to have interaction with tacrolimus, such as calcium channel blockers, anti-epileptics, anti-mycotics and macrolide antibiotics were excluded from this study. Additionally, patients who suffered from gastrointestinal tract disease, liver disease or other disorders that may alter the absorption of tacrolimus were also excluded. Apart from tacrolimus and steroids, the patients were normally put on azathioprine, however some patients preferred to use mycophenolic acid on advice of their private physician. The dosage of azathioprine was $1.5 \mathrm{mg} / \mathrm{kg} / \mathrm{day}$, while the dosage of mycophenolic acid was 0.5 gram twice daily. The initial tacrolimus dosage, administrated twice daily, was $0.3 \mathrm{mg} / \mathrm{kg}$ per day for all patients. The daily tacrolimus dose was then adjusted according to the $A_{U} \mathrm{C}_{0-12}$ value, which was kept at around $100-150 \mathrm{ng} \times \mathrm{hr} / \mathrm{ml}$ during the first three months. After three months the target $\mathrm{AUC}_{0-12}$ value was decreased at around $80-100 \mathrm{ng} \times \mathrm{hr} / \mathrm{ml}$ for long term maintenance. These $\mathrm{AUC}_{0-12}$ values were based on our previous pilot study ${ }^{12}$ and the experiences obtained in our transplantation centers. The steroid regimen for the first month was $30 \mathrm{mg} /$ day of oral prednisolone, progressively tapered by $2.5 \mathrm{mg}$ every two weeks until a daily maintenance dose of $5 \mathrm{mg}$. Demographic as well as clinical data were collected at the time of the tacrolimus blood sample collection.

\section{Determination whole blood tacrolimus concentrations}

Blood samples were collected 2 (C2) and 4 (C4) hours after the morning tacrolimus administration. Tacrolimus blood concentrations were determined in ethylene diamine tetra-acetic acid (EDTA) whole blood using a semi-automated microparticle enzyme immunoassay (MEIA) on an IMx II clinical analyser (Abbott Laboratories, Abbott Park, IL, USA). The two tacrolimus blood concentrations determined were used to calculate the $\mathrm{AUC}_{0-12}$ according to the equation based strategy as described earlier ${ }^{12}: \mathrm{AUC}_{0-12}=$ $16.2+2.4 \times \mathrm{C} 2+5.9 \times \mathrm{C} 4$. Dose-normalized $\mathrm{AUC}\left(\mathrm{dnAUC}_{0-12}\right)$ were calculated by dividing the $\mathrm{AUC}_{0-12}$ by the corresponding 24 hour dose on a milligrams per kilogram basis.

\section{DNA isolation}

Genomic DNA was extracted from 103 Chinese renal transplant recipients by using $200 \mu \mathrm{l}$ EDTA anticoagulated blood for isolation with a QIAamp blood mini kit (Qiagen, Leusden, the Netherlands) according to the manufacturers' instructions. 


\section{Primers and probes for the PXR A11156C and T11193C polymorphisms}

The real-time PCR fluorescence resonance energy transfer (FRET) assays were designed and optimized in our laboratory. Genotyping for the PXR A11156C and T11193C polymorphisms was performed using the primers F22: 5'-CAA TCA gTT AAA CAC ACC ggA g-'3 (sense; 81370-391) and R22: 5'-TTT TAT gTT CTT ACg CCg gAg T-'3 (anti-sense; 81766-745) to amplify a $397 \mathrm{bp}$ part from the PXR gene which covers both $\mathrm{A} 11156 \mathrm{C}$ and $\mathrm{T} 11193 \mathrm{C}$ polymorphisms in the 3'-untranslated region (3' UTR) of the PXR gene (Genbank acces no: AF364606). Detection of the PXR A11156C polymorphism was carried out using the anchor probe 56A22: 5'-TTT Tgg gAA ATg TAg CCC Tgg gT-'3 (sense; 81553-575) which was labelled at the 5'-end with LCRed640 and phosphorylated at the 3 '-end to block extension from the sensor probe 56P22AL: 5'-CAT TCC ACA CCT AXA gAA CTA-'3 (sense; 81532-551) which is complementary to the PXR 11156A polymorphism. This 3'-fluorescence labelled sensor probe, in which the polymorphic locked nucleic acid (LNA) nucleotide is underlined binds with a distance of one base 5 ' to the detection probe. A locked nucleic acid (indicated as XA in the sensor probe 56P22AL ) was necessary to discriminate both melting peaks ${ }^{13}$. Detection of the PXR T11193C polymorphism was carried out using the anchor probe 93A22: 5'-ACC CAg ggC TAC ATT TCC CAA AA-'3 (anti-sense; 81575-553) which was labelled at the 5'-end with LCRed640 and phosphorylated at the 3' end to block extension from the sensor probe 93P22: 5'-CTT TTg CCT TgA TTT ggC ATT A-'3 (anti-sense; 81598577 ) which is complementary to the PXR $11193 \mathrm{C}$ polymorphism. This 3'-fluorescence labelled sensor probe, in which the polymorphic nucleotide is underlined binds with a distance of one base 5' to the detection probe. The PCR mixture for both real-time PCR FRET assays contained: $3.2 \mu \mathrm{l}$ sterile water; $3.0 \mathrm{mM} \mathrm{MgCl} 2 ; 1.0 \mu \mathrm{l} \mathrm{LC} \mathrm{Faststart} \mathrm{DNA}$ Master Hybridization Probes (Roche Diagnostics GmbH, Mannheim, Germany); $0.5 \mu \mathrm{M}$ of each primer and $0.2 \mu \mathrm{M}$ of both sensor and anchor probe (TIB MOLBIOL, Berlin, Germany). After adding 1.0 $\mu$ containing 50-100 ng genomic DNA to the PCR mixture, the total volume was $10 \mu \mathrm{l}$. The PCR protocol included the following steps: denaturation for ten minutes at $95^{\circ} \mathrm{C} ; 45$ cycles at $95^{\circ} \mathrm{C}$ for ten seconds, $55^{\circ} \mathrm{C}$ for ten seconds and $72^{\circ} \mathrm{C}$ for 16 seconds. After amplification was completed, a melting curve was recorded by cooling to $45^{\circ} \mathrm{C}\left(20^{\circ} \mathrm{C} /\right.$ second $)$ holding at $45^{\circ} \mathrm{C}$ for one minute and then heating slowly to $70^{\circ} \mathrm{C}$ at $0.2^{\circ} \mathrm{C} /$ second.

\section{Primers and probes for the PXR A7635G and C8055T polymorphism}

Additionally, a real-time PCR FRET assay was designed and optimised for the PXR A7635G polymorphism. Genotyping for the PXR A7635G polymorphism was performed using the primers F23: 5'-gAg CTg TCT gCT ggg TTg Tg-'3 (sense; 77928-974) and R23: 5'-ggT CCT CgA Tgg gCA AgT C-'3 (anti-sense; 78136-118) to amplify a $209 \mathrm{bp}$ part from the PXR gene which covers the A7635G polymorphisms in intron 5 (Genbank 
access no: AF364606). Detection of the PXR A7635G polymorphism was carried out using the anchor probe A23: 5'-ATT ATg ggA Tgg CTg CTg gTg CCg gC-'3 (sense; 78039-064) which was labelled at the 5'- end with LCRed640 and phosphorylated at the 3'- end to block extension from the sensor probe, P23: 5'-CCT CTC ACC CCC AAC TTC T-'3 which is complementary to the PXR 7635A polymorphism. This 3'-fluorescence labelled sensor probe, in which the polymorphic nucleotide is underlined binds with a distance of one base 5 ' to the detection probe. Finally, a real-time PCR FRET assay was designed, optimised and validated for the PXR C8055T polymorphism. Genotyping for the PXR C8055T polymorphism was performed using the primers F24: 5'-gCT ggA TTA AAg CAT gTA CTT CA-'3 (sense; 78312-330) and R24: 5'-ggC CTg CAT CAg CAC ATA CT-'3 (anti-sense; 78558-539) to amplify a 246 bp part from the PXR gene which covers the C8055T polymorphisms in intron 6 (Genbank access no: AF364606). Detection of the PXR C8055T polymorphism was carried out using the anchor probe A24: 5'-TCC ACA ggT ggC TTC CAg CAA CTT CTA CTg-'3 (sense; 78454-483) which was labelled at the 5'- end with LCRed705 and phosphorylated at the 3'- end to block extension from the sensor probe. P24: 5'-CTg CCC CTC CAT CCT gTT ACC-' 3 which is complementary to the PXR $8055 \mathrm{C}$ polymorphism. This 3'-fluorescence labelled sensor probe, in which the polymorphic nucleotide is underlined binds with a distance of one base $5^{\prime}$ to the detection probe. The PCR mixture for the real-time PCR FRET assays for the PXR A7635G and C8055T polymorphisms contained: $5.2 \mu$ l sterile water; $2.0 \mathrm{mM} \mathrm{MgCl}$; $1.0 \mu \mathrm{l}$ LC Faststart DNA Master Hybridization Probes (Roche Diagnostics $\mathrm{GmbH}$, Mannheim, Germany); $0.6 \mu \mathrm{M}$ of each primer and $0.2 \mu \mathrm{M}$ of both sensor and anchor probe (TIB MOLBIOL, Berlin, Germany). After adding $1.0 \mu \mathrm{l}$ containing 50-100 ng genomic DNA to the PCR mixture the total volume was $10 \mu \mathrm{l}$. The PCR protocol for the two PXR polymorphisms A7635G and C8055T included the following steps: denaturation for ten minutes at $95^{\circ} \mathrm{C} ; 40$ cycles at $95^{\circ} \mathrm{C}$ for 10 seconds, $55^{\circ} \mathrm{C}$ for ten seconds and $72^{\circ} \mathrm{C}$ for ten seconds. After amplification was completed, a melting curve was recorded by heating to $95^{\circ} \mathrm{C}\left(20^{\circ} \mathrm{C} /\right.$ second) holding at $95^{\circ} \mathrm{C}$ for 30 seconds; subsequently cooling to $40^{\circ} \mathrm{C}\left(20^{\circ} \mathrm{C} /\right.$ second $)$ holding at $40^{\circ} \mathrm{C}$ for one minute and then heating slowly to $75^{\circ} \mathrm{C}$ at $0.1^{\circ} \mathrm{C} /$ second. All real-time PCR and melting curve analyses were performed on a LightCycler (Roche Diagnostics, Almere, the Netherlands). Additionally, sequencing is performed on a capillary sequencer ABI Prism 3100 using the Bridge version 1.1 sequence kit (Both products from Applied Biosystems, Fostercity, USA) and is used for identifying the presence of the expected PXR polymorphisms. The sequenced samples are used as controls in the different realtime PCR FRET assays.

\section{Statistical analysis}

The statistical analysis of the data was performed with use of the statistical software SPSS 11.0 for windows (Chicago, IL, USA). Patients' genotypes were used as categorical independent variables for analysis of continuous clinical and 
pharmacological variables. To examine the population homogeneity of the patients, the genotype frequencies of the PXR polymorphisms were tested against Hardy-Weinberg equilibrium by the Pearson's goodness-of-fit test. For analysis of the daily dose of tacrolimus $(\mathrm{mg} / \mathrm{kg} / \mathrm{day})$ and the $\operatorname{dnAUC}_{0-12}(\mathrm{ng} \times \mathrm{hr} / \mathrm{ml}$ per $\mathrm{mg} / \mathrm{kg})$, groups were compared using non-parametric statistical tests. To compare two groups we used the Mann-Whitney test, and to compare several groups, the Kruskal Wallis test. $P$ values less than 0.05 were considered statistically significant. All values are expressed as median and range unless stated otherwise.

\section{Results}

\section{Real-time PCR FRET assays}

After analysing 103 DNA samples obtained from Chinese renal transplant recipients the melting point of the sensor probe for the PXR A11156C polymorphism was $58.7 \pm 0.08^{\circ} \mathrm{C}(n=113)$ when hybridised to the PXR $11156 \mathrm{~A}$ allele and $51.9 \pm 0.11^{\circ} \mathrm{C}$ $(n=93)$ when hybridised to the PXR 11156C allele, whereas for the PXR T11193C polymorphism, the melting point of the sensor probe was $56.4 \pm 0.16^{\circ} \mathrm{C}(\mathrm{n}=113)$ when hybridised to the PXR $11193 \mathrm{~T}$ allele and $61.3 \pm 0.14^{\circ} \mathrm{C}(\mathrm{n}=93)$ when hybridised to the PXR 11193C allele. In addition, for the PXR A7635G polymorphism, the melting point of the sensor probe was $61.2 \pm 0.19^{\circ} \mathrm{C}(n=95)$ when hybridised to the PXR 7635A allele and $55.0 \pm 0.11^{\circ} \mathrm{C}(n=111)$ for the PXR $7635 \mathrm{G}$ allele, whereas for the PXR C8055T polymorphism, the melting point of the sensor probe was $64.7 \pm 0.32^{\circ} \mathrm{C}(\mathrm{n}=116)$ when hybridised to the PXR $8055 \mathrm{C}$ allele and $58.1 \pm 0.33^{\circ} \mathrm{C}(n=90)$ when hybridised to the PXR 8055T allele. Heterozygote samples for all studied polymorphisms showed both melting peaks. The presence of the expected polymorphisms was confirmed by sequencing the different allelic variants of the PXR gene according to a direct sequence procedure on a capillary sequencer $A B I$ Prism 3100 using the Bridge version 1.1 sequence kit (Both products from Applied Biosystems, Fostercity, USA).

\section{Distribution of allele frequencies}

Table 11.1 illustrates the demographic characteristics of 103 Chinese renal transplant recipients included in the present study while Table 11.2 shows the distribution of the allele frequencies and genotypes of the PXR polymorphisms among Chinese transplant recipients examined in the present study. Moreover, Table 11.2 summarised the allele frequencies from Caucasians and African-American individuals. 
Table 11.1 Demographic characteristics of the renal transplant recipients

\begin{tabular}{|c|c|}
\hline Demographic characteristics & \\
\hline Gender (male/female) & $58 / 45$ \\
\hline Age (years, mean $\pm \mathrm{SD}$, (range)) & $43.1 \pm 11.1(21-77)$ \\
\hline Weight $(\mathrm{kg}$, mean $\pm \mathrm{SD},($ range $))$ & $62.5 \pm 11.4(37.4-87.8)$ \\
\hline \multicolumn{2}{|l|}{ Primary kidney disease } \\
\hline Glomerulonephritis & 57 \\
\hline Chronic pyelonephritis & 1 \\
\hline Diabetic nephropathy & 10 \\
\hline Hypertensive nephropathy & 9 \\
\hline Polycystic kidney disease & 2 \\
\hline Obstructive Uropathy & 3 \\
\hline Unknown & 18 \\
\hline Other & 3 \\
\hline \multicolumn{2}{|l|}{ Transplantation number } \\
\hline First & 97 \\
\hline Second & 6 \\
\hline Tacrolimus dose (mg/kg body weight/day, mean $\pm \mathrm{SD}$, (range)) & $0.067 \pm 0.032(0.01-0.18)$ \\
\hline Tacrolimus conc. 2 hour post dose ( $\mathrm{ng} / \mathrm{ml}$, mean $\pm \mathrm{SD}$, (range)) & $13.5 \pm 4.30(5.7-29.4)$ \\
\hline Tacrolimus conc. 4 hour post dose $(\mathrm{ng} / \mathrm{ml}$, mean $\pm \mathrm{SD}$, (range)) & $8.7 \pm 2.60(2.3-16.4)$ \\
\hline $\mathrm{AUC}_{0-12}(\mathrm{ng} \times \mathrm{hr} / \mathrm{ml}$, mean, (range) $)$ & $100.3(47.8-183.5)$ \\
\hline $\mathrm{DnAUC}_{0-12}(\mathrm{ng} \times \mathrm{hr} / \mathrm{ml}$ per mg/kg body weight, mean, (range)) & $1940(300-11125)$ \\
\hline Use of azathiopurine/mycophenolate mofetil & $78 / 25$ \\
\hline Current steroid dose $(\mathrm{mg}$, mean $\pm \mathrm{SD}$, (range)) & $6.98 \pm 2.37(4-25)$ \\
\hline Time since transplantation (days, mean, (range)) & $977(133-4982)$ \\
\hline Haemoglobin (mmol/l, mean $\pm \mathrm{SD}$, (range) ref. $\delta 8.2-11.0$,, $7.3-9.7)$ & $12.8 \pm 2.0(8.5-19)$ \\
\hline Haematocrit fraction (mean $\pm \mathrm{SD}$, (range) ref. ${ }^{\lambda} 0.41-0.52, q 0.36-0.48$ ) & $0.38 \pm 0.058(0.25-0.57)$ \\
\hline 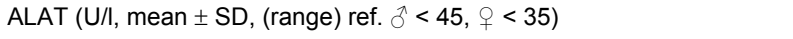 & $22 \pm 18(8-147)$ \\
\hline Serum albumin (g/l, mean $\pm \mathrm{SD}$, (range) ref. $34-45)$ & $43 \pm 3.2(34-50)$ \\
\hline Serum creatinine $(\mu \mathrm{mol} / \mathrm{l}$, mean $\pm \mathrm{SD}$, (range) ref. $71-110$,, $53-97)$ & $156 \pm 76(62-462)$ \\
\hline
\end{tabular}

Ref. are the reference values applied in the clinical chemistry and haematology laboratories of the University Hospital in Maastricht. $\delta$ male, o female.

In total, $79.6 \%(n=82)$ of the Chinese renal transplant recipients have a similar haplotype for these four PXR polymorphisms. The allele frequencies of the Chinese renal transplant patients examined were found to be $45.1 \%$ (11156C and 11193C), $53.9 \%(7635 \mathrm{G})$ and $43.7 \%$ (8055T) which is not in line with those published in previous studies $^{9,10}$. However, these studies determined the allele frequencies in Caucasians or African Americans which may explain the differences. According to the Pearson's goodness-of-fit test the genotype frequencies of these PXR polymorphisms differed not significantly from the Hardy-Weinberg equilibrium $(P>0.05)$. 
Table 11.2 Distribution allele frequencies/genotypes PXR polymorphisms.

\begin{tabular}{lccc}
\hline PXR Polymorphisms & $\begin{array}{c}\text { Genotype } \\
\mathrm{n}(\%)\end{array}$ & $\begin{array}{c}\text { Allele frequency } \\
\mathrm{n}(\%)\end{array}$ & $\begin{array}{c}\text { Allele frequencies observed in } \\
\text { other studies }\end{array}$ \\
\hline A7635G & AA: $20(19.4 \%)$ & AA: $95(46.1 \%)$ & AA: $65 \%{ }^{\mathrm{a}}, 23 \%{ }^{\mathrm{a}}, 32 \%{ }^{\mathrm{b}}$ \\
& AG: $55(53.4 \%)$ & & \\
& GG: $28(27.2 \%)$ & GG: $111(53.9 \%)$ & GG: $35 \%^{\mathrm{a}}, 77 \%{ }^{\mathrm{a}}, 68 \%{ }^{\mathrm{b}}$ \\
C8055T & CC: $33(32.0 \%)$ & CC: $116(56.3 \%)$ & CC: $85 \%^{\mathrm{a}}, 82 \%{ }^{\mathrm{a}}, 84 \%$ \\
& CT: $50(48.5 \%)$ & & \\
A11156C & TT: $20(19.4 \%)$ & TT: $90(43.7 \%)$ & TT: $15 \%{ }^{\mathrm{a}}, 18 \%{ }^{\mathrm{a}}, 16 \%$ \\
& AA: $31(30.1 \%)$ & AA: $113(54.9 \%)$ & AA: $84 \%{ }^{\mathrm{a}}, 67 \%{ }^{\mathrm{a}}$ \\
T11193C & AC: $51(49.5 \%)$ & & \\
& CC: $21(20.4 \%)$ & CC: $93(45.1 \%)$ & CC: $16 \%{ }^{\mathrm{a}}, 33 \%{ }^{\mathrm{a}}$ \\
& TT: $31(30.1 \%)$ & TT: $113(54.9 \%)$ & TT: $84 \%{ }^{\mathrm{a}}, 67 \%{ }^{\mathrm{a}}$ \\
& TC: $51(49.5 \%)$ & & \\
& CC: $21(20.4 \%)$ & CC: $93(45.1 \%)$ & CC: $16 \%{ }^{\mathrm{a}}, 33 \%{ }^{\mathrm{a}}$ \\
\hline
\end{tabular}

${ }^{\text {a }}$ Zhang et al. ${ }^{9}$ determined for 150 alleles originated from Caucasians and 22 alleles originated from African Americans the allele frequencies of these PXR polymorphisms. ${ }^{\mathrm{b}}$ Bosch et al. ${ }^{10}$ determined for 200 alleles obtained from healthy Caucasian volunteers the allele frequencies of these PXR polymorphisms.

\section{Influence of the different PXR allelic variants on the pharmacokinetic tacrolimus profiles}

Since identical genotype distributions were found among the Chinese renal transplant recipients for the PXR polymorphisms $\mathrm{A} 11156 \mathrm{C}$ and $\mathrm{T} 11193 \mathrm{C}$, the difference observed between the dnAUC $\mathrm{C}_{0-12}$ was also the same. A significant higher $\operatorname{dnAUC}_{0-12}$ (1864 versus $1334 \mathrm{ng} \times \mathrm{hr} / \mathrm{ml}$ per mg/kg; Mann-Whitney, $P=0.038$ and 1918 versus $1342 \mathrm{ng} \times \mathrm{hr} / \mathrm{ml}$ per $\mathrm{mg} / \mathrm{kg}$; Mann-Whitney, $P=0.038$ ) was observed for carriers of respectively the PXR 7635AA and 11156AA/11193TT genotypes compared to the PXR 7635GG and $11156 \mathrm{CC} / 11193 \mathrm{CC}$ genotypes while a strong trend towards a lower $\mathrm{dnAUC}_{0-12}$ (1882 versus $1390 \mathrm{ng} \times \mathrm{hr} / \mathrm{ml}$ per $\mathrm{mg} / \mathrm{kg}$; Mann-Whitney, $P=0.088$ ) was observed between carriers of the PXR 8055CC genotype compared to carriers of the PXR 8055TT genotype. Additionally, similar results were obtained for the daily tacrolimus dose, a significantly higher daily tacrolimus dose $(0.052$ versus $0.070 \mathrm{mg} / \mathrm{kg} / \mathrm{day}$; MannWhitney, $P=0.042$ and 0.051 versus $0.070 \mathrm{mg} / \mathrm{kg} /$ day; Mann-Whitney, $P=0.061$ ) was observed for carriers of respectively the PXR 7635AA and 11156AA/11193TT genotypes compared to the PXR 7635GG and 11156CC/11193CC genotypes while a strong trend towards a higher daily tacrolimus dose $(0.052$ versus $0.070 \mathrm{mg} / \mathrm{kg} / \mathrm{day}$; Mann-Whitney, $P=0.108$ ) was observed between carriers of the PXR 8055CC genotype compared to carriers of the PXR 8055TT genotype. Figure 11.1A-D illustrate the effect of the different PXR polymorphisms on the dnAUC $\mathrm{C}_{0-12}$ recorded in 103 Chinese renal transplant recipients. Furthermore, the PXR haplotypes consisting of the four polymorphisms are associated with the $\mathrm{dnAUC}_{0-12}$, as is shown in Figure 11.1E. 


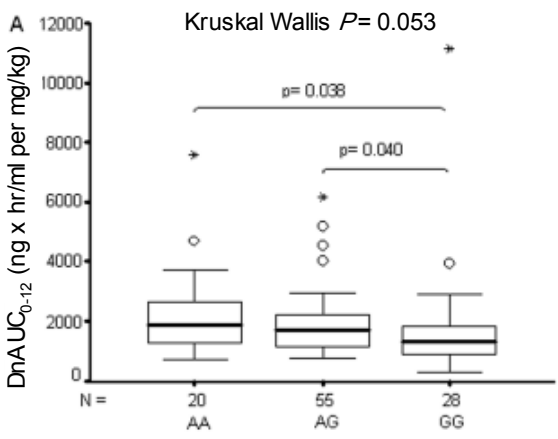

PXRA7635G polymorphism
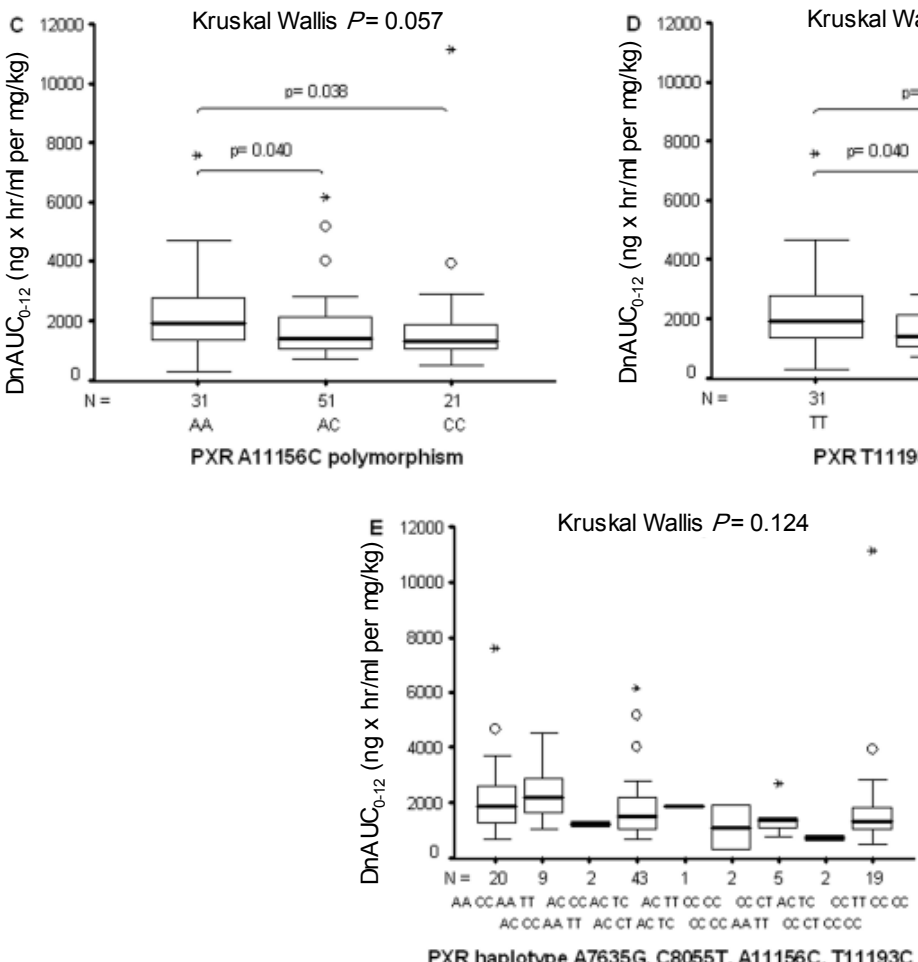

PXR haplotype A7635G, C8055T, A11156C, T11193C
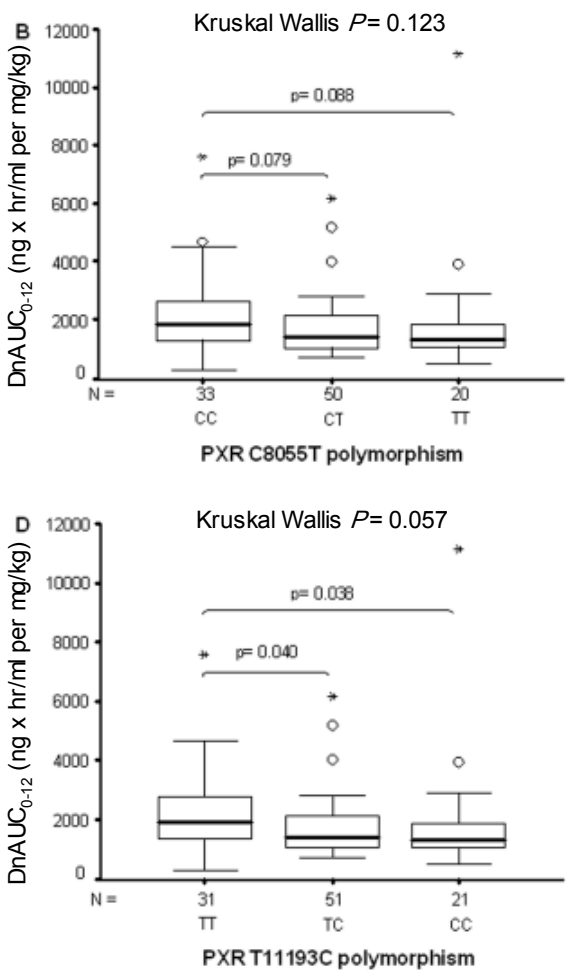

XRT11193C polymorphism

Figure 11.1 Influence of the PXR A7635G, C8055T, A11156C and T11193C genotypes on the area under the time tacrolimus concentration curve $\left(\mathrm{AUC}_{0-12}\right)$ that were recorded in 103 stable Chinese renal transplant recipients. Figure 11.1 illustrates the boxplots of the distribution of the dose normalized $\mathrm{AUC}_{0-12}(\mathrm{ng} \times \mathrm{hr} / \mathrm{ml}$ per $\mathrm{mg} / \mathrm{kg})$ clustered according to the (A) PXR A7635G genotype, (B) PXR C8055T genotype, (C) PXR A11156C genotype, (D) PXR T11193C genotype and (E) the PXR haplotypes consisting of the PXR polymorphisms A7635G, C8055T, A11156C and T11193C. The open circles indicate an outlier value at more than 1.5 box lengths above the box, while the asterices indicate an extreme value at more than 3 box lengths above the box. 
However, previously we ${ }^{14}$ demonstrated in the same renal transplant patient group an important impact of the CYP3A5 A6986G polymorphism on the tacrolimus concentrations whereas a minor association was reported between both ABCB1 polymorphisms G2677T/A and C3435T and the tacrolimus concentration. To exclude influence of one of these polymorphisms, the renal transplant recipients were categorized on their CYP3A5 and ABCB1 G2677T/A, C3435T genotype in order to examine solely the effect of the four PXR polymorphisms on the dnAUC $0-12$ and the daily tacrolimus dose. After categorizing the patients for respectively the CYP3A5 A6986G, ABCB1 G2677T/A and ABCB1 C3435T genotype there is, as is illustrated in Figure 11.2A-C, a tendency towards a lower dnAUC $\mathrm{C}_{0-12}$ within the groups of the combination ABCB1 polymorphisms and the PXR A7635G polymorphism. Although these data are not shown, similar results were observed for the PXR polymorphisms C8055T, A11156C and T11193C. Additionally, comparable results were achieved for the daily tacrolimus dose requirement and the four PXR polymorphisms.

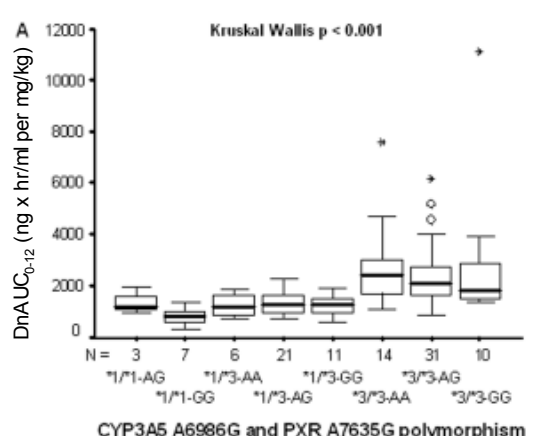

CYP3A5 A6986G and PXR A7635G polymorphism

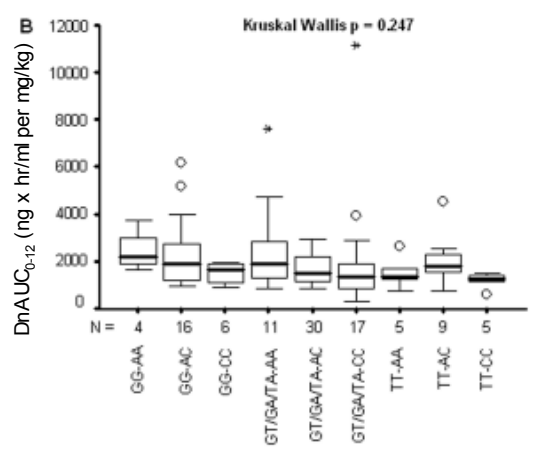

Combination of ABCB1 G2677TIA and PXR A7635G

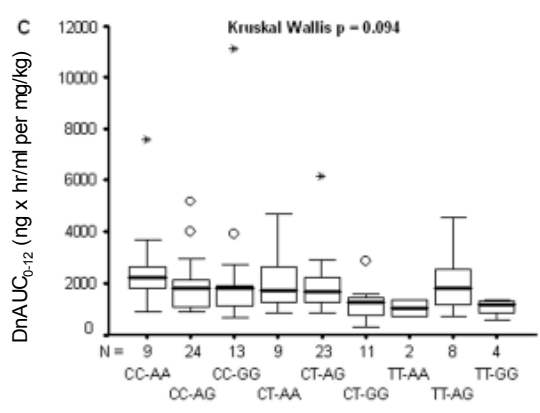

Combination of ABCB1 C3435T and PXR A7635G

Figure 11.2 Boxplots of the distribution of the dose normalized $\mathrm{AUC}_{0-12}(\mathrm{ng} \times \mathrm{hr} / \mathrm{ml}$ per $\mathrm{mg} / \mathrm{kg})$ clustered according to (A) the combination of respectively CYP3A5 A6986G and PXR A7635G, (B) ABCB1 G2677T/A and PXR A7635G genotypes and (C) ABCB1 C3435T and PXR A7635G genotypes. The open circles indicate an outlier value at more than 1.5 box lengths above the box, while the asterices indicate an extreme value at more than 3 box lengths above the box. 


\section{Discussion}

Tacrolimus is predominantely metabolized by CYP3A iso-enzymes into 13-Odemethyltacrolimus in the liver and the intestine ${ }^{15-19}$. Although CYP3A4 and CYP3A5 are the most important members of the CYP3A family, the CYP3A5 A6986G polymorphism is the only relevant polymorphism in the CYP3A4 and CYP3A5 genes which has a relative high allele frequency in different populations and a significant impact on the tacrolimus pharmacokinetics. Although CYP3A4 expression shows a large interindividual variation, this can not only be explained by the polymorphisms in the CYP3A4 gene ${ }^{1}$. Elucidation of the mechanisms underlying CYP3A gene expression may be important for the role of the interindividual variation in the tacrolimus pharmacokinetics. Moreover, there is also conflicting evidence regarding the role of the individual $A B C B 1$ polymorphisms and $A B C B 1$ haplotypes in the tacrolimus pharmacokinetics. Several studies reported a significant impact of the ABCB1 polymorphisms or haplotypes on the tacrolimus trough $\left(C_{0}\right)$ concentrations $^{20-26}$ while other studies found no association between the different genotypes of the ABCB1 polymorphisms or $A B C B 1$ haplotypes and the tacrolimus $C_{0}$ concentrations $^{27-32}$ or pharmacokinetics ${ }^{14,33,34}$. Since PXR is emerged as a transcriptional regulator of the expression of different members of the CYP450 family, polymorphisms in the PXR gene may influence the PXR activity and thereby the expression of these CYP450s. PXR binds as a heterodimer with RXR to the functional direct repeat-3 (DR-3) response element and to the functional everted repeat-6 (ER-6) response element in the proximal promoter region of the CYP3A4 gene while the CYP3A5 gene only contains the functional ER-6 response element in the promoter. In addition, the PXR/RXR heterodimer also binds to the functional direct repeat-4 (DR-4) response element in the ABCB1 promoter ${ }^{5,6}$. Zhang et al. ${ }^{9}$ found that the $7635 \mathrm{~A}$ to $\mathrm{G}$ transition in intron 5 of the PXR gene was associated with higher magnitude of induction of intestinal CYP3A by rifampicin. Individuals homozygous for the $7635 \mathrm{G}$ allele had a twofold higher induction of CYP3A compared to those homozygous for 7635A. An $8055 \mathrm{C}$ to T substitution was also associated with intestinal CYP3A phenotype that was more inducible. Individuals carrying at least one T-allele had twofold higher levels of intestinal CYP3A following rifampicin treatment compared to individuals homozygous for the $8055 \mathrm{C}$ allele. The 3'-untranslated region (3' UTR) polymorphisms 11156A to C and 11193T to C showed that those individuals heterozygous with at least one $11156 \mathrm{C}$ or one $11193 \mathrm{C}$ allele had 1.45-fold lower P-glycoprotein levels in gut biopsies compared to those with homozygous $11156 \mathrm{~A}$ and $11193 \mathrm{~T}$ alleles. Since no CYP3A4*1B variant allele is found in this Chinese renal transplant patient group ${ }^{14}$, there is no influence of the CYP3A4*1B variant allele on the CYP3A4 expression and thereby on the dnAUC $\mathrm{C}_{0-12}$ of tacrolimus. However, to exclude the effect of the CYP3A5*3 variant allele and the individual $A B C B 1$ polymorphisms G2677T/A and C3435T or ABCB1 haplotypes, the renal transplant population is categorized according to the CYP3A5 A6986G, ABCB1 G2677T/A and C3435T genotype. In the present study a significant difference was observed regarding 
the PXR polymorphisms A7635G, A11156C and T11193C when the dnAUC $0-12$ was plotted versus the corresponding PXR polymorphisms of the 103 Chinese renal transplant patient recipients while a trend was observed for the PXR C8055T polymorphism. These results underline the in vitro findings demonstrated by Zhang et al. ${ }^{9}$. However, after excluding the effect of the CYP3A5 A6986G polymorphism and the ABCB1 polymorphisms G2677T/A and C3435T, only a trend is observed within the patients that were carrier of a similar genotype for the CYP3A5 A6986G or ABCB1 G2677T/A, ABCB1 C3435T polymorphisms. Probably due to the presence of at least eight different groups with other genotype combinations it is likely that the small number of patients included in one group has a relevant impact on these findings. Additional studies with larger patient numbers included in each group could possibly confirm our preliminary results.

\section{Conclusion}

We described real-time PCR FRET assays for four PXR polymorphisms and determined the allele frequency of these four PXR polymorphisms in a Chinese renal transplant recipient group. Moreover, a strong trend towards a lower $\operatorname{dnAUC}_{0-12}$ is found for individuals carrying a variant PXR allele suggesting that these PXR polymorphisms may play a role in the tacrolimus metabolism. 


\section{References}

1. Lee SJ, Goldstein JA. Functionally defective or altered CYP3A4 and CYP3A5 single nucleotide polymorphisms and their detection with genotyping tests. Pharmacogenomics 2005;6:357-71.

2. Lehmann JM, McKee DD, Watson MA, Willson TM, Moore JT, Kliewer SA. The human orphan nuclear receptor PXR is activated by compounds that regulate CYP3A4 gene expression and cause drug interactions. J Clin Invest 1998;102:1016-23.

3. Blumberg B, Sabbagh W, Jr., Juguilon H, Bolado J, Jr., van Meter CM, Ong ES, Evans RM. SXR, a novel steroid and xenobiotic-sensing nuclear receptor. Genes Dev 1998;12:3195-205.

4. Bertilsson G, Heidrich J, Svensson K, Asman M, Jendeberg L, Sydow-Backman M, Ohlsson $\mathrm{R}$, Postlind $\mathrm{H}$, Blomquist $\mathrm{P}$, Berkenstam A.. Identification of a human nuclear receptor defines a new signaling pathway for CYP3A induction. Proc Natl Acad Sci U S A 1998;95:12208-13.

5. Synold TW, Dussault I, Forman BM. The orphan nuclear receptor SXR coordinately regulates drug metabolism and efflux. Nat Med 2001;7:584-90.

6. Geick A, Eichelbaum M, Burk O. Nuclear receptor response elements mediate induction of intestinal MDR1 by rifampin. J Biol Chem 2001;276:14581-7.

7. Moore JT, Kliewer SA. Use of the nuclear receptor PXR to predict drug interactions. Toxicology 2000;153:1-10.

8. Kliewer SA, Goodwin B, Willson TM. The nuclear pregnane $X$ receptor: a key regulator of xenobiotic metabolism. Endocr Rev 2002;23:687-702.

9. Zhang J, Kuehl P, Green ED, Touchman JW, Watkins PB, Daly A, Hall SD, Maurel P, Relling M, Brimer C, Yasuda K, Wrighton SA, Hancock M, Kim RB, Strom S, Thummel K, Russell CG, Hudson JR Jr, Schuetz EG, Boguski MS. The human pregnane $X$ receptor: genomic structure and identification and functional characterization of natural allelic variants. Pharmacogenetics 2001;11:555-72.

10. Bosch TM, Deenen M, Pruntel R, Smits PH, Schellens JH, Beijnen JH, Meijerman I. Screening for polymorphisms in the PXR gene in a Dutch population. Eur J Clin Pharmacol 2006;62:395-9.

11. Hustert E, Zibat A, Presecan-Siedel E, Eiselt R, Mueller R, Fuss C, Brehm I, Brinkmann U, Eichelbaum M, Wojnowski L, Burk O. Natural protein variants of pregnane $X$ receptor with altered transactivation activity toward CYP3A4. Drug Metab Dispos 2001;29:1454-9.

12. Wong KM, Shek CC, Chau KF, Li CS. Abbreviated tacrolimus area-under-the-curve monitoring for renal transplant recipients. Am J Kidney Dis 2000;35:660-6.

13. Op den Buijsch RA, de Vries JE, Loots WJ, Landt O, Wijnen PA, van Dieijen-Visser MP, et al. Genotyping of the PXR A11156C polymorphism with locked nucleic acid containing fluorogenic probes. Pharmacogenomics J 2005;5:72-4.

14. Cheung CY, Op den Buijsch RA, Wong KM, Chan HW, Chau KF, Li CS, Leung KT, Kwan TH, de Vrie JE, Wijnen PA, van Dieijen-Visser MP, Bekers O. Influence of different allelic variants of the CYP3A and ABCB1 genes on the tacrolimus pharmacokinetic profile of Chinese renal transplant recipients. Pharmacogenomics 2006;7:563-74.

15. Vincent SH, Karanam BV, Painter SK, Chiu SH. In vitro metabolism of FK-506 in rat, rabbit, and human liver microsomes: identification of a major metabolite and of cytochrome P450 3A as the major enzymes responsible for its metabolism. Arch Biochem Biophys 1992;294: 454-60.

16. Lhoest $\mathrm{G}$, Wallemacq $\mathrm{P}$, Verbeeck R. Isolation and mass spectrometric identification of five metabolites of FK-506, a novel macrolide immunosuppressive agent, from human plasma. Pharm Acta Helv 1991;66:302-6.

17. Lhoest GJ, Maton N, Latinne D, Laurent A, Verbeeck RK. 15-Desmethyl FK-506 and 15,31desmethyl FK-506 from human liver microsomes: isolation, identification (by fast atom bombardment mass spectrometry and NMR), and evaluation of in vitro immunosuppressive activity. Clin Chem 1994;40:740-4. 
18. Christians U, Kruse C, Kownatzki R, Schiebel HM, Schwinzer R, Sattler M, et al. Measurement of FK 506 by HPLC and isolation and characterization of its metabolites. Transplant Proc 1991;23:940-1.

19. Sattler M, Guengerich FP, Yun CH, Christians U, Sewing KF. Cytochrome P-450 3A enzymes are responsible for biotransformation of FK506 and rapamycin in man and rat. Drug Metab Dispos 1992;20:753-61.

20. Asano T, Nishimoto K, Hayakawa M. Increased tacrolimus trough levels in association with severe diarrhea, a case report. Transplant Proc 2004;36:2096-7.

21. Anglicheau D, Verstuyft C, Laurent-Puig P, Becquemont L, Schlageter MH, Cassinat B, et al. Association of the multidrug resistance-1 gene single-nucleotide polymorphisms with the tacrolimus dose requirements in renal transplant recipients. J Am Soc Nephrol 2003;14: 1889-96.

22. MacPhee IA, Fredericks S, Tai T, Syrris P, Carter ND, Johnston A, Goldberg L, Holt DW. Tacrolimus pharmacogenetics: polymorphisms associated with expression of cytochrome p4503A5 and P-glycoprotein correlate with dose requirement. Transplantation 2002;74: 1486-9.

23. Zheng H, Webber S, Zeevi A, Schuetz E, Zhang J, Bowman P, Boyle G, Law Y, Miller S, Lamba J, Burckart GJ. Tacrolimus dosing in pediatric heart transplant patients is related to CYP3A5 and MDR1 gene polymorphisms. Am J Transplant 2003;3:477-83.

24. Zheng H, Zeevi A, Schuetz E, Lamba J, McCurry K, Griffith BP, Webber S, Ristich J, Dauber J, lacono A, Grgurich W, Zaldonis D, McDade K, Zhang J, Burckart GJ. Tacrolimus dosing in adult lung transplant patients is related to cytochrome P4503A5 gene polymorphism. J Clin Pharmacol 2004;44:135-40.

25. Wang J, Zeevi A, McCurry K, Schuetz E, Zheng H, lacono A, McDade K, Zaldonis D, Webber $S$, Watanabe RM, Burckart GJ. Impact of ABCB1 (MDR1) haplotypes on tacrolimus dosing in adult lung transplant patients who are CYP3A5 ${ }^{*} 3 /{ }^{*} 3$ non-expressors. Transpl Immunol 2006;15:235-40.

26. Akbas SH, Bilgen T, Keser I, Tuncer M, Yucetin L, Tosun O, Gultekin M, Luleci G. The effect of MDR1 (ABCB1) polymorphism on the pharmacokinetic of tacrolimus in Turkish renal transplant recipients. Transplant Proc 2006;38:1290-2.

27. Hesselink DA, van Schaik RH, van der Heiden IP, van der Werf M, Gregoor PJ, Lindemans J, Weimar W, van Gelder T. Genetic polymorphisms of the CYP3A4, CYP3A5, and MDR-1 genes and pharmacokinetics of the calcineurin inhibitors cyclosporine and tacrolimus. Clin Pharmacol Ther 2003;74:245-54.

28. Haufroid V, Mourad M, Van Kerckhove V, Wawrzyniak J, De Meyer M, Eddour DC, Malaise J, Lison D, Squifflet JP, Wallemacq P. The effect of CYP3A5 and MDR1 (ABCB1) polymorphisms on cyclosporine and tacrolimus dose requirements and trough blood levels in stable renal transplant patients. Pharmacogenetics 2004;14:147-54.

29. Mai I, Perloff ES, Bauer S, Goldammer M, Johne A, Filler G, Budde K, Roots I. MDR1 haplotypes derived from exons 21 and 26 do not affect the steady-state pharmacokinetics of tacrolimus in renal transplant patients. Br J Clin Pharmacol 2004;58:548-53.

30. Goto M, Masuda S, Saito H, Uemoto S, Kiuchi T, Tanaka K, Inui K. C3435T polymorphism in the MDR1 gene affects the enterocyte expression level of CYP3A4 rather than Pgp in recipients of living-donor liver transplantation. Pharmacogenetics 2002;12:451-7.

31. Goto M, Masuda S, Kiuchi T, Ogura Y, Oike F, Okuda M, Tanaka K, Inui K. CYP3A5*1carrying graft liver reduces the concentration/oral dose ratio of tacrolimus in recipients of living-donor liver transplantation. Pharmacogenetics 2004;14:471-8.

32. Hebert MF, Dowling AL, Gierwatowski C, Lin YS, Edwards KL, Davis CL, Marsh CL, Schuetz EG, Thummel KE. Association between ABCB1 (multidrug resistance transporter) genotype and post-liver transplantation renal dysfunction in patients receiving calcineurin inhibitors. Pharmacogenetics 2003;13:661-74.

33. Tada H, Tsuchiya N, Satoh S, Kagaya H, Li Z, Sato K, Miura M, Suzuki T, Kato T, Habuchi T. Impact of CYP3A5 and MDR1(ABCB1) C3435T polymorphisms on the pharmacokinetics of tacrolimus in renal transplant recipients. Transplant Proc 2005;37:1730-2. 
34. Tsuchiya N, Satoh S, Tada H, Li Z, Ohyama C, Sato K, Suzuki T, Habuchi T, Kato T. Influence of CYP3A5 and MDR1 (ABCB1) polymorphisms on the pharmacokinetics of tacrolimus in renal transplant recipients. Transplantation 2004;78:1182-7. 


\section{Chapter 12}

\section{Influence of pregnane $\mathrm{X}$ receptor (PXR) polymorphisms on the pharmacokinetics of tacrolimus in renal transplant recipients}

Robert A.M. Op den Buijsch, Johan E. de Vries, Chi Yuen Cheung, Leo M.L. Stolk, Maarten H.L. Christiaans, Nas A. Undre, Petal A.H.M. Wijnen,

Marja P. van Dieijen-Visser, Otto Bekers 


\section{Abstract}

Tacrolimus has a narrow therapeutic index and shows substantial interindividual variability in its pharmacokinetic characteristics. The pregnane $X$ receptor (PXR) identified as a transcriptional regulator of cytochrome P450 3A4 may play a role in the tacrolimus metabolism. In this study, the role of PXR polymorphisms is examined in an early and a late posttransplant patient group with and without corticosteroids.

Twenty-six early and thirty-seven late posttransplant patients were genotyped for PXR polymorphisms. The dose-normalised trough concentrations, area under the time concentration curves $\left(\mathrm{dnAUC}_{0-12}\right)$ and maximum concentrations were determined and correlated with the corresponding PXR genotypes.

Early posttransplant patients carrying PXR variant alleles have significantly lower dnAUC $_{0-12}$ (1858 versus $1243 \mathrm{ng} \times \mathrm{hr} / \mathrm{ml}$ per $\mathrm{mg} / \mathrm{kg}$; Mann-Whitney, $P=0.040$ ) compared to patients that carry PXR wild type alleles while in the late posttransplant patient group no difference is observed regarding the dnAUC $\mathrm{C}_{0-12}$.

Early posttransplant patients carrying PXR variant alleles using corticosteroids have lower pharmacokinetic parameters compared to patients carrying PXR wild type alleles. 


\section{Introduction}

Tacrolimus, a member of the calcineurin inhibitor family, has highly variable pharmacokinetic characteristics and a narrow therapeutic index which complicates its daily dose requirement. Achieving optimal exposure is of critical importance especially during the initial period after transplantation, when the risk of rejection or toxicological dosis is the greatest. Therefore, identification of predictive parameters for an optimal tacrolimus dosage would be of great value in clinical practice to determine the best possible therapeutic tacrolimus concentration. The CYP3A iso-enzymes mainly represented by CYP3A4 and CYP3A5 have been identified as the most important enzymes responsible for the tacrolimus metabolism ${ }^{1}$. Although a number of polymorphic CYP3A4 alleles have been identified (http://www.imm.ki.se/CYPalleles/cyp3a4.htm), these are rare and do not contribute significantly to the CYP3A4 expression variability ${ }^{2}$. In contrast to CYP3A4, the expression of CYP3A5 is determined predominantly by polymorphisms ${ }^{3-9}$. Tacrolimus is also a substrate for $\mathrm{P}$-glycoprotein ( $\mathrm{P}$-gp), the product of the adenosine triphosphate-binding cassette gene $B 1$ (ABCB1) which is also known as multidrug resistance gene-1 (MDR1) $)^{10}$. P-gp is an ATP-dependent efflux pump that contributes to the protection of the body from environmental toxins by limiting their absorption from the gut lumen or increasing their biliairy and urinary excretion and is thus able to modulate the bioavailability of tacrolimus. The nuclear hormone receptors are transcription factors regulating the induction of many genes. Kliewer ${ }^{11}$ and Blumberg ${ }^{12}$ demonstrated that one member of this family, the pregnane $X$ receptor/steroid and xenobiotic receptor (PXR/SXR) mediates steroid and drug induction of detoxification genes including the drug metabolizing enzyme CYP3A and the drug transporter ABCB1. Since CYP3A4 catalyses the oxidative metabolism of onehalf of the clinically administered drugs and $A B C B 1$ effluxes many drugs from human enterocytes and hepatocytes, administration of PXR ligands leads to accelerated clearance of co-administered CYP3A4 and $\mathrm{ABCB} 1$ substrates and are thus a major basis for drug interactions. Moreover, there is significant variation among individuals in the extent to which rifampicin can induce hepatic and intestinal CYP3A4 and ABCB1 expression in humans ${ }^{13}$. Single nucleotide polymorphisms (SNPs) in PXR may be a major contributor in the induction variability of CYP3A4 and ABCB1. Zhang et al. ${ }^{13}$ identified 38 polymorphisms in the PXR gene and found that the $7635 \mathrm{~A}$ to $\mathrm{G}$ transition, and the $8055 \mathrm{C}$ to $T$ substitution in respectively intron 5 and 6 of the PXR gene was associated with a higher magnitude of induction of intestinal CYP3A by rifampicin. In addition, the 3'-untranslated (3' UTR) region polymorphisms 11156A to $C$ and 11193T to C showed that those individuals heterozygous with at least one $11156 \mathrm{C}$ or one $11193 \mathrm{C}$ allele had 1.45-fold lower P-glycoprotein levels in gut biopsies compared to those with homozygous $11156 \mathrm{~A}$ and $11193 \mathrm{~T}$ alleles. Moreover, Bosch et al. ${ }^{14}$ recently identified 8 new allelic variants in the PXR gene and determined the allele frequencies of 24 PXR polymorphisms in 100 Dutch volunteers. Additionally, several studies already described an interaction between corticosteroids and tacrolimus however the exact mechanism 
behind this interaction has never been elucidated ${ }^{15-17}$. In the present study, 26 early using corticosteroids and 37 late using no corticosteroids posttransplant patients are genotyped for PXR polymorphisms A7635G, C8055T, A11156C and T11193C. The genotypes of these renal transplant patients are associated with their corresponding pharmacokinetic parameters (dose-normalised trough $\left(\mathrm{C}_{0}\right)$ concentration, dosenormalised area under the time concentration curve (dnAUC $\mathrm{C}_{0-12}$ ) and dose-normalised maximum concentration $\left(\mathrm{dnC}_{\max }\right)$ to examine whether these PXR polymorphisms eventually in combination with the ude of corticosteroid have an influence on the interindividual variability in the tacrolimus pharmacokinetics.

\section{Patients and methods}

\section{Study population}

In total 63 Caucasian renal transplant recipients divided over two different groups of whom in the past for clinical reasons (group I) or for a clinical trial (group II) a 12 hour time tacrolimus concentration curve was performed, were included in this study. Group I included early posttransplant patients that used corticosteroids with a short median time after transplantation and a large variability in the tacrolimus $\mathrm{AUC}_{0-12}$ compared to the late posttransplant recipients of group II that used no corticosteroids. Table 12.1 illustrates that most pharmacokinetic profiles of the patients included in group I were recorded within 6 weeks after transplantation while group II included patients that underwent a renal transplantation at least 1 year ago. Patients were not allowed to take food until 1 hour after ingesting the tacrolimus dose and were not allowed to take grapefruit juice after transplantation to prevent alterations in the tacrolimus metabolism. In addition, patients that suffer from gastrointestinal, liver disease or other disorders that may alter the absorption of tacrolimus were also disqualified for inclusion in both groups. Prior to the blood sample collection, there had been no tacrolimus dose change for at least three days in both groups. After overnight fasting the blood samples were collected immediately pre $\left(\mathrm{C}_{0}\right)$ and $0.5\left(\mathrm{C}_{0.5}\right), 1\left(\mathrm{C}_{1}\right), 2\left(\mathrm{C}_{2}\right), 3\left(\mathrm{C}_{3}\right), 4\left(\mathrm{C}_{4}\right), 5\left(\mathrm{C}_{5}\right), 7.5\left(\mathrm{C}_{7.5}\right)$ and 12 $\left(\mathrm{C}_{12}\right)$ hours after the morning tacrolimus administration. Demographic as well as clinical data were determined at the time of recording the 12 hour time tacrolimus concentration curve. The renal transplant recipients of both groups underwent a renal transplantation in the University Hospital of Maastricht, the Netherlands. 
Table 12.1 Demographic characteristics of the both renal transplant recipients groups.

\begin{tabular}{|c|c|c|}
\hline Demographic characteristics & Group I & Group II \\
\hline Gender (male/female) & $18 / 8$ & $24 / 13$ \\
\hline Age (years, mean \pm SD) & $43.0 \pm 13.2$ & $51.3 \pm 10.9$ \\
\hline Length $(\mathrm{cm}$, mean $\pm \mathrm{SD})$ & $172 \pm 8.2$ & $174 \pm 8.4$ \\
\hline Weight $(\mathrm{kg}$, mean $\pm \mathrm{SD})$ & $69.1 \pm 15.9$ & $77.4 \pm 13.5$ \\
\hline Body Mass Index $\left(\mathrm{kg} / \mathrm{m}^{2}\right.$, mean $\left.\pm \mathrm{SD}\right)$ & $23.3 \pm 4.40$ & $25.6 \pm 3.42$ \\
\hline \multicolumn{3}{|l|}{ Primary kidney disease } \\
\hline Glomerulonephritis & 4 & 1 \\
\hline Chronic pyelonephritis & 2 & 2 \\
\hline IgA nephropathy & 3 & 4 \\
\hline Hypertensive nephropathy & 4 & 7 \\
\hline Diabetes Mellitus nephropathy & 4 & 0 \\
\hline Polycystic kidney disease & 1 & 8 \\
\hline Unknown & 1 & 4 \\
\hline Other & 7 & 11 \\
\hline \multicolumn{3}{|l|}{ Transplantation number } \\
\hline First & 20 & 30 \\
\hline Second & 5 & 6 \\
\hline Third or more & 1 & 1 \\
\hline Tacrolimus mono therapy & 1 & 29 \\
\hline Tacrolimus dose (mg/kg/day, mean \pm SD) & $0.39 \pm 0.231$ & $0.054 \pm 0.029$ \\
\hline $\mathrm{C}_{0}(\mathrm{ng} / \mathrm{ml}$, mean $\pm \mathrm{SD})$ & $16.8 \pm 5.83$ & $6.59 \pm 1.39$ \\
\hline $\mathrm{AUC}_{0-12}(\mathrm{ng} \times \mathrm{hr} / \mathrm{ml}$, mean $\pm \mathrm{SD})$ & $305.0 \pm 96.8$ & $122.5 \pm 31.1$ \\
\hline $\mathrm{C}_{\max }(\mathrm{ng} / \mathrm{ml}$, mean $\pm \mathrm{SD})$ & $56.3 \pm 21.3$ & $20.9 \pm 6.5$ \\
\hline $\mathrm{T}_{\max }(\mathrm{hr}$, mean $\pm \mathrm{SD})$ & $1.46 \pm 1.33$ & $1.24 \pm 0.43$ \\
\hline Use of azothiopurine, $\mathrm{MMF}^{\mathrm{a}}$, rapamycine, steroids & $11 / 3 / 4 / 26$ & $3 / 4 / 0 / 0$ \\
\hline \multicolumn{3}{|l|}{ Current steroid dose (mg, dose, no. patients) } \\
\hline 0 mg/day & 3 & 37 \\
\hline $5 \mathrm{mg} /$ day & 2 & 0 \\
\hline 8 mg/day & 2 & 0 \\
\hline $10 \mathrm{mg} / \mathrm{day}$ & 10 & 0 \\
\hline $15 \mathrm{mg} /$ day & 4 & 0 \\
\hline $20 \mathrm{mg} / \mathrm{day}$ & 3 & 0 \\
\hline$>20 \mathrm{mg} /$ day & 2 & 0 \\
\hline Time since transplantation (days, median, (range)) & $18(3-74)$ & $1465(453-4128)$ \\
\hline Haemoglobin $(\mathrm{mmol} / \mathrm{l}$, mean $\pm \mathrm{SD})$ & $5.43 \pm 1.08$ & $8.52 \pm 0.83$ \\
\hline Haematocrit fraction (mean $\pm S D$ ) & $0.25 \pm 0.07$ & $0.41 \pm 0.04$ \\
\hline $\operatorname{ALAT}(\mathrm{U} / \mathrm{l}$, mean $\pm \mathrm{SD})$ & $34 \pm 34$ & $24 \pm 13$ \\
\hline ASAT (U/I, mean $\pm S D)$ & $22 \pm 18$ & $17 \pm 10$ \\
\hline Serum albumin (g/l, mean $\pm S D$, ) & $30.7 \pm 3.86$ & $37.0 \pm 3.84$ \\
\hline Serum creatinine $(\mu \mathrm{mol} / \mathrm{l}$, median $\pm \mathrm{SD})$ & $331 \pm 293$ & $125 \pm 29$ \\
\hline Creatinine (Cockcroft-Gault; $\mathrm{ml} / \mathrm{min}$, median $\pm \mathrm{SD}$ ) & $37.5 \pm 28.4$ & $56.0 \pm 26.6$ \\
\hline
\end{tabular}

${ }^{\text {a }}$ mycophenolate mofetil

\section{Ethics}

The study was performed in accordance to the Declaration of Helsinki and its amendments. The protocol was approved by the local Medical Ethics Committee and written informed consent for participation in this study was obtained from all patients. 


\section{Tacrolimus concentration determinations}

The tacrolimus blood concentrations were determined in ethylene diamine tetra-acetic acid (EDTA) whole blood, using a microparticle enzyme immunoassay with a monoclonal antibody (IMx II assay; Abbott Laboratories, Abbott Park, IL, USA) for group I and a method based on HPLC tandem mass spectrometry (MS/MS) for group II. Both methods were performed in laboratories that participate in the International Tacrolimus Proficiency Testing Scheme. The tacrolimus $\mathrm{C}_{0}$ concentration, the peak blood concentration $\left(\mathrm{C}_{\max }\right)$ during the assessed time interval and the time at which the highest blood concentration was observed $\left(T_{\max }\right)$ were determined directly from the time versus tacrolimus blood concentration data. Additionally, the area under the time concentration curve $\left(\mathrm{AUC}_{0-12}\right)$ was calculated from the time versus tacrolimus concentration plot using the linear trapezoidal rule in MWPharm 3.50 (Mediware, Groningen, the Netherlands). $\mathrm{DnC}_{0}, \mathrm{dnAUC}_{0-12}$ and $\mathrm{dnC}_{\max }$ were calculated by dividing the $\mathrm{C}_{0}, \mathrm{AUC}_{0-12}$ and $\mathrm{C}_{\max }$ respectively by the corresponding morning dose on a milligram per kilogram basis.

\section{DNA isolation}

Genomic DNA isolation was performed by using $200 \mu$ EDTA anticoagulated blood for isolation with a QIAamp blood mini kit (Qiagen, Leusden, the Netherlands) according to the manufacturers' instructions.

\section{Genotyping of PXR polymorphisms}

Real-time PCR fluorescence resonance energy transfer (FRET) assays on the LightCycler (Roche Diagnostics, Almere, the Netherlands) were used for genotyping, PXR polymorphisms A7635G, C8055T, A11156C and T11193C using the same primers and probes compared to a previous publication (Op den Buijsch et al., submitted). For each polymorphism, heterozygote samples were sequenced according to a direct sequence procedure on a capillary sequencer $A B I$ Prism 3100 using the Bridge version 1.1 sequence kit (both products from Applied Biosystems, Fostercity, USA) and used in every real-time PCR FRET assay run as control sample.

\section{Statistical analysis}

Statistical analysis of the data was performed with use of the statistical software SPSS 11.0 for windows (Chicago, IL, USA). To examine the population homogeneity of the patients, the genotype frequencies of the PXR polymorphisms were tested against Hardy-Weinberg equilibrium by the Pearson's goodness-of-fit test ${ }^{18}$. For analysis of the daily tacrolimus dose $\left(\mathrm{mg} / \mathrm{kg} /\right.$ day), $\mathrm{dnC}_{0}(\mathrm{ng} / \mathrm{ml}$ per $\mathrm{mg} / \mathrm{kg}), \mathrm{dnAUC}_{0-12}(\mathrm{ng} \times \mathrm{hr} / \mathrm{ml}$ per $\mathrm{mg} / \mathrm{kg}), \mathrm{dnC}_{\max }\left(\mathrm{ng} / \mathrm{ml}\right.$ per $\mathrm{mg} / \mathrm{kg}$ ) and $\mathrm{T}_{\max }(\mathrm{hr})$, groups were compared using non parametric statistical tests. To compare two groups we used the Mann-Whitney test, and to compare several groups the Kruskal Wallis test. $P$ values less than 0.05 were 
considered statistically significant. All values are expressed as median and range unless stated otherwise.

\section{Results}

\section{The distribution of allele frequencies of four PXR polymorphisms}

The clinical characteristics of the early posttransplant group using corticosteroids (group I) and a late posttransplant group using no corticosteroids (group II) that were enrolled in our study are shown in Table 12.1. Table 12.2 and 12.3 show the genotype frequencies of the different PXR polymorphisms that were determined. After genotyping the renal transplant patients for four PXR polymorphisms, the frequency of the 7635AA genotype is $36.5 \%(n=23)$, for the 7635AC genotype $50.8 \%(n=32)$ and for the 7635GG $12.7 \%(n=8)$. In addition, the frequency of the $8055 \mathrm{CC}$ genotype is $68.3 \%$ ( $n=43$ ), for the 8055 CT genotype $30.2 \%(n=19)$ and for the 8055TT genotype $1.5 \%$ $(n=1)$ whereas the genotypes for the PXR polymorphisms A11156C and T11193C are in complete concordance with the genotypes of the PXR C8055T polymorphism. There is a complete haplotype between the following three PXR polymorphisms C8055T, $\mathrm{A} 11156 \mathrm{C}$ and $\mathrm{T} 11193 \mathrm{C}$. The allele frequencies of the Caucasian renal transplant patients examined were found to be $31.7 \%$ (7635G) and $16.7 \%(8055 \mathrm{~T}, 11156 \mathrm{C}$ and $11193 \mathrm{~T})$ which is in line with those published in previous studies ${ }^{13,14}$. The genotype frequencies of both renal transplant recipient groups were not significantly different from that predicted by the Hardy-Weinberg equation.

Table 12.2 Influence of PXR allelic variants on the pharmacokinetic tacrolimus parameters of the early posttransplant recipients in group $\mathrm{I}$.

\begin{tabular}{|c|c|c|c|c|c|c|}
\hline Genotype & $\begin{array}{l}\text { N } \\
\text { No }\end{array}$ & $\begin{array}{l}\text { Allelic } \\
\text { status }\end{array}$ & $\begin{array}{c}\text { Dose } \\
\text { (mg/kg/day) }\end{array}$ & $\begin{array}{c}\mathrm{DnC}_{0} \\
(\mathrm{ng} / \mathrm{ml} \text { per } \mathrm{mg} / \mathrm{kg})\end{array}$ & $\begin{array}{c}\text { DnAUC }_{0-12} \\
(\mathrm{ng} \times \mathrm{hr} / \mathrm{ml} \text { per } \mathrm{mg} / \mathrm{kg})\end{array}$ & $\begin{array}{c}\mathrm{DnC}_{\max } \\
(\mathrm{ng} / \mathrm{ml} \text { per } \mathrm{mg} / \mathrm{kg})\end{array}$ \\
\hline PXR & 6 & $\mathrm{~A} / \mathrm{A}$ & $0.464(0.25-0.79)$ & $83.7(40-123)$ & 1526 (824-2066) & $236(187-454)$ \\
\hline \multirow[t]{2}{*}{ A7635G } & 16 & $A / G$ & $0.259(0.04-0.80)$ & $90.9(42-1329)$ & $1801(839-15721)$ & $400(89-1535)$ \\
\hline & 4 & $\mathrm{G} / \mathrm{G}$ & $0.420(0.34-0.78)$ & $60.8(32-76)$ & $1298(922-1423)$ & $332(184-380)$ \\
\hline PXR & 16 & $\mathrm{C} / \mathrm{C}$ & $0.271(0.04-0.79)$ & $110.5(40-1329)^{b}$ & $1858(824-15721)^{a}$ & $402(176-1535)^{b}$ \\
\hline \multirow[t]{2}{*}{ C8055T } & 10 & $\mathrm{C} / \mathrm{T}$ & $0.435(0.07-0.80)$ & $63.7(32-421)^{\mathrm{b}}$ & $1244(839-5954)^{a}$ & $293(89-686)^{b}$ \\
\hline & 0 & $T / T$ & ---- & ---- & ---- & ---- \\
\hline PXR & 16 & $\mathrm{~A} / \mathrm{A}$ & $0.271(0.04-0.79)$ & $110.5(40-1329)^{b}$ & $1858(824-15721)^{a}$ & $402(176-1535)^{b}$ \\
\hline \multirow[t]{2}{*}{ A11156C } & 10 & $\mathrm{~A} / \mathrm{C}$ & $0.435(0.07-0.80)$ & $63.7(32-421)^{\mathrm{b}}$ & $1244(839-5954)^{a}$ & $293(89-686)^{b}$ \\
\hline & 0 & $\mathrm{C} / \mathrm{C}$ & ---- & ---- & ---- & ---- \\
\hline PXR & 16 & $\mathrm{~T} / \mathrm{T}$ & $0.271(0.04-0.79)$ & $110.5(40-1329)^{b}$ & $1858(824-15721)^{a}$ & $402(176-1535)^{b}$ \\
\hline \multirow[t]{2}{*}{ T11193C } & 10 & $\mathrm{~T} / \mathrm{C}$ & $0.435(0.07-0.80)$ & $63.7(32-421)^{\mathrm{b}}$ & $1244(839-5954)^{a}$ & $293(89-686)^{b}$ \\
\hline & 0 & $\mathrm{C} / \mathrm{C}$ & ----- & ---- & ---- & ---- \\
\hline
\end{tabular}

Values are indicated as median and (range), ${ }^{\mathrm{a}} P<0.05 ;{ }^{\mathrm{b}} P<0.10$ (Mann-Whitney). 
Table 12.3 Influence of PXR allelic variants on the pharmacokinetic tacrolimus parameters of the late posttransplant recipients in group II.

\begin{tabular}{lrccccc}
\hline Genotype & $\begin{array}{r}\text { N } \\
\text { No }\end{array}$ & $\begin{array}{c}\text { Allelic } \\
\text { status }\end{array}$ & $\begin{array}{c}\text { Dose } \\
\text { (mg/kg/day) }\end{array}$ & $\begin{array}{c}\text { DnC0 } \\
(\mathrm{ng} / \mathrm{ml} \text { per } \mathrm{mg} / \mathrm{kg})\end{array}$ & $\begin{array}{c}\text { DnAUC0-12 } \\
(\mathrm{ng} \times \mathrm{hr} / \mathrm{ml} \text { per mg/kg) }\end{array}$ & $\begin{array}{c}\text { DnCmax } \\
(\mathrm{ng} / \mathrm{ml} \mathrm{per} \mathrm{mg/kg})\end{array}$ \\
\hline PXR & 17 & A/A & $0.051(0.02-0.13)$ & $254(70-669)$ & $4973(1355-11994)$ & $820(294-1729)$ \\
A7635G & 16 & A/G & $0.049(0.02-0.14)$ & $286(87-640)$ & $4642(1662-11504)$ & $642(308-1493)$ \\
& 4 & G/G & $0.042(0.03-0.07)$ & $257(121-598)$ & $4488(2766-9320)$ & $814(504-1086)$ \\
& & & & & & \\
PXR & 27 & C/C & $0.044(0.02-0.13)$ & $275(70-669)$ & $4761(1355-11994)$ & $795(294-1729)$ \\
C8055T & 9 & C/T & $0.052(0.02-0.14)$ & $278(87-416)$ & $4510(1662-6854)$ & $646(308-981)$ \\
& 1 & T/T & 0.038 & 223 & 4465 & 810 \\
PXR & 27 & A/A & $0.044(0.02-0.13)$ & $275(70-669)$ & $4761(1355-11994)$ & $795(294-1729)$ \\
A11156C & 9 & A/C & $0.052(0.02-0.14)$ & $278(87-416)$ & $4510(1662-6854)$ & $646(308-981)$ \\
& 1 & C/C & 0.038 & 223 & 4465 & 810 \\
PXR & 27 & T/T & $0.044(0.02-0.13)$ & $275(70-669)$ & $4761(1355-11994)$ & $795(294-1729)$ \\
T11193C & 9 & T/C & $0.052(0.02-0.14)$ & $278(87-416)$ & $4510(1662-6854)$ & $646(308-981)$ \\
& 1 & C/C & 0.038 & 223 & 4465 & 810 \\
\hline
\end{tabular}

Values are indicated as median and (range).

\section{Influence of the different PXR allelic variants on the pharmacokinetic tacrolimus profiles}

The early posttransplant recipients carrying a PXR 8055T, 11156C and 11193T variant allele have a significantly lower and clinical relevant $\mathrm{dnAUC}_{0-12}$ (1858 versus 1243 $\mathrm{ng} \times \mathrm{hr} / \mathrm{ml}$ per $\mathrm{mg} / \mathrm{kg}$; Mann-Whitney, $P=0.040$ ) or a strong trendency towards a lower $\mathrm{dnC}_{0}$ (111 versus $64 \mathrm{ng} / \mathrm{ml}$ per $\mathrm{mg} / \mathrm{kg}$; Mann-Whitney, $P=0.073$ ) or lower $\mathrm{dnC}_{\max }(402$ versus $293 \mathrm{ng} / \mathrm{ml}$ per $\mathrm{mg} / \mathrm{kg}$; Mann-Whitney, $P=0.073$ ) compared to the carriers of the PXR 8055C, 11156A and 11193T wild type allele while in contrast no significant difference is observed regarding the pharmacokinetic parameters between carriers of the different PXR genotypes included in the corticosteroid group (group II). Figure 12.1A-D illustrate the effect of the different PXR polymorphisms on the $\operatorname{dnAUC}_{0-12}$ recorded in 26 early and 37 late posttransplant recipients.

Furthermore, the PXR haplotypes consisting of four polymorphisms are associated with the $\mathrm{dnAUC}_{0-12}$ for the early as well as the late posttransplant patients, as is shown in Figure 12.1E and 12.1F.

However, previously Op den Buijsch et al. (Op den Buijsch et al., submitted) demonstrated in the same renal transplant patient group an important impact of the CYP3A5 A6986G polymorphism on the tacrolimus concentrations whereas no association was reported between both ABCB1 polymorphisms G2677T/A and C3435T and the tacrolimus concentration. To exclude influence of one of these polymorphisms, the renal transplant recipients were based on their CYP3A4 A-392G and CYP3A5 A6986G genotype categorized in order to examine solely the effect of the four PXR polymorphisms on the $\mathrm{dnAUC}_{0-12}$. As is illustrated in Figure 12.2, there is a trend visible 
of the PXR C8055T, A11156C and T11193C after categorizing the patients for respectively the CYP3A4 A-392G and CYP3A5 A6986G polymorphisms. Additionally, Table 12.4 and 12.5 illustrate the influence of the combination of respectively CYP3A4 A-392G and CYP3A5 A6986G with the two PXR polymorphisms A7635G and C8055T.

Table 12.4 Influence of the combination of PXR and CYP3A4, CYP3A5 allelic variants on the pharmacokinetic tacrolimus parameters of the early posttransplant recipients in group I.

\begin{tabular}{|c|c|c|c|c|c|c|}
\hline $\begin{array}{l}\text { Genotype } \\
\text { combinations }\end{array}$ & $\begin{array}{l}\mathrm{N} \\
\text { No }\end{array}$ & $\begin{array}{l}\text { Allelic } \\
\text { status }\end{array}$ & $\begin{array}{c}\text { Dose } \\
\text { (mg/kg/day) }\end{array}$ & $\begin{array}{c}\mathrm{DnC}_{0} \\
(\mathrm{ng} / \mathrm{ml} \text { per } \mathrm{mg} / \mathrm{kg})\end{array}$ & $\begin{array}{c}\text { DnAUC }_{0-12} \\
(\mathrm{ng} \times \mathrm{hr} / \mathrm{ml} \text { per } \\
\mathrm{mg} / \mathrm{kg})\end{array}$ & $\begin{array}{c}\mathrm{DnC}_{\max } \\
(\mathrm{ng} / \mathrm{ml} \text { per } \mathrm{mg} / \mathrm{kg})\end{array}$ \\
\hline PXR/CYP3A4 & 3 & AA-AA & $0.28(0.25-0.72)$ & $114(40-123)$ & 1920 (824-2066) & $386(187-454)$ \\
\hline \multirow[t]{4}{*}{ A7635G/A-392G } & 16 & AG-AA & $0.26(0.04-0.80)$ & $91(42-1329)$ & 1801 (839-15721) & $400(89-1535)$ \\
\hline & 2 & GG-AA & $0.35(0.34-0.35)$ & $69(63-76)$ & $1372(1321-1423)$ & $353(327-380)$ \\
\hline & 3 & AA-AG & $0.50(0.43-0.79)$ & $60(55-107)$ & $1333(1220-1796)$ & $216(212-256)$ \\
\hline & 2 & GG-AG & $0.63(0.49-0.78)$ & $46(32-59)$ & $1098(922-1275)$ & $261(184-338)$ \\
\hline PXR/CYP3A5 & 1 & AA-GG & $0.78^{*}$ & $32^{*}$ & $922^{*}$ & $184^{*}$ \\
\hline \multirow[t]{6}{*}{ A7635G/A6986G } & 4 & AA-AG & $0.61(0.43-0.79)^{*}$ & $58(40-107)^{*}$ & $1277(824-1796)^{*}$ & $214(187-256)^{*}$ \\
\hline & 3 & AG-AG & $0.64(0.45-0.80)^{*}$ & $50(42-65)^{*}$ & $1042(864-1167)^{*}$ & $172(89-260)^{*}$ \\
\hline & 2 & GG-AG & $0.42(0.35-0.49)^{*}$ & $61(59-63)^{*}$ & $1298(1275-1321)^{*}$ & $359(338-380)^{*}$ \\
\hline & 3 & AA-GG & $0.28(0.25-0.54)^{*}$ & $114(45-123)^{*}$ & $1920(839-2066)^{*}$ & $386(90-454)^{*}$ \\
\hline & 12 & AG-GG & $0.23(0.04-0.59)^{*}$ & $174(51-1329)^{*}$ & $\begin{array}{l}2455(1103- \\
15721)^{*}\end{array}$ & $473(176-1535)^{\star}$ \\
\hline & 1 & GG-GG & $0.34^{*}$ & $76^{*}$ & $1423^{*}$ & $327^{*}$ \\
\hline PXR /CYP3A4 & 13 & CC-AA & $0.25(0.04-0.72)^{* *}$ & $123(40-1329)$ & $2030(824-15721)$ & $454(176-1535)^{* *}$ \\
\hline \multirow[t]{3}{*}{ C8055T/A-392G } & 9 & CT-AA & $0.42(0.07-0.80)^{\star *}$ & $65(42-421)$ & 1321 (839-5954) & $327(89-686)^{* *}$ \\
\hline & 3 & CC-AG & $0.50(0.43-0.79)^{* *}$ & $60(55-107)$ & $1333(1220-1796)$ & $216(212-256)^{\star *}$ \\
\hline & 1 & CT-AG & $0.78^{\star *}$ & 32 & 922 & $184^{\star *}$ \\
\hline PXR/CYP3A5 & 1 & CT-AA & $0.78^{*}$ & $32^{*}$ & $922^{*}$ & $184^{*}$ \\
\hline \multirow[t]{4}{*}{ C8055T/A6986G } & 5 & CC-AG & $0.50(0.43-0.79)^{*}$ & $59(40-107)^{*}$ & $1275(824-1796)^{*}$ & $216(187-338)^{*}$ \\
\hline & 4 & CT-AG & $0.550 .35-0.80)^{*}$ & $53(42-65)^{*}$ & $1132(864-1321)^{*}$ & $213(89-380)^{*}$ \\
\hline & 11 & CC-GG & $0.25(0.04-0.59)^{*}$ & $167(51-1329)^{*}$ & $\begin{array}{l}2066(1103- \\
15721)^{*}\end{array}$ & $471(176-1535)^{*}$ \\
\hline & 5 & CT-GG & $0.34(0.07-0.54)^{*}$ & $90(45-421)^{*}$ & $1715(839-5954)^{*}$ & $381(90-686)^{*}$ \\
\hline
\end{tabular}


Table 12.5 Influence of the combination of PXR and CYP3A4, CYP3A5 allelic variants on the pharmacokinetic tacrolimus parameters of the late posttransplant recipients in group II.

\begin{tabular}{|c|c|c|c|c|c|c|}
\hline $\begin{array}{l}\text { Genotype } \\
\text { combinations }\end{array}$ & $\begin{array}{l}\mathrm{N} \\
\text { No }\end{array}$ & $\begin{array}{l}\text { Allelic } \\
\text { status }\end{array}$ & $\begin{array}{c}\text { Dose } \\
\text { (mg/kg/day) }\end{array}$ & $\begin{array}{c}\mathrm{DnC}_{0} \\
(\mathrm{ng} / \mathrm{ml} \text { per } \mathrm{mg} / \mathrm{kg})\end{array}$ & $\begin{array}{c}\operatorname{DnAUC}_{0-12} \\
(\mathrm{ng} \times \mathrm{hr} / \mathrm{ml} \text { per } \mathrm{mg} / \mathrm{kg})\end{array}$ & $\begin{array}{c}\mathrm{DnC}_{\max } \\
(\mathrm{ng} / \mathrm{ml} \text { per mg/kg) }\end{array}$ \\
\hline CYP3A4/PXR & 17 & AA-AA & $0.05(0.02-0.13)$ & 254 (70-669) & $4973(1355-11994)$ & $820(294-1729)$ \\
\hline \multirow[t]{3}{*}{ A7635G/A-392G } & 16 & AG-AA & $0.05(0.02-0.14)$ & $286(87-640)$ & $4642(1662-11504)$ & $642(308-1493)$ \\
\hline & 3 & GG-AA & $0.04(0.03-0.05)$ & $289(223-598)$ & $4511(4465-9320)$ & $818(810-1086)$ \\
\hline & 1 & GG-AG & 0.07 & 121 & 2766 & 504 \\
\hline PXR/CYP3A5 & 1 & $A A-A G$ & 0.13 & $70^{* *}$ & $1355^{* *}$ & $294^{* *}$ \\
\hline \multirow[t]{5}{*}{ A7635G/A6986G } & 3 & AG-AG & $0.10(0.05-0.14)$ & $87(87-248)^{* *}$ & $1663(1662-4057)^{* *}$ & $461(308-646)^{* *}$ \\
\hline & 1 & GG-AG & 0.07 & $121^{*+*}$ & 2766 & $504^{*+}$ \\
\hline & 16 & AA-GG & $0.05(0.02-0.11)$ & $264(0.02-0.11)^{* *}$ & * $4991(2227-11994) *$ & $842(495-1729)^{*+}$ \\
\hline & 13 & AG-GG & $0.04(0.02-0.07)$ & $295(128-640)^{* *}$ & $4761(2673-11504)^{* *}$ & $643(465-1493)^{* *}$ \\
\hline & 3 & GG-GG & $0.04(0.03-0.05)$ & $290(223-598)^{* *}$ & $4511(4465-9320)^{+*}$ & $818(810-1086)^{* t}$ \\
\hline PXR /CYP3A4 & 26 & CC-AA & $0.04(0.02-0.13)$ & $279(70-669)$ & $4867(1355-11994)$ & $808(294-1729)$ \\
\hline \multirow[t]{3}{*}{ C8055T/A-392G } & 9 & CT-AA & $0.05(0.02-0.14)$ & $278(87-416)$ & $4511(1662-6854)$ & $646(308-981)$ \\
\hline & 1 & TT-AA & 0.04 & 223 & 4465 & 810 \\
\hline & 1 & CC-AG & 0.07 & 121 & 2766 & 504 \\
\hline PXR/CYP3A5 & 3 & CC-AG & $0.10(0.07-0.13)^{* *}$ & $87(70-121)^{*}$ & $1663(1355-2766)^{*}$ & $461(294-504)^{*}$ \\
\hline \multirow[t]{4}{*}{ C8055T/A6986G } & 2 & CT-AG & $0.10(0.05-0.14)^{* *}$ & $168(87-248)^{*}$ & $2859(1662-4057)^{*}$ & $477(308-646)^{*}$ \\
\hline & 24 & CC-GG & $0.04(0.02-0.11)^{* *}$ & $289(118-669)^{*}$ & $4992(2227-11194)^{*}$ & $842(495-1729)^{*}$ \\
\hline & 7 & CT-GG & $0.05(0.02-0.07)^{* *}$ & $290(128-416)^{*}$ & $4567(2673-6854)^{*}$ & $676(465-981)^{+}$ \\
\hline & 1 & TT-GG & $0.04^{* *}$ & $223^{*}$ & $4465^{*}$ & $810^{*}$ \\
\hline
\end{tabular}

Values are indicated as median and (range), ${ }^{*} P<0.05 ;{ }^{* \star} P<0.10$ (Kruskal Wallis). 

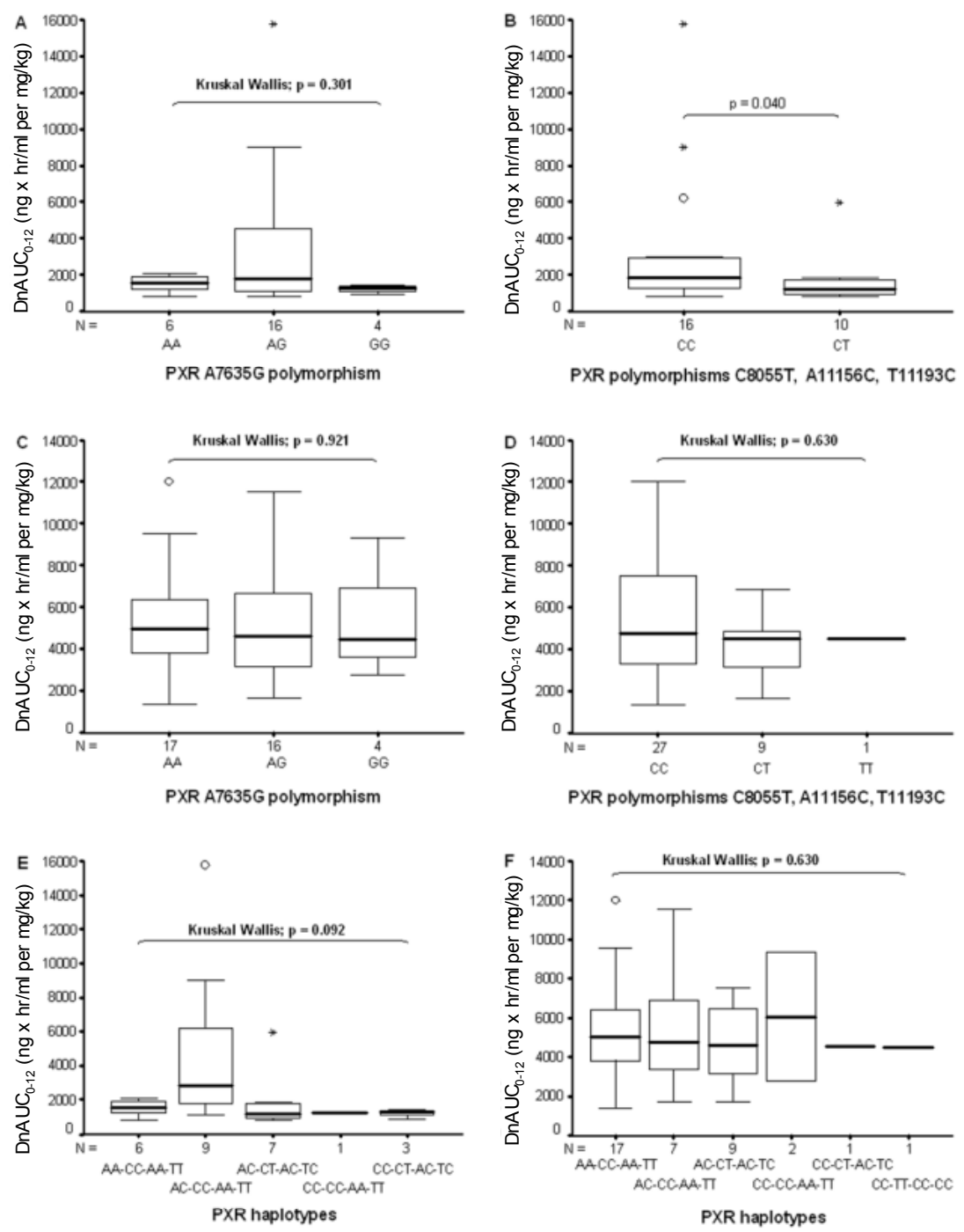

Figure 12.1 Influence of the PXR A7635G, C8055T, A11156C and T11193C genotypes on the area under the time tacrolimus concentration curve $\left(\mathrm{AUC}_{0-12}\right)$ that were recorded in 26 early and 37 late posttransplant patients. Figure 12.1 illustrates the boxplots of the distribution of the dose-normalized $\mathrm{AUC}_{0-12}(\mathrm{ng} \times \mathrm{hr} / \mathrm{ml}$ per $\mathrm{mg} / \mathrm{kg})$ clustered according to the PXR A7635G genotype, PXR C8055T, A11156C and T11193C genotype for the early posttransplant patient group (A and $B$ ) and the late posttransplant patient group ( $C$ and $D$ ). Figure 12.1 E and $F$ show the boxplots of the distribution of the dose-normalized $\mathrm{AUC}_{0-12}(\mathrm{ng} \times \mathrm{hr} / \mathrm{ml}$ per $\mathrm{mg} / \mathrm{kg})$ clustered according to the PXR haplotypes consisting of the PXR polymorphisms A7635G, C8055T, A11156C and T11193C in respectively the early and the late posttransplant patient group. Open circles indicate an outlier value at more than 1.5 box lengths above the box while asterices indicate an extreme value at more than 3 box lengths above the box. 

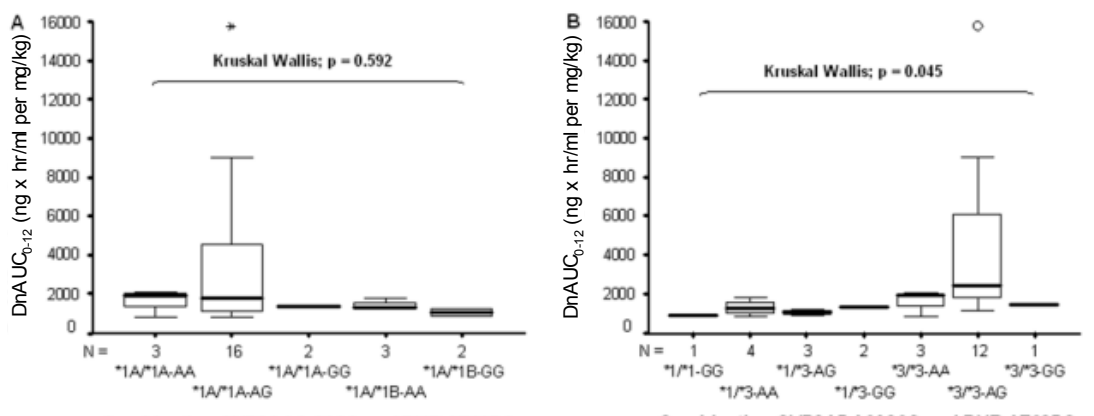

Combination CYP3A4 A-392G and PXR A7635G

Combination CYP3A5 A6986G and PXR A7635G
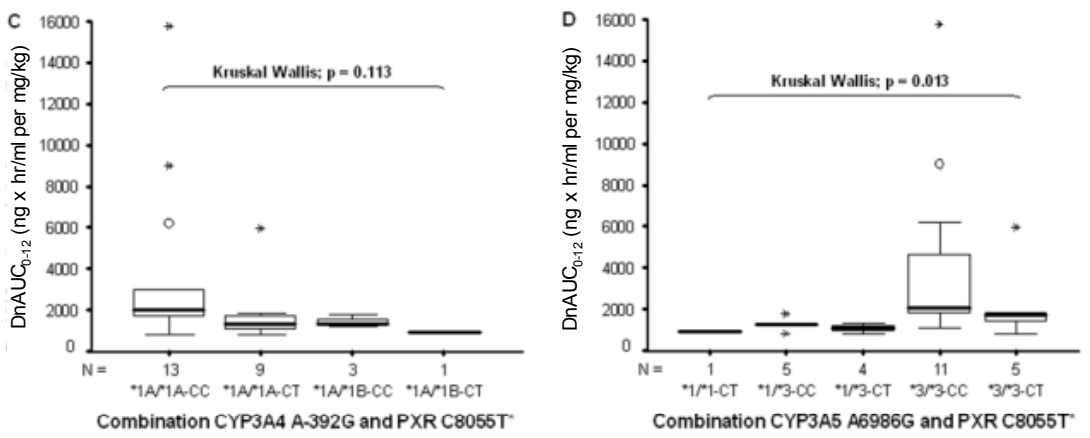

Figure 12.2 Figure 12.2 illustrates the boxplots of the distribution of the dose-normalized $\mathrm{AUC}_{0-12}$ ( $\mathrm{ng} \times \mathrm{hr} / \mathrm{ml}$ per $\mathrm{mg} / \mathrm{kg}$ ) clustered according to respectively (A) the combination of CYP3A4 A-392G and PXR A7635G, (B) the combination of CYP3A5 A6986G and PXR A7635G, (C) the combination of CYP3A4 A-392G and PXR C8055T and (D) the combination of CYP3A5 A6986G and PXR C8055T in the early posttransplant patient group. " indicates that the PXR polymorphisms A11156C and T11193C show exactly the same figures. Open circles indicate an outlier value at more than 1.5 box lengths above the box while asterices indicate an extreme value at more than 3 box lengths above the box.

\section{Discussion}

After genotyping 63 renal transplant patients divided into 26 early posttransplant recipients and 37 late posttransplant recipients it appeared that there is a complete PXR haplotype consisting of the polymorphisms C8055T, A11156C and T11193C. Although the genotypes of the four PXR polymorphisms differed not significantly between the early posttransplant recipient group and the late posttransplant recipient group, there is a difference in response between the different allelic variants of the PXR polymorphisms. The carriers of variant PXR alleles in the early renal transplant recipients showed a significant trend towards lower pharmacokinetic parameters $\left(\mathrm{dnC}_{0}\right.$, 
$\mathrm{dnAUC}_{0-12}$ and $\mathrm{dnC}_{\max }$ ) compared to carriers of wild type PXR alleles. However, patients included in the late posttransplant group that carry a variant PXR allele showed no trend towards lower pharmacokinetic parameters for tacrolimus compared to the patients that carried wild type alleles. Almost all renal transplant recipients included in group I used steroids as an additive immunosuppressivum while no of the 37 renal transplant recipients included in group II used corticosteroids. Previously, van Duijnhoven et al. ${ }^{15}$ first described an increase of the tacrolimus $\mathrm{C}_{0}$ concentration after corticosteroid withdrawal while two other studies ${ }^{16,17}$ also described a similar interaction between corticosteroids and tacrolimus. Induction of PXR by corticosteroids may lead to a higher expression of PXR and thereby to a higher expression of CYP3A4 and ABCB1 which may result in a higher daily tacrolimus dosage to maintain the pharmacokinetic parameters of tacrolimus within the therapeutic range. Differences in the tacrolimus $\mathrm{C}_{0}$ concentrations after administrating corticosteroids or withdrawing corticosteroids in transplant patients may be explained by polymorphisms present in the PXR gene. Zhang et al. ${ }^{13}$ demonstrated for the variant allele of the two PXR polymorphisms A7635G and C8055T a trend towards a higher of intestinal CYP3A after induction with rifampicin.

In addition, a tendency was reported to lower P-glycoprotein concentrations regarding carriers of the 3'-untranslated region variant alleles of the PXR polymorphisms 11156A to $C$ and $11193 T$ to $C$.

Our findings indicate that there is an inclination towards a lower $\mathrm{dnC}_{0}, \mathrm{dnAUC}_{0-12}$ and $\mathrm{dnC}_{\max }$ for patients who are carrier of at least one variant allele of the PXR polymorphisms examined. Remarkably, this trend was only observed in the early posttransplant patient group while the genotypes of the different PXR polymorphisms showed no trends towards lower pharmacokinetic parameters in the late posttransplant patient group. Due to the lack of corticosteroid use in the late posttransplant recipient group, the influence of PXR polymorphisms on the pharmacokinetic parameters of tacrolimus appears to be minor which may explain the discrepancy between the early and the late posttransplant recipient group. Summarized, tacrolimus is predominantly metabolised by the CYP3A iso-enzymes while the ABCB1 modulates its bioavailability. Although there is a high interindividual variation in the expression of CYP3A4 and $A B C B 1$, genetic polymorphisms can not exclusively explain the difference in CYP3A4 and $A B C B 1$ expression. $P X R$ has been identified as a transcriptional regulator of CYP3A4 and ABCB1. In the present study, four variant alleles of PXR polymorphisms A7635G, C8055T, A11156C and T11193C show a trend towards lower pharmacokinetic parameters however only in the early posttransplant patient group and not in the late posttransplant patient group. Since PXR polymorphisms demonstrate an effect in the early posttransplant group we hypothesized that the PXR polymorphisms have only an effect on the pharmacokinetic parameters of tacrolimus after induction by e.g. corticosteroids. Our findings indicate that PXR polymorphisms may play a role in tacrolimus metabolism although their role is dependent of the presence and/or of inductive drug or chemical components in the transplant patients. 


\section{References}

1. Sattler M, Guengerich FP, Yun CH, Christians U, Sewing KF. Cytochrome P-450 3A enzymes are responsible for biotransformation of FK506 and rapamycin in man and rat. Drug Metab Dispos 1992;20:753-61.

2. Lee SJ, Goldstein JA. Functionally defective or altered CYP3A4 and CYP3A5 single nucleotide polymorphisms and their detection with genotyping tests. Pharmacogenomics 2005;6:357-71.

3. Roy JN, Lajoie J, Zijenah LS, Barama A, Poirier C, Ward BJ, Roger M. CYP3A5 genetic polymorphisms in different ethnic populations. Drug Metab Dispos 2005;33:884-7.

4. Kuehl P, Zhang J, Lin Y, Lamba J, Assem M, Schuetz J, Watkins PB, Daly A, Wrighton SA, Hall SD, Maurel P, Relling M, Brimer C, Yasuda K, Venkataramanan R, Strom S, Thummel K, Boguski MS, Schuetz E. Sequence diversity in CYP3A promoters and characterization of the genetic basis of polymorphic CYP3A5 expression. Nat Genet 2001;27:383-91.

5. Jounaidi Y, Hyrailles V, Gervot L, Maurel P. Detection of CYP3A5 allelic variant: a candidate for the polymorphic expression of the protein? Biochem Biophys Res Commun 1996;221: 466-70.

6. Chou FC, Tzeng SJ, Huang JD. Genetic polymorphism of cytochrome P450 3A5 in Chinese. Drug Metab Dispos 2001;29:1205-9.

7. Hustert E, Haberl M, Burk O, Wolbold R, He YQ, Klein K, Nuessler AC, Neuhaus P, Klattig J, Eiselt R, Koch I, Zibat A, Brockmoller J, Halpert JR, Zanger UM, Wojnowski L. The genetic determinants of the CYP3A5 polymorphism. Pharmacogenetics 2001;11:773-9.

8. Lee SJ, Usmani KA, Chanas B, Ghanayem B, Xi T, Hodgson E, Mohrenweiser HW, Goldstein JA. Genetic findings and functional studies of human CYP3A5 single nucleotide polymorphisms in different ethnic groups. Pharmacogenetics 2003;13:461-72.

9. Xie HG, Wood AJ, Kim RB, Stein CM, Wilkinson GR. Genetic variability in CYP3A5 and its possible consequences. Pharmacogenomics 2004;5:243-72.

10. Saeki T, Ueda K, Tanigawara Y, Hori R, Komano T. Human P-glycoprotein transports cyclosporin A and FK506. J Biol Chem 1993;268:6077-6080.

11. Kliewer SA, Moore JT, Wade L, Staudinger JL, Watson MA, Jones SA, McKee DD, Oliver BB, Willson TM, Zetterstrom RH, Perlmann T, Lehmann JM. An orphan nuclear receptor activated by pregnanes defines a novel steroid signaling pathway. Cell 1998;92:73-82.

12. Blumberg B, Sabbagh W, Jr., Juguilon H, Bolado J, Jr., van Meter CM, Ong ES, Evans RM. SXR, a novel steroid and xenobiotic-sensing nuclear receptor. Genes Dev 1998;12:3195-205.

13. Zhang J, Kuehl P, Green ED, Touchman JW, Watkins PB, Daly A, Hall SD, Maurel P, Relling M, Brimer C, Yasuda K, Wrighton SA, Hancock M, Kim RB, Strom S, Thummel K, Russell CG, Hudson JR Jr, Schuetz EG, Boguski MS. The human pregnane $X$ receptor: genomic structure and identification and functional characterization of natural allelic variants. Pharmacogenetics 2001;11:555-72.

14. Bosch TM, Deenen M, Pruntel R, Smits PH, Schellens JH, Beijnen JH, Meijerman I. Screening for polymorphisms in the PXR gene in a Dutch population. Eur J Clin Pharmacol 2006;62:395-9.

15. van Duijnhoven EM, Boots JM, Christiaans MH, Stolk LM, Undre NA, van Hooff JP. Increase in tacrolimus trough levels after steroid withdrawal. Transpl Int 2003;16:721-5.

16. Hesselink DA, Ngyuen H, Wabbijn M, Gregoor PJ, Steyerberg EW, van Riemsdijk IC, Weimar W, van Gelder T. Tacrolimus dose requirement in renal transplant recipients is significantly higher when used in combination with corticosteroids. Br J Clin Pharmacol 2003;56:327-30.

17. Anglicheau D, Flamant M, Schlageter MH, Martinez F, Cassinat B, Beaune $\mathrm{P}$, Legendre C, Thervet $\mathrm{E}$. Pharmacokinetic interaction between corticosteroids and tacrolimus after renal transplantation. Nephrol Dial Transplant 2003;18:2409-14.

18. Sasieni PD. From genotypes to genes: doubling the sample size. Biometrics 1997;53: 1253-61. 


\section{Chapter 13}

General discussion 


\section{General discussion}

On 31 december 2006, in total 1394 patients were waiting for a kidney (1054), heart (44), lung (141) or liver (155) donor organ although in 2006 only 360 kidney, 37 heart, 52 lung and 83 liver transplantations were performed in the Netherlands ${ }^{1}$. Once the patients have received a well-functioning donor organ, the quality of life will improve significantly. However, all patients that receive a donor organ have to cope with a lifelong treatment by immunosuppressants like the calcineurin inhibitors: cyclosporin and/or tacrolimus, the mTOR inhibitors: sirolimus and/or everolimus, mycophenolic acid and azathiopurin, which all have highly variable pharmacokinetic characteristics and a small therapeutic index. The clinical consequences and impact for a patient with a subtherapeutic or toxic tacrolimus blood level can be very serious as was discussed in CHAPTER 2. Therefore, therapeutic monitoring of the immunosuppressant blood concentrations currently performed by trough $\left(\mathrm{C}_{0}\right)$ concentrations is inevitable. In the last five year many studies appeared regarding tacrolimus trough $\left(\mathrm{C}_{0}\right)$ levels of renal, liver and heart transplant recipients in association with the genotypes of the CYP3A4 A392G, CYP3A5 A6986G and ABCB1 C1236T, G2677T/A, C3435T polymorphisms2. Although all studies described a significant impact of the CYP3A5 A6986G polymorphism on the tacrolimus blood levels, conflicting results are reported about the contribution of the individual $A B C B 1$ polymorphisms or $A B C B 1$ haplotypes. Due to the large variation in the transplant patient populations that have been examined in the different studies, it is possible that a minor influence of the ABCB1 polymorphisms has not been noticed. The studies differ in the type of transplantation performed, number of patients included, time after transplantation, co-medication received by the patients and whether a trough level or a complete 12-hour AUC is determined. So it is likely that a polymorphism, that has a minor influence on the tacrolimus blood concentrations, due to this large variety in transplant patient population demonstrates contrasting results among these studies.

Tacrolimus is for the most part metabolised into 13-O-demethyltacrolimus by members of the CYP3A family and specifically CYP3A4 and CYP3A5. Additionally CHAPTER 7, 8 and 9 clearly point out that the members CYP3A4 and CYP3A5 of the cytochrome P450 $3 A$ family are involved the most in the tacrolimus metabolisation process whereby CYP3A5 is able to metabolise tacrolimus with a $60 \%$ higher efficiency than CYP3A4. Recently, Kamden et al. ${ }^{3}$ demonstrated with in vitro experiments that the CYP3A4 and CYP3A5 members of the CYP3A iso-enzyme family are predominantly responsible for the metabolisation of tacrolimus. However, Strassburg et $a l^{4}{ }^{4}$ demonstrated that tacrolimus is mainly glucuronidated by UGT2B7. Within the UGT2B7 gene several single nucleotide polymorphisms (SNPs) have been identified. One of the first UGT2B7 polymorphisms identified is the polymorphism H268Y (C802T). Since UGT2B7 is responsible for the metabolisation of the two most important metabolites of morphine, several studies ${ }^{5-8}$ examined whether there is an association between patients carrying a wild type or variant allele for the UGT2B7 C802T polymorphism. Conflicting evidence 
has been reported regarding the contribution of this UGT2B7 C802T polymorphism on the blood concentrations of morphine. Differences between the results of these studies may be caused by the drug administration of morphine (oral or intravenous), the numbers of patients included and if co-medication is used by the patients. Duguay et al. ${ }^{6}$ recently identified two novel polymorphisms located in the promoter area of the UGT2B7 gene. Although two novel UGT2B7 polymorphisms in the UGT2B7 promoter area are identified, only for the UGT2B7 -79G variant allele a difference in UGT2B7 expression is found. However, no differences in the glucuronidation ratios of morphine have been found, after genotyping 50 cancer patients receiving morphine on a long-term basis. In CHAPTER 10 three UGT2B7 polymorphisms are correlated to the tacrolimus exposure in a Chinese renal transplant population. Although quantitative evidence regarding the amount of tacrolimus glucuronidation is still lacking, it remains interesting to see that these UGT2B7 polymorphisms may have a significant contribution on the variability of the tacrolimus exposure. Despite the fact that CYP3A4 and CYP3A5 are mainly responsible for the metabolisation of tacrolimus only one polymorphism present in the CYP3A5 gene namely the CYP3A5 $6986 \mathrm{G}$ or CYP3A5*3 variant allele has a high allelic frequency in different ethnic populations and has a significant contribution on the tacrolimus $\mathrm{C}_{0}$ concentrations or other pharmacokinetic tacrolimus parameters. Even though there are several other functional CYP3A5 polymorphisms identified ${ }^{9}$, the allele frequency is very low in different ethnic populations and thus the contribution of these polymorphisms on the tacrolimus exposure is minor. Although CYP3A4 plays, like CYP3A5, an important role in the tacrolimus metabolism only the CYP3A4*1B variant allele has a relatively high allele frequency in Caucasians. However, due to a high linkage equilibrium between the CYP3A4*1B and the CYP3A5*1 it is difficult to examine whether the gene-dose contribution obtained is solely due to the CYP3A4*1B variant allele, or that the effect is caused by the high linkage with the CYP3A5*1 allele. Since polymorphisms in the CYP3A iso-enzymes can only partly explain the variation in the tacrolimus blood concentrations, it is likely that other genes are also (in)directly involved in the tacrolimus metabolism. The pregnane $X$ receptor (PXR) is a member of the nuclear receptor (NR) family of ligand-activated transcription factors that include the steroid, retinoid and thyroid hormone receptors, as well as many orphan receptors from which physiological ligands have yet to be identified ${ }^{10,11}$. PXR is highly expressed in the liver and intestine, were it binds as a heterodimer with the 9-cis retinoic acid receptor (RXR; NR2B) to previously characterized xenobiotic response elements in CYP3A gene promoters and importantly, $\mathrm{PXR}$ is activated by the spectrum of chemicals that are known to induce CYP3A gene expression ${ }^{12}$. Previously, Zhang et al. ${ }^{13}$ identified 38 polymorphisms in the PXR gene of which only eight polymorphisms present in either the 3'-untranslated (UTR) or intronic region seem to demonstrate an effect on the erythromycin breath test, CYP3A4 mRNA/villin or ABCB1 mRNA/villin after rifampicin induction. However, this study was performed with a low number of patients. Op den Buijsch et al. (Submitted; CHAPTER 11) demonstrated after genotyping 103 Chinese renal transplant recipients for four PXR polymorphisms, that these PXR polymorphisms 
have a significant influence on the tacrolimus exposure. Additionally, Op den Buijsch et al. (Submitted; CHAPTER 12) examined the influence of these four PXR polymorphisms on the pharmacokinetic tacrolimus parameters $\mathrm{C}_{0}, \mathrm{AUC}_{0-12}, \mathrm{C}_{\max }$, and $\mathrm{T}_{\max }$ in both an early using corticosteroids and a late using no corticosteroids renal transplant recipient group. Although the PXR genotypes of these early and late posttransplant recipient group did not significantly differ from each other, a significant contribution for the PXR polymorphism is only found in the early transplant recipient group which used corticosteroids. Previously, three different studies reported an increase of the tacrolimus $\mathrm{C}_{0}$ concentration when the corticosteroid therapy was stopped ${ }^{14-16}$. Possibly, PXR polymorphisms are responsible for the mechanism behind the difference in tacrolimus $\mathrm{C}_{0}$ concentration observed.

\section{Conclusions based on the research presented in this thesis are:}

The commercial DNA isolation kits (QIAamp blood mini kit, Roche High Pure PCR Template Preparation Kit and Puregene) have an extraction efficiency of approximately $30 \%$.

Real-time PCR FRET assays developed and validated in our laboratory can be used perfectly for genotyping in a clinical setting. Most limited sampling strategies for tacrolimus that already appeared in literature give a better indication of the tacrolimus exposure than the morning tacrolimus $\mathrm{C}_{0}$ concentrations used nowadays.

The single nucleotide polymorphism (SNP) A6986G in the CYP3A5 gene has a major impact on the tacrolimus exposure calculated with a limited sampling strategy, and on the $\mathrm{dnC}_{0}, \mathrm{dnAUC} \mathrm{C}_{0-12}$, and $\mathrm{dnC}_{\max }$. This CYP3A5 A6986G polymorphism can explain the variation observed in the $\mathrm{AUC}_{0-12}$ calculated with a two time point limited sampling strategy for approximately $35 \%$ in a Chinese renal transplant population.

Conflicting results were observed for the ABCB1 polymorphisms C1236T, G2677T/A and $\mathrm{C} 3435 \mathrm{~T}$ in the Chinese and the Caucasian renal transplant recipient group which is in line with literature.

Although it is known that tacrolimus is also glucuronidated mainly by UGT2B7, the UGT2B7 polymorphisms G-79A, T-66C and C802T have no influence on the tacrolimus exposure in a Chinese renal transplant patient group that is calculated with a two time point limited sampling strategy.

An interesting finding was observed for the PXR polymorphisms A7635G, C8055T, $\mathrm{A} 11156 \mathrm{C}$ and $\mathrm{T} 11193 \mathrm{C}$. In the Chinese renal transplant recipients a significant 
difference was observed for the PXR polymorphisms A7635G and A11156C, T11193C while a trend was observed for the PXR polymorphism C8055T. Although after categorizing the renal transplant patients in different groups based on their CYP3A5 and ABCB1 genotype no significant difference was observed, a trend regarding a lower tacrolimus exposure for renal transplant patients carrying a variant allele for these PXR polymorphisms remained.

The fact that these PXR polymorphisms only have an effect on the tacrolimus exposure in early posttransplant patients that use high corticosteroid dosages indicates that induction of PXR by corticosteroids is a prerequisite for a contribution of PXR polymorphisms on the tacrolimus exposure. This finding also confirms the results of several studies that found lower tacrolimus concentration in early transplant patients using a high daily corticosteroid dose while a higher tacrolimus concentration is observed for the late posttransplant patient using a lower daily corticosteroid dose.

\section{Directions for future research}

Because all patients that receive a donor organ have to undergo lifelong treatment by immunosuppressants, an accurate follow up with close monitoring of the immunosuppressant blood concentrations of these patients is required. By receiving a donor organ the patients' health and their quality of life increases enormously, although these patients have to ingest at least one immunosuppressant twice a day, with often several other medications. Due to their highly variable pharmacokinetic charactericstics, all immunosuppressants, like the calcineurin inhibitors tacrolimus and cyclosporine, mTOR inhibitors sirolimus and everolimus, mycophenolic acid and azathiopurin all require close monitoring of the blood concentrations on a regular basis. Recently, Hoogtanders et al. ${ }^{17}$ demonstrated a dried blood spot (DBS) method which is able to determine the tacrolimus concentration with capillary blood which can be obtained with a fingerprick by the patients themselves. Additionally, Wijnen et al. (Submitted) described a non-commercial DBS method for isolating DNA from capillary blood. Both DBS methods have a lot of advantages regarding the patient, logistics, storage, time and total costs. Recently, several studies reported that a limited sampling strategy consisting of two or three time sample points within 4 hours after the morning tacrolimus ingestion, have firstly a better correlation with the complete 12-hour area under the time tacrolimus concentration $\left(\mathrm{AUC}_{0-12}\right)$ curve and secondly according to a comprehensive study of Op den Buijsch et al (Submitted) the absolute prediction error (APE) of most limited sampling strategies are better than the APE of the trough concentrations $\mathrm{C}_{0}$ and $\mathrm{C}_{12}$. Therefore, we concluded that all limited sampling strategies that already appeared in literature could generate a reliable prediction of the complete 12-hour $\mathrm{AUC}_{0-12}$ although in new settings careful evaluation of their reliability with an own transplant population is advisable. Its is known that the immunosuppressant blood concentrations 
are most variable in the early period after transplantation. A better indication of the initial starting dose for each individual patient may contribute to a decrease in the variation of the tacrolimus blood concentrations and thus to a lower incidence of subtherapeutic or toxic blood concentrations, which ultimately lead to rejection or adverse drug reactions. Tacrolimus is mainly metabolized due to cytochrome P450 (CYP450) 3A iso-enzymes into 13-O-demethyltacrolimus, which has almost no immunosuppressive activity. The most relevant single nucleotide polymorphism (SNP) in the CYP3A iso-enzymes is the CYP3A5 A6986G polymorphism. Kamden et al. ${ }^{3}$ recently demonstrated that the CYP3A subfamily is the only CYP450 iso-enzyme that has a significant contribution in vitro on the tacrolimus metabolisation. Additionally, they demonstrated that CYP3A5 is able to metabolise tacrolimus with a $60 \%$ higher efficiency rate compared to CYP3A4.

Regarding the contribution of the adenosine triphosphate binding cassette B1 (ABCB1) polymorphisms C1236T, G2677T/A and C3435T or ABCB1 haplotypes there is conflicting evidence on their role in the tacrolimus metabolism. Although a few studies found a significant association between the individual ABCB1 polymorphisms or ABCB1 haplotypes, no unambiguous evidence is found for their contribution. Several reasons can justify a discrepancy in the results of the studies that already appeared such as a pharmacokinetic $\left(\mathrm{C}_{0} ; \mathrm{C}_{2}, \mathrm{C}_{4}\right.$; or $\left.\mathrm{AUC}_{0-12}\right)$ or genetic (SNP versus haplotype) analyses that were performed. Moreover, the sample size of the study cohorts and the time after transplantation points at which a possible ABCB1 genotype effect was assessed, differed between studies. Previously, Strassburg et al. ${ }^{4}$ demonstrated that cyclosporine and tacrolimus are also glucuronidated especially by UGT2B7. More recently, Bhasker et $a l^{18}{ }^{18}$ identified the UGT2B7 C816T polymorphism and Dugauy et al. ${ }^{6}$ reported about two novel UGT2B7 polymorphisms which are located in the UGT2B7 promoter area. However, Op den Buijsch et al. (Pharmacogenomics, submitted) first described that three possible relevant polymorphisms in the UGT2B7 gene have no significant influence on the tacrolimus exposure in a Chinese renal transplant population. Because, polymorphisms present in the different CYP3A iso-enzymes, the UGT2B7 gene and the $A B C B 1$ gene can only partly elucidate the variation in the tacrolimus blood concentration, other genes may possibly also have a significant contribution to the tacrolimus blood concentration. However, even when transplant patients achieve therapeutic drug concentrations of the immunosuppressive drugs, rejection and drug toxicity are not eliminated ${ }^{19}$. Recently, Op den Buijsch et al. (Submitted) demonstrated that polymorphisms located in the PXR gene may also explain the variability in the tacrolimus exposure. Especially, since the PXR polymorphisms seem to have influence in patients only early after transplantation when the daily corticosteroid dose is highest. These studies indicate that genes are not only directly, but also indirectly involved in the tacrolimus metabolism may contribute to the variability of the tacrolimus blood concentration. More recently, a study examining new onset diabetes after transplantation in tacrolimus treated renal transplant patients, showed that the CYP3A5*3, ABCB1 3435T and 2677T/A polymorphisms did not appear to be risk factors. This was, however, a small cohort of 70 subjects, only 10 of which developed 
new onset diabetes after transplantation and therefore may not have been sufficiently powerful statistically ${ }^{20}$. Polymorphisms in target proteins have been previously identified: FK binding protein for tacrolimus and mTOR inhibitors ${ }^{21}$, cyclophylin for cyclosporine ${ }^{22}$ and inosine monophosphate dehydrogenase for mycophenolic acid ${ }^{23}$. However, there are as yet no published studies on any potential pharmacogenetic effect. After identification of a number of polymorphisms in several genes that are involved in the tacrolimus metabolism a microarray with all these polymorphisms included, may identify those transplant patients that need an aberrant daily tacrolimus dose or even another type of immunosuppressant. In the end this multi-pharmacogenetic approach will result in a better immunosuppressive pharmacotherapy for each individual transplant patients and lesser rejections and adverse drug reactions are likely to occur.

But even when patients are genotyped for polymorphisms in all these genes involved in both the metabolism (pharmacokinetics) and the drug receptor interaction (pharmacodynamics) of tacrolimus, still a large area of unsolved mysteries will remain. Numerous exogenic and endogenic compounds have a minor to large inhibitory or inductive effect on the CYP3A iso-enzymes, the UGT2B7 enzyme and the drug transporter P-glycoprotein which all are involved in the tacrolimus metabolism. To obtain an idea of the total amount of CYP3A iso-enzymes that are active in the liver an erythromycine breath test is developed ${ }^{1,24-26}$. By using this erythromycine breath test one is able to determine the actual amount of CYP3A present in the patients' liver. This CYP3A amount determined by the erythromycin breath test may provide a better indication of the CYP3A activity than solely genotyping for CYP3A polymorphisms so that the tacrolimus pharmacokinetics for each individual patient may be predicted more accurately. 


\section{References}

1. http://www.transplantatiestichting.nl/index.php?id=cijfers_organen_transplantaties_actueel.

2. Armendariz Y, Pou L, Cantarell C, Lopez R, Perello M, Capdevila L. Evaluation of a limited sampling strategy to estimate area under the curve of tacrolimus in adult renal transplant patients. Ther Drug Monit 2005;27:431-4.

3. Balbontin FG, Kiberd B, Squires J, Singh D, Fraser A, Belitsky P, Lawen J. Tacrolimus monitoring by simplified sparse sampling under the concentration time curve. Transplant Proc 2003;35:2445-8.

4. Kuypers DR, Claes K, Evenepoel P, Maes B, Coosemans W, Pirenne J, Vanrenterghem Y. Time-related clinical determinants of long-term tacrolimus pharmacokinetics in combination therapy with mycophenolic acid and corticosteroids: a prospective study in one hundred de novo renal transplant recipients. Clin Pharmacokinet 2004;43:741-62.

5. Wong KM, Shek CC, Chau KF, Li CS. Abbreviated tacrolimus area-under-the-curve monitoring for renal transplant recipients. Am J Kidney Dis 2000;35:660-6.

6. Stolk LM, Van Duijnhoven EM, Christiaans MH, van Hooff JP. Trough levels of tacrolimus. Ther Drug Monit 2002;24:573; author reply 573-4.

7. Pisitkun T, Eiam-Ong S, Chusil S, Praditpornsilpa K, Pansin P, Tungsanga K. The roles of C4 and AUC0-4 in monitoring of tacrolimus in stable kidney transplant patients. Transplant Proc 2002;34:3173-5.

8. $\mathrm{Ku}$ YM, Min DI. An abbreviated area-under-the-curve monitoring for tacrolimus in patients with liver transplants. Ther Drug Monit 1998;20:219-23.

9. Aumente Rubio MD, Arizon del Prado JM, Lopez Malo de Molina MD, Cardenas Aranzana M, Segura Saint-Gerons J, Lopez Granados A, et al. Clinical pharmacokinetics of tacrolimus in heart transplantation: new strategies of monitoring. Transplant Proc 2003;35:1988-91.

10. Sgrosso JL, Araujo GL, Vazquez MC. Tacrolimus pharmacokinetics in heart transplant. Transplant Proc 2002;34:142-3.

11. Ragette $\mathrm{R}$, Kamler M, Weinreich $\mathrm{G}$, Teschler $\mathrm{H}$, Jakob $\mathrm{H}$. Tacrolimus pharmacokinetics in lung transplantation: new strategies for monitoring. J Heart Lung Transplant 2005;24:1315-9.

12. Scholten EM, Cremers SC, Schoemaker RC, Rowshani AT, van Kan EJ, den Hartigh J, Paul LC, de Fijter JW. AUC-guided dosing of tacrolimus prevents progressive systemic overexposure in renal transplant recipients. Kidney Int 2005;67:2440-7.

13. Ting LS, Villeneuve E, Ensom MH. Beyond cyclosporine: a systematic review of limited sampling strategies for other immunosuppressants. Ther Drug Monit 2006;28:419-30.

14. Hesselink DA, van Gelder T, van Schaik RH. The pharmacogenetics of calcineurin inhibitors: one step closer toward individualized immunosuppression? Pharmacogenomics 2005;6: 323-337.

15. Kamdem LK, Streit F, Zanger UM, Brockmoller J, Oellerich M, Armstrong VW, Wojnowski L. Contribution of CYP3A5 to the in vitro hepatic clearance of tacrolimus. Clin Chem 2005;51:1374-81.

16. Strassburg CP, Barut A, Obermayer-Straub P, Li Q, Nguyen N, Tukey RH, Manns MP. Identification of cyclosporine $A$ and tacrolimus glucuronidation in human liver and the gastrointestinal tract by a differentially expressed UDP-glucuronosyltransferase: UGT2B7. J Hepatol 2001;34: 865-72.

17. Sawyer MB, Innocenti F, Das S, Cheng C, Ramirez J, Pantle-Fisher FH, Wright C, Badner J, Pei D, Boyett JM, Cook E Jr, Ratain MJ. A pharmacogenetic study of uridine diphosphateglucuronosyltransferase $2 \mathrm{~B} 7$ in patients receiving morphine. Clin Pharmacol Ther 2003;73:566-74.

18. Duguay $\mathrm{Y}$, Baar $\mathrm{C}$, Skorpen $\mathrm{F}$, Guillemette $\mathrm{C}$. A novel functional polymorphism in the uridine diphosphate-glucuronosyltransferase 2B7 promoter with significant impact on promoter activity. Clin Pharmacol Ther 2004;75:223-33. 
19. Holthe M, Klepstad P, Zahlsen K, Borchgrevink PC, Hagen L, Dale O, Kaasa S, Krokan HE, Skorpen F. Morphine glucuronide-to-morphine plasma ratios are unaffected by the UGT2B7 $\mathrm{H} 268 \mathrm{Y}$ and UGT1A1*28 polymorphisms in cancer patients on chronic morphine therapy. Eur J Clin Pharmacol 2002;58:353-6.

20. Holthe M, Rakvag TN, Klepstad P, Idle JR, Kaasa S, Krokan HE, Skorpen F. Sequence variations in the UDP-glucuronosyltransferase 2B7 (UGT2B7) gene: identification of 10 novel single nucleotide polymorphisms (SNPs) and analysis of their relevance to morphine glucuronidation in cancer patients. Pharmacogenomics J 2003;3:17-26.

21. Xie HG, Wood AJ, Kim RB, Stein CM, Wilkinson GR. Genetic variability in CYP3A5 and its possible consequences. Pharmacogenomics 2004;5:243-72.

22. Giguere V. Orphan nuclear receptors: from gene to function. Endocr Rev 1999;20:689-725.

23. Mangelsdorf DJ, Thummel C, Beato M, Herrlich P, Schutz G, Umesono K, Blumberg B, Kastner P, Mark M, Chambon P, Evans RM. The nuclear receptor superfamily: the second decade. Cell 1995;83:835-9.

24. Kliewer SA, Goodwin B, Willson TM. The nuclear pregnane $X$ receptor: a key regulator of xenobiotic metabolism. Endocr Rev 2002;23:687-702.

25. Zhang J, Kuehl P, Green ED, Touchman JW, Watkins PB, Daly A, Hall SD, Maurel P, Relling M, Brimer C, Yasuda K, Wrighton SA, Hancock M, Kim RB, Strom S, Thummel K, Russell CG, Hudson JR Jr, Schuetz EG, Boguski MS. The human pregnane $X$ receptor: genomic structure and identification and functional characterization of natural allelic variants. Pharmacogenetics 2001;11:555-72.

26. Anglicheau D, Flamant M, Schlageter MH, Martinez F, Cassinat B, Beaune P, Legendre C, Thervet E. Pharmacokinetic interaction between corticosteroids and tacrolimus after renal transplantation. Nephrol Dial Transplant 2003;18:2409-14.

27. Hesselink DA, Ngyuen H, Wabbijn M, Gregoor PJ, Steyerberg EW, van Riemsdijk IC, Weimar W, van Gelder T. Tacrolimus dose requirement in renal transplant recipients is significantly higher when used in combination with corticosteroids. Br J Clin Pharmacol 2003;56:327-30.

28. van Duijnhoven EM, Boots JM, Christiaans MH, Stolk LM, Undre NA, van Hooff JP. Increase in tacrolimus trough levels after steroid withdrawal. Transpl Int 2003;16:721-5.

29. Hoogtanders K, van der Heijden J, Christiaans M, Edelbroek P, van Hooff JP, Stolk LM. Therapeutic drug monitoring of tacrolimus with the dried blood spot method. J Pharm Biomed Anal 2007;44:658-64.

30. Bhasker CR, McKinnon W, Stone A, Lo AC, Kubota T, Ishizaki T, Miners JO. Genetic polymorphism of UDP-glucuronosyltransferase 2B7 (UGT2B7) at amino acid 268: ethnic diversity of alleles and potential clinical significance. Pharmacogenetics 2000;10:679-85.

31. Mahalati K, Belitsky P, Sketris I, West K, Panek R. Neoral monitoring by simplified sparse sampling area under the concentration-time curve: its relationship to acute rejection and cyclosporine nephrotoxicity early after kidney transplantation. Transplantation 1999;68:55-62.

32. Numakura K, Satoh S, Tsuchiya N, Horikawa $Y$, Inoue T, Kakinuma H, Matsuura S, Saito M, Tada H, Suzuki T, Habuchi T. Clinical and genetic risk factors for posttransplant diabetes mellitus in adult renal transplant recipients treated with tacrolimus. Transplantation 2005;80:1419-24.

33. Fruman DA, Wood MA, Gjertson CK, Katz HR, Burakoff SJ, Bierer BE. FK506 binding protein 12 mediates sensitivity to both FK506 and rapamycin in murine mast cells. Eur J Immunol 1995;25:563-71.

34. Cardenas ME, Lim E, Heitman J. Mutations that perturb cyclophilin A ligand binding pocket confer cyclosporin A resistance in Saccharomyces cerevisiae. J Biol Chem 1995;270:209971002.

35. Bowne SJ, Sullivan LS, Blanton SH, Cepko CL, Blackshaw S, Birch DG, HughbanksWheaton D, Heckenlively JR, Daiger SP. Mutations in the inosine monophosphate dehydrogenase 1 gene (IMPDH1) cause the RP10 form of autosomal dominant retinitis pigmentosa. Hum Mol Genet 2002;11:559-68.

36. Cocking CW, E; McIntyre, J; Preton, T; Choonara, I. Drug metabolism studie in the newborn infant and children using an oral erythromycin breath test. Paediatric and Perinatal Drug Therapy 2006;7:172-177. 
37. Chiou WL, Jeong HY, Wu TC, Ma C. Use of the erythromycin breath test for in vivo assessments of cytochrome P4503A activity and dosage individualization. Clin Pharmacol Ther 2001;70:305-10.

38. Paine MF, Wagner DA, Hoffmaster KA, Watkins PB. Cytochrome P450 3A4 and Pglycoprotein mediate the interaction between an oral erythromycin breath test and rifampin. Clin Pharmacol Ther 2002;72:524-35.

39. Rivory LP, Slaviero KA, Hoskins JM, Clarke SJ. The erythromycin breath test for the prediction of drug clearance. Clin Pharmacokinet 2001;40:151-8. 
Summary 


\section{Summary}

In 2006, a total of 1054 patients were waiting for a donor kidney in the Netherlands, while in the same year only 360 kidney transplantations were performed. Not only the life expectancy but also the quality of life increases enormously after the patient has received a well-functioning donor kidney. However, ten years after transplantation only approximately half of all donor kidneys is still functioning well. The loss of transplantated kidneys is caused by a not well-functioning transplanted kidney (chronic transplant disfunctioning) and more often by the decease of the patient despite a well-functioning transplant kidney. The patients' death is, in that case, often caused by heart and circulation diseases.

However, all patients that receive a donor organ have to cope with a lifelong treatment of immunosuppressants, which all have highly variable pharmacokinetic characteristics and a small therapeutic index. The maintenance immunosuppressive therapy consisted, from 1980 until 1995, of cyclosporine (Neoral ${ }^{\circledR}$ ) with corticosteroids and azathiopurin (Immuran ${ }^{\circledR}$ ). In 1995 a few new immunosuppressants became available: tacrolimus (Prograft ${ }^{\circledR}$ ) a drug which can be used as a cornerstone for the pharmacotherapy, mycophenolate mofetil (Cellcept ${ }^{\circledR}$ ) and sirolimus (Rapamune ${ }^{\circledR}$ ), which can be used as additive immunosuppressive drugs. When tacrolimus is administrated instead of cyclosporine, acute rejections appeared to occur less often. This is the case for corticosteroid-sensitive as well as for corticosteroid-insensitive rejections. Due to the fact that acute rejection and especially corticosteroid-insensitive acute rejection is associated with a higher risk of chronic transplant-disfunction, it was expected that the use of tacrolimus will lead to a better transplantation survival than cyclosporine usage. In the meantime there are strong indications that these expectancies are justified. Furthermore the use of tacrolimus instead of cyclosporine leads to an improvement of several lipoproteins (HDL, LDL) and lipids (triglycerides) in the blood and to a lower blood pressure. These factors are also associated with chronic transplant disfunction and thereby with mortality as a result of heart and circulation diseases after transplantation. However, after using tacrolimus it is also assessed that the incidence of diabetes mellitus after transplantation occurs more often than with the use of cyclosporine. This would, in the end, cancel all the previously mentioned advantages regarding the increased survival of the transplant kidney and the increased survival of the patient.

After in CHAPTER 1 the outline and the aim of this thesis is described, CHAPTER 2 gives a complete review of the tacrolimus metabolism, (absorption, distribution, metabolisation and elimination). The high variable pharmacokinetic characteristics of tacrolimus in combination with a small therapeutic index emphasized the need for close monitoring of the tacrolimus blood concentrations. Additionally, CHAPTER 2 describes different methodologies used nowadays to measure the tacrolimus exposure, pharmacokinetic parameters, trough $\left(\mathrm{C}_{0}\right)$ levels, abbreviated area under the time tacrolimus concentration curve $\mathrm{AUC}_{0-12}$ ) or complete 12-hour $\mathrm{AUC}_{0-12}$ and the apparatus 
used (IMx II or LC-MS/MS). Furthermore, the genetic and non-genetic factors that may play a role on the tacrolimus metabolism are summarized and finally the clinical consequences and impact on a patient with a sub-therapeutic or toxic tacrolimus blood level is discussed.

Before real-time polymerase chain reaction (PCR) can be performed using fluorogenic probes, DNA isolation from the ethylene diamine tetra-acetic acid (EDTA) whole blood samples is required. Although several commercial DNA isolation kits are available to extract DNA from whole blood samples, less information is available regarding the extraction efficiency and the quality of the isolated DNA. CHAPTER 3 presents a study that compares three commercially available DNA isolation kits, QIAamp blood mini kit (Qiagen, Leusden, the Netherlands), Roche High Pure DNA Preparation kit (Roche Diagnostics, Mannheim, Germany), Puregene (Biozyme, Landgraaf, the Netherlands) regarding to their ability to extract DNA from whole blood samples as well as the DNA quality.

In the early nineties, the real-time PCR technology introduced a new dimension in the PCR technology, amplification and detection is possible in one single PCR cup, plate or capillary. The defined cycle threshold $\left(C_{t}\right)$ values can be used to determine the quantity of DNA that is present in the PCR cup, whereas a difference between wild type and variant allele DNA in probe attachment can be used for genotyping using the real-time PCR technology. Due to its speed, less contamination risk, less hands on time and a PCR and detection method in one, real-time PCR has gained an enormous interest among molecular biologists. An application that is used widely in real-time PCR is the fluorescence resonance energy transfer (FRET) methodology. A feature of this real-time PCR FRET technology is that two individual fluorescent probes are complimentary to the PCR product near the polymorphic position. Another characteristic of the FRET technology are the melting curves. After the final cyclus, the generated PCR product is cooled down to a certain temperature after which it is denaturated once more. The double stranded PCR product is heated with a speed of 0.1 to $0.2^{\circ} \mathrm{C} /$ second until the desired temperature. During this heating procedure the fluorescence signal is measured continuously. If the nucleotide located on the polymorphic position in the sensor probe is complementary to the nucleotide located at the polymorphic position in the multiplied DNA, there is a relatively strong bond between these nucleotides and the fluorescence signal will decrease in strength only at a high temperature. This in contrast to a not complementary nucleotide in the PCR product that will result in a less stable bond and consequently will result in a fluorescence signal decreasing at a lower temperature. By calculating the negative derivative of this decrease in fluorescence signal, a melting peak for the wild type and the variant allele samples is obtained.

Due to the composition of some of the DNA sequence, e.g. a long $A / T$ rich area, it is necessary to design a sensor probe, the probe that covers the polymorphic position, that is long enough in order to obtain a melting temperature that is sufficiently high. As a result of the increased length of such a sensor probe, the influence of the none complementary nucleotide becomes significantly less compared to a shorter sensor 
probe. CHAPTER 4 demonstrates that the incorporation of a locked nucleic acid (LNA) significantly improved the genotyping of the PXR A11156C polymorphism. Especially, heterozygotes could be discriminated clearly by showing two melting peaks, whereas the probes without a LNA were not able to separate melting peaks in the melting curve analysis. Therefore, we conclude that a LNA within a sensor probe may improve the discriminating power of FRET assays significantly.

In order to set up a fast and consistent assay for the organic anion transporting polypeptide 1B1 (OATP1B1) polymorphisms, in CHAPTER 5 rapid speed PCR FRET assays on the LightCycler are developed for these OATP1B1 polymorphisms. A LNA on the polymorphic location within the sensor probe was necessary to discriminate both alleles of the OATP1B1 T521C polymorphism. To confirm the reliability of both real-time PCR FRET assays, these new methods were validated by genotyping 120 samples using a PCR restriction fragment length polymorphism (RFLP) assay and an allelespecific PCR. The results of the real-time PCR FRET assays were completely in line with the conventional PCR methods, indicating that the real-time PCR FRET assays are appropriate for clinical settings.

In most transplant centres monitoring of the tacrolimus blood concentration is performed by $\mathrm{C}_{0}$ concentrations after the morning tacrolimus administration. However, conflicting evidence is present regarding the usefulness of these morning tacrolimus $\mathrm{C}_{0}$ concentrations. Knowing this, several studies recently developed a limited sampling strategy (LSS) for tacrolimus using stepwise multiple regression analysis or Bayesian fitting to predict the $A \cup C_{0-12}$ as accurate as possible, since the $A \cup C_{0-12}$ is considered to be the gold standard of measuring the total tacrolimus exposure.

Most of these studies that developed a LSS for tacrolimus used no independent transplant patient population to validate their limited sampling strategies. In CHAPTER 6 several LSS that are recently published, are evaluated using an independent wellcharacterised stable renal transplant patient population. The performance of 24 LSS in 37 renal transplant patients with known $\mathrm{AUC}_{0-12}$ has been evaluated and the results were also compared with the predictability of the trough concentrations, $\mathrm{C}_{0}$ and $\mathrm{C}_{12}$. The criterion was an absolute prediction error (APE\%) that differs less than $15 \%$ from the complete $\mathrm{AUC}_{0-12}$. Thirteen of the $18(72 \%)$ LSS based on regression analysis were capable of predicting at least $90 \%$ of the 37 individual $A U_{0-12}$ within an APE of $15 \%$. Predictions based on $\mathrm{C}_{0}$ and $\mathrm{C}_{12}$ and Bayesian fitting were lower than $90 \%: 62 \%$ and $67 \%$, respectively. In contrast to a recent publication we observed no clear differences in the predictive capacities when a LSS was developed, using 12-hour pharmacokinetic profiles recorded from heart or lung transplant recipients in our renal transplant recipients. Therefore, LSS using $\mathrm{C}_{0}, \mathrm{C}_{2}$ and/or $\mathrm{C}_{4}$ are in our opinion a better alternative for the $\mathrm{C}_{0}$ concentration, used nowadays for monitoring tacrolimus. The different LSS available in current literature for tacrolimus monitoring could generate adequate predictions although cautious evaluation of the reliability of these LSS is mandatory. Tacrolimus is predominantely metabolised by cytochrome P450 (CYP450) 3A isoenzymes into 13-O-desmethyltacrolimus, which has a neglectable immunosuppressive 
activity. CHAPTER 7 and 8 demonstrate in a Chinese and Caucasian renal transplant patient population, that the CYP3A5 A6986G polymorphisms is the most relevant polymorphism present in the CYP450 3A iso-enzyme family, with a significant impact on both the tacrolimus exposure and the daily tacrolimus dose. In CHAPTER 7 the association of CYP3A and $A B C B 1$ polymorphisms with the $\mathrm{AUC}_{0-12}$ calculated using a two time point sample strategy is evaluated. The CYP3A and ABCB1 genotypes are determined by real-time PCR FRET assays in 103 Chinese renal transplant recipients and consequently related to their $\operatorname{dnAUC}_{0-12}$. A significant allele-dependent effect (Kruskal-Wallis; $P<0.001$ ) is observed between the CYP3A5*3 polymorphism and the dose-normalized (dn)AUC $\mathrm{C}_{0-12}$. Multiple regression analysis showed that the CYP3A5*3 polymorphism is the most significant independent variable and explained $35 \%$ of the dose requirement variability in relation to tacrolimus use. Regarding the ABCB1 G2677T/A and C3435T polymorphisms, a trend is observed between the different genotypes and the dnAUC $\mathrm{C}_{0-12}$. CHAPTER 8 described two different renal transplant recipient groups which are used to examine the influence of CYP3A and ABCB1 polymorphisms on the daily tacrolimus dose and several pharmacokinetic parameters. In total 63 Caucasian renal transplant recipients divided into 26 early and 37 late post transplant recipients were genotyped for CYP3A and ABCB1 polymorphisms. The pharmacokinetic parameters of tacrolimus were determined for all renal transplant recipients and correlated with their corresponding genotypes. A significant difference in allele frequencies of the CYP3A4*1B $(P=0.028)$ and CYP3A5*1 $(P=0.022)$ alleles was observed between the early and late posttransplant recipient group. Significant higher $\mathrm{dnC}_{0}, \mathrm{dn} \mathrm{AUC}_{0-12}$, and $\mathrm{dnC}_{\max }$ were observed for carriers of the CYP3A5*3 variant allele in both renal transplant patient groups. Except for the daily tacrolimus dose $(P=0.025)$ no significant differences were observed for carriers of the CYP3A4*1B variant allele. Neither the individual $A B C B 1$ polymorphisms nor the ABCB1 haplotypes were associated with any pharmacokinetic parameter. Additionally, in CHAPTER 9 the allele frequency of the CYP3A7*1C variant allele in a Caucasian and a Chinese renal transplant patient population is examined. Since CYP3A7*1C variant alleles were only found among the Caucasian renal transplant recipients only these patients were used to study the association between the CYP3A7*1C variant allele and the different pharmacokinetic parameters for tacrolimus. An allele frequency of respectively $2.8 \%$ and $0.0 \%$ was found after genotyping 70 Caucasian and 103 Chinese renal transplant recipients for the CYP3A7*1C allele using a real-time PCR FRET assay. Heterozygous carriers of the CYP3A7*1C allele showed no significant lower $C_{0}$ levels, $A^{*} C_{0-12}$ or $C_{\max }$ for tacrolimus compared to the carriers of the CYP3A7*1 allele. The variant alleles of UGT2B7 polymorphisms G-79A, T-66C and C816T with an allele frequency of respectively, $0.0 \%, 5.8 \%$ and $29.6 \%$ showed no significant differences on both the $\mathrm{dnAUC}_{0-12}$ and the daily tacrolimus dose compared to carriers of the wild type UGT2B7 alleles when the patients were categorized based on their CYP3A5 A6986G, ABCB1 G2677T/A and ABCB1 C3435T genotype. Despite the fact that tacrolimus is extensively glucuronidated by UGT2B7, according to a previous study, the three relevant 
polymorphisms present in the UGT2B7 gene seem to have no influence on the tacrolimus exposure in the Chinese renal transplant population, which is in line regarding the results obtained from the another in vitro study.

However, also polymorphisms in genes that are indirectly involved in the tacrolimus metabolism seem to play an important role. The pregnane $X$ receptor (PXR) plays an important role in the regulation of the expression of CYP450 iso-enzymes, 5'-uridine diphosphate glucuronosyltransferase (UGT) enzymes and the drug transporter ABCB1 which are directly involved in the tacrolimus metabolism. In CHAPTER 11 the influence of four individual PXR polymorphism and PXR haplotypes is examined on the tacrolimus exposure in a Chinese renal transplant population. Individuals carrying a variant allele for the PXR polymorphisms A7635G, C8055T, A11156C and T11193C, associated with increased expression of CYP3A4 or $A B C B 1$, had a lower dnAUC ${ }_{0-12}$ for tacrolimus compared to individuals carrying the wild type variant for these PXR polymorphisms (respectively, Mann-Whitney; $P=0.038, P=0.088, P=0.038$ and $P=0.038$ ). The results in CHAPTER 11 suggests that the four PXR polymorphisms are associated with a strong trend towards a lower dnAUC $\mathrm{C}_{0-12}$ of tacrolimus which confirms the role of PXR in the CYP3A and ABCB1 expression and thereby on the tacrolimus metabolism. Additionally, CHAPTER 12 describes the influence of both the daily corticosteroid dosage and these four PXR polymorphisms on the different pharmacokinetic tacrolimus parameters in an early and a late Caucasian posttransplant recipient group. However, non-genetic factors like, gender, age, haematocrit and time after transplantation seem also to play a role in the variability of the tacrolimus exposure between renal transplant recipients. Up until now therapeutic drug monitoring of tacrolimus is still performed by measuring $\mathrm{C}_{0}$ concentrations, although recently several studies point out that a LSS consisting of two or three sample time points within 4 hour after the morning tacrolimus ingestion, gives a significantly better reflection of the complete $A_{U} C_{0-12}$. In order to decrease the variability in the tacrolimus exposure of transplant recipients it is also recommendable to look for possible drug interactions with tacrolimus and possible interactions with other CYP450 inducers or inhibitors like St. John's wort or grapefruit juice.

Summarized the research presented in this thesis reflects on the comparison of several commercially available DNA isolation kits with respect to their isolation capacities, several real-time PCR FRET assays for different polymorphisms that are designed, optimised and validated in our laboratory and additionally in renal transplant recipients with a different ethnic origin (Caucasian and Chinese) the influence of several genetic (CYP3A, ABCB1, UGT2B7 and PXR polymorphisms) and non-genetic factors (gender, age, haematocrit and time after transplantation) are examined on the tacrolimus exposure using a different methodology to determine the tacrolimus exposure (abbreviated $\mathrm{AUC}_{0-12}$ and complete $\mathrm{AUC}_{0-12}$ ). 
Samenvatting 


\section{Samenvatting}

In 2006 wachtten in Nederland 1054 patiënten op een donornier, terwijl in hetzelfde jaar slechts 360 niertransplantaties werden uitgevoerd. Niet alleen de levensverwachting maar ook de kwaliteit van leven verbetert enorm nadat de patiënt een donornier heeft ontvangen. Echter 10 jaar na transplantatie functioneert nog maar ongeveer de helft van alle donornieren. Het verlies van getransplanteerde nieren wordt veroorzaakt door niet goed functionerende getransplanteerde nieren en nog vaker door het overlijden van de patiënt ondanks een goed functioneerde nier. Het overlijden van deze patiënten wordt vaak veroorzaakt door hart- en vaatziekten. Alle patiënten die een donororgaan ontvangen moeten hun hele leven behandeld worden met immunosuppressiva, die allemaal sterk variërende farmacokinetische karakteristieken en een smalle therapeutische index hebben. De immunosuppressieve onderhoudstherapie bestaat van 1980 tot 1995 uit cyclosporine (Neoral ${ }^{\circledR}$ ) met corticosteroïden en azathiopurine $\left(\right.$ Immuran $^{\circledR}$ ). In 1995 kwamen enkele nieuwe immunosuppressiva beschikbaar: tacrolimus (Prograft ${ }^{\circledR}$ ) een geneesmiddel dat gebruikt kan worden als een hoeksteen voor de farmacotherapie, mycofenolaat mofetil (Cellcept ${ }^{\circledR}$ ) en sirolimus (Rapamune ${ }^{\circledR}$ ), welke gebruikt kunnen worden als aanvullende immunosuppressieve geneesmiddelen. Wanneer in plaats van cyclosporine tacrolimus wordt gegeven komen er minder vaak acute afstotingen voor. Dit is het geval voor zowel corticosteroïd-gevoelige als corticosteroïd-ongevoelige acute afstotingen. Doordat acute afstoting en zeker corticosteroïd-ongevoelige acute afstoting geassocieerd wordt met een hoger risico op chronische transplantaat-disfunctie, was het te verwachten dat het gebruik van tacrolimus zou leiden tot een betere transplantatie overleving dan met cyclosporine gebruik. Ondertussen zijn er sterke aanwijzingen dat deze verwachtingen zijn gerechtvaardigd. Verder leidt het gebruik van tacrolimus, in plaats van cyclosporine tot een verbetering van diverse lipoproteïnen (HDL, LDL) en lipiden (triglyceriden) in het bloed en tot een lagere bloeddruk. Deze factoren zijn ook geassocieerd met chronische transplantaat disfunctie en daardoor met mortaliteit als resultaat van hart- en vaatziekten na transplantatie. Bij tacrolimus gebruik is ook vastgesteld dat de incidentie van diabetes mellitus na transplantatie vaker voorkomt dan bij cyclosporine gebruik. Dit zou uiteindelijk de eerder beschreven voordelen ten aanzien van een vergrote overleving van de getransplanteerde nier en de verhoogde overleving van de patiënt teniet doen. Nadat in HOOFDSTUK 1 het overzicht en het doel van dit proefschrift is beschreven, geeft HOOFDSTUK 2 een compleet overzicht van het tacrolimus metabolisme (absorptie, distributie, metabolisatie en eliminatie). De sterk variërende farmacokinetische karakteristieken van tacrolimus in combinatie met een smalle therapeutische index benadrukt de noodzaak tot het nauwkeurig volgen van de tacrolimus bloed concentraties. Vervolgens beschrijft HOOFDSTUK 2 verschillende methoden die tegenwoordig gebruikt worden om de tacrolimus blootstelling te meten, farmacokinetische parameters, dalspiegels $\left(C_{0}\right)$, verkorte oppervlakte onder de tijd tacrolimus concentratie curve $\left(\mathrm{AUC}_{0-12}\right)$ of complete 12-uurs $\mathrm{AUC}_{0-12}$ en de apparatuur welke gebruikt worden (IMx II of LC-MS/MS) om de tacrolimus spiegels te meten. 
Verder zijn de genetische en niet-genetische factoren die een rol zouden kunnen spelen samengevat en tenslotte is er een discussie over de klinische consequenties en de impact van sub-therapeutische of toxische tacrolimus bloedspiegels voor de patiënt. Voordat de real-time polymerase kettingreactie (PCR) kan worden uitgevoerd, die gebruikmaakt van fluorescentie probes, is DNA isolatie uit ethyleen diamine tetra azijnzuur (EDTA) volbloed monsters vereist. Alhoewel verschillende commerciële DNA isolatie kits beschikbaar zijn om DNA te extraheren uit volbloed monsters, is er weinig informatie beschikbaar ten aanzien van de extractie efficienties en de kwaliteit van het geïsoleerde DNA. HOOFDSTUK 3 vergelijkt drie commercieel beschikbare DNA isolatie kits, QIAamp blood mini kit (Qiagen, Leusden, Nederland), Roche High Pure PCR Template Preparation Kit (Roche Diagnostics, Mannheim, Duitsland) en Puregene (Biozyme, Landgraaf, Nederland) ten aanzien van hun capaciteit om DNA te isoleren uit volbloed monsters en de verkregen DNA kwaliteit. In de begin jaren 90, introduceerde de real-time PCR technologie een nieuwe dimensie binnen de PCR technologie, omdat amplificatie en detectie mogelijk werd in één enkel PCR cupje, plaat of capillair. De gedefinieerde drempel cyclus $\left(\mathrm{C}_{\mathrm{t}}\right)$ waarde kan gebruikt worden om de DNA kwantiteit, welke aanwezig is in het PCR cupje te bepalen, terwijl een verschil tussen het wild type en variant allel DNA in de probe aanhechting kan worden gebruikt voor genotypering met real-time PCR technologie. Door zijn analysesnelheid, verminderd risico op contaminatie, geringe arbeidstijd en een PCR en detectiemethode in één, heeft realtime PCR een enorme interesse gewekt onder de moleculair biologen. Een toepassing die algemeen wordt gebruikt in de real-time PCR is de "fluorescence resonance energy transfer" (FRET) methodologie. Een kenmerk van deze real-time PCR FRET technologie is dat twee individuele fluorescentie probes complementair zijn aan het PCR product dichtbij de polymorfe positie. Een ander karakteristiek van de FRET technologie zijn de smeltcurves. Na de laatste cyclus, wordt het PCR product nadat het is afgekoeld tot een bepaalde temperatuur nogmaals gedenatureerd. Het dubbelstrengs PCR product wordt verwarmd met een snelheid van 0.1 tot $0.2^{\circ} \mathrm{C} /$ seconde tot de gewenste temperatuur. Gedurende deze opwarmingsprocedure wordt het fluorescentiesignaal continue gemeten. Als het nucleotide dat gepositioneerd is op de polymorfe positie in de sensor probe complementair is aan het nucleotide gepositioneerd in de polymorfe positie in het vermenigvuldigde DNA, is er een relatief sterke binding tussen deze nucleotiden. Het fluorescentiesignaal zal alleen bij een hoge temperatuur afnemen in sterkte. Dit in tegenstelling tot een niet complementair nucleotide in het PCR product dat een minder stabiele binding tot gevolg heeft en uiteindelijk zal resulteren in een afname in het fluorescentiesignaal bij een lagere temperatuur. Door het berekenen van de negatieve afgeleide van de afname in dit fluorescentiesignaal, wordt een smeltpiek voor het wild type en de variant allel monsters verkregen. Door de samenstelling van de DNA sequentie, bijv. een lang $A / T$ rijk gebied, is het noodzakelijk om een sensor probe te ontwerpen, de probe die de polymorfe positie omvat en die lang genoeg is om een voldoende hoge smelttemperatuur te krijgen. Als resultaat van de vergrote lengte van zo'n sensor probe wordt de invloed van het niet complementaire nucleotide significant minder in vergelijking met een kortere sensor probe. HOOFDSTUK 4 toont aan dat het 
inbouwen van een "locked nucleic acid" (LNA) het genotyperen van de PXR A11156C polymorfisme significant verbeterde. Vooral heterozygoten zijn duidelijker te onderscheiden door het verschijnen van twee smeltpieken, terwijl de probes zonder een LNA bij een smeltcurve analyse niet in staat zijn om deze smeltpieken te scheiden. Daarom concluderen we dat een LNA binnen een sensor probe het discriminerend vermogen van een FRET assay kan verbeteren. In HOOFDSTUK 5 zijn snelle en consistente assays voor organic anion transporting polypeptide 1B1 (OATP1B1) polymorfismen door middel van snelle PCR FRET assays op de LightCycler ontwikkeld. Een LNA op de polymorfe locatie binnen de sensor probe was noodzakelijk om de twee allelen van het OATP1B1 T521C polymorfismen te onderscheiden. Om de betrouwbaarheid van beide real-time PCR FRET assays te bevestigen, werden deze nieuwe methoden gevalideerd door 120 monsters te genotyperen met een PCR "restriction fragment length polymorphism" (RFLP) assay en een allel-specifieke PCR. De resultaten van de real-time PCR FRET assays komen volledig overeen met de conventionele PCR methoden wat aangeeft dat de real-time PCR FRET assays geschikt zijn voor een klinische omgeving. In de meeste transplantatie centra wordt het monitoren van de tacrolimus bloed concentraties uitgevoerd met $\mathrm{C}_{0}$ concentraties na de ochtend tacrolimus inname, ondanks dat er bewijs beschikbaar is dat de bruikbaarheid van deze ochtend tacrolimus $\mathrm{C}_{0}$ spiegels niet optimaal is. Dit wetende, hebben verschillende studies een "limited sampling strategy (LSS)" ontwikkeld met stapsgewijze multiple regression analysis of Bayesian fitting om de $\mathrm{AUC}_{0-12}$ zo nauwkeurig mogelijk te voorspellen. Dit omdat de $\mathrm{AUC}_{0-12}$ gezien wordt als de gouden standaard voor het meten van de totale tacrolimus concentratie. Veel van deze studies die een LSS ontwikkelde voor tacrolimus gebruikten geen onafhankelijke transplantatie patiënten populatie om de LSS te valideren. In HOOFDSTUK 6 worden verschillende LSS die recentelijk zijn gepubliceerd geëvalueerd met een onafhankelijke goed gekarakteriseerde stabiele niertransplantatie patiënten populatie. De prestaties van 24 LSS in 37 niertransplantatie patiënten met een bekende $\mathrm{AUC}_{0-12}$ is geëvalueerd en de resultaten worden tevens vergeleken met de voorspelbaarheid van de dalspiegels $\left(\mathrm{C}_{0}\right.$ en $\mathrm{C}_{12}$ ). Het criterium was een absolute voorspelbaarheidsfout (APE\%) die minder dan $15 \%$ verschilt van de complete $\mathrm{AUC}_{0-12}$. Dertien van de 18 (72\%) LSS zijn gebaseerd op regressie analyse en in staat om tenminste $90 \%$ van de 37 individuele $\mathrm{AUC}_{0-12}$ binnen een $\mathrm{APE} \%$ van $15 \%$ te voorspellen. Voorspellingen gebaseerd op $\mathrm{C}_{0}$ en $\mathrm{C}_{12}$ en Bayesian fitting zijn lager dan $90 \%$ : respectievelijk, $62 \%$ en $67 \%$. In tegenstelling tot een recente publicatie hebben we in onze resultaten geen duidelijke verschillen waargenomen in de voorspellende capaciteiten, wanneer een LSS was ontwikkeld door een studie op basis van 12-uurs farmacokinetische profielen, die opgenomen zijn van hart of long transplantatie patiënten bij validatie in onze niertransplantatie patiënten groep. Daarom zijn LSS met $\mathrm{C}_{0}, \mathrm{C}_{2}$ en/of $\mathrm{C}_{4}$ naar onze mening een beter alternatief voor de $\mathrm{C}_{0}$ concentratie. De verschillende LSS beschikbaar in de huidige literatuur voor het monitoren van tacrolimus zouden adequate voorspellingen kunnen genereren alhoewel een voorzichtige evaluatie voor de betrouwbaarheid van deze LSS verplicht is. Tacrolimus wordt voornamelijk gemetaboliseerd door cytochroom P450 (CYP450) 3A iso-enzymen in 13-O-desmethyltacrolimus, die een 
verwaarloosbare immunosuppressieve activiteit heeft. In de HOOFDSTUK 7 en 8 tonen we in een Chinese en Caucasische niertransplantatie patiënten populatie aan, dat het CYP3A5 A6986G polymorfisme het meest relevante polymorfisme is in de CYP450 3A iso-enzym familie, met een significante impact op zowel de tacrolimus blootstelling als de dagelijkse tacrolimus dosering. In HOOFDSTUK 7 wordt de associatie tussen CYP3A en $A B C B 1$ polymorfismen en de $A \cup C_{0-12}$, berekend met een tweetijdspunt strategie, geëvalueerd. De CYP3A en ABCB1 genotypes zijn bepaald met real-time PCR FRET assays in 103 Chinese niertransplantatie patiënten en vervolgens gerelateerd aan de dosis genormaliseerde $(\mathrm{dn}) \mathrm{AUC}_{0-12}$. Een significant allel-afhankelijk effect (Kruskal-Wallis; $P<0.001$ ) is waargenomen tussen het CYP3A5*3 polymorfisme en de $\mathrm{dnAUC}_{0-12}$. Multiple regression analyse toonde aan dat het CYP3A5*3 polymorfisme de meest significante onafhankelijke variabele is en $35 \%$ van de variabiliteit in de dosering verklaarde in relatie tot het tacrolimus gebruik. Ten aanzien de ABCB1 G2677T/A en C3435T polymorfismen is er een trend waargenomen tussen de verschillende genotypen en de dnAUC ${ }_{0-12}$. HOOFDSTUK 8 beschrijft twee verschillende niertransplantatie patiënten groepen welke worden gebruikt om te onderzoeken wat de invloed is van CYP3A en ABCB1 polymorfisme op de dagelijkse tacrolimus dosering en verschillende farmacokinetische parameters. In totaal zijn 63 Kaukasische niertransplantatie patiënten verdeeld in 26 vroege en 37 late posttransplantatie patiënten gegenotypeerd voor CYP3A en ABCB1 polymorfismen. De farmacokinetische parameters van tacrolimus worden bepaald voor alle niertransplantatie patiënten en gecorreleerd aan hun correspondeerde genotypes. Een significant verschil in allel frequenties wordt waargenomen voor CYP3A4*1B $(P=0.028)$ en CYP3A5*1 $(P=0.022)$ allelen tussen de vroege en late posttransplantatie patiënten groep. Significant hogere $d_{n} C_{0}, d_{n} A U C_{0-12}$ en $\mathrm{dnC}_{\max }$ werden waargenomen voor dragers van het CYP3A5*3 variant allel in beide niertransplantatie patiënten groepen. Behalve voor de dagelijkse tacrolimus dosering $(P=0.025)$ werd geen significant verschil waargenomen voor dragers van de CYP3A4*1B variant allel. Zowel de individuele ABCB1 polymorfismen als de ABCB1 haplotypen zijn geassocieerd met iedere farmacokinetische parameter. Vervolgens is in HOOFDSTUK 9 de allel frequentie van het CYP3A7*1C variant allel onderzocht en tevens de invloed van CYP3A7 ${ }^{*} 1 \mathrm{C}$ op de verschillende farmacokinetische parameters van tacrolimus. Een allel frequentie van respectievelijk $2.8 \%$ en $0.0 \%$ werd gevonden na het genotyperen van 70 Kaukasische en 103 Chinese niertransplantatie patiënten voor het CYP3A7*1C variant allel met een real-time PCR FRET assay. Heterozygote dragers van het CYP3A7 ${ }^{*} 1 \mathrm{C}$ allel vertoonden geen significant lagere $\mathrm{dnC}_{0}$ spiegels, $\mathrm{dnAUC}_{0-12}$ of $\mathrm{dnC}_{\max }$ voor tacrolimus in vergelijking met de dragers van het CYP3A $7{ }^{*} 1$ allel. In HOOFDSTUK 10 vertoonde de variant allelen van de UGT2B7 polymorfismen G-79A, $\mathrm{T}-66 \mathrm{C}$ en $\mathrm{C} 816 \mathrm{~T}$ met een allel frequentie van respectievelijk, $0.0 \%, 5.8 \%$ en $29.6 \%$ geen significante verschillen met zowel de dnAUC $_{0-12}$ als de dagelijkse tacrolimus dosering vergeleken met dragers van wild type UGT2B7 allelen wanneer de patiënten worden gecategoriseerd op basis van hun CYP3A5 A6986G, ABCB1 G2677T/A en ABCB1 C3435T genotype. Ondanks het feit dat tacrolimus wordt geglucuronideerd door UGT2B7 vertonen de drie relevante polymorfismen in het UGT2B7 gen geen invloed op 
de tacrolimus blootstelling in de Chinese niertransplantatie patiënten groep. Hoewel polymorfismen in genen die indirect betrokken zijn bij het tacrolimus metabolisme ook een belangrijke rol schijnen te spelen. De pregnane $X$ receptor (PXR) speelt een belangrijke rol in de expressie regulatie van CYP450 iso-enzymen, 5'-uridine diphosphate glucuronosyltransferase (UGT) enzymes en de geneesmiddeltransporter ABCB1, welke direct zijn betrokken in het tacrolimus metabolisme. In HOOFDSTUK 11 wordt de invloed van vier individuele PXR polymorfismen en PXR haplotypen onderzocht op de tacrolimus blootstelling in een Chinese niertransplantatie patiënt populatie. Individuen die drager zijn van een variant allel voor de PXR polymorfismen A7635G, C8055T, A11156C en T11193C, worden geassocieerd met een hogere expressie van CYP3A4 of ABCB1 in vergelijking met individuen die drager zijn van de wild type variant (Mann-Whitney; respectievelijk, $P=0.038, P=0.088 P=0.038$ en $P=0.038$ ). De resultaten in HOOFDSTUK 11 suggereren dat de vier PXR polymorfismen geassocieerd zijn met een sterke trend naar een lagere $\operatorname{dn} A \cup C_{0-12}$ van tacrolimus, wat de rol bevestigt van PXR bij de CYP3A en ABCB1 expressie en daardoor ook op het tacrolimus metabolisme. Vervolgens wordt in HOOFDSTUK 12 de invloed van zowel de dagelijkse corticosteroid dosering en deze vier PXR polymorfismen op de verschillende farmacokinetische tacrolimus parameters in een vroege en een late Kaukasische posttransplantatie patiënten groep beschreven. Alhoewel niet genetische factoren zoals geslacht, leeftijd, hematocriet en tijd na transplantatie ook een belangrijke rol schijnen te spelen in de variabiliteit van de tacrolimus blootstelling tussen niertransplantatie patiënten. Tot nu toe wordt het therapeutisch monitoren van tacrolimus nog steeds uitgevoerd door het meten $\mathrm{C}_{0}$ concentraties, hoewel recentelijk verschillende studies aangeven dat de LSS die bestaan uit twee of drie tijdstippen waarop monster worden afgenomen binnen vier uur na de ochtend tacrolimus inname, een significant betere afspiegeling geeft van de complete $\mathrm{AUC}_{0-12}$. Om de variabiliteit in de tacrolimus blootstelling van de transplantatie patiënten te verlagen is het ook aan te bevelen om te kijken naar mogelijke geneesmiddelinteracties met tacrolimus en mogelijke interacties met andere CYP450 inducers en remmers, zoals St. Janskruid of grapefruitsap.

Samengevat, het onderzoek dat wordt gepresenteerd in dit proefschrift omvat de vergelijking van verschillende commercieel verkrijgbare DNA isolatie kits ten aanzien van hun isolatie capaciteiten, diverse real-time PCR FRET assays voor verschillende polymorfismen werden ontworpen in ons laboratorium, geoptimaliseerd en gevalideerd en verder is in niertransplantatie patiënten van een verschillende etnische oorsprong (Kaukasisch en Chinees) de invloed van verschillende genetische (CYP3A, ABCB1, UGT2B7 en PXR polymorfismen) en niet genetische factoren (geslacht, leeftijd, hematocriet en tijd na transplantatie) onderzocht op de tacrolimus spiegels met verschillende methodologieën om de diverse farmacokinetische parameters voor tacrolimus te bepalen (verkorte $\mathrm{AUC}_{0-12}$ en complete $\mathrm{AUC}_{0-12}$ ). 
Abbreviations 


\section{Abbreviations}

\begin{tabular}{|c|c|}
\hline$A^{260} / A^{280}$ & ratio absorption at $260 \mathrm{~nm}$ and $280 \mathrm{~nm}$ \\
\hline ABCB1 & adenosine triphosphate binding cassette B1 gene \\
\hline $\mathrm{ABCC} 1$ & adenosine triphosphate binding cassette $\mathrm{C} 1$ gene \\
\hline ALAT & alanine aminotransferase \\
\hline ANOVA & analysis of variance between groups \\
\hline ARMS & amplification refractory mutation system \\
\hline ASAT & aspartate aminotransferase \\
\hline$A \cup C_{0-12}$ & 12 hour area under the time concentration curve \\
\hline bp & base pair \\
\hline $\mathrm{C}_{0}$ & trough tacrolimus level (concentration) \\
\hline $\mathrm{C}_{1}$ & tacrolimus blood concentration 1 hour after tacrolimus administration \\
\hline $\mathrm{C}_{2}$ & tacrolimus blood concentration 2 hour after tacrolimus administration \\
\hline $\mathrm{C}_{3}$ & tacrolimus blood concentration 3 hour after tacrolimus administration \\
\hline $\mathrm{C}_{4}$ & tacrolimus blood concentration 4 hour after tacrolimus administration \\
\hline $\mathrm{C}_{5}$ & tacrolimus blood concentration 5 hour after tacrolimus administration \\
\hline $\mathrm{C}_{7.5}$ & tacrolimus blood concentration 7.5 hour after tacrolimus administration \\
\hline $\mathrm{C}_{9}$ & tacrolimus blood concentration 9 hour after tacrolimus administration \\
\hline $\mathrm{C}_{12}$ & tacrolimus blood concentration 12 hour after tacrolimus administration \\
\hline $\mathrm{C}_{\max }$ & the maximum tacrolimus concentration reached \\
\hline cAMP & cyclic adenosine monophosphatase \\
\hline CAR & constitutive androstane receptor \\
\hline c-MOAT & canalicular-Multispecific Organic Anion Transporter \\
\hline CREB & cAMP-response element binding protein \\
\hline $\mathrm{Ct}$ & Cycle threshold \\
\hline CYP3A4 & cytochrome P450 3A4 iso-enzyme \\
\hline CYP3A5 & cytochrome P450 3A5 iso-enzyme \\
\hline CYP3A7 & cytochrome P450 3A7 iso-enzyme \\
\hline DNA & deoxyribonucleic acid \\
\hline $\operatorname{dnAUC} \mathrm{C}_{0-12}$ & dose-normalized tacrolimus area under the time concentration curve \\
\hline $\mathrm{dnC}_{0}$ & dose-normalized tacrolimus trough level (concentration) \\
\hline EDTA & ethylene diamine tetra-acetic acid \\
\hline FAM & fluorescein \\
\hline FKBP-12 & FK506-binding protein-12 \\
\hline FKBP-52 & FK506-binding protein-52 \\
\hline FRET & fluorescence resonance energy transfer \\
\hline GR & glucocorticosteroid receptor \\
\hline HPLC & high performance liquid chromatography \\
\hline IL & interleukin \\
\hline INF & interferon \\
\hline LNA & locked nucleic acids \\
\hline
\end{tabular}




$\begin{array}{ll}\text { MDR1 } & \text { multidrug resistance 1 } \\ \text { MMF } & \text { mycophenolate mofetil } \\ \text { mRNA } & \text { messenger ribonucleic acid } \\ \text { MRP2 } & \text { multidrug resistance-associated protein 2 } \\ \text { MS } & \text { mass spectrometry } \\ \text { NF-ATc } & \text { nuclear factor of activated T-cells } \\ \text { NR1I2 } & \text { nuclear receptor 1I2 } \\ \text { NR1I3 } & \text { nuclear receptor 1I3 } \\ \text { NR1H4 } & \text { nuclear receptor 1H4 } \\ \text { OATP1B1 } & \text { organic anion transporting polypeptide 1B1 } \\ \text { OATP-C } & \text { organic anion transporting polypeptide C } \\ \text { OD } & \text { optical density } \\ \text { PCR } & \text { polymerase chain reaction } \\ \text { PNA } & \text { peptide nucleic acid } \\ \text { PXR } & \text { pregnane } X \text { receptor } \\ r & \text { multiple regression correlation coefficient } \\ \text { RFLP } & \text { restriction fragment length polymorphism } \\ r_{p} & \text { Pearson correlation coefficient } \\ r_{s} & \text { Spearman correlation coefficient } \\ \text { RXR } & \text { retinoid X receptor } \\ \text { SLCO1B1 } & \text { solute carrier organic anion transporter family, member 1B1 } \\ \text { SNP } & \text { single nucleotide polymorphism } \\ \text { SXR } & \text { steroid and xenobiotic receptor } \\ t_{1 / 2} & \text { half life time tacrolimus } \\ \text { TAMRA } & \text { tetramethylrhodamine } \\ T_{\text {max }} & \text { time required to reach the maximum tacrolimus concentration } \\ \text { TNF } & \text { tumor necrosis factor } \\ \text { UV spectrometry } & \text { ultraviolet spectrometry } \\ \text { UDP } & \text { uridine diphosphate } \\ \text { UGT2B7 } & \text { uridine diphosphate glucuronosyltransferases 2B7 } \\ \text { WBC } & \end{array}$


List of publications 


\section{List of publications}

1. Bekers O, Op den Buijsch RAM, de Vries JE, Wijnen PAHM, van Dieijen-Visser MP. Capillary electrophoretic detection in apolipoprotein E genotyping; Electrophoresis. 2002;23:1878-81

2. Op den Buijsch RAM, de Vries JE, Loots WJ, Landt O, Wijnen PAHM, van Dieijen-Visser MP, Bekers $\mathrm{O}$. Genotyping of the PXR A11156C polymorphism with locked nucleic acid containing fluorogenic probes. Pharmacogenomics J. 2005;5:72-4.

3. Op den Buijsch RAM, Bekers O, Wijnen PAHM, van Dieijen-Visser MP, de Vries JE, Bekers, O. Rapid genotyping of the OATP1B1 polymorphisms A388G and T521C with real-time PCR FRET assays. Pharmacogenomics. 2005;6:393-7.

4. Cheung CY, Op den Buijsch RAM, Wong KM, Chan HW, Chau KF, Li CS, Leung KT, Kwan TH, de Vries JE, Wijnen PAHM, van Dieijen-Visser MP, Bekers O. Influence of different allelic variants of the CYP3A and ABCB1 genes on the tacrolimus pharmacokinetic profile of Chinese renal transplant recipients. Pharmacogenomics. 2006;7:563-74.

5. Op den Buijsch RAM, de Vries JE, ten Kate J, Wijnen PAHM, Rothkrantz-Kos S, van DieijenVisser MP, Bekers, O. Comparison of DNA Isolation Kits to extract DNA from Whole Blood Samples. Current Genomics 2006;7:73-8.

6. Op den Buijsch RAM, Cheung CY, De Vries JE, Wijnen PAHM, Van Dieijen-Visser MP, Bekers $O$. Influence of cytochrome P $4503 A 5$ and multidrug resistance-1 gene single nucleotide polymorphisms (SNPs) on the tacrolimus area under the curve (AUC) in renal transplant recipients. Ned Tijdschr Klin Chem Labgeneesk 2006;31:204-6.

7. Op den Buijsch RAM, van der Plas A, Stolk LML, Christiaans MHL, van Hooff JP, van DieijenVisser MP, Bekers O. Evaluation of Limited Sampling Strategies for Tacrolimus. Submitted

8. Op den Buijsch RAM; Cheung CY; Wong KM; Chan HW; Chau KF; Li CS; Leung KT; Kwan $\mathrm{TH}$; de Vries, JE; Wijnen PAHM; van Dieijen-Visser MP; Bekers O. Influence of Allelic Variants of Uridine Diphosphate-Glucuronosyltransferase (UGT) 2B7 on the Tacrolimus Pharmacokinetics. Submitted

9. Op den Buijsch RAM, Cheung CY, Liu YL, Chan HW, Chau KF, Li CS, Leung KT, Kwan TH, de Vries JE, Wijnen PAHM, van Dieijen-Visser MP, Bekers O. Pregnane X Receptor (PXR) Polymorphisms involved in the Tacrolimus Pharmacokinetics. Submitted

10. Op den Buijsch RAM, Christiaans MHL, Stolk LML, de Vries JE, Chi Yuen Cheung, Undre NA, van Hooff JP, van Dieijen-Visser MP, Bekers O; Tacrolimus Pharmacokinetics and Pharmacogenetics: Influence of Adenosine Triphosphate-binding cassette B1 (ABCB1) and Cytochrome (CYP) 3A Polymorphisms. Submitted

11. Drent M, Wijnen PAHM, Kuijpers PMJC, Koek GH, Neef C, Op den Buijsch RAM, Bast A, Bekers O. Cytochrome P450 Pharmacogenetics as a Possible Predictor of Pulmonary Drug Toxicity. Submitted

12. Op den Buijsch RAM, Cheung Chi Yuen, de Vries JE, Stolk LML, Christiaans MHL, Undre NA, Wijnen PAHM, van Dieijen - Visser MP, Bekers O. Cytochrome P450 3A7 (CYP3A7) *1C Allelic Variant is not associated with the Tacrolimus Pharmacokinetics in Renal Transplant Recepients. Submitted

13. Op den Buijsch RAM, de Vries JE, Cheung Chi Yuen, Stolk LML, Christiaans MHL, Undre NA, Wijnen PAHM, van Dieijen - Visser MP, Bekers O. Influence of Pregnane X Receptor on the Pharmacokinetics of Tacrolimus in Renal Transplant Recipients. Submitted

14. Op den Buijsch RAM, van Dieijen - Visser MP, Bekers O. Cytochrome P450 iso-enzymes (CYP) and variability in drug metabolism, a review. Submitted

15. Wijnen PAHM, Op den Buijsch RAM, Cheung CY, van der Heijden J, Hoogtanders K, Stolk LML, van Dieijen-Visser MP, Neef C, Bekers O. Genotyping with a dried blood spot method: an useful technique for application in Pharmacogenetics. Submitted

16. Op den Buijsch RAM, Wijnen PAHM, van Dieijen-Visser MP, Bekers O. Pharmacokinetics and Pharmacogenetics of Tacrolimus. Submitted 


\section{Abstracts}

1. de Vries JE, Wijnen PAHM, Op den Buijsch RAM, Van Dieijen-Visser MP, Bekers O. Use of cell lysates in real-time PCR applications. Ned Tijdschr Klin Chem 2002; 27 (2): page 65.

2. Bekers O, de Vries, JE, Wijnen PAHM, Op den Buijsch RAM, Van Dieijen-Visser MP. Use of cell lysates in real-time PCR applications. Poster abstract - 18th ICCC 2002 Kyoto: S115.

3. Op den Buijsch RAM, de Vries JE, Wijnen PAHM, ten Kate J, van Dieijen-Visser MP, Bekers O. Use of WBC counts to Quantify DNA in Real-time PCR. Euregio Congress Aachen 2003: A93.

4. Op den Buijsch RAM, de Vries JE, Wijnen PAHM, ten Kate J, van Dieijen-Visser MP, Bekers $\mathrm{O}$, Use of WBC counts as an additive tool in quantitative real time PCR applications. Ned Tijdschr Klin Chem Labgeneesk 2003; 28 (2): page 59.

5. Op den Buijsch RAM, deVries JE, Wijnen PAHM, ten Kate J, van Dieijen-Visser MP, Bekers $\mathrm{O}$. Use of WBC counts as an additive tool in quantitative real time PCR applications. European meeting on molecular diagnostics 2003.

6. Op den Buijsch RAM, de Vries JE, Wijnen PAHM, ten Kate J, van Dieijen-Visser MP, Bekers O. Use of WBC counts to Quantify DNA in Real-time PCR. Euregio Congress Aachen 2003: A93.

7. Op den Buijsch RAM, de Vries JE, Wijnen PAHM, van Dieijen-Visser MP, Bekers O. Genotyping of CYP3A5 allelic variants by fluorgenic probes using the LightCycler. Ned Tijdschr Klin Chem Labgeneesk 2004; 29 (2): page 67.

8. Op den Buijsch RAM, Bekers O, Wijnen PAHM, ten Kate J, van Dieijen-Visser MP, de Vries JE. Comparison of three isolation kits to extract DNA from whole blood samples for quantitative real-time PCR. Ned Tijdschr Klin Chem Labgeneesk 2004; 29 (2): page 67.

9. Op den Buijsch RAM, Bekers O, Christiaans M, Stolk L, Cheung S, van Hooff J, van DieijenVisser MP, De Vries JE. MDR1 and CYP450 gene polymorphisms and $12 \mathrm{hr}$ AUC pharmacokinetics of tacrolimus. Ned Tijdschr Klin Chem Labgeneesk 2005; 30 (2): page 77.

10. Op den Buijsch RAM, de Vries JE, Cheung CY, Wong KM, Wijnen PAHM, van Dieijen-Visser $\mathrm{MP}$, Bekers $\mathrm{O}$. Influence of different allelic variants of cytochrome P450 $3 \mathrm{~A}$ and multidrug resistance-1 gene on the tacrolimus pharmacogenetic profile of chinese renal transplant recipients. Ned Tijdschr Klin Chem Labgeneesk 2006; 31 (2): page 91.

11. Bekers O, Op den Buijsch RAM, de Vries JE, Cheung CY, Wong KM, Wijnen PAHM, van Dieijen-Visser MP. Influence of cytochrome P450 3A and multidrug resistance -1 polymorphisms on the tacrolimus pharmacokinetic profile of renal transplant recipients. Third Santorini Biologie Prospective Conference Sep 29-Oct 22006.

12. Op den Buijsch RAM, Christiaans MHL,. Stolk LML, de Vries JE, van Hooff JP, van DieijenVisser MP and Bekers O. Tacrolimus Pharmacokinetics and Pharmacogenetics: Influence of Adenosine Triphosphate-binding Cassette B1 (ABCB1) and Cytochrome (CYP) 3A Polymorphisms. Accepted as a poster presentation on Euromedlab, Monday, June $4^{\text {th }} 2007$, RAl Congress Centre Amsterdam.

13. Op den Buijsch RAM, Cheung CY, Wijnen PAHM, van Dieijen-Visser MP and Bekers O. Influence of Allelic Variants of Uridine Diphosphate-Glucuronosyltransferase (UGT) 2B7 on the Tacrolimus Pharmacokinetics. Accepted as a poster presentation on Euromedlab, Monday, June $4^{\text {th }} 2007$, RAI Congress Centre Amsterdam.

14. Op den Buijsch RAM, Cheung CY, de Vries JE, Wijnen PAHM, van Dieijen-Visser MP and Bekers O. Pregnane $X$ Receptor (PXR) Polymorphisms involved in the Tacrolimus Pharmacokinetics. Accepted as a poster presentation on Euromedlab, Monday, June $4^{\text {th }}$ 2007, RAI Congress Centre Amsterdam.

15. Op den Buijsch RAM, van de Plas A, Bekers O, Christiaans MHL, van Hooff JP, van DieijenVisser MP and Stolk LML. Evaluation of Limited Sampling Strategies for Tacrolimus. Accepted as an oral presentation on the Wetenschappelijke mededelingendag klinische farmacologie, vrijdag 30 maart 2007, Jaarbeursgebouw Utrecht. 
16. Op den Buijsch RAM, Wijnen PAHM, van der Heijden J, Hoogtanders K, Stolk LML, van Dieijen-Visser MP, Neef $C$ and Bekers O. Genotyping with a dried blood spot method: a useful technique for application in Pharmacogenomics. Accepted as a poster presentation on the Wetenschappelijke mededelingendag klinische farmacologie, vrijdag 30 maart 2007, Jaarbeursgebouw Utrecht.

17. Op den Buijsch RAM, Wijnen PAHM, van der Heijden J, Hoogtanders K, Stolk LML, van Dieijen-Visser MP, Neef $\mathrm{C}$ and Bekers O. Genotyping with a dried blood spot method: a useful technique for application in Pharmacogenomics. Submitted European meeting on molecular diagnostics October $18^{\text {th }}$ and $19^{\text {th }} 2007$, Kurhaus, Scheveningen The Hague.

18. Op den Buijsch RAM, Cheung CY, de Vries JE, Wijnen PAHM, van Dieijen-Visser MP and Bekers O. Pregnane X Receptor (PXR) Polymorphisms involved in the Tacrolimus Pharmacokinetics. Submitted European meeting on molecular diagnostics October $18^{\text {th }}$ and $19^{\text {th }} 2007$, Kurhaus, Scheveningen The Hague.

19. Op den Buijsch RAM, Cheung CY, Wijnen PAHM, van Dieijen-Visser MP and Bekers O. Influence of Allelic Variants of Uridine Diphosphate-Glucuronosyltransferase (UGT) 2B7 on the Tacrolimus Pharmacokinetics. Submitted European meeting on molecular diagnostics October $18^{\text {th }}$ and $19^{\text {th }} 2007$, Kurhaus, Scheveningen The Hague.

20. Op den Buijsch RAM, van de Plas A, Bekers O, Christiaans MHL, van Hooff JP, van DieijenVisser MP and Stolk LML. Evaluation of Limited Sampling Strategies for Tacrolimus. Submitted IATDMCT meeting Nice, France September 2007:9-14.

21. Op den Buijsch RAM, Wijnen PAHM, van der Heijden J, Hoogtanders K, Stolk LML, van Dieijen-Visser MP, Neef $C$ and Bekers $O$. Genotyping with a dried blood spot method: a useful technique for application in Pharmacogenomics. Submitted IATDMCT meeting Nice, France September 9-14, 2007

22. Op den Buijsch RAM, Cheung CY, de Vries JE, Wijnen PAHM, van Dieijen-Visser MP and Bekers O. Pregnane $X$ Receptor (PXR) Polymorphisms involved in the Tacrolimus Pharmacokinetics. Submitted IATDMCT meeting Nice, France September 20074:9-14. 
Dankwoord 
224 


\section{Dankwoord}

Voor het verrichten van onderzoek is de hulp van anderen altijd onontbeerlijk. Zonder die hulp had ik dit proefschrift dan ook niet kunnen voltooien. In dit hoofdstuk van mijn proefschrift wil ik iedereen dan ook bedanken, die zijn/haar steentje aan dit werk heeft bijgedragen. Hoewel ik velen bij naam zal noemen, kan het misschien toch nog voorkomen dat ik iemand niet persoonlijk noem. Hierbij wil ik diegenen laten weten dat dit geen opzettelijke nalatigheid betreft, maar dat ook naar hen mijn dank uitgaat.

Op de eerste plaats wil ik alle niertransplantatie patiënten in Nederland en Hong Kong bedanken die bereidwillig hun vertrouwen hebben geschonken aan een aantal onderzoeken die zijn beschreven in dit proefschrift. Ik hoop met dit proefschrift een bescheiden bijdrage te kunnen leveren aan het inzicht in de farmacokinetiek en farmacogenetica van tacrolimus bij niertransplantatie patiënten.

Mijn promotor, Prof. dr. Marja P. van Dieijen-Visser, beste Marja, promoveren gaat gepaard met hoogtepunten en dieptepunten al leken voor mij op sommige momenten de dieptepunten te overheersen. Ik ben je dankbaar voor het vertrouwen en de tijd die ik tijdens deze periode van je heb gekregen om mijn onderzoek te hervatten en succesvol te beëindigen. Ook al was je niet direct betrokken bij mijn onderzoekslijn, je vond toch wel altijd tijd om kritisch naar de 'laatste' versie van de artikelen te kijken voordat deze opgestuurd werden. Marja, bedankt hiervoor.

Mijn copromotor, Dr. Otto Bekers, beste Otto, ik denk dat je niet veel moeite hebt gehad om me te motiveren voor het onderzoek, maar dat je des te meer inspanning hebt moeten leveren om me te temperen voor de talloze ideeën. Zeker omdat na een paar jaar onderzoek, de onderzoekslijn voor het proefschrift nog niet echt helder was en ik snakte naar een publicatie ter bevestiging van al ons werk. De aanvankelijke onderzoekslijn: vrij DNA bij patiënten met een colon carcinoom gaf niet het gewenste resultaat. Gelukkig leidde de overstap naar farmacogenetisch onderzoek bij niertransplantatie patiënten tot meer succes. Otto, ik ben je dankbaar voor de steun, vrijheid en de mogelijkheden die ik binnen het onderzoek heb gekregen.

Dr. Johan E. de Vries, beste Johan, vooral in het beginstadium van mijn promotieonderzoek, toen ik nog zoekende was naar een goede onderzoekslijn, heb ik veel gehad aan jouw inbreng. Telkens zocht je samen met mij naar verklaringen voor "afwijkende" resultaten en hielp je me op weg bij het bedenken van vervolgexperimenten. Ook toen de switch naar farmacogenetisch onderzoek bij niertransplantatie patiënten werd gemaakt, hebben we talloze malen gesproken over het tacrolimus metabolisme en een multi-genetische aanpak om de variatie in de tacrolimus concentratie bij deze patiënten te verminderen. Johan, bedankt hiervoor. 
Petal Wijnen, beste Petal, de nauwkeurigheid en precisie die noodzakelijk zijn voor het moleculair biologisch werk heb je mij fantastisch aangeleerd. Maar niet alleen het aanleren van deze technieken, ook je hulp bij het opzetten van (real-time) PCR methoden, en het doorlezen en verbeteren van de losse artikelen en het corrigeren van de uiteindelijke versie van mijn proefschrift. Petal, ik ben je erg dankbaar voor deze hulp. Daarom ben ik ook erg blij dat jij samen met mijn zus paranimf wilt zijn tijdens mijn promotie. Ik hoop dat ik nog eens getuige mag zijn van de verdediging van jouw proefschrift.

Dr. Joop ten Kate, beste Joop, helaas is de eerste onderzoekslijn: 'vrij DNA in plasma bij patiënten met een colon carcinoom' nauwelijks van de grond gekomen. Desondanks is het toch gelukt om een artikel waarin we met $z$ 'n allen enorm veel tijd in hebben gestoken gepubliceerd te krijgen. Joop, ik heb het enorm gewaardeerd dat je tijd hebt willen vrijmaken voor het bediscussiëren, meedenken en herschrijven van het artikel over het vergelijken van DNA isolatiekits.

Dr. Leo M.L. Stolk, beste Leo, met veel plezier kijk ik terug op onze samenwerking, vooral de momenten wanneer ik binnenliep en we samen al snel op tal van ideeën kwamen die nader onderzocht konden worden. Verder heb ik het ook zeer gewaardeerd dat je de artikelen snel corrigeerde en tijd maakte om deze correcties te bespreken. Concreet heeft onze samenwerking ook veel opgeleverd: een artikel over de CYP3A en $A B C B 1$ polymorfismen in relatie met de 12 uurs curves van tacrolimus bij niertransplantatie patienten en later het evalueren van diverse limited sampling strategies voor tacrolimus. Leo, bedankt voor deze samenwerking en ik hoop dat we in de toekomst samen nog veel artikelen kunnen schrijven.

Drs. Afke van de Plas, beste Afke, bedankt voor je hulp bij het opzoeken van data en het corrigeren van diverse versies van het limited sampling artikel. Gelukkig is alle moeite die we er met z'n allen hebben ingestopt beloond door de acceptatie van het artikel.

Henk Kattebeld, beste Henk, bedankt voor het verzenden en selecteren van bloedbuizen van de transplantatie patiënten die tacrolimus kregen. Zonder deze verzameling van het juiste patiënten materiaal hadden verschillende studies die beschreven zijn in dit proefschrift nooit kunnen worden uitgevoerd. Henk bedankt!

Dr. Maarten H.L. Christiaans, beste Maarten, na een wat moeizame start is het toch gelukt om binnen het azM het farmacogenetisch onderzoek bij niertransplantatie patiënten van de grond te krijgen. Doordat we door jou de beschikking kregen over een goed gedocumenteerde niertransplantatie patiënten populatie was het mogelijk om diverse artikelen met deze populatie te schrijven. Maarten, hartelijk dank hiervoor. 
Dr. Simon C.Y. Cheung (Queen Elizabeth Hospital, Kowloon, Hong Kong), dear Simon, we met each other during your foreign nephrology training at the internal medicine department in the azM. We were both enthusiastic about pharmacogenetics in renal transplant recipients and therefore we decided to start a study with Chinese renal transplant recipients. I'm very proud that our cooperation is still a success and resulted up until now in several publications. I hope that we can continue our collaboration in future and that many publications will follow.

Dr. Olfert Landt (TIB MOLBIOL, Berlin, Deutschland). Bester Olfert und kollegen, fast gleich nach meinen anfang des PhD studiums in 2001 auf der abteilung klinische chemie in das Universitätskrankenhaus von Maastricht hatten wir contact. Sie haben mir geholfen bei der entwicklung von neuer real-time PCR Fluorescence Resonance Energy Transfer (FRET) assays und das beantworten von vielen fragen über real-time PCR. Insgesamt haben wir mein erstes wissenschaftliches Artikel über das introducieren von einen LNA nucleotid in einer FRET probe geschrieben. Olfert und kollegen, ich bin euch sehr dankbar für all eure hilfe und die ausgezeichnete zusammenarbeit die ich von ihr bekommen habe und ich hoffe für die Zukunft das wir noch viel zusammen arbeiten können.

Snježana, Jart, Jaap, Etienne en Judith, tijdens de vijf jaar op het klinische chemisch laboratorium heb ik kennis mogen maken met verschillende kamergenoten.

Jart, erg gemakkelijk was je kennis over computers, waar ik de afgelopen jaren dankbaar gebruik van heb mogen maken. Snježana, ik heb dankbaar gebruik gemaakt van jouw kennis over statistiek en SPSS, zeker voor het artikel over de DNA isolatie kit vergelijking waar ikzelf door de bomen het bos niet meer zag voor wat betreft de statistiek. Jaap, door de komst van jou ben ik verhuist naar het kantoor waar later Etienne en Judith ook bijkwamen. Als kamergenoot heb ik je dus niet echt gekend maar ik vond het wel altijd interessant om met jou over farmacogenetica te discussiëren. Etienne, door jouw komst kwam er voor mij een einde aan de eenzaamheid op de kamer. Ondanks dat we een totaal verschillende onderzoekslijn hadden, heb ik het als erg leerzaam ervaren om van gedachten te wisselen over elkaars onderzoek. Ook je hulp voor bij het maken van plaatjes voor de verschillende artikelen was bij tijd en wijle erg welkom. Judith, als laatste erbij gekomen en als enige vrouw zittend tussen de twee mannen op de 'onderzoekskamer' wist je je kranig te weren. Zwart wit gezien is onderzoek doen veel afzien en af en toe een succesje boeken. Dat hebben we alle drie ondervonden in de periode dat ik bij jullie op de kamer zat.

Alle medewerkers van het laboratorium klinische chemie, hematologie en immunologie, inclusief diegenen die inmiddels het lab hebben verlaten, hartelijk dank voor het feit dat ik mijn experimenten heb kunnen uitvoeren in een gezellige en behulpzame omgeving. Verder hoop ik dat jullie na het lezen van het proefschrift een iets duidelijker beeld krijgen van het onderzoek waarmee ik de afgelopen vijf jaar bezig ben geweest. 
De leden van de beoordelingscommissie: Prof. dr. A. Bast (voorzitter), Prof. dr. M. Drent, Prof. dr. C. Neef, Prof. dr. H.J. Guchelaar, Prof. dr. K.M.L. Leunissen, jullie wil ik bedanken voor de bereidwilligheid om dit proefschrift te doorgronden.

Tiny Wouters, jouw precisie en nauwkeurigheid bij het verwerken van de losse artikelen en teksten tot een toonbaar proefschrift blijft van onschatbare waarde. Zonder jou had ik dit nooit voor elkaar gekregen en was de uiteindelijke afronding van het proefschrift nooit zo vlot verlopen.

Beste Pap, Nellie en Joyce, bedankt voor jullie onvoorwaardelijke steun en liefde zeker in de moeilijke perioden die ik heb gehad tijdens mijn promotie. Zonder jullie steun zou ik het een stuk moeilijker hebben gehad om het proefschrift te voltooien. Joyce, bedankt dat je paranimf wilt zijn op mijn promotie.

En tot slot Rianne, lieve Rianne, een speciale plaats voor jou. Tijdens de vijf jaren dat we samenwonen in Maastricht heb je als geen ander ervaren, hoe groot de last kan zijn die zo'n promotieonderzoek met zich mee kan brengen. Bedankt voor je begrip, geduld en morele steun door je geloof in mij wat me tijdens de moeilijkere perioden sterkte om door te gaan. 
Curriculum vitae 
Curriculum vitae 


\section{Curriculum vitae}

Robert Antonius Maria Op den Buijsch werd op 15 oktober 1973 geboren in Nederweert. In 1992 behaalde hij het hoger algemeen voortgezet onderwijs (HAVO) diploma aan de Philips van Horne Scholengemeenschap te Weert, waar hij in 1994 ook zijn atheneum diploma kreeg uitgereikt. Nadat hij was uitgeloot voor de studie geneeskunde werd in september 1994 begonnen met de opleiding farmacie aan de Universiteit Utrecht. Na het behalen van zijn doctoraal farmacie in 1999 volgde hij de postdoctorale apothekersopleiding welke in november 2000 werd afgerond.

Vervolgens begon hij in februari 2001 als tweede apotheker bij apotheek Pluymaekers in Utrecht waar hij een ongeveer een jaar heeft gewerkt. Tijdens de studie farmacie was de interesse voor analyse, toxicologie en klinische chemie gewekt. Gedurende de periode dat hij werkzaam was als openbaar apotheker heeft hij gezocht naar opleidingsplek voor klinische chemicus. Toen duidelijk werd dat er betere perspectieven voor zo'n opleidingplek zijn als je gepromoveerd bent, was de assistent in opleidingsplaats (AIO) op het klinisch chemisch laboratorium in het academisch ziekenhuis Maastricht precies wat hij zocht. In januari 2001 werd dan ook onder supervisie van prof. dr. M.P. van Dieijen-Visser en dr. O. Bekers gestart met deze onderzoeksplaats.

Aanvankelijk werd gestart met onderzoek om genetische afwijkingen die bij colon kanker patiënten die aanwezig zijn in de colon tumor, terug te vinden in het circulerend DNA uit het bloed van deze patiënten. Hiermee zou bij colon kanker patiënten in de toekomst beter vervolgd kunnen worden of de (chemo) therapie aldanniet succes vol is. Helaas verliep de opzet en het verloop van deze onderzoekslijn erg traag en werd na twee jaar overgestapt naar farmacogenetisch onderzoek bij niertransplantatie patiënten. Door meer inzicht in genetische verschillen tussen patiënten in de enzymen en transporters die betrokken zijn bij de metabolisatie van immunosuppressiva kan in de toekomst mogelijk beter worden voorspeld hoe gedoseerd moet worden bij elke individuele patiënt. Dit om vooral om beter in te kunnen spelen op eventuele op subtherapeutische en toxische doseringen. De resultaten van dit onderzoek wordt vandaag gepresenteerd in dit proefschrift. Na zijn promotie is hij bij het ILD-Care centrum onder leiding van prof dr. M. Drent begonnen als CYP consulent. 